\title{
Teaching and Learning in Higher Education in the Time of COVID-19
}

\section{Editors:}

Nhlanhla Mkhize, Nobuhle Ndimande-Hlongwa, Labby Ramrathan, Johannes A. Smit

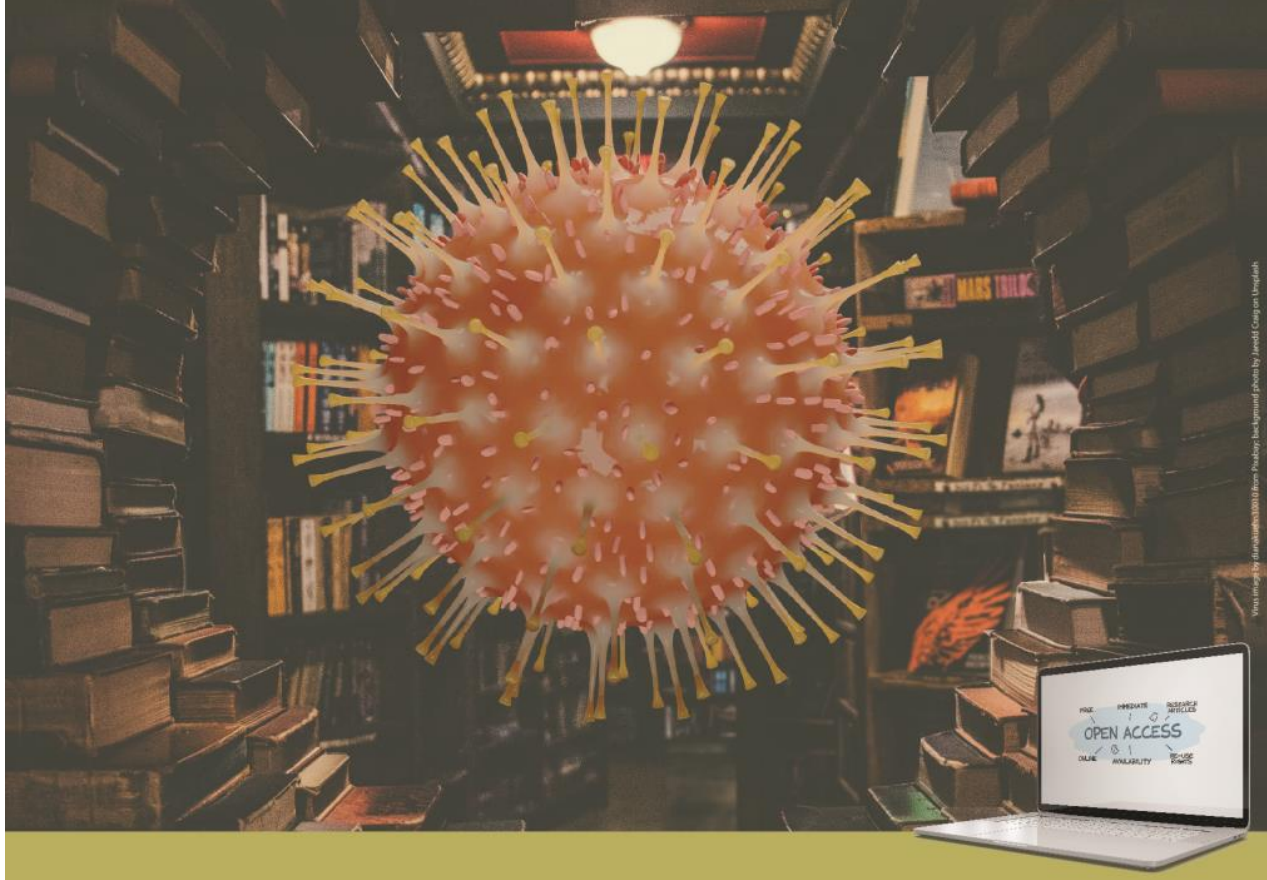

Alternation African Scholarship Book Series, Volume \#03 



\title{
Alternation African Scholarship Book Series (AASBS)
}

General Editors

Nhlanhla Mkhize; Relebohile Moletsane; Nobuhle Ndimande-Hlongwa; Sarah Mosoetsa; Labby Ramrathan; Johannes A. Smit

\begin{abstract}
Lead-Editors
Nyna Amin University of KwaZulu-Natal; Vivienne Bozalek Cape Peninsula University of Technology; Denzil Chetty University of South Africa; Rubby Dhunpath University of KwaZuluNatal; Bekithemba Dube University of the Free State; Maserole Kgari-Masondo University of KwaZulu-Natal; Rembrandt Klopper University of Zululand; Simangaliso Kumalo University of KwaZulu-Natal; Sam Lubbe Mangosuthu University of Technology; Sadhana Manik University

of KwaZulu-Natal; Cheryl Mohamed Sayeed University of KwaZulu-Natal; Herbert Moyo University of KwaZulu-Natal; Priya Narismulu University of KwaZulu-Natal; Thengani Ngwenya Durban University of Technology; Maheshvari Naidu University of KwaZulu-Natal; Beatrice Okyere-Manu University of KwaZulu-Natal; Kunle Oparinde Durban University of Technology; Michael Samuel University of KwaZulu-Natal; Upasana Gitanjali Singh University of KwaZuluNatal; Lilian Siwila University of KwaZulu-Natal.
\end{abstract}

Alternation research groups have made decisive and far-sighted knowledge production contributions in the interdisciplinary Arts and Humanities arena for more than twenty-five years. From 2020, it adds the Alternation African Scholarship Book Series (AASBS) to its research outputs system. Via its incisive thematically-focused inter-, multi-, and transdisciplinary, as well as digitally-informed, research approaches, the AASBS not only advances the frontiers of knowledge in Africa's institutions of Higher Learning in designated focus areas, but also critically generates scholarship of, by and with the people(s) of our continent. Historically the research draws on the rich traditions of interactive African intellectualisations, from its earliest civilisations, through struggles for liberation and freedom, to independence and growth. It opens up future epistemic opportunities through intellectual initiative and resourcefulness, while critically contributing to the international advancement of knowledge on all relevant levels. Contributing to research-led constructive, transformative and substantial discourse development in our programmes and disciplines, it also aims at impacting the wellbeing of our people foundationally and all-inclusively in the present. All forms of scientific and social challenge which Africa's societies and communities face, need to be problematised

and researched in the Arts and Humanities, in the interest of cooperative and conscientious

responsible knowledge generation and foundational conceptual and methodological research impacts. We serve the hopes and aspirations of the people of Africa.

AASBS is committed to the highest levels of inclusive, factually correct and critical, sociallyresponsive and socially-accountable evidence-based research analyses and outputs. Each chapter is reviewed by at least two independent peer reviewers. Through its editing and peerreview system, each volume also builds research leadership, research expertise, and interactive research acumen, capacity and capabilities. 


\section{Alternation African Scholarship Book Series \\ (AASBS)}

Ramrathan, L., N. Ndimande-Hlongwa, N. Mkhize \& J.A. Smit (eds.). Rethinking the Humanities Curriculum in the Time of COVID-19. Volume \#01.

Ndimande-Hlongwa, N., L. Ramrathan, N. Mkhize \& J.A. Smit (eds.). Technology-based Teaching and Learning in Higher Education during the Time of COVID-19. Volume \#02.

Mkhize, N., N. Ndimande-Hlongwa, L. Ramrathan \& J.A. Smit (eds.). Teaching and Learning in Higher Education in the Time of COVID-19. Volume \#03.

Smit, J.A., N. Mkhize, N. Ndimande-Hlongwa \& L. Ramrathan (eds.). Learner and Subject at the Dawn of Digital Humanities Online ResearchLed Teaching and Learning. Volume \#04.

Amin, N. \& R. Dhunpath (eds.). (Re)Learning to Teach in the Context of Crises. Volume \#05.

Bob, U. (ed.). The COVID-19 Pandemic: Impacts of the Corona Virus on Sport and Society. Volume \#06.

Manik, S. (ed.). Sports amidst a Global Pandemic: Crisis, Capitulation and Creativity during COVID-19. Volume \#07. 


\title{
Teaching and Learning in Higher Education in the Time of COV TD-19
}

\author{
Editors \\ Nhlanhla Mkhize \\ Nobuhle Ndimande-Hlongwa \\ Labby Ramrathan \\ Johannes A. Smit
}

2020 
Published in 2020 in South Africa

CSSALL Publishers (Pty) Ltd

c/o POSTNET SUITE 158

Private Bag X9118

Pietermaritzburg

KwaZulu-Natal

3200

cssall123@gmail.com

Editor-in-Chief: Prof J.A. Smit

University of KwaZulu-Natal

smitj@ukzn.ac.za

Alternation African Scholarship Book Series Volume \#03

(C) CSSALL Publishers (Pty) Ltd

Title: Teaching and Learning in Higher Education in the Time of COVID-19 Editors: Nhlanhla Mkhize, Nobuhle Ndimande-Hlongwa, Labby Ramrathan, and Johannes A. Smit

ISBN: 978-0-9869936-4-0

DOI Number: https://doi.org/10.29086/978-0-9869936-4-0/2020/AASBS03

Cover design by Abdulbaqi Badru

University of Kwazulu-Natal

badrua@ukzn.ac.za

All rights reserved. No part of this publication may be reproduced, stored in a retrieval system, or transmitted in any form or by any means electronic, mechanical, photocopying, recording or otherwise, without the prior permission of the copyright holder and publisher.

CSSALL has no responsibility for the persistence or accuracy of URLs for external or third-party internet websites referred to in this volume, and does not guarantee that any content on such websites is, or will remain, accurate or appropriate.

Printed and bound by Print Connection, Tel (031) 202-7766; 202-7766 


\section{Preface}

Emerging first in Wuhan, China, followed by its spread to other parts of the world, COVID-19 has had governments globally, systematically initiate a variety of forms of intervention, to curb its spread. These include lockdowns, the restriction of movement, forms of social distancing and sanitizing practices, as well as the requirement that citizens wear face-masks. Since the responses took place according to regional exigencies and directives, and were not uniform and equally comprehensive, internationally, they have also had diverse effects. Ranging from shortcomings in medical and health care provisioning, through economic downturns and fears of the increase in practices of governance surveillance, to the disrupting of schooling and tertiary education systems, sports, and cultural and religious events and practices, COVID-19 bodily, mentally, materially and socially, destructively affected the whole world. Apart from its continued deadly impacts, and barring the arrival of universally effective vaccines, the spectre of COVID19 's expected second surge with the arrival of winter in the northern hemisphere, also have populations across the world readying themselves to learn to live with the presence of infection on a continuous basis.

Given this very brief and though limited scenario, this Preface provides the context for the first seven volumes of the Alternation African Scholarship Book Series (AASBS).

Focused on the impacts of COVID-19 on the Higher Education sector, especially from curriculum perspectives, at all levels and a sample of disciplines and subjects, the first four volumes were in principle conceptualised by the Alternation Editorial Committee (AEC), on 31 March 2020.

This initial project problematisation has grown into twelve research groups with seven AASBS volumes, and five Alternation Journal issues in production. Indications are that even if the world is rid of COVID-19 through vaccination - which might not happen in the near future - its impacts will be lasting. In the short to medium term we may also have to learn to live with the reality of the presence of the pandemic, and possibilities of infection and potential resultant death. These dynamics are being traced in the research, in, as well as outside academe, as we learn to transform and adapt to new realities, possibilities, risks, and drawbacks, of digital education and media. 
In many ways COVID-19 brought communities of teaching and learning closer together across the usual social and professional divides. The hope is to ensure the optimal wellbeing for the greatest possible number of our fellow human beings (Ubuntu), and for staff and students to benefit from available existing and (digitally-) constructed resources. This outcome motivates each moment of our collective research-led teaching and learning, even though distance and disease threaten all.

The research produced by the Alternation research groups constitute a small part of how academia attempts to both engage the conundrums and provide academic leadership amidst the effects and opportunities of COVID-19. And for this we want to thank the lead-editors and their teams, as well as all the colleagues from across southern Africa who have responded positively, and affirmatively to our call.

And for their endeavor, and sleepless days and nights of rescuing our sick and caring for those passing away, we want to dedicate these, the first number of volumes of our Alternation African Scholarship Book Series, to our courageous medical staff, those who provide comfort, relief and succor to our sick and those passing away, as well as the singular worker, mostly unrecognized, that kept the wheels of life and optimal wellbeing turning. Thank you, colleagues. And go well. Siyabonga, hamba kahle!

Prof Johannes A. Smit

Editor-in-Chief: AASBS 


\section{Contents}

\section{Johannes A. Smit}

Preface

Contents vii

Contributors ix

Nhlanhla Mkhize, Nobuhle Ndimande-Hlongwa, Labby Ramrathan, and Johannes A. Smit

Editorial: Teaching and Learning in Higher Education in the Time of COVID-19

Zinhle P. Nkosi, Nokukhanya Y. Ngcobo, Ayub Sheik and Nellie N. Ngcongo-James

Confronting the COVID-19 Challenge at a University in South Africa .... 16

\section{Langa Khumalo}

Using Corpora in Online isiZulu Language Teaching

Busisiwe P. Ncama and Sinegugu E. Duma

Delivery of Clinical Teaching and Learning for Health Sciences Students during the National Lockdown in Response to Covid-19: A Pragmatic Approach at the University of KwaZulu-Natal

Christina Kgari-Masondo and Zoleka Mkhabela Implications of the Minister of Higher Education's 'no child left behind' on African Child during the Coronavirus Pandemic in South Africa

Jayaluxmi Naidoo

Flipped Learning within Mathematics Teacher Education in

KwaZulu-Natal: Embracing Connectivism in Response to the COVID-19 Pandemi

Vasanthrie Naidoo and Maureen Nokuthula Sibiya COVID-19: Raising the Bar on Education Technology to 'Flatten the Curve' 
Aruna Ankiah-Gangadeen, Yesha Mahadeo-Doorgakant, and A. Goburdhun Covid-19: A Liability or Serendipity for Teacher education? Exploring Lockdown as an Opportunity for 'Innovative Disruption' in TEPs ......... 124

Vino Paideya

Understanding Remote Teaching and Learning Challenges amidst the COVID-19 Pandemic to Enhance Professional Development:

A Systematic Review of Peer-Reviewed Journal Articles, 2012 - 2020 ... 142

\section{Lungi Sosibo}

Redressing Inequalities while Envisioning University Student Teaching during the COVID-19 Lockdown: Lessons from \#RhodesMustFall and \#FeesMustFall

Kasturi Behari-Leak and Suren Behari

Leadership amidst the COVID-19 Crisis: Exploring a Curriculum for Servant Leadership in Higher Education and Beyond 187

Acknowledgment of Reviewers 210 


\section{Contributors}

Dr. Aruna Ankiah-Gangadeen is an Associated Professor and the Head of School of Arts and Humanities at the Mauritius Institute of Education. She obtained a BA(Hons) and Masters in English from the University of Delhi, India; an MEd in TESOL from the University of Leeds, UK; and a PhD in education from the University of KwaZulu Natal, South Africa. She is involved in teacher education, curriculum development and research. She has so far participated in the production of the National Curriculum Framework and coordinated a number of panels for the writing of English textbooks for primary and secondary levels. Her research interests include language teaching and learning in multilingual contexts; curriculum, policy and practice; and teacher identity. She has published papers and presented at conferences on these areas. a.ankiah@mie.ac.mu; https://orcid.org/00000002-4106-3951

Dr. Suren Behari is the Director of Engineering at a financial services company in California, USA. He received his Bachelor of Science degree in Mathematics and Statistics from the University of Durban-Westville, South Africa. He moved to the United States and worked as a software engineer and later as a senior product manager. Behari has spoken at a variety of businesses, events and conferences around the world. He received his MBA in e-Business from the University of Southern Queensland in 2012 and Ph.D. in Information Systems from the University of Southern Queensland in 2018. $\mathrm{He}$ is an Adjunct Lecturer at the University of Southern Queensland, and his research interests are Information Technology Service Management (ITSM), Big Data Analytics, and Metrics that Matter. Suren.behari@gmail.com; https://orcid.org/0000-0002-8700-2644;

Prof. Kasturi Behari-Leak (PhD) is an Associate Professor, Deputy Dean and interim Director of the Academic Staff and Professional Development in the Centre for Higher Education Development at UCT. Her work focuses on the interplay between institutional and disciplinary structures and culture and their contingent influence on academics' critical agency in current contexts. She is President of the Higher Education Learning and Teaching Association of Southern Africa (HELTASA); President-elect for ICED (2020-2021) and President of ICED (2021-2023); project leader of a national academic staff development collaborative project and co-chair of the Curriculum Change 
Working Group at UCT (2016-2018), focusing on decolonisation, decolonising pedagogies and decolonising the curriculum.

kasturi.behari-leak@uct.ac.za; https://orcid.org/0000-0001-9744-510X

Prof. Sinegugu E. Duma, holds a Doctor of Philosophy from UCT, Masters Degree in Nursing Education from UKZN, BA Cur in Nursing Education and Nursing Administration from UNISA, Diploma in Nursing (General, Psychiatric, Community Health) and Midwifery from the Natal College of Nursing and a certificate in Sexual Assault Forensic Nursing from Johns Hopkins School of Nursing. She is currently serving as the Dean of Teaching and Learning, College of Health Sciences, University of KwaZulu-Natal.

Dumas1@ukzn.ac.za; https://orcid.org/0000-0002-2489-8770

Seema Goburdhun (PhD) is an Associate Professor, and Head of Social Studies Department at the Mauritius Institute of Education. She holds a PhD in History from Banaras Hindu University, India and Masters in Education from the University of Brighton, UK. She teaches History of Mauritius to pre-service and in-service teachers and has been involved in the production of innovative pedagogical resources to promote the learning of History in schools. She is also engaged in developing curriculum materials for both primary and secondary school learners. Her research interests include teaching and learning of History, Heritage Education, teacher education and curriculum development. She is currently the Principal Investigator of a research project which focuses on understanding teachers' perception of Social Studies since its introduction in the school curriculum in Mauritius and the challenges encountered by the curriculum developers in the preparation of a Social Studies curriculum that can satisfy the exigencies of all quarters of the population. s.goburdhun@mie.ac.mu; https://orcid.org/0000-0003-4574-3513

Dr. Maserole Christina Kgari-Masondo is an ordained Pastor, Apostle and Bishop at The People of God Christian Ministries International. She is the founder and director of the ministry. She is a motivational teacher and counsellor. Also she is a certified marriage officer. She is currently a Senior Lecturer of Economic History at Howard College at the University of Kwa Zulu- Natal. Where she is a Cluster leader of Culture that focuses on Anthropology and Tourism. Her research interests are in socio-environmental concerns, decolonisation, indigenous knowledge, forced removals, teaching 
and learning matters and gender issues. Kgarimasondo@ukzn.ac.za; https://orcid.org/0000-0002-1850-6363

Prof. Langa Khumalo is an Associate Professor in the Department of Linguistics at the University of KwaZulu-Natal. He served the University of KwaZulu-Natal as the Director of Language Planning and Development Office since January 2014. He initiated and led the development of the isiZulu National Corpus (INC) at UKZN to be the biggest corpus in African Languages, the English-IsiZulu Parallel Corpus (EIPC) and the IsiZulu Oral Corpus (IOC). khumalol@ukzn.ac.za; https://orcid.org/0000-0002-2694-9105

Dr. Yesha Devi Mahadeo-Doorgakant (PhD) is Lecturer at Mauritius Institute of Education. Her work focuses on educational linguistics and understanding multilingual educational systems and how languages are learnt/taught in multilingual contexts. She is currently the principal investigator of a research project at MIE which is exploring the pedagogical practices of educators using the English Grade 7-9 textbooks in different secondary schools. She received her Bachelor in Joint Humanities (English and French) from University of Mauritius and her Masters in Applied Language Studies from University of Westminster. She graduated from University of KwaZulu Natal in 2017 with her PhD in Education. Her main research interests are multilingualism and learning/teaching of languages in multilingual contexts. y.doorgakant@mie.ac.mu; https://orcid.org/0000$\underline{0002-5134-6189}$

Zoleka Mkhabela has worked at North-West University, Potchefstroom Campus before joining the University of KwaZulu-Natal, Edgewood Campus, where she taught History Education. Zoleka Mkhabela is currently a $\mathrm{PhD}$ candidate focusing on the South African school curriculum and land reform. Her research interests are in History education (particularly controversial issues); South African Curriculum focusing on inequalities and social justice; African history and African consciousness. zoleka.mkhabela@gmail.com

Prof. Nhlanhla Mkhize is the Deputy Vice-Chancellor and Head of the College of Humanities at the University of KwaZulu-Natal, South Africa. He is the former Dean of the Faculty of Humanities, and former Dean and Head of the School of Psychology at the University of KwaZulu-Natal. He co-led the roll-out of the Certificate Course in Community Based Work with Child- 
ren and youth, a joint initiative of REPSSI and the University of KwaZuluNatal, which was implemented in 10 countries in the SADEC region. He is currently leading an integrated psychosocial intervention project to assist vulnerable communities to respond to the mental health and social implications of the COVID-19 pandemic in the KwaZulu-Natal province, South Africa. He holds a PhD in Psychology and has published articles and book chapters on various aspects of Afrikan Psychology, Afrikan Ethics, and the use of Afrikan Languages as a vehicle to transform higher education in South Africa. He is one of the founding members of the Forum of Afrikan Psychology and former President of the South African Humanities Deans' Association (SAHUDA). Mkhize@ukzn.ac.za; https://orcid.org/0000-0002$\underline{0088-5780}$

Prof. Jayaluxmi Naidoo is an Associate Professor and Academic Leader: Postgraduate Certificate in Education: University of KwaZulu-Natal (UKZN), South Africa. Her research interests include exploring technologybased pedagogy for mathematics, indigenous knowledge systems and mathematics, mathematics teacher training and development. naidooj2@ukzn.ac.za; https://orcid.org/0000-0003-3433-5354

Dr. Vasanthrie Naidoo is a Registered Critical Care nurse and Senior lecturer at the Department of Nursing - Durban University of Technology, KwaZulu-Natal. Her research interests include Critical care, Nursing education and Cross-border education and research. vasanthrien@dut.ac.za; https://orcid.org/0000-0003-2740-5983

Prof. Busisiwe Ncama is serving as the Deputy Vice Chancellor, College of Health Sciences at University of KwaZulu-Natal. She holds a BCur Degree from UNISA, MCur and PhD in Health Sciences from the University of KwaZulu-Natal. Ncamab@ukzn.ac.za; https://orcid.org/0000-0002-8084$\underline{4910}$

Prof. Nobuhle Ndimande-Hlongwa is Dean and Head of School of the School of Arts, and former Dean of Teaching and Learning and an Associate Professor in the College of Humanities at the University of KwaZulu-Natal. She is an author of the scholarly book titled Ukuhlelwa Kolimi, (Shooter \& Shuter, 2009) translated as Language Planning. She co-guest edited a special issue of Alternation Journal 17,1 (2010) with the theme, Multilingualism for Access, Language Development and Language Intellectualisation. She is 
also the Editorial Secretary of Nomina Africana Journal. She was a member of the Ministerial Advisory Panel on the development of African Languages in Higher Education. She is a Commissioner for the Linguistic Human Rights Tribunal within the Pan South African Languages Board (PanSALB). hlongwan1@ukzn.ac.za; https://orcid.org/0000-0001-9597-8690

Dr. Nokukhanya Ngcobo is a lecturer at the University of KwaZulu-Natal, in the School of Education. Her research interests are language and gender, critical literacy, youth, health, sexuality, HIV and AIDS in education, cultural identity and media and mother-tongue based bilingualism. Ngcobon13@ukzn.ac.za; https://orcid.org/0000-0002-1738-6195

Mrs. Nellie Ngcongo-James is a lecturer in the Languages and Arts Cluster, School of Education, College of Humanities, at the University of KwaZuluNatal. Her research interests include Drama Education, Shakespeare and Decoloniality. ngcongojamesn@ukzn.ac.za; https://orcid.org/0000-00022153-6870

Dr. Zinhle P. Nkosi is a Senior Lecturer in the Languages and Arts Cluster, School of Education, College of Humanities, at the University of KwaZuluNatal. She has worked in the same institution since 2009. Her research interests include language and education research and literature. Nkosiz@ukzn.ac.za; https://orcid.org/0000-0001-6086-3252

Dr. Vino Paideya is a Senior lecturer and first year coordinator in the School of Chemistry \& Physics at University of KwaZulu- Natal. Her qualifications include a Bachelor's degree in Science (BSc) and a $\mathrm{PhD}$ in education. Research interests are first year student experiences, chemistry education, student academic support programmes (Supplemental Instruction) and institutional research projects. She has published her work in several peer reviewed journals and conference proceedings in her field of interest. paideya@ukzn.ac.za; https://orcid.org/0000-0002-5231-2458

Prof. Maureen Nokuthula Sibiya is the Deputy Vice-Chancellor: Teaching and Learning at the Durban University of Technology, KwaZulu-Natal. She is NRF-C3 rated and her research focus areas include Primary Health Care, Nursing Education and Health Systems research. nokuthulas@dut.ac.za; https://orcid.org/0000-0003-1220-1478 
Prof. Ayub Sheik is Associate Professor in the Department of English Education at the University of KwaZulu-Natal. He has taught at various universities in the United Arab Emirates. He was also an Andrew Mellon Postdoctoral Fellow at the University of KwaZulu-Natal as well as a visiting DAAD scholar at the University of Essen in Germany. His research preoccupations are period poetry, teaching Shakespeare, Narratology as well as the supervision of students in English Education. sheika@ukzn.ac.za; https://orcird.org/0000-0002-8633-3740

Prof. Zilungile Lungi Sosibo is a Head of Department of the Senior Phase \& Further Education \& Training (SP\&FET) Department in the Faculty of Education at Cape Peninsula University of Technology, Cape Town, South Africa. Her research focuses mainly on Diversity and Transformation in Higher Education. Over the years, she has obtained the NRF Knowledge, Interchange and Collaboration (KIC) grant in 2016 and 2018; the NRF Competitive Grants for Unrated Researchers in 2014 - 2016 \& 2017 - 2019); as well as several other grants from CPUT. She and her team successfully hosted the 2018 45th international conference of the Southern African Society of Education (SASE) which took place on 03 - 05 October 2018 in Cape Town, South Africa. She boasts research partnerships with Nova Southeastern University in Fort Lauderdale in Florida, USA; Adeyemi College of Education and Tai Solarin University of Education in Nigeria; as well as with Kwame Nkrumah University of Science \& Technology in Ghana. She has served on Umalusi Council (2006 - 2014); Council on Higher Education (CHE) (2011-2015); Northlink College Council (2009 - 2011); and CPUT Council (2018- Present). SosiboL@cput.ac.za; https://orcird.org/0000-0002-2424-7337

Prof. Labby Ramrathan is a Professor at the School of Education at the University of KwaZulu-Natal and a NRF rated researcher. He simultaneously serves as President of the South African Education Research Association (SAERA). He has been involved in several institutional, national and international project works and has published widely in these areas of scholarship. Currently he is leading the College of Humanities, UKZN, curriculum transformation process within the context of decolonization. ramrathanp@ukzn.ac.za; https://orcid.org/0000-0001-9963-0675 
Prof. Johannes A. Smit, is Professor of Religion and Social Transformation, Chair: Humanities Institute, and former Dean and Head of School of the School of Religion, Philosophy and Classics, and the School of Arts (Acting), UKZN. He is the founding editor of the Alternation Journal, ([1994] 1996), as well as of the Alternation African Scholarship Book Series (2020), and served as research chair of the former Faculty of Arts/ Humanities. He has a lifelong commitment to interdisciplinary learning and critical research capacity development in the Arts and Humanities. He was also President of the Association for the study of Religion in Southern Africa (ASRSA), editor-in-chief of the Journal for the Study of Religion (in Southern Africa), teaches Comparative Religion (main focus Christianity), and is the founder of the postgraduate Programme in Religion and Social Transformation in 2000, that has graduated in excess of 300 postgraduate students, until 2011. smitj@ukzn.ac.za; http://orcid.org/0000-0003-1792$\underline{5256}$ 


\section{Editorial}

\section{Teaching and Learning in Higher Education in the Time of COVID-19}

\section{Nhlanhla Mkhize}

ORCID iD: https://orcid.org/0000-0002-0088-5780

Nobuhle Ndimande-Hlongwa

ORCID iD: https://orcid.org/0000-0001-9597-8690

\section{Labby Ramrathan}

ORCID iD: $\underline{\text { https://orcid.org/0000-0001-9963-0675 }}$

\section{Johannes A. Smit \\ ORCID iD: http://orcid.org/0000-0003-1792-5256}

Globally, the COVID-19 pandemic brought basic and higher education almost to a complete standstill, leading to educational institutions exploring mechanisms to 'save the academic year' while ensuring that 'no learner was left behind'. According to UNESCO, 9.8 million African students are experiencing a disruption in their studies due to the closure of higher education institutions. South Africa, like other countries, implemented a hard lockdown to contain the spread of the pandemic while preparing the health care system to respond to the expected increases in COVID-19 patients. Fearing contamination from the virus, the management of higher education institutions quickly arranged for students to return home and turned to emergency remote online/ e-learning to save the academic year.

However, a transition to an online mode is complicated on a continent where only $24 \%$ of the population has access to the internet. 
Emergency remote teaching and learning poses several challenges for a country such as South Africa, where the economic disparities between the rich and the poor are among the largest in the world (Tregenna \& Tsela 2012). Further, the digital divide in the country mirrors the racial inequalities of the apartheid era, whereby the greatest proportion of learners with limited access to smart phones, computers and who also have connectivity challenges, are predominantly Black African and Coloured. It is not surprising, therefore, that the greatest debate to date concerning the massive roll out of emergency online teaching and learning by higher education institutions has focused on matters of justice: the learners' differential access to technology-enhanced learning, connectivity issues, and unconducive learning environments due to over-crowding and other challenges experienced in the home sphere. du Preez and le Grange (2020: 92) specifically point out that in South Africa there is 'unequal access to technologies used in online learning as well as unequal access to data and connectivity' and a large percentage of the population do not have access to the internet at home. It is not surprising, therefore, that many of the chapters in this edited volume tackle the challenges posed by digital inequalities.

The challenges of emergency online learning are however not circumscribed to limited resources on the part of the students; many institutions of higher learning were not ready to shift to e-learning instantly. Teaching practices (the theory and the practical/ clinical components) also had to be transformed, almost overnight, to be in line with the pedagogy of online teaching and learning. It should be recognized that to suddenly require the academic staff to change from face-to-face contact teaching to technology-mediated teaching and learning calls for a major paradigm shift on their part. Teaching and learning is not about the technical delivery of information, from one source to another; it is an integral part of one's identity and hence it should be conceptualized in social and relational terms. It is a social practice.

Borrowing from Doston's (2014) analysis of epistemic oppression, Bartunek and Moch's (1987) notions of First, Second, and Third Order changes are used here to illustrate the kind of transformation and paradigm shift that is required on the part of academics and institutions to fully embrace e-learning. According to Bartunek and Moch (1987:486), first-order change involves 'the tacit reinforcement of present understandings' and does not require any changes in the organizational schemata themselves. As 
Doston (2014) notes, this kind of change is often resorted to when there are inefficiencies in the system and only results in attempts to change strategies or behaviors in order to fit the solution to already-existing beliefs and assumptions, without interfering with the latter.

Applied to the responses that higher education institutions implemented in response to the challenges of COVID-19, first-order change could be equated to simply moving one's content online, without interrogating the pedagogy of online learning, nor taking into account the lived realities of the learners during the pandemic. Hence, this solution addresses the fact that the classroom is inaccessible to both the learner and the educator; the latter's attempt at resolving the problem is to get the content to the student. As some of the chapters in this edited volume argue, an approach of this nature is problematic as it does not take cognizance of the social, economic, and social realities of the learners, amongst others.

Pohlhaus (2012: 3) makes a strong argument in favour of recognizing the sociality of knowers. She avers that: 'The knower's situatedness refers to the situations in which the knower finds herself repeatedly over time due to the social relations that position her in the world' (emphasis in original). Pohlhaus (2012: 3) continues and opines that out of this situatedness arises 'particular habits of attention that may attune the knower to others' habits of attention or not, depending upon one's social vulnerability ... social position has a bearing on what parts of the world are prominent to the knower and what parts of the world are not'. In their account of reflexivity, Bourdieu and Wacquant (1992) make a similar argument. They argue that we should go beyond the prior-understandings and social origins that condition our understanding and reflect upon 'the position that the analyst occupies ... in the microcosm of the academic field, ... in the objective space of possible positions offered to him or her at a given moment, and, beyond, in the field of power' (Bourdieu \& Wacquant 1992: 39, emphasis in original). The events that were unfolding as institutions of higher learning were responding to the challenge of the COVID-19 pandemic were, ultimately, about power.

The above-mentioned position is commensurate with the social and cultural tradition in Psychology (Vygotsky 1981), which argues that learning is socially and culturally-mediated by means of tools such as language, in the zone of proximal development (comprising the gap between what the learner can accomplish by themselves and what he/ she can accomplish when learning is facilitated by a competent adult or peer). A mere provision of 
gadgets ignores that learning takes place at the zones of contact, between people, who are also situated in culture. Providing data and computers to students to learn from home, without addressing the students as situated knowers, and the pedagogical issues surrounding online learning, addresses the problem only at the level of first-order change. The social and cultural positionality of the learners, such as their crowded living environments, their access to linguistic tools, and even the real possibility of gender-based violence, are left un-interrogated.

Second-order change involves an alteration of the organizational schemata themselves, the shared epistemic resources or mental constructs by means of which the organization collectively makes sense of the world (Bartunek \& Moch 1987; Doston 2014). When the mental constructs and epistemic resources are no longer sufficient to fulfil organizational goals, it is the interpretive frameworks or the schemata themselves that ought to be changed, resulting in second-order change. Second-order change involves changes in the group's values and their ways of thinking and feeling in relation to a particular problem or domain, thereby leading to new strategies (Bartunek \& Moch 1987; Doston 2014). In the context of the COVID-19 experience, second-order change occurs when we begin to see the issues from the perspective of the marginalized students, and we become sensitive to the full range of their experiences. At this stage, the student emerges in our understanding as an umuntu, a human being who is deserving of our respect and compassion independently of their standing in life. When this level of change occurs, a space is opened for those affected by COVID-19, be they staff or the students, to communicate their accounts in full and be heard, rather than being discounted as insignificant.

Medina (2012) refers to the process whereby communicative obstacles prevent others differentially from expressing their views, leading to them being silenced, as hermeneutical injustice. Relinquishing power and privilege, in order to listen attentively to the experiences of the other who is less privileged than us, is an integral part of second-order change. A few chapters in this edition explore these issues with reference to the concept of ubuntu and the invaluableness of human life independently of whose life is at stake. In this regard, our responses to the COVID-19 pandemic and its impact on higher education can benefit from the several attempts to infuse the philosophy of ubuntu into open distance learning (ODL) (Letseka 2016; Mashile \& Matoane 2016). 
Third-order change involves 'the training of organizational members to be aware of their present schemata and thereby more able to change these schemata as they see fit (Bartunek \& Moch 1987:486). As the organization develops the capacity to reflect upon itself, it gradually becomes able to identify 'and alter elements of operative, instituted social imaginaries that inform and preserve organizational schemata' (Doston 2014:119). In the context of a university, this calls upon us to take a step back to become aware of our epistemological systems and cultural traditions, their limitations, and change them where this is required. In the context of COVID-19, institutions of higher learning were called upon to reflect deeply on their epistemologies, their limits, their deeply-held beliefs and identities about ourselves and others. This according to Bartunek and Moch (1994) is the most difficult aspect of change.

The chapters in this edited volume talk to various aspects of firstorder, second-order, and third-order changes that were implemented by institutions of learning in South Africa, in their attempts to respond to the COVID-19 pandemic. These changes were concurrent, although the degree of the implementation of each level of change, and successes, vary. The chapters also reflect on various aspects of epistemic exclusions (Doston 2014) and hermeneutical injustices (Medina 2012) that were witnessed, and call for an implementation of an ubuntu approach in higher education institutions' responses to the COVID-19 pandemic; a social justice perspective that frames the problem using the perspective of both/ and thinking, rather than the binary logic of us (management, government) vs. them (students) (Alinia 2015).

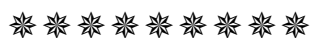

In Chapter 1, 'Confronting the COVID-19 Challenge at a University in South Africa', Zinhle P. Nkosi, Nokukhanya Y. Ngcobo, Ayub Sheik and Nellie N. Ngcongo-James report on the University of KwaZulu-Natal's response to the impact of COVID-19. This constituted extensive planning among all stakeholders at the university, in ensuring that students and staff are well equipped to confront the pandemic. This chapter aims to highlight how the university has responded to the institutional closure and how it has protected its integrity in ensuring that teaching and learning is not compromised. For the purposes of this chapter, only data sourced from 
lecturers is discussed. In a bid to save as much of the 2020 first semester as possible, the University management required academics to put their content on-line, to be accessed by students. This also required academics reviewing module content, approaches to teaching, modes of delivery, and assessment strategies. By way of illustration, in order to present a class lecture, lecturers have undergone several training and workshop sessions on remote teaching, on Zoom live teaching, as a replacement for traditional classroom teaching, for example. The chapter focuses on the School of Education, and reports on its programmes. Collection of data was impacted by the lockdown and legal requirements of social distancing. Consequently, interviews through the Zoom App were conducted with eight lecturers located in the Languages and Arts Cluster, within the School of Education. Document analysis was also used to establish what plans and programmes were in place in response to the COVID-19 pandemic. Amongst findings, it is evident that the University of KwaZulu-Natal (UKZN) has taken proactive measures in ensuring that teaching and learning continue, and every lecturer has access to resources for remote teaching and learning. Whilst cognisant of the fact that the University is still in its infant stage of remote teaching and learning, the study indicates that staff are responding positively to these changes and that despite the pandemic, morale remains high.

The impact of the Covid-19 global pandemic on higher education in South Africa has inspired the academy to adopt new pedagogies in the teaching of African languages. The second chapter shows that through the use of an isiZulu corpus, African language courses can be offered online, using digital humanities methodologies such as the AntConc concordance program. African languages are resource-scarce languages (Bosch et al. 2007; Pretorius \& Bosch 2003; Keet \& Khumalo 2017). This scarcity includes the paucity of exhaustive grammatical descriptions, the compilation of both large and specialized corpus resources, and the development of machine-readable lexicons. A corpus is thus carefully designed and systematically collected natural language data from a variety of text types and sources following a particular set of principles, which constitute a sample that statistically reflects the use of that particular language, and is processed, stored and accessed by means of computers.

In Chapter 2, then, 'Using Corpora in Online isiZulu Language Teaching', Langa Khumalo argues for a novel way of teaching African languages, particularly isiZulu, using corpora and lexical software as open- 
source online resources. UKZN has developed the isiZulu national corpus (INC) to be the biggest African language corpus, as well as two other corpus typologies, the English-isiZulu Parallel Corpus (EiPC) and the IsiZulu Oral Corpus (IOC), that are available as digital resources for language research and language teaching. Using AntConc, which is a freeware concordance program for Windows, African languages courses can be offered online in response to the COVID-19 education lockdown.

In Chapter 3, 'Delivery of Clinical Teaching and Learning for Health Sciences Students during the National Lockdown in Response to COVID-19: A Pragmatic Approach at the University Of KwaZuluNatal', Busisiwe P. Ncama and Sinegugu E. Duma argue that COVID-19 has posed a challenge to teaching and learning at institutions of higher education in South Africa, but even more so in the delivery of clinically focused programmes that require experiential learning to happen in healthcare settings, which are the epicentre for combating the COVID-19 epidemic. The national lockdown, which resulted in the abrupt closure of university residences and the withdrawal of students from healthcare settings to promote physical distancing and reduce the spread of COVID-19, also disrupted the core principles of clinical placement and clinical rotation - the main delivery mode of all clinically focused programmes in the College of Health Sciences (CHS), University of KwaZulu-Natal.

The impact of the sudden withdrawal of students from clinical placement because of the national lockdown to flatten the curve of the spread of COVID-19, is huge for clinical learning. Although it is possible to extend time for clinical placement and achievement of clinical learning outcomes once the epidemic is over for students in pre-clinical years and junior years, the same cannot be said for senior and final-year health science students. The latter have to achieve all the exit-level outcomes of programmes, and meet the requirements of the professional bodies before graduating and registering as qualified health professionals.

Yet, final-year health sciences students can gain a lot of knowledge and experience in managing epidemics of this nature by being in the frontline, working and learning side by side all other health professionals in fighting this epidemic. Even so, the reality is that students are novices, and thus at greater risk of being infected with COVID-19 in their line of duty, than experienced professionals. Therefore, a careful balance needs to be reached in meeting their clinical training needs. 
With regard to 'Implications of the Minister of Higher Education's "no child left behind" on an African Child during the Corona Virus Pandemic in South Africa', in Chapter 4, Christina KgariMasondo and Zoleka Mkhabela point to the fact that the global decolonisation of education in higher learning encourages scholars to revisit the African past for inspiration to deal with contemporary education problems deterring students from enjoying the education they deserve. The current global Corona pandemic has exacerbated the inequalities existing in societies, leading to education institutions finding it difficult to ensure that all students equal access teaching and learning. In South Africa, the majority of students are African, and they reside in rural ecologies that lack infrastructure like electricity and running water. Many of such students lack resources to engage in the current exclusively technology-based education, due to poverty and funding needs. Despite that, the Minister of Higher Education, Dr. Blade Nzimande, introduced the principle of "no child left behind' during the implementation of online teaching. Yet, this was done without providing ways and means of attaining that. The chapter interrogates the feasibility of not leaving any child behind, especially those in rural ecologies who have no access to online teaching and learning gadgets and struggle with electronic network access. Existing research indicates that there is a lack of acknowledgement of African teachers' voices about solutions to their students' experiences drawing on indigenous knowledge, in matters that the government introduces in varied contexts. Therefore, the chapter reports on a qualitative study through the auto-ethnographic observations and reflections of two African lecturers about the 'silenced' narratives of diverse African students' living contexts that need to be accommodated in the implementation of online teaching and learning, and so ensure they are not left behind during the era of pandemic. For this project, we draw on one of the IsiZulu idioms, umuntu akalahlwa (a human person is not disposable), as a way of mitigating the concern of 'no child left behind'. The study concludes that umuntu akalahlwa is a pedagogy that can be used in unsilencing measures that inhibit students from accessing online teaching and learning as it safeguards the human rights of all students.

In chapter 5, 'Flipped Learning within Mathematics Teacher Education in KwaZulu-Natal, South Africa: Embracing Connectivism in Response to the COVID-19 Pandemic', Jayaluxmi Naidoo positions the research focus within the context of the fact that the COVID-19 pandemic has 
disrupted life-encompassing societal and educational lockdowns globally. Higher Education Institutions are undertaking various approaches to complete the academic semester remotely while seeking to maintain academic integrity. Within the Fourth Industrial Revolution, digital tools are viewed as essential in facilitating remote learning. Globally, institutions are introducing virtual and remote learning within their curricula. In mathematics education contexts, coupled with embracing remote learning, are issues of what it means to incorporate flipped learning within the context of COVID-19. Naidoo's chapter draws attention to a qualitative study that explored mathematics education students' perceptions of flipped learning within the context of the pandemic. The study was framed by connectivism, which is a network learning theory guided by the view that learning is a process whereby new information is continuously being acquired. Participants were invited to interactive virtual workshops focusing on flipped mathematics learning within the context of the COVID-19 outbreak. Subsequently, participants were interviewed online, based on their perceptions of flipped mathematics learning. The findings of this study indicate that there are challenges with using flipped learning and the advantages of collaboration inspired by flipped learning within the context of COVID-19. Globally, these findings have relevance when considering the perceptions and implications of flipped mathematics learning within the context of the COVID-19 pandemic.

Chapter 6, by Vasanthrie Naidoo and Maureen Nokuthula Sibiya, 'COVID-19: Raising the Bar on Education Technology to "Flatten the Curve", introduce essential knowledge and discusses key issues related to quality assurance practices with distance learning. This is in the broader context of the World Health Organization's announcement that the current outbreak of the Coronavirus disease (COVID-19), health crises have constituted a public health emergency of international concern. It has necessitated international lockdowns of countries as part of strict infection control protocols. The COVID-19 pandemic has also become a major challenge for most learning institutions around the world, making this disease a pervasive force shaping and challenging higher education as it faces the new realities of distance education. The pandemic crises have affected the continuity of learning and the delivery of course material at higher education institutions. To remain relevant, tertiary education institutions have had to reinvent their learning environments in order to embrace distance education whilst still trying to maintain effective student-lecturer relationships. Various 
dimensions of quality assurance challenges often surround the facilitation and delivery of distance education or multimedia platforms of teaching and learning, prompting the need for rigid quality control principles to guide programme or course delivery. Notably, there is still a need to identify functional deficits and challenges of distance education programmes from a learning and teaching perspective. So, deriving from their own experiences, and research with distance education, Vasanthrie Naidoo and Maureen Nokuthula Sibiya, deals with seminal scholarly insights and key issues related to quality assurance practices with distance learning. Stimulating discussion and establishing a connectivity between quality assurance practices and online teaching and learning programmes, this chapter also offers valuable insight into forthcoming as well as existing curriculum developers who plan to engage in distance education curriculum development and delivery.

The sudden onslaught of the Covid-19 pandemic around the globe has forced the shut-down from the outside world, compelling everyone to review existing practices at all levels. The norms derived from life - personal and professional - as it used to be lived, are no longer relevant during the pandemic and new practices are being adopted to cope within confinement measures. In their 'Covid-19: A Liability or Serendipity for Teacher Education? Exploring Lockdown as an Opportunity for 'Innovative Disruption' in TEPs', Aruna Ankiah-Gangadeen, Yesha MahadeoDoorgakant and Seema Goburdhun study the impact of confinement on Teacher Education Programmes (TEPs) within a Mauritian Tertiary Education Institution (TEI) where, for years, management invested massively in technological resources and attempted to bring about a paradigm shift in teaching, but with little success. It is noted though, that, following the lockdown, teaching shifted from prevailing and predominant face-to-face sessions to online modalities within a span of days. With teacher educators having been propelled out of their comfort zones, and being currently engaged with new modes for course delivery, the authors seek to understand how the lockdown has unleashed new potential and possibilities with regard to TEPs, at the level of curriculum content and transaction. Rather than adopting a deficit view of the situation, knowing fully well that the abrupt shift to online teaching inevitably carries its dose of liabilities and problems, the authors deliberately focus on positive experiences and fresh perspectives that may serve to revamp TEPs as far as scope and currency are concerned. 
The case study on which this chapter is based, was anchored in Appreciative Inquiry and adopted a grounded approach to data generation and analysis. To allow for the production of rich textured data emanating from varied perspectives, participants constituted teacher educators with different areas of specialisation. The findings revealed that the forceful shift to online learning brought about an awareness of opportunities afforded by online teaching and learning modes as well as more willingness to continue along these lines in the future. It also provided insights into the shortcomings of the TEPs with regards to skills and attitudes to be developed.

In Chapter 8, 'Understanding Remote Teaching and Learning Challenges amidst the COVID-19 Pandemic to Enhance Professional Development: A Systematic Review of Peer-Reviewed Journal Articles, 2012-2020', Vino Paideya produces a systematic review of scholarly focused on academics' remote teaching experiences, from 2012 to 2020 . She points out that remote teaching and learning for many higher educational institutions nationally and internationally have become a growing response to enacting contingency plans to contain and manage the effects and impact of the COVID 19 virus pandemic. Yet, many institutions have been developing and encouraging such remote online teaching and learning for many years. Focused on the literature, her research explores the challenges experienced with novice online teaching and learning practices. Although several reviews exist that focus on specific aspects of online teaching and learning and blending learning practices, there has been no broad overview of literature exploring recent trends and challenges of remote teaching and learning. Data sets were divided into three main themes: the student, lecturer, curriculum needs. Research analysis over this period suggests that challenges in remote education need to be addressed through ongoing provision of professional development for lecturers, trainings for students, and technical support for content development. Paideya's research indicates that there is a need to identify credible novice online teaching and learning practices during the transition from face-to-face to online learning during the time of COVID-19. She also provides a contemporary picture of challenges that can be avoided with the implementation of remote teaching and learning during COVID-19.

Lungi Sosibo, in Chapter 9, focuses on 'Redressing Inequalities while Envisioning University Student Teaching during COVID-19 Lockdown: Lessons from \#RhodesMustFall and \#FeesMustFall'. The 
chapter's point of departure is that the intensity of COVID-19 is currently not the same in developed and developing countries. It appears that developed countries are heavily burdened by the impacts of the COVID-19 pandemic. The instability brought about by this pandemic has serious ramifications for the country's economy and schooling at all levels. In order to flatten the curve, the South African government implemented the lockdown of the country, which meant no contact learning could occur. Consequently, the decision was made by departments of education, schools and universities to offer remote teaching and learning. This chapter reports on the efforts made by one South African higher education institution (HEI) to save the 2020 academic project in the midst of COVID-19 lockdown, based on the author's experiences and observations. Results revealed that during the COVID-19 lockdown, HEIs operated at different stages of preparedness regarding provision of remote teaching and learning. The author argues that prioritising remote teaching and learning after the 2015-2016 \#RhodesMustFall and \#FeesMustFall student protests should have prepared South African HEIs better to meet curriculum demands emanating from COVID-19 lockdown. Furthermore, had all institutions increased capacity development and ensured wider staff and student accessibility to resources, the curriculum would have been delivered efficiently during the COVID-19 lockdown. The chapter concludes by showing how the COVID-19 lockdown has transformed and reshaped the manner in which teaching should be done in the future.

Finally, in Chapter 10, 'Leadership amidst the COVID-19 Crisis: Exploring a Curriculum for Servant Leadership in HE and Beyond', Kasturi Behari-Leak and Suren Behari, bring this volume to a close. The novel Coronavirus (COVID-19) has spread rapidly across the globe, leaving practically no-one unaffected. Evidence suggests that this virus does not discriminate against anyone: every race, gender, class, faith, ethnicity and nation have experienced disruption and disorder as a result. It is a demonstration of our common humanity, of our sameness. Through participant observations, the authors, located in South Africa and the United States, offer personal perspectives, observations and experiences of leadership practices at local, national and international levels. By means of this chapter, they explore how leadership as agency can be strengthened and consolidated in the Higher Education curriculum. The chapter draws on the scholarship and theoretical principles of leader-less and leader-full models, to advance an argument for 'servant-leadership' at the individual, community, 
organisation, national and global echelons of society. The proposed actionoriented leadership curriculum is based on a model of servant leadership that encourages us all to work together to devise ways to make each individual and citizen more capable of managing and responding to change and disruption in critical, empathic and socially responsive ways.

\section{Conclusion}

The chapters in this edited volume reflect on the various challenges that were experienced by higher education institutions, in their attempts to facilitate the transition to online teaching and learning, in response to the COVID-19 pandemic. We have reflected on these institutional responses using the notion of first, second, and third-order change. The chapter highlight resource challenges and the pedagogical and epistemological obstacles that were encountered, thus making the notion of 'leaving no learner behind', difficult. Ultimately, institutions' responses to online teaching and learning is a matter of social justice. Not only should they take into account the social and cultural positionality of the learners: they should also be informed by both/ and thinking, which is commensurate with the Ubuntu paradigm.

\section{References}

Alinia, M. 2015. On Black Feminist Thought: Thinking Oppression and Resistance through the Intersectional Paradigm. Ethnic and Racial Studies 38,13:2334 - 2340.

https://doi.org/10.1080/01419870.2015.1058492

Bartunek, J.M. \& M. K. Moch 1987. First-order, Second-order, and Thirdorder Change and Organizational Development Interventions: A Cognitive Approach. The Journal of Applied Behavioral Science 23,4: $483-500$.

https://doi.org/10.1177/002188638702300404

Bartunek, J. M. \& M. K. Moch 1994. Third Order Organizational Change and the Western Mystical Tradition. Journal of Organizational Change Management 7,1:24 - 41.

https://doi.org/10.1108/09534819410050795

Bosch, S.E., L. Pretorius \& J. Jones 2007. Towards Machine-Readable 
Nhlanhla Mkhize, et al.

Lexicons for South African Bantu Languages. Nordic Journal of African Studies 16,2: 131 - 145.

Bourdieu, P. \& L.J.D. Wacquant. 1992. An Introduction to Reflexive Sociology. Chicago. University of Chicago Press.

Doston, K. 2014. Conceptualizing Epistemic Oppression. Social Epistemology: A Journal of Knowledge, Culture and Policy 28,2:115 -138. https://doi.org/10.1080/02691728.2013.782585

Du Preez, P. \& L. le Grange. 2020. The Covid-19 Pandemic, Online Teaching/ Learning, the Digital Divide, and Epistemological Access. http://alternation.ukzn.ac.za/Files/books/series-01/01/06-Du-Preez.pdf

Keet, C.M. \& L. Khumalo 2017. Toward Verbalizing Ontologies in isiZulu. In Davies, B., L. Kaljurand \& D. Kuhn (eds.): Controlled Natural Language Proceedings. Switzerland: Springer.

Letseka, M. 2016. Introduction: Open Distance Learning (ODL) and the Philosophy of Ubuntu. In Letseka, M. (ed.): Open Distance Learning through the Philosophy of Ubuntu. New York: Nova Science Publishers. Mashile, E.O. \& M.C. Matoane 2016. Leadership in ODL Institutions: An Ubuntu Perspective. In Letseka, M. (ed.): Open Distance Learning through the Philosophy of Ubuntu. New York: Nova Science Publishers. Medina, J. 2012. Hermeneutical Injustice and Polyphonic Contextualism:

Social Sciences and Shared Hermeneutical Responsibilities. Social Epistemology: A Journal of Knowledge, Culture and Policy 26,2: 201 220.

https://doi.org/10.1080/02691728.2011.652214

Pohlhaus, G. 2012. Relational Knowing and Epistemic Injustice: Toward a Theory of wilful Hermeneutical Ignorance. Hypatia: A Journal of Feminist Philosophy 27,4: 715-735.

https://doi.org/10.1111/j.1527-2001.2011.01222.x

Pretorius, L. \& S.E. Bosch 2003. Finite State Computational Morphology: An Analyzer Prototype for Zulu. Machine Translation 18: 195 - 216.

https://doi.org/10.1007/s10590-004-2477-4

Tregenna, F \& M. Tsela. 2012. Inequality in South Africa: The Distribution of Income, Expenditure and Earnings. Development Southern Africa 29,1: 35 - 61. https://doi.org/10.1080/0376835X.2012.645640

Vygotsky, L.S. 1981. The Genesis of Higher Mental Functions. In Wertsch, J.V. (ed.): The Concept of Activity in Soviet Psychology. Armonk, NY: Sharpe. 
Professor Nhlanhla Mkhize

DVC and Head of the College of Humanities School of Applied Human Sciences

University of KwaZulu-Natal Durban, Edgewood \& Pietermaritzburg Mkhize@ukzn.ac.za

Professor Nobuhle Ndimande-Hlongwa Dean of and Head of School School of Arts

University of KwaZulu-Natal Howard College, Durban \& Pietermaritzburg Hlongwan1@ukzn.ac.za

Professor Labby Ramrathan School of Education, and President of SAERA 2019-2021

University of KwaZulu-Natal

Edgewood

Durban ramrathanp@ukzn.ac.za

Professor Johannes A. Smit Chair and Director: Humanities Institute School of Religion, Philosophy and Classics University of KwaZulu-Natal Durban, Edgewood \& Pietermaritzburg smitj@ukzn.ac.za 


\title{
Confronting the COVID-19 Challenge at a University in South Africa
}

\author{
Zinhle P. Nkosi
}

ORCID ID: https://orcid.org/0000-0001-6086-3252

\author{
Nokukhanya Y. Ngcobo
}

ORCID ID: https://orcid.org/0000-0002-1738-6195

\section{Ayub Sheik \\ ORCID ID: $\underline{\text { https://orcid.org/0000-0002-8633-3740 }}$}

\section{Nellie N. Ngcongo-James \\ ORCID ID: https://orcid.org/0000-0002-2153-6870}

\begin{abstract}
According to UNESCO, 9.8 million African students are experiencing a disruption in their studies due to the closure of higher education institutions. The danger of contamination from the coronavirus has forced institutions to move their courses online. However, a transition to an online mode is complicated on a continent where only $24 \%$ of the population has access to the internet. This study reports on the University of KwaZulu-Natal's response to the impact of COVID-19. This constituted extensive planning among all stakeholders at the university, in ensuring that students and staff are well equipped to confront the pandemic. This paper aims to highlight how the university has responded to the institutional closure and how it has protected its integrity in ensuring that teaching and learning is not compromised. For the purposes of this paper, only data sourced from lecturers will be discussed. In a bid to save as much of the 2020 first semester as possible, the University management required academics to put their content on-line, to be accessed by students. This also required academics reviewing module content, approaches to teaching, modes of delivery, and assessment strategies. By way of
\end{abstract}


illustration, in order to present a class lecture, lecturers have undergone several training and workshop sessions on remote teaching, for example, Zoom live teaching as a replacement for traditional classroom teaching. This paper aims to focus on the School of Education, and reports on its programmes. Collection of data was impacted by the lockdown and legal requirements of social distancing. Consequently, interviews through the Zoom App were conducted with eight lecturers located in the Languages and Arts Cluster, within the School of Education. Document analysis was also used to establish what plans and programmes were in place in response to the COVID-19 pandemic. Amongst findings, it is evident that the University of KwaZulu-Natal (UKZN) has taken proactive measures in ensuring that teaching and learning continue and every lecturer has access to resources for remote teaching and learning. Whilst cognisant of the fact that the University is still in its infant stage of remote teaching and learning, the study indicates that staff are responding positively to these changes and that despite the pandemic, moral remains high.

Keywords: COVID-19, remote teaching, online assessment, staff training, lockdown regulations, teaching and learning.

\section{Introduction}

The Coronavirus pandemic has severely disrupted almost every aspect of normal life. A dramatic increase in unemployment, unprecedented stress on household incomes, alarming reports of infection and death as well as restrictions on movement in the lockdown have collectively posed an unprecedented challenge to universities. Whilst struggling with mitigating the costs of free education for most students, lack of suitable infrastructure, decolonising the curricula and concerted efforts to transform the educational landscape, universities are now faced with a pandemic that has forced the closure of all campuses and heralded the switch from traditional to online learning. This sudden, forced migration to virtual teaching has presented new challenges. This study explores lecturer perceptions of how the University of KwaZulu-Natal mediated these challenges.

\section{Literature Review}

As the world faces the scourge of the COVID 19, higher education institutions 
have had to respond quickly and decisively (Huang et al. 2020). According to Bao (2020) when the epidemic hit China, universities were forced to move teaching and learning online. The Chinese Ministry of Education took the lead in the migration to online learning initiative and entitled it 'Disrupted Classes, Undisrupted Learning' (Huang et al. 2020). This title is apt for the situation in which UKZN finds itself in trying to save the academic year 2020.

As in China, UKZN has reacted by shifting teaching and learning on to online platforms. This took the form of emergency remote teaching (ERT). Hodges et al. (2020) describe ERT as a temporary solution to education that replaces face-to-face delivery. They opine that:

the primary objective in these circumstances is not to re-create a robust educational ecosystem but rather to provide temporary access to instruction and instructional supports in a manner that is quick to set up and is reliably available during an emergency or crisis (Hodges et al. 2020: 6).

ERT is an immediate response to the impact of COVID-19 on UKZN's delivery of teaching and learning. The main challenges UKZN has faced are anxieties brought on by the digital divide and existing social inequalities (Czerniewicz \& Brown, 2010). Whilst UKZN has free WIFI and many computer labs, many students lack resources. Furthermore, many are not computer literate. UKZN therefore acted decisively by putting measures in place and moved to learning online, provided staff support which includes training, counselling and research opportunities. WIFI routers and data and laptops were arranged for first year students.

These are contingency plans, as Minister Nzimande puts it in his Ministerial briefing on 30 April 2020 where he stated, 'There is no full online education, it is just for support' (Nzimande 2020). At the same time, 'No student must be left behind'.

Mineo (2020) points out that:

Generally speaking, the most economically challenged in our society will be the most vulnerable in this crisis, and the most advantaged are most likely to survive it without losing too much ground ... Twentyfirst century learning absolutely requires technology and internet. We can't leave this to chance or the accident of birth. 
This insight signals where UKZN should be directing its resources and expertise. Given the pandemic, online personal testimony in University newsletters was also used to provide insight.

Finding ways to grade students who lack access to Wi-Fi or are overwhelmed by conditions at home has posed a challenge at many education institutions. The inequities have initiated a conversation about assessment. Educators have been forced to innovate and revised syllabi and extend deadlines as remedial measures (Simonetti 2020).

Art History Professor, Charlene Villaseñor Black at UCLA, wanted to assure to students unsettled by the pandemic:

I want students to have an awareness that we have been here before and an awareness of how the arts can provide sustenance, respite, and hope for us. This is the moment to really think about how the humanities and the arts make us more human (Migdol 2020).

Christina Wyman (2020: 1), in Inside HigherEd, commented:

Like educators across the country, my plan for the second half of the semester came to a screeching halt in March and left me dealing with unforeseen issues. Should I demand synchronous meetings or to give students the space and time to navigate our content independently? Which parts of the curriculum now seem superfluous under the circumstances? To what extent should I incorporate technology that I would not have otherwise used? How can I maintain at least some course integrity while remaining realistic about the pandemic's impact on my - and their - responsibilities?

The pandemic has also taxed teachers' wellbeing and emotional state. Ferguson (2020), in the Calgary Herald reports that after three months of remote learning, teachers are exhausted, isolated and concerned about safety protocols. According to the survey, which collected responses from 8100 teachers, up to 70 per cent are feeling exhausted and disconnected from students, with some losing sleep over learning struggles and some students' inability to adapt to remote learning (Ferguson 2020).

According to Professor Benjamin Ola Akande, African universities could become more creative in changing 'what we do and how we do it, as we 
prepare for the future, post-COVID-19'. Those successful in pivoting towards pandemic-related challenges and those willing to revert to pre-pandemic behaviour:

I believe the institutions that welcome this opportunity to introspect intentionally will become much stronger; their education process will become much more effective. Those who will revert to the way they were doing things before will be embracing irrelevance (Green 2020).

The faculty at the National University of Singapore successfully created an engaging virtual course for students. The team devised a three-pronged approach. The first was to strengthen student-teacher interaction to create a social connection. While students are waiting for class to start, they use the chat function to ask them how they were doing. During the first session, they oriented them to the course structure and requirements. This initial connection made them feel more comfortable with using this channel to offer questions and comments during the class. Also, they reminded students to turn on their videos. This makes them more responsible for paying attention and to avoid succumbing to other distractions associated with learning from home (Fung 2020).

Finally, a review of the pandemic and its implications for higher education suggests that a focused study in the School of Education at UKZN, in respect of remote teaching and learning as a reaction to the pandemic, has not been addressed expansively. This gap therefore serves as a warrant for this study. The study adds to our understanding of UKZN's efforts to mitigate the deleterious effects of the pandemic on teaching and learning, as well as unintentional opportunities that it may present.

\section{Theoretical Framework}

The article adopts a holistic e-Learning systems theoretical framework as proposed by Apacirio, Bacao \& Oliveria (2016), which is framed within three core components, people, technology and service. These components are crucial when examining e-Learning systems as they provide 'stakeholder groups' and their interaction with e-Learning systems; the technologies which enable interaction of the different users and support to integrate content, 
enable communication and collaboration tools; e-Learning services integrate all the activities corresponding to pedagogical models and to instructional strategies (Aparicio, Bacao \& Oliveira 2016). Within this theoretical framework, the authors want to demonstrate how the University of KwaZuluNatal has responded to the institutional closure due to COVID-19 lockdown regulations and how it prepared its academic staff to embark on e-Learning.

This theoretical framework is apt for our research as we want to investigate how the University has readied itself in ensuring that the academic year is saved, while also complying with lockdown restrictions. This includes getting staff ready to teach and assess via online tools, and also programmes initiated for the purpose of confronting the virus. As authors, we will use this lens to understand academics' perceptions on how they view the success or failure of the University in confronting the corona virus.

\section{Methodology}

We used a qualitative study approach in this research. Polinghorne (1989, cited in Maree 2016: 53) avers that qualitative research relies on words rather than numerical data, and employs meaning-based rather than statistical forms of data analysis. Furthermore, qualitative research is naturalistic, meaning that it focuses on natural settings where interaction occurs in its natural setting. Cohen, Manion and Morrison (2011) affirm that human beings construct their own meanings about situations, and that meaning arises out of social situations and is handled through interpretive processes. With this, the purpose of adopting qualitative approach in the research was to acquire authentic data from the participants, in which they articulated their own statements regarding their readiness towards remote teaching during the time of COVID-19 lockdown, and also, what they viewed as challenges and prospects. Therefore, data of this nature was obtained and analysed through statements and not statistics.

The study also operated under the interpretivist paradigm. According to Bertram and Christiansen (2016), for interpretivists, the purpose of education research is to understand the meaning which informs human behaviour. This is due to the reason that interpretivists believe that there is no single reality or truth about the social world, but rather a set of realities or truths which are historical, local, specific, and non-generalizable (Guba \& Lincoln 1994). Therefore, research results are not out there, waiting to be picked up by 
the researcher, but they are generated by the researcher, through interpretation (Guba \& Lincoln 1994). This paradigm was chosen because as researchers in this study, we wanted to make interpretations based on the interviews presented by the participants, with the purpose of understanding how they felt they had readied themselves to confront the COVID-19 pandemic, and what they considered as the challenges and successes according to their perceptions.

A case study research design was used in the study. The choice of the case study research design in the current study is influenced by Cohen et al.'s (2011: 289) observation that the approach provides a unique example of a phenomenon in a real situation, enabling people to understand ideas more clearly than simply presenting them with abstract theories or principles. We conducted telephone interviews with eight members of staff, as well as discussions through zoom. These lecturers participated voluntarily in the study. Six of the members were from the isiZulu Discipline, whilst two were from the English Discipline.

Due to lockdown restrictions it was impossible for us to conduct semistructured interviews. The participants comprised both contract and permanent lecturers in the Languages and Arts Cluster (in the School of Education). We also used document analysis as a data gathering technique. Nieuwenhuis (in Maree 2016: 88), states:

When you use documents (textual data) as a data gathering technique, you focus on all types of written communications that may shed light on the phenomenon investigated. Such data sources may include published and unpublished documents, company reports, memoranda, agendas, administrative documents, letters, reports, newspaper articles, email messages, or any document that is connected to the investigation.

We collected documents that would shed light on the University preparedness on confronting the pandemic. These included University reports, programmes designed to confront the pandemic, and e-mail communication from the University Leadership. All these became useful during document analysis, which was used to ascertain what plans and programmes were in place to mitigate the effect of the pandemic on teaching and learning.

Ethical issues included obtaining informed consent from participants, explanation regarding their rights to participation, and the issue of confiden- 
tiality. To preserve confidentiality, pseudonyms were used. The purpose and aims of the study were explained to all participants.

Reliability and validity protocols were also followed. The aim was to determine whether the data collected and the conclusions arrived at were consonant between researchers and participants. Member checking was implemented via e-mail and Zoom technology, by discussing the draft report with participants to ascertain the accuracy of their input. The researchers are mindful of pre-existing bias that may arise from researching their own institution and in particular, their own department. Cohen et al. (2011) state that in order to achieve greater validity, researchers need to minimize the amount of bias as much as possible. For this reason, peer debriefing was used to enhance the validity of the research. Finally, an external auditor was asked to review the entire process of research so that an objective assessment may be arrived at.

\section{Findings and Discussion}

UKZN has confronted the pandemic in multiple way. One of the measures has been moving to online teaching, which is something new to many staff. It was for this reason that the University provided staff with data packages for them to be able to work from home. Some data discussed here were gathered through telephone interviews, zoom discussions with staff, and also document analysis. The following is a discussion on what the participating lecturers perceive as strides taken by the University to prepare for online teaching, in relation to staff:

\subsection{Provision of off-Campus Wi-Fi Access for Staff}

The University has made it a priority to provide each staff member with data packages, for the access of $\mathrm{Wi}-\mathrm{Fi}$, while working remotely, in response to the COVID-19 lockdown regulations, which among others, encourage 'social distancing' and 'stay at home'. Strictly adhering to the lockdown regulations, all staff members were considered for such support. This is evident in the extract below:

.... We are talking about the staff members in your Clusters listed in the attached document that received the packages during the second 
Zinhle P. Nkosi et al.

tranche distribution. Their details together with the details of their packages are now needed in the template provided (email from Mandla*, 6 May 2020).

This shows that staff were provided with data packages, as a fundamental commitment by the University to ensure its staff would be able to work from home.

\subsection{Teaching Plans}

All the participating lecturers pointed out that the University had plans in place to ensure that teaching and learning continues. These included training of staff on using various teaching strategies suitable for online learning, online assessment training, distant supervision of $\mathrm{PhD}$ research, and so forth. For example, the UKZN Principles of the Teaching and Learning Project Plan during the COVID-19-related Restrictions for Students and for Academic Staff Document (2020) states that:

As we approach the official launch of the UKZN remote teaching and learning mode, it is important that we reflect on it closely after the dryrun: what we shall do, how we shall do it, who will provide guidance for the good practices enshrined in the plan, and importantly, how we shall collect the monitoring and evaluation data that will be used to determine how well we are faring in our novel venture. It is important that we learn from initial practices soon in order to improve our system, going forward (UKZN 2020: 2).

This attests to the forward thinking and planning initiated by the University. The dry run exposed operational shortcomings and the University was quick to provide support in this regard. To many staff members, engagement with Zoom was a novel experience that had to be mastered with practice. Attending the tutorial workshops and enlisting the help of support structures, enabled staff to successfully manage online teaching.

\subsubsection{Revision of Module Outlines}

Numerous staff communication documents, for example, emails from the Uni- 
versity Leadership to staff, are evidence that revisions were made by the University staff to ensure consonance with online teaching. Lecturers had to revise module templates for all modules to suit the online teaching requirements. Such revisions included revising module content, teaching strategies, nature of activities, and assessment strategies. Some staff found this very challenging as they had to decide on outcomes, content and assessment to omit. This is evident in Zizile's comment below:

When one designs outcomes, content and assessment tasks for a module, you do it in such a way that it progresses gradually from easy to complex. So, when you are asked to cut out stuff that you might not cover due to lost time, it becomes difficult to decide on the sections you want to leave out because to you they are all important (Zizile 23/04/2020).

Based on the above comment, one realizes the emotional and psychological strain some staff members were under. After the submission of the templates, staff members were asked to prepare teaching materials for Moodle. We received diverse responses in this regard. Some staff members were very receptive and excited about online teaching as we see in the illuminative quotations below from Musa and Ravil:

This was great and it gave me an opportunity to experiment with innovative teaching tools. These e-Learning tools can be manipu-lated to perform a variety of functions which in turn facilitate a better learning process (Musa 24/04/2020).

I loved it ... it gives a lot of flexibility on time and geographical location. It enables students to work on their own pace without any hindrance and they can access materials from anywhere. This will surely enhance the learning process (Ravil 24/04/2020)

From these quotations, one realizes that these academics were enthusiastic about the move to online teaching as it gave them an opportunity to use a wide range of instructional strategies and appropriate media to enhance learning process. However, there were those who had other preferences:

I understand that the University is doing this because of covid-19 and 
were are unable to have face-to-face instruction on campus. For me, I believe human interaction is essential as I am able to give prudent advice to students there and there unlike teaching online (Zodwa 23/4/25).

Lecturers put things in context and students engage robustly as they debate issues face-to-face. I believe in real world and not the virtual one. Don't get me wrong, I am not against online teaching but I would prefer it as a support to my lectures. I understand that circumstances now force us to use it (Thulani 24/04/2020).

\subsubsection{The Dry Run}

The University made use of a dry run to pilot how the actual online teaching would take place and to troubleshoot. With this, academics were not expected to teach new content and to record assessment marks. The aim was to ascertain lecturers' readiness to engage with online learning.

After the dry run was finished, a virtual engagement day with some academic staff was organised, with the aim of reflecting on the online teaching and learning. Each cluster presented a report. Three key issues were highlighted:

1. What enablers and constraints were encountered during the Dry Run?

2. What is the level and extent of student participation/engagement?

3. What measures were or will be put in place to overcome challenges of remote teaching and assessment?

The following were some of the positive staff responses in relation to the first question, as noted in the School of Education Virtual Engagement Day Report:

- Positive Student responses: Some excited to participate; some logging in, accessing and downloading material; some downloading videos; some actively engaging - encouraging and motivating.

- Means of communication: WhatsApp and Zoom chats have proved to be successful as a means of communication with some students. 
- Successful strategies: PowerPoint with Audio, pre-recorded lectures, and written-out lectures appear to be user-friendly for students who may access material where and when they want.

- Use of Zoom: Appear best kept for questions, discussion and revision.

- Use of Kaltura: Appear useful to save large video-recordings.

- Inclusion of contract staff and markers on Moodle.

- Assessment via email and Moodle: Some students have indicated a willingness to use online submission tools for assessment.

However, some responses were negative. Below are some of the examples:

- Some difficulties were noted with essay assignments on Moodle.

- Some staff still struggling with some features of Zoom, Moodle, online assessment, and Power Point with Audio - need continued staff workshops and training.

- Data consumption is too high when conducting lectures through Zoom conferencing.

- Audio-recorded PowerPoint presentation is much better that teaching through Zoom.

- Workshops are sometimes overwhelming - too much taught at one go - difficult to process - if connectivity or sound fails on either side, miss much of what has occurred - suggest shorter workshops with smaller content chunks.

- Poor network connectivity resulted in interruptions when teaching via Zoom.

With regard to the second question, the following was highlighted:

- Varying levels of student engagement - as low as $17 \%$ to as high as $99 \%$.

- Many students lack focus and enthusiasm to engage.

- There was some engagement on Moodle and WhatsApp; responses to email and Moodle were low.

- WhatsApp group - despite rules of engagement, much fooling around, private conversations and jokes; some rudeness and 
Zinhle P. Nkosi et al.

abuse - generally a lack of focus - often many messages being sent within the day, not all relevant or work-related.

- $\quad$ Lack of computer literacy hinders engagement.

Thulani commented:

This is very frustrating, because the students are not responding and one might be perceived as someone who is not doing his duties. But I think they are either influenced or confused by all the statements uttered on mainstream media and social networks (1/05/2020).

This shows that academics were stressed. Some bemoaned the lack of leadership and directions from the Minister of Higher Education, Dr Blade Nzimande, whom they felt was unable to present a concrete and decisive plan of action. Thobani stated,

... this whole confusion is caused by the lack of leadership from our Minister, Dr Nzimande, who up until now has not presented any visionary guidance (Thobani, 1/5/2020).

With regard to the third question, 'What measures were or will be put in place to overcome challenges of remote teaching and assessment', the following issues arose:

- $\quad$ A need to keep Moodle and WhatsApp as parallel mediums to engage students. Post/share materials/documents on both platforms.

- Microsoft Teams and Google Meet are proving to be very useful to enable access and engagement, even on cellphones.

- A YouTube channel has been set up to post videos (Music Education).

- Besides Moodle, Zoom and WhatsApp, there is a need to research other possible platforms.

- Asynchronous teaching and learning (Recorded lectures, Power Point with audio, written out lectures) - much more user-friendly than synchronous real-time teaching and learning - students may access when and where they want.

- Class representatives' involvement was very useful. 
The above examples show that the University has readied itself to confront the corona virus challenges, and that even though online learning might have challenges, participating lecturers are supportive.

\subsubsection{Staff Training for Online Teaching}

All the participants pointed out that the University toils industriously in training staff. All participants agreed that training sessions and workshops have been organised by the University to prepare them for online teaching, and these were fruitful.

UKZN also ensured that no staff was left behind, utilising the following: teaching through the use of Zoom platform, which included how to host a meeting, how to be a participant and use the Zoom tools, how to use PowerPoint with or without audio and also the use of online assessment tools. Some were innovative with teaching strategies such as blended learning, or the use of flipped classrooms, whilst others continued with the traditional method of PowerPoint presentations. Thus, when the University decided to move to online teaching, there was a need to train staff to acquaint them with different interaction and communicative online platforms.

The training started on-campus before the lockdown was imposed and continued during lockdown via Zoom. The use of Zoom during workshops and meetings has instilled confidence in staff to engage, operate and acquaint themselves with this interactive and communicative platform.

\subsubsection{Training Academics on using Zoom and Moodle Technologies} Academics were expected to engage with their students through Zoom and also Moodle platforms. More importantly, staff were trained on Zoom conferenceing. Participants indicated the following.

Of the eight participating lecturers, six mentioned Zoom conferencing and its benefits. Below is a brief discussion about the benefits of using Zoom conferencing.

\section{Zoom Conferencing}

The main benefit of Zoom conferencing is that it made the virtual classroom a reality. It also saved student and staff transportation costs as they could work 
from home. Its chatroom and discussion forums promoted deep immersive learning as well as enabling participation.

A second point was its simplicity and user-friendliness. Six of the participants mentioned simplicity and user-friendliness as key benefits of zoom conferencing. They indicated that the use of Zoom conferencing during teaching was of importance due to its simplicity and user-friendliness. For example, video lessons through Zoom technology were vital, as students could access them at any time. Also, one does not need to travel; therefore travelling costs are omitted. Some students were found never or seldom to have visited the Moodle site, according to the Moodle-recorded visits per student. Therefore, the lecturers indicated that the use of zoom conferencing made the lessons vibrant, effective, and enjoyable to students during their live teaching. For example, Zodwa prefers the use of Zoom conferencing to WhatsApp or Skype, due to its simplicity and user-friendliness. 'I find it [Zoom conferencing] simple and user-friendly more than Skype and WhatsApp' (Zodwa). This suggests that the transition to the virtual classroom was made successfully.

\section{Moodle Technologies}

Most of the academic staff used traditional methods of assessments. Thus, the University also provided training through demonstrations and PowerPoint with audio presentations. Academics were shown how to prepare quizzes, paragraph and essay type questions, and also how to assess these online, using Moodle. Some academics found the exercise both challenging and intriguing as evident in Rival's comment:

Oh! I was so excited to engage with all these technological assessment tools the workshop facilitator demonstrated to us. I was practising as he was presenting so that I internalise procedure. For me, it was challenging but at the same time exciting, as I was exposed to new assessment strategies (Rival 27/4/2020)

I wish to thank the University for organising all these training sessions for us who are new to all this online teaching, and particularly the presenters who have done the job diligently, to ensure all of us are 
equipped with skills to teach and assess online, ... skills we never dreamt about before ... (Nqobile 28/4/2020).

\subsubsection{Library Support}

UKZN has made a substantial investment in e-books and other online resources. E-book portals such as Ebscohost e-book collection, Proquest Ebook Central, IEEE Xplore book collection and Knovel Chemistry, Mathematics and Physics books were added to the existing portfolio of online resources. It is important to note that all these measures have been in place even before the Corona virus outbreak.

\subsubsection{Students with a Disability}

Document analysis revealed that students with disability received good care. This includes e-mails written to staff to alert them about such students. The following is an example of communication to staff:

I trust you are well and keeping safe. I write to you with regards to student Bhabhiza (pseudonym) who is in receipt of specialized services from the disability unit. She is registered for the following modules ... She will require 15 minutes extra for every one hour in tests and exams and extended time for assignment submissions-to be decided upon by the student and the lecturer (Thandi /2020).

This correspondence shows the pastoral care extended to disabled students. Lecturers were also patient and supportive of these students.

\section{Discussion}

The article has reported on the outcomes of a study exploring academics' perceptions and experiences of moving to online teaching within the context of COVID-19. The majority of the participants commended the response taken by the University to move to online teaching. Furthermore, they commended the support the University gave to academics and appreciated the support by online teaching specialists. This shows that the University catered for 
individual needs of all staff and students. Participants also saw online teaching as important to complement teaching at universities even beyond the COVID19 outbreak. It would appear that they consider online teaching as an integral part of a university learning experience, even for a university where learning is pre-dominantly campus based. This suggests a major paradigm shift, which Hart and Christensen (2002) refer to as 'the disruptive technology' of elearning as the university gravitates towards blended learning.

It is significant that online learning avails knowledge to users disregarding time restrictions and geographic proximity (Sun et al. 2008). It was also of concern that most students might not have access to the internet connection as they came from disadvantaged rural communities. While the benefits of online learning are well-documented (Williams \& Goldberg 2005; Aparicio, Bacao \& Oliveria 2016; Stephen \& Preist 2017; Gordijn, Oosterhout \& Dijkstra 2017; Petschenka et al. 2017), it continues to exclude students from disadvantaged communities. The virtual classroom discussed included Moodle forums, the use of Zoom, Kaltura and WhatsApp. In many cases it allowed for deep, immersive learning and increased self-regulated learning practices.

\section{Conclusion}

The Coronavirus pandemic has necessitated a paradigm shift in the way we view higher education. Our study indicates that the switch to the virtual classroom was undertaken successfully, albeit that this is still in an infant stage and therefore premature to draw definitive conclusions. Whilst cognisant of the fact that online teaching and learning at university are at a relatively early stage, research suggests that lecturers positively embrace online teaching and that despite the pandemic, moral is generally high.

\section{Recommendations}

The paper recommends that universities across the globe need to ensure that no student or staff is left behind. Universities should ensure training in virtual teaching continues as a permanent fixture of staff training. Finally, we encourage lecturers to use the poll feature on Zoom, which focuses student attention and make learning an enjoyable, interactive event. 


\section{References}

Aparicio, M., F. Bacao \& T. Oliveira 2016. An e-Learning Theoretical Framework. Educational Technology and Society 19,1: 292 - 307.

Bao, W. 2020. COVID -19 and Online Teaching in Higher Education: A Case Study of Peking University. Available at: https://onlinelibrary.wiley. com/doi/full/10.1002/hbe2.191 (Accessed on 10 June 2020.) https://doi.org/10.1002/hbe2.191 PMid:32510042 PMCid:PMC7262082 Bertram, C. \& I. Christiansen 2016. Understanding Research: An Introduction to Reading Research. Pretoria: Van Schaik Publishers.

Cohen L., L. Manion \& K. Morrison 2011. Research Methods in Education. $7^{\text {th }}$ Edition. London \& New York: Routledge.

Czerniewicz, L. \& C. Brown 2010. Born into the Digital Age in the South of Africa: The Reconfiguration of the 'Digital Citizen'. In DirchinckHolfeld, L., V. Hodgson \& C. Jones et al. (eds.): Proceedings of the $7^{\text {th }}$ International Conference on Networked Learning. Aalborg.

Ferguson, E. 10 June 2020. Teachers Feel Exhausted, Isolated and Worried about Safety for Fall: Survey. Calgary Herald. Available at: https://calgaryherald.com/news/local-news/teachers-feel-exhaustedisolated-and-worried-about-safety-for-fall-survey

Fung, M. 10 June 2020. How to Create Engaging Online Learning amid COVID-19 Pandemic: Lessons from Singapore. Available at: https://menafn.com/1100300636/How-to-create-engaging-onlinelearning-amid-COVID-19-pandemic-lessons-from-Singapore

Gordijn, J., A. Oosterhout \& W. Dijkstra 2017. Innovation Mathematics Projects Blended Education in Practice: A Case Study at Delft University of Technology. Proceedings of EDULEARN17 Conference 3 - 5 July 2017, Barcelona, Spain, 9766-9774.

https://doi.org/10.21125/edulearn.2017.0881

Green, M. 2020 June 4. Making the Most of an 'Equal Opportunity Pandemic'.

University World News. Available at: https://www.universityworld news.com/post.php?story $=20200603074007154$

Guba, E.G. \& Y.S. Lincoln 1994. Competing Paradigms in Qualitative Research. In Denzin, N.K. \& Y.S. Lincoln (eds.): Handbook of Qualitative Research. Thousand Oaks: Sage Publications, Inc.

Hart, S. \& C. Christensen 2002. Moving from an Instructionist to a Constructivist Multimedia Learning Environment. Journal of Educational 
Zinhle P. Nkosi et al.

Multimedia and Hypermedia 9,3: 195 - 205.

Hodges, C., S. Moore, B. Lockee, T. Trust \& A. Bond 2020. The Difference

between Emergency Remote Teaching \& Online Learning. Available at:

http://danielschristian.com/learning-ecosystems/2020/03/29/ the-

difference-between-emergency-remote-teaching-online-learning-hodgesmoore-lockee-trust-bond/

(Accessed on 2 June 2020.)

Huang, R.H., D.J. Liu, A. Tlili, J.F. Yang \& H.H. Wang 2020. Handbook on

Facilitating Flexible Learning During Educational Disruption: The

Chinese Experience in Maintaining Undisrupted Learning in COVID-19

Outbreak. Beijing: Smart Learning Institute of Beijing Normal

University.

Maree, K. 2016. First Steps in Research. Pretoria: Van Schaik Publishers.

Migdol, R. 09 June 2020. Faculty Get Creative to Teach Perspectives on the

COVID-19 Pandemic. UCLA Newsroom. Available at: https://news

room.ucla.edu/stories/ucla-faculty-covid-19-pandemic-fiat-lux

Mineo, L. 2020. Time to Fix American Education with Race-for-space Resolve.

Available at: https://news.harvard.edu/gazette/story/ 2020/04/the-

pandemics-impact-on-education/ (Accessed on 10 April 2020.)

Nieuwenhuis, J. 2016. Analysing Qualitative Data. In Maree, K. (ed.:) First

Steps in Research. Pretoria: Van Schaik Publishers.

Nzimande, B. 2020. Blade Nzimande's Statement on Government Plans to

Save the 2020 University Year. Available at:

https://www.timeslive.co.za/news/south-africa/2020-04-30-in-full-blade-

nzimandes-statement-on-government-plans-to-save-the-2020-universityyear/ (30 April 2020.)

Petschenka, A., S. Heinrich, J. Liebscher, C. Helmstedt \& J. van Ackerem 2017. Development of Process of E-Learning at the University Duisburg-

Essen: Lessons Learnt and Future Tasks. Proceedings of EDULEARN17

Conference, 3 - 5 July 2017, Barcelona, Spain, 8646-8652.

https://doi.org/10.21125/edulearn.2017.0617

Simonetti, I. June 12 2020. It May be that I Never Go Back to the Grading

System. VOX. Available at: https://www.vox.com/first-person/

2020/6/12/21288116/coronavirus-covid-19-schools-teachers-grading

(Accessed on 13 May 2020.)

Stephens, T. \& E. Preist 2017. Developing $21^{\text {st }}$ Century Learning Skills in

Students Using a Blended Learning Program in a Learning Management 
System. Proceedings of EDULEARN17 Conference 3 - 5 July 2017, Barcelona, Spain, 9766-9774.

https://doi.org/10.21125/edulearn.2017.0085

Sun, P.C., R.J. Tsai, G. Finger, Y.Y. Chen \& D. Yeh 2008. What Drives Successful e-Learning? An Empirical Investigation of the Critical Factors Influencing Learner Satisfaction. Computer \& Education 50,4: 1183 1202. https://doi.org/10.1016/j.compedu.2006.11.007

The University of KwaZulu-Natal 2020. Virtual Engagement Day Report: Reflecting on the Online Teaching \& Learning Dry Run. Thursday, 28 May 2020. Durban: The University of KwaZulu-Natal.

The University of KwaZulu-Natal 2020. Principles of the Teaching and Learning Project Plan during the COVID-19 Related Restrictions for Students and for Academic Staff. Available at:

http://utlo.ukzn.ac.za/Libraries/Documents/Project_Plan_Principles_Re mote_online_learning_Approved_27May2020.sflb.ashx

(Accessed on 02 June 2020.)

Williams, J.B. \& M.A. Goldberg 2005. The Evolution of E-Learning. 22 $2^{\text {nd }}$ ASCILITE Conference, Brisbane, Australia.

Wyman, C. 2020, May 4. Difficult Home Lives and the Other Side of Educational Access. HigherEd. Available at: https://www.inside highered.com/advice/2020/05/14/teaching-students-difficult-home-livesduring-pandemic-opinion

(Accessed on 30 May 2020.)

Zinhle Primrose Nkosi Senior Lecturer Languages \& Arts Cluster University of KwaZulu-Natal Durban Nkosiz@ukzn.ac.za

Nokukhanya Yvonne Ngcobo Lecturer Languages \& Arts Cluster University of KwaZulu-Natal Durban $\underline{\text { Ngcobon13@ukzn.ac.za }}$ 
Zinhle P. Nkosi et al.

Ayub Sheik

Associate Professor

Languages \& Arts Cluster

University of KwaZulu-Natal

Durban

$\underline{\text { Sheika@ukzn.ac.za }}$

Nellie Ngcongo-James

Languages and Arts Cluster

School of Education

College of Humanities

University of KwaZulu-Natal

ngcongojamesn@ukzn.ac.za 


\title{
Using Corpora in Online isiZulu Language Teaching
}

\author{
Langa Khumalo \\ ORCID iD: https://orcid.org/0000-0002-2694-9105
}

\section{Abstract}

The impact of the Covid-19 global pandemic on higher education in South Africa has inspired the academy to adopt new pedagogies in the teaching of African languages. This chapter shows that through the use of an isiZulu corpus, African language courses can be offered online, using digital humanities methodologies such as the AntConc concordance program. African languages are resource-scarce languages (Bosch et al. 2007; Pretorius \& Bosch 2003; Keet \& Khumalo 2014). This scarcity includes the paucity of exhaustive grammatical descriptions, the compilation of both large and specialized corpus resources, and the development of machine-readable lexicons. A corpus is thus carefully designed and systematically collected natural language data from a variety of text types and sources following a particular set of principles, which constitute a sample that statistically reflects the use of that particular language, and is processed, stored and accessed by means of computers. This chapter argues for a novel way of teaching African languages, particularly isiZulu, using corpora and lexical software as open-source online resources. UKZN has developed the isiZulu national corpus (INC) to be the biggest African language corpus, as well as two other corpus typologies, the English-isiZulu Parallel Corpus (EiPC) and the IsiZulu Oral Corpus (IOC), that are available as digital resources for language research and language teaching. Using AntConc, which is a freeware concordance program for Windows, African languages courses can be offered online in response to the Covid-19 education lockdown.

Keywords: Covid-19, Corpus, human language technology, language, teaching, digital humanities. 


\section{Introduction}

The Covid-19 global pandemic, which primarily affects health, has had a telling effect on many sectors, including the higher education sector. The global crisis has resulted in many countries taking unusual measures such as closing schools, colleges and universities in a massive lockdown in order to stem the spread of the novel coronavirus. The higher education sector has been compelled to come up with responsive measures to address the disruption of the academic programmes. Efforts are under way to migrate to online teaching and learning on a hitherto untested and unprecedented scale for most universities in South Africa. Student assessments have provided a rare challenge, with some institutions opting to cancel them altogether. A further challenge is networked communication, which is not available to most students, is very poor, is exorbitant and is disrupted by power interruptions. Other hidden challenges are the complexities of home schooling, with some homes just not suitable for any learning to take place privately.

The migration of teaching and learning to remote learning via online platforms presents a further challenge to the teaching of African languages. Most African languages have no digital presence. This means that they have no processed natural language data that is stored in a reusable format online. They are in this sense viewed as resource-scarce languages. The paucity of resources includes lack of exhaustive linguistic descriptions, the absence of large and specialized corpora, and machine-readable lexicons. As a result, the development of human language technologies and other computational resources has been scarce for most African languages. Crucially, because of the generally diminished status and limited use of these languages, attraction of funding resources is also poor (Bosch et al. 2008; Pretorius \& Bosch 2003; Keet \& Khumalo 2014). This is notably the bane of most African languages. It is our argument that computational solutions and funding resources are an important precursor to the development of African languages. Computational tools in the current context of the Fourth Industrial Revolution (4IR) and Big Data analytics are important enablers in accelerating the introduction and use of African languages in the academy.

The University of KwaZulu-Natal (henceforth UKZN) has made advances in the development of isiZulu as one of its two official languages (UKZN Language Policy 2014). It is notable that isiZulu is the most popular 
South African language by first language speakers, with about $25 \%$ of a population of about 58 million (www.gov.za). Since 2014, UKZN has developed the isiZulu national corpus (INC) to be the biggest African language corpus with 31.7 million running words, and two other corpus typologies, the English-isiZulu Parallel Corpus (EiPC) and the IsiZulu Oral Corpus (IOC), that are available as digital resources for language research and language teaching. We thus argue in this position paper that using these corpus resources, UKZN can teach isiZulu online in response to the Covid-19 education lockdown.

\section{Corpora and Digital Humanities Methods}

Digital Humanities methods involve the use of novel computational methods, such as computer software and carefully processed and machine-readable data to solve research problems in the humanities and social sciences or to challenge existing theoretical assumptions. In order to address the disruption that has been brought about as a result of the Coronavirus pandemic, the imperative exists to transform pedagogies at our universities. This entails using technology to improve the student experience through digitizing content and using digital methodologies in teaching and learning. It is in this sense that the advancing scholarship of Digital Humanities comes to the fore. The scholarship of Digital Humanities promotes and advances digital research and teaching across all arts and humanities disciplines using cutting-edge technological resources, providing scholars with new ways of looking at old problems, while simultaneously advancing (new) knowledge and novel pedagogies. Digital Humanities provides a bridge between the traditional practices of research and technology-driven research to scholars straddling quintessential humanist approaches and modern digital methodologies, tools and frameworks to support them in novel avenues of enquiry. It is a growing scholarship in the Humanities and Social Sciences that is spurred by advances in computing and digital spheres and providing new collaboration with engineering and computer (and techno) sciences. African language corpora (corpus, singular) as digital resources provide African linguists with an opportunity to teach African languages in a novel and technology-driven way. A corpus is carefully designed and systematically collected natural language data from a judiciously selected variety of text types and sources following a 


\section{Langa Khumalo}

particular set of principles, which constitutes a sample that statistically reflects the use of that particular language, and is processed, stored in a reusable format in order to be accessed by means of computers (Khumalo, forthcoming). The size of the corpus and the source from which it is created depend on the intended purpose.

The INC is a Language for General Purpose (LGP) with 31.7 million running words of written text data, currently the largest African language corpus. It is an organic monitor corpus with a sufficient balance in terms of text types and thematic content. The INC is a web-based open-source resource. The URL for the INC is: https://iznc.ukzn.ac.za/.

Table 1. The INC Statistics.

\begin{tabular}{|c|c|c|c|c|}
\hline & File name (IsiZulu) & File name (English) & Number of files & Word tokens \\
\hline 1. & Inoveli & IsiZulu novels & 487 & 9679532 \\
\hline 2. & Isolezwe & Isolezwe newspaper & 489 & 7289832 \\
\hline 3. & UmAfrika & UmAfrika newspaper & 76 & 5735962 \\
\hline 4. & Ilanga & Ilanga newspaper & 970 & 4361605 \\
\hline 5. & Izindaba zabantu & Izindaba zabantu newspaper & 43 & 2376468 \\
\hline 6. & Ezasegagasini & Metro ezasegagasini newspaper & 61 & 782377 \\
\hline 7. & Ibhayibheli & The Bible & 1 & 435481 \\
\hline 8. & Umthetho & The Hansard & 194 & 367998 \\
\hline 9. & Zulumanuscripts & Dissertations & 19 & 287684 \\
\hline 10. & Umngenelo & Literature competition short stories & 16 & 130698 \\
\hline 11. & Ingede & Ingede newspaper & 14 & 125972 \\
\hline 12. & Uhlelo & Zulu grammar textbooks & 2 & 84416 \\
\hline 13. & Zulusimama & kznonline newsletter & 4 & 34525 \\
\hline 14. & Umthethosisekelo & The Constitution of the Republic & 1 & 32410 \\
\hline 15. & Amanothi & Lecture notes & 4 & 27447 \\
\hline 16. & Zuluplay & The play amaseko & 1 & 16694 \\
\hline 17. & Amantshontsho & A Bible lesson & 1 & 4974 \\
\hline 18. & Inganekwane & Folktales & 1 & 1709 \\
\hline \multicolumn{3}{|r|}{ Total number of files in the INC } & 2384 & \\
\hline & & Total number of tokens in the INC & & 31775784 \\
\hline
\end{tabular}

Table 1 shows the genre of text assorted as filenames, the number of the files of each genre and the tokens, also known as running words. 
The INC is one of the three corpus typologies. The second is the isiZulu Oral Corpus (IOC). UKZN embarked on fieldwork across KwaZuluNatal Province's nine districts, collecting oral speech data of 1000 hours of digital recordings. This oral corpus is being processed for addition into the INC. The addition of the oral corpus will help to achieve a healthy balance of both written and spoken text types in the INC. The third corpus is a parallel corpus, which is a collection of texts that are translated from one language $\mathrm{L}_{1}$ (the source language) to the other language $\mathrm{L}_{2}$ or language $\mathrm{L}_{\mathrm{X}}$ (the target language(s)).

In 2017 UKZN initiated a process to create a bilingual parallel corpus of English and isiZulu. The imperative to create the English-IsiZulu Parallel Corpus (EiPC) was inspired by the massive textual production in the two languages, as a result of conformity to the language policy, which stipulates that whenever possible, administrative and academic information must be made available in the University's two official languages. The EiPC currently has 15503 parallel-sentence data in both English and isiZulu. It is on the basis of the EiPC that a Data-Driven Machine Translation (DDMT) approach will be employed to build a machine translation tool. The DDMT approach uses the data theory as a framework to curate and train the data that is based on the corpus such as the EIPC. For an under-resourced language such as isiZulu, the exigency exists to create such a tool in order to automate the translations between the two languages, since human translation cannot cater for the translation demand (Kituku et al. 2016:1).

Corpora have been widely used in linguistics research and beyond. They are at the core of many human language technologies like spellcheckers, machine learning, translators and lexicons. For many developed languages, corpora are increasingly used to provide excellent facilities for teaching and learning. Furthermore, since there is a connection between language and culture, by analysing a corpus, much can be learned about the communities represented in a corpus. Specialised corpora have also been applied in disease surveillance (Brownstein, Freifeld \& Madoff 2009) and customer sentiment analysis in business (Pak \& Paroubek 2010).

Perhaps it is useful to briefly highlight and reference some contestations in Corpus Linguistics (CL). While it has become prevalent in CL studies to use large bodies of processed natural languages data in order to 
address theoretical issues, it is still contested whether CL is a tool, method(ology), discipline, theory or framework. Leech (1992: 106), TogniniBonelli (2001: 1) and Teubert (2005: 2) view CL as a theory. McEnery and Wilson (1996), Meyer (2002), Bowker and Pearson (2002) and McEnery et al. (2006: 7f.) view CL as a methodology.

[...] corpus linguistics is a whole system of methods and principles of how to apply corpora in language studies and teaching/learning, it certainly has a theoretical status. Yet theoretical status is not theory in itself (McEnery et al. 2006: 7f.).

It is evinced in this chapter that CL as a methodology is useful in language teaching and modelling grammatical descriptions.

\section{Corpora for Language Teaching}

Corpora can be used at multiple levels in order to contribute to effective language teaching in first or additional language learning. Corpora provide valuable information on the frequency of use of both grammatical or functional words, and content or lexical elements. Corpora are useful in providing additional information to intuition by providing evidence on attested use of language, and thus can influence the content and design of language modules positively. Corpora provide real, natural languages usage examples, which are not immediately available to a language teacher who uses illustrative, madeup examples that are based on intuition. Corpora can enhance language description as language learning moves away from introspection-based research, resulting in improved pedagogical grammars and more informative dictionaries.

In a study on corpus-based teaching of Northern Sotho, Taljard (2012) observes that it is unsurprising that the pedagogy of language teaching for African languages lags far behind when compared to languages such as English. The traditional pedagogical material available for most African languages are notably inadequate in that they are premised on the structural model of grammatical description with no reference to frequency of use, real natural language usage and the communicative value of grammatical struc- 
tures. The selection and sequencing of learning material are criticised in this study for its reliance on anecdotal evidence or on the intuition of the language teacher, which evidentially is often wide off the mark when compared to corpus data. It is the argument in this chapter that the use of corpus data provides the language teacher with guidance on both macro- and micro-level with regard to the content of the curriculum (Taljard 2012).

In order to access digital data that are stored in a computer, one needs a text analysis software programme that can assist in querying the corpus data. There are several software programmes such as Sketch Engine, WordSmith Tools, and AntConc. Sketch Engine, which has been developed by Lexical Computing since 2003, is the most advanced tool, with corpus management functions and complex text analysis systems. The WordSmith Tools, which was developed by Mike Scott and was first released in 1996, currently has version 7. It is an integrated suite of three main programmes, which include the WordList, Concord and Keyword. AntConc, which was developed by Laurence Anthony, is a freeware, multiplatform tool for carrying out corpus linguistics research and data-driven learning. As a multiplatform tool it can run on any computer with MS Windows, Macintosh OS X, and Linux. Sketch Engine and WordSmith Tools are proprietary; hence, prohibitive for massive online student learning. Because AntConc is a freeware tool and can be used on different operating system, it is ideal for isizulu online teaching and learning.

Antconc contains seven tools. The user can easily access them and navigate from one tool to the other. These tools include the Concordance tool, the Concordance Plot tool, the File View tool, the Clusters tool, the Collocates tool, the Word List tool, and the Keyword List tool. These tools are useful in analysing various word units, word-in-context, word clusters, words and their preferred grammatical or semantic collocates (or combinations), most frequent and less frequent words, etc. In this study we sampled the INC in order to have a smaller sample corpus that we queried, using AntConc in order to demonstrate that isiZulu corpus can be used through a freeware software programme in teaching and learning isiZulu at UKZN. A sample corpus of about 110000 running words generated from five (5) written texts was queried. Figure 1 is a screenshot showing a word list generated using the AntConc software. It shows the most frequent words generated from the sample corpus. 


\section{Langa Khumalo}

Figure 1. A wordlist of the most frequent words

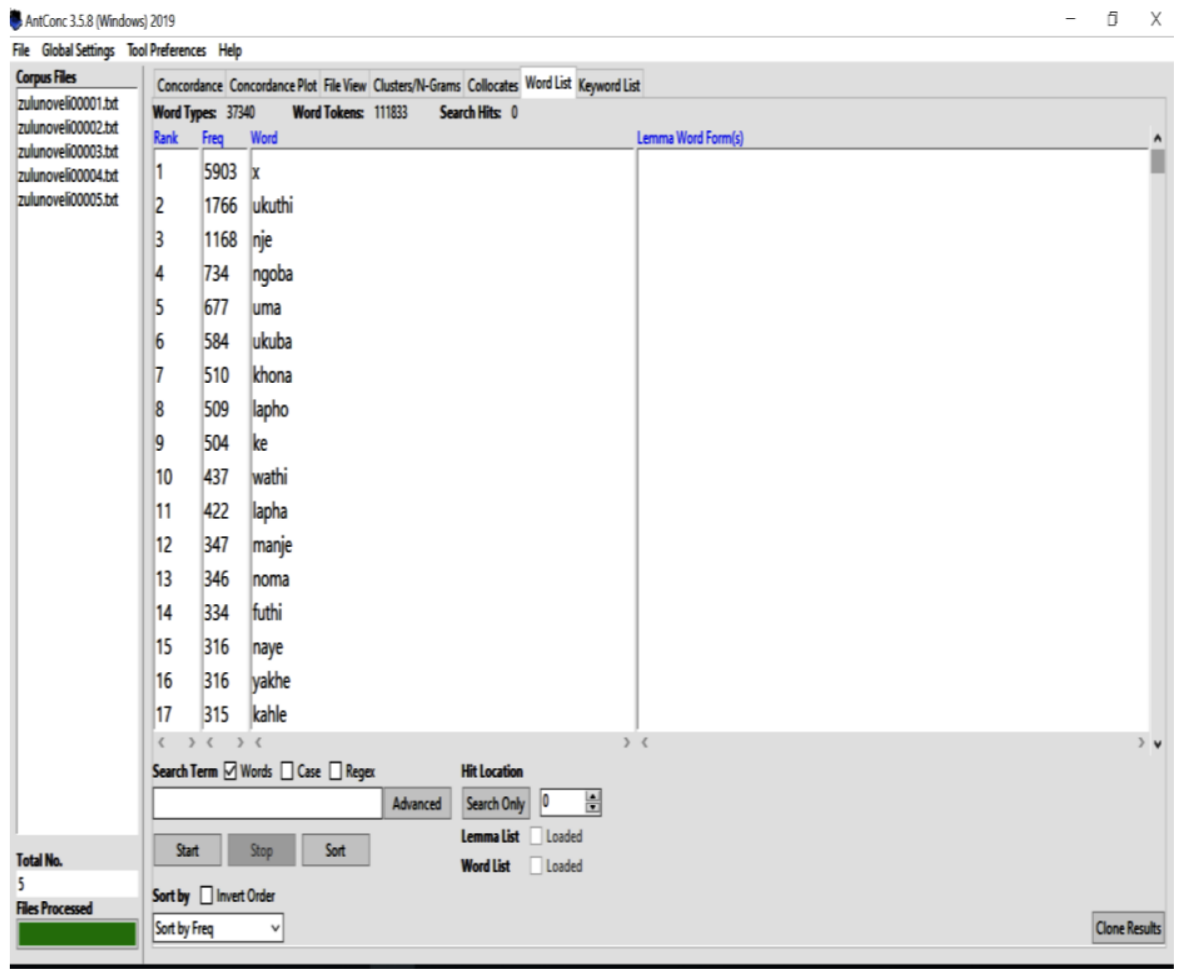

The wordlist in Figure 1 flows from the most frequent word to the least frequent in a descending order. Rank stands for the number the word occupies in the list of the words that are in the word list, and Freq. is the number of times a word occurs in the corpus. The ten most frequent words in the sample corpus of the INC are ukuthi, nje, ngoba, uma, ukuba, khona, lapho, ke and wathi. All these words are function or grammatical words belonging to a closed word class. The closed word classes are concords, connectives, numerals, pronouns, etc. Studies in corpus linguistics show that frequency lists are commonly dominated by function words. However, this information is not intuitively available to a language learner. Hence the importance of a corpus in language learning. 
Following this corpus evidence, the first task in language learning would be to identify closed word classes in isiZulu, and then putting all the words in the frequency list in their correct word classes. Then a concordance search, done by clicking on the isolated word (e.g. click on line 2 ukuthi), would show the function word $u k u t h i$ as used in its typical context in the corpus (see example 1). This provides new insights to the learners as they see various contexts in which the word is used in natural language.

Example 1. Concordance lines for ukuthi
1. angibazondi 267 abantu besilisa ngoba ngiyazi
ukuthi
abababi bonke. Ngikholelwa ekutheni inhliziyo
2. liyobe limshonele. Watshela amabutho akhe
ukuthi
ababheke kuzo zonke izindonga zendawo
3. esiyinkinga emzini wakho. Nawe uzibonele
ukuthi
abafowethu bakwaDubazana banjani. Siyabhubha
4. uNyokana akungenanga ngisho iphela. Okusobala ukuthi
abagqekezi babone ukuthi angibalulekile, ngiyimp
5. Angihlalanga khona kuyona ngoba ngibona ukuthi
abaNguni laba osengitshela ngabo ngeke
6. nazo zithule ngoba mhlawumbe zingazi
ukuthi
abaningi besizwe bakhalelani kayikho into
7. ihlane igcwele amathambo bangaqondi
abantu abaningi kangaka bebebulawa yini
8. nengifikelwa yizwi ngakho elithi angikusho, ukuthi
abantu bakithi bonke bedukile, babalekelene
9. yawakhuluma kukuba induna yayo seyiyitshelile ukuthi
abantu bayo (inkosi) mabasale sebehlala
10. thanda mngani wami. Ukhulunyiswa ngukwazi ukuthi
abantu besilisa kabethembeke kangakanani.

It is notable that $\boldsymbol{x}$ is ranked as number 1 on the word list in Figure 1 . However, this is not a word. $\boldsymbol{X}$, is the number of times that numbers have been counted in the corpus. Again, using this corpus freeware a concordance search for more context will illuminate this, as shown in example 2 below. The concordance examples in both example 1 and example 2 can be exported to a word document.

\section{Example 2. Concordance line for $x$}

1. ukungalaleli lokhu kwenu. Ngibeke u।

2. ngilahlekelwe enye ingxenye yami? $\times 94$ ।

3. phaphama uThabekhulu, wethuka, wadonsa amathe. $\mathrm{x}$

4. aphuma uMakhosazana, watholoza encika ngonina. $I x$

5. phansi lithi, $\mid x 93$ Makabongwe uThixo.।

6. $\mid x 96 u$ aqhubeke abeke $\mathrm{u} \mid$

\author{
96a, abeke ulx96e; \\ $93 \mathrm{~A}$, dade, wahluphekalx $96 \mathrm{ke}$ \\ 93A, emsebenzini!|x94 Wethuka noMaZondi, \\ 93A, kanti usunentombi engaka! Bonke \\ 94 3.3.A Ucingo lwangena ngehora leshumi \\ 96aa; ngibeke ulx96ee,
}

The Word List Tool allows one to export the word list into a word document. 
Table 2. Showing 20 most frequent words

\begin{tabular}{|c|c|c|}
\hline Rank & Frequency & Word \\
\hline 1 & 5903 & $\mathrm{x}$ \\
\hline 2 & 1766 & ukuthi \\
\hline 3 & 1168 & nje \\
\hline 4 & 734 & ngoba \\
\hline 5 & 677 & uma \\
\hline 6 & 584 & ukuba \\
\hline 7 & 510 & khona \\
\hline 8 & 509 & lapho \\
\hline 9 & 504 & ke \\
\hline 10 & 437 & wathi \\
\hline 11 & 422 & lapha \\
\hline 12 & 347 & manje \\
\hline 13 & 346 & noma \\
\hline 14 & 334 & futhi \\
\hline 15 & 316 & naye \\
\hline 16 & 316 & yakhe \\
\hline 17 & 315 & kahle \\
\hline 18 & 308 & phansi \\
\hline 19 & 300 & Ujeqe \\
\hline 20 & 291 & Njengoba \\
\hline
\end{tabular}

Table 3. Showing 10 most frequent content words

\begin{tabular}{|l|l|l|}
\hline Rank & Frequency & Word \\
\hline 10 & 437 & wathi \\
\hline 19 & 300 & ujeqe \\
\hline 23 & 262 & inkosi \\
\hline 27 & 212 & abantu \\
\hline 28 & 206 & udubazana \\
\hline 33 & 191 & ethi \\
\hline 34 & 188 & umazondi \\
\hline 35 & 184 & amehlo \\
\hline 39 & 173 & uthabekulu \\
\hline 43 & 161 & ikhanda \\
\hline
\end{tabular}

It is also possible to export the entire word list without the limitation of the screen as shown in the screen shot in Figure 1. Table 2 shows an expanded word list. While most of the words in Table 2 are still function words, ujeqe (19) is a content word. Unlike grammatical words whose function is structural, content words refer to word units that carry a semantic content, which contributes to the meaning of a sentence they occur in. Nouns and verbs are the main examples of these types of words.

It is possible in a corpus class to further isolate content words from function words. This again can be a linguistic exercise that students can do 
computationally. Table 3 below shows the 10 most frequent content words in the sample corpus of the INC that we queried. The content words are of interest to linguists and lexicographers. Linguists study their morphology, their morphosyntax and semantics. Lexicographers are interested in them because content words are the words that make up dictionaries. Since lexicography is the science of dictionary making, the frequency, concordance and collocation of content words are of scientific interest to a lexicographer. This computational approach to language study and language analysis makes the work of a linguist and that of a lexicographer more efficient, error-free and faster than it would be if it were done manually through human effort.

For example, one of the crucial decisions a lexicographer has to make in dictionary making is which word to include, or which word to exclude in a dictionary. With the availability of online resources such as AntConc, Summers (1996: 261) posits that 'all aspects of lexicography are influenced by frequency'. Headword selection for a particular dictionary becomes informed by the frequency through a statistical analysis, rather than a subjective intuitive exercise of a lone lexicographer. Frequency lists also provide developers of second language teaching material with the most relevant words, phrases, and expressions to teach. Frequency lists also shed more light on the most common words in isiZulu linguistic domain. These words may be the ones which characteristically typify the domain. According to Kilgarriff (1997: 135) 'The more common it is, the more important it is to know it'.

Content words provide a whole gamut of both linguistic and cultural information that is contained in a language. While the corpus enables one to isolate verbs and nouns as shown in Table 4 and Table $5^{1}$, the frequency list suggests more insights. Table 4 is a list of the 12 most frequent verbs in the sample INC corpus that we queried. The first six most frequent verbs in this list are a variant of the main verb -thi (say). This is a monosyllabic verb, which can be inflected in a variety of ways, as shown in the word list. This verb and

${ }^{1}$ This can be enhanced if the corpus is annotated, which means some kind of linguistic analysis has been performed on the text. This includes marking up text with parts-of-speech markers or tags, which makes data retrieval from the corpus more precise, and fast. 


\section{Langa Khumalo}

its verb forms provide an interesting lesson in inflectional morphology and verb conjugation in isiZulu.

Table 4. Showing frequency list of verbs

\begin{tabular}{|l|l|l|}
\hline Rank & Frequency & Word \\
\hline 10 & 437 & wathi \\
\hline 33 & 191 & ethi \\
\hline 71 & 113 & athi \\
\hline 91 & 99 & bathi \\
\hline 98 & 96 & uthi \\
\hline 99 & 95 & yathi \\
\hline 128 & 76 & wabona \\
\hline 153 & 66 & wahlala \\
\hline 154 & 66 & wangena \\
\hline 155 & 66 & waphuma \\
\hline 237 & 48 & wasukuma \\
\hline 3529 & 4 & \\
\hline
\end{tabular}

Table 5. Showing frequency list of 5 nouns

\begin{tabular}{|l|l|l|}
\hline Rank & Frequency & Word \\
\hline 23 & 262 & inkosi \\
\hline 35 & 184 & amehlo \\
\hline 43 & 161 & ikhanda \\
\hline 57 & 129 & izinkomo \\
\hline 70 & 115 & amabutho \\
\hline
\end{tabular}

The nouns in Table 5 also provide interesting insights. A noun is made up of two formatives, a prefix and a stem. This is an interesting aspect of the morphology of the nouns in isiZulu. While each noun in isiZulu is allocated a specific noun class, there are some nouns that are difficult to classify (Keet \& Khumalo 2017), which makes it an interesting linguistic unit of study. The isiZulu noun class system is a distinct pairing of singular and plural nominal forms. However, there are interesting examples of nouns that do not seem to take a singular form. Because of the agglutinating nature of isiZulu, coupled with a conjunctive writing system, which glues together elements of an isiZulu word, as a result, a number of noun class prefixes in isiZulu are phonologically conditioned and yet others are homographs. 
There are interesting studies that seek to explicate the generation of, and semantic motivation for, the various noun class assignments, not just in isiZulu but in Bantu studies. It is our argument that access to massive corpus data can lead to new insights in this area. It is also interesting that the focus on the noun covers areas such as phonology, morphology and semantics. Corpus studies also provide for an extended focus. For instance, in Table 5 above, the noun inkosi (the king), izinkomo (cattle) and amabutho (the warriors) are ranked 23, 57 and 70 in the frequency list. These words are all in the top 100 most frequent words, and top five most frequent nouns in the sample corpus. This suggests that inkosi (the king) occupies a very important seat in the organization of the Zulu people. The high frequency of izinkomo (cattle) also suggests that they must have a significant cultural influence in the Zulu social organization. The word amabutho (warriors) makes reference to the history of the Zulu people, when armies where organised in terms of amabutho (warriors). In order to study these highly frequent words further and deeper, the concordance tool provides more context, and a student delves into a deeper sociocultural worldview using evidence that is immediately available by means of an electronic corpus. The use of a corpus in language teaching clearly extends beyond language structure and second language learning, but extends into very interesting sociocultural and historical topics.

The corpus-based approach is also interesting for both linguists and lexicographers in the area of semantics and sense disambiguation, respectively. In the area of semantics, homographs present interesting challenges, particularly for second language learners, when words are spelt the same way but have different meanings. Table 6 is an example of a homograph in isiZulu.

Table 6. Showing frequency of the word noun inyanga

\begin{tabular}{|l|l|l|}
\hline Rank & Frequency & Word \\
\hline 201 & 53 & inyanga \\
\hline
\end{tabular}

The word inyanga is ranked just outside the top 200 most frequent words in the sample corpus. A concordance search, done by clicking on the word inyan$g a$, produces the following concordances lines shown in Example 3 below. 


\section{Langa Khumalo}

Example 3. Concordance lines for inyanga

1. nani zanuse ngoba kufike lapha

2. oyenzayo wesabeka bathi abazange bayibone

inyanga ebhulayo neyelaphayo yaseSwazini. Ngayizwa

inyanga enje kwaZulu. Wanikwa ukuba angene

inyanga enkulu kuphela, ubulawu bezulu. Lapha

3. ukuba ibe yisibonda somhlaba. "Kukhona

4. yokuficwa kukaJeqe enjengofileyo ogwini nokuthi

inyanga enkulu yasesiqhingini imthathile, kuhle angesabi,

5. unina weNkosi nabo bangene kukhona

inyanga enkulu yeNkosi. Kwaphela isonto uJeqe

6. singabe sisaba bikho isidingo sokulinda

inyanga ezayo, ungagcina usuqale ngalo isonto

7. eNkosi nenyanga bevimbeleke kuleyondlu, ibaphethe inyanga ibagcaba, iphalazisa iNkosi ngezintelezi ezinkulu

8. kade ilala endlini yamakhosi namadlozi.

Inyanga ilandele uJeqe bayolala elawini likaJeqe.

9. uphuze utshwala besundu nobamaganu, uyokufa

inyanga ingakapheli. Kodwa ungakadluli kusasa

10. bangena emotweni eyangena umgwaqo lapho

inyanga ishona ithi gqwambi ngale kwezintaba.

The dominant sense as shown in concordance lines $1,2,3,4,5,6$, and 8 is that of inyanga as a traditional doctor or traditional healer. In line 9 inyanga refers to the month, and line 10 inyanga is referring to the moon. In lexicography such data provide usage examples that are typical in natural language. It is also very useful in disambiguating various senses, as shown above. This is important to a lexicographer, as meaning reference is an intrinsic part of a dictionary.

\section{Conclusion}

The global lockdown of education institutions as a result of the coronavirus pandemic has forced many institutions to rethink the mode of delivering their course offerings. This entails preparing pedagogical materials to be made available in a structured way and available on an online platform that is accessible in digital forms. The challenge that this mode of delivery poses in the teaching of African languages is that most African languages are underresourced. They do not have resources online that are immediately available to learners such as corpora, spellcheckers, and morphological and grammatical analysers.

However, we have shown in this study that UKZN has made progress in developing isiZulu, which has put it in a good position to be offered online. The INC is a very important resource that can be used in the teaching and learning of isiZulu via the digital mode of delivery. Using novel Digital Humanities approaches that infuse computational approaches in the teaching 
of courses in the Humanities and Social Sciences, we have shown that the teaching of isiZulu phonology, morphology, morphosyntax, and semantics can be done online using the AntConc freeware and the open-source INC. This study also shows that the corpus approach can extend the learning and teaching of isizulu to lexicography and lexicographic practice, sociocultural and historical spheres.

\section{Acknowledgements}

I am grateful to Ms. Neo Putini for corpus access, sampling and corpus queries. I am also grateful for comments from the two anonymous reviewers.

\section{References}

Bosch, S.E., L. Pretorius \& J. Jones 2007. Towards Machine-Readable Lexicons for South African Bantu languages. Nordic Journal of African Studies 16,2: 131 - 145.

Bowker, L. \& J. Pearson 2002. Working with Specialized Language: A Practical Guide to Using Corpora. London: Routledge.

https://doi.org/10.4324/9780203469255 PMCid:PMC1732030

Brownstein, J.S., C.C. Freifeld \& L.C. Madoff 2009. Digital Disease Detection

Harnessing the Web for Public Health Surveillance. New England Journal of Medicine 360: 2153 - 2157. https://doi.org/10.1056/NEJMp0900702

PMid:19423867 PMCid:PMC2917042

isiZulu National Corpus. languagematters@ukzn. Available at:

https://iznc.ukzn.ac.za/

Khumalo, L. forthcoming. Corpora as Agency in the Intellectualization of African Languages. In Kaschula, R. \& H.E. Wolff (eds.): The Transformative Power of Language: From Postcolonial to Knowledge Society in Africa. Cambridge: CUP.

Keet, C.M. \& L. Khumalo 2017. Grammar Rules for the isiZulu Complex Verb. Southern African Linguistics and Applied Language Studies 35,2: 183 - 200. https://doi.org/10.2989/16073614.2017.1358097

Keet, C.M. \& L. Khumalo 2017. Toward Verbalizing Ontologies in isiZulu. In

Davies, B., L. Kaljurand \& D. Kuhn (eds.): Controlled Natural Language Proceedings. Switzerland: Springer. 
Kilgarriff, A. 1997. Putting Frequencies in the Dictionary. International Journal of Lexicography 10,2: 135 - 155.

https://doi.org/10.1093/ijl/10.2.135

Kituku, B., L. Muchemi \& W. Nganga. 2016. Framework for Many to One Machine Translation. International Journal of Advanced Research in Computer Science and Software Engineering 6,5: 103 - 110.

Language Policy of the University of KwaZulu-Natal 2006. Available at: http://utlo.ukzn.ac.za/Libraries/November_2011_Conferences/APPEND

IX_D4_Language_Policy_-_Council_approved_010906.sflb.ashx Language Policy of the University of KwaZulu-Natal 2014. Ref:

CO/02/0109/06. Unpublished.

Leech, G.N. 1992. Corpora and Theories of Linguistic Performance. In Svartvik, J. (ed.): Directions in Corpus Linguistics. Proceedings of Nobel Symposium 82, Stockholm, 4 - 8 August. Berlin/New York: Mouton de Gruyter.

McEnery, T. \& A. Wilson. 1996. Corpus Linguistics. Edinburgh: Edinburgh University Press.

McEnery, T., R. Xiao \& Y. Tono. 2006. Corpus-based Language Studies: An Advanced Resource Book. London/New York: Routledge.

Meyer, C.F. 2002. English Corpus Linguistics: An Introduction. Cambridge: Cambridge University Press.

https://doi.org/10.1017/CBO9780511606311

Pak, A. \& P. Paroubek. 2010. Twitter as a Corpus for Sentiment Analysis and Opinion Mining. Paper presented at the LREC. 17-23 May, Valletta, Malta.

Pretorius, L. \& S.E. Bosch. 2003. Finite State Computational Morphology: An Analyzer Prototype for Zulu. Machine Translation 18: 195 - 216. https://doi.org/10.1007/s10590-004-2477-4

South Africa's People: Languages. Available at:

https://www.gov.za/about-sa/south-africas-people\#languages

Summers, D. 1996. Computer Lexicography: The Importance of Representativeness in Relation to Frequency. In Thomas, J. \& M. Short (eds.): Using Corpora for Language Research: Studies in Honour of Geoffrey Leech. London/New York: Longman.

Taljard, E. 2012. Corpus-based Language Teaching: An African Language 
Perspective. Southern African Linguistics and Applied Language Studies 30,3: 377 - 393. https://doi.org/10.2989/16073614.2012.739318 Teubert, W. 2005. My Version of Corpus Linguistics. International Journal of Corpus Linguistics 10,1: 1 - 13. https://doi.org/10.1075/ijcl.10.1.01teu Tognini-Bonelli, E. 2001. Corpus Linguistics at Work. Amsterdam/

Philadelphia: John Benjamins. https://doi.org/10.1075/scl.6

Langa Khumalo Director University Language Planning and Development Office University of KwaZulu-Natal Durban khumalol@ukzn.ac.za 


\section{Delivery of Clinical Teaching and Learning for Health Sciences Students during the National Lockdown in Response to COVID-19: A Pragmatic Approach at the University of KwaZulu-Natal}

\section{Busisiwe P. Ncama}

ORCID iD: https://orcid.org/0000-0002-8084-4910

\section{Sinegugu E. Duma}

ORCID iD: https://orcid.org/0000-0002-2489-8770

\section{Abstract}

COVID-19 has posed a challenge to teaching and learning at institutions of higher education in South Africa, but even more so in the delivery of clinically focused programmes that require experiential learning to happen in healthcare settings, which are the epicentre for combating the COVID-19 epidemic. The national lockdown, which resulted in the abrupt closure of university residences and the withdrawal of students from healthcare settings to promote physical distancing and reduce the spread of COVID-19 also disrupted the core principles of clinical placement and clinical rotation - the main delivery mode of all clinically focused programmes in the College of Health Sciences (CHS), University of KwaZulu-Natal.

The impact of sudden the withdrawal of students from clinical placement because of the national lockdown to flatten the curve of the spread of COVID-19 is huge for clinical learning. Although it is possible to extend time for clinical placement and achievement of clinical learning outcomes once the epidemic is over for students in pre-clinical years and junior years, the same cannot be said for senior and final-year health science students who have to achieve all the exit-level outcomes of programmes and meet the 
requirements of the professional bodies before graduating and registering as qualified health professionals.

Final-year health sciences students can gain a lot of knowledge and experience in managing epidemics of this nature by being in the frontline, working and learning side by side all other health professionals in fighting this epidemic. However, the reality is that students are novices, and thus at more risk of being infected with COVID-19 in their line of duty than experienced professionals; therefore, a careful balance needs to be reached in meeting their clinical training needs.

This chapter discusses the pragmatic approach to the delivery of clinical programmes, ethical and legal considerations associated with placing students in clinical settings during national lockdown, and the closure of higher education institutions in response to the COVID-19 epidemic.

Keywords: COVID-19, Clinical placement, Clinical rotation, health science students, medical students, national lockdown

\section{Introduction}

COVID-19 has posed a challenge to teaching and learning at institutions of higher education in South Africa, but even more so in the delivery of clinically focused programmes, which require experiential learning to happen in healthcare settings, which are the epicentre for combating the COVID-19 epidemic. The national lockdown, which resulted in the abrupt closure of university residences and withdrawal of students from healthcare settings to promote social distancing and reduce the spread of COVID-19 also disrupted the core principles of clinical placement and clinical rotation - the main delivery mode of all clinically focused programmes in the College of Health Sciences, University of KwaZulu-Natal.

Students in disciplines that require no clinical teaching may receive virtual teaching and assessments during the national lockdown. There is even a possibility of extending the time to catch up for any lost teaching and assessment time for such programmes. Such possibilities are slim for clinically focused programmes, because the mode of teaching these programmes relies on clinical placements and clinical rotation in healthcare settings, including hospitals and community health clinics throughout the province of KwaZulu- 
Natal. Although it is possible, for students in pre-clinical years and junior years to extend time for clinical placement and achievement of clinical learning outcomes once the epidemic is over, the same cannot be said for senior and final-year health science students who have to achieve all the exit-level outcomes of programmes in order to meet the requirements of the professional bodies before graduating and registering as qualified health professionals.

Final-year health sciences students can gain a lot of knowledge and experience in managing epidemics of this nature by being in the frontline, working and learning side by side all other health professionals in fighting this epidemic. However, the reality is that students are novices, and thus at more risk of being infected with COVID 19 in their line of duty than experienced professionals are. Therefore, the adoption of a pragmatic approach to the delivery of clinical programmes is needed to allow for a smooth return of health sciences students to health services for experiential learning during clinical placement and clinical rotation during national lockdown and closure of higher education institutions in response to the COVID-19 epidemic. Paramount to the smooth return of students to clinical placement is the University's commitment to students' health and safety. This requires engagement with student leadership, academics involved in clinical teaching and clinical supervision of students and other relevant stakeholders.

The CHS is a multi-professional institution spread across four of the five campuses of the University of KwaZulu-Natal, including the School of Clinical Medicine, the School of Health Sciences, the School of Nursing and Public Health and the School of Laboratory Medicine and Medical Sciences. The College provides a unified and holistic approach to theoretical and clinical teaching at both undergraduate and postgraduate levels. It offers the following undergraduate Bachelor Degrees:

- MBChB and the Medical students returning from Cuba under the Nelson Mandela Fidel Castro Programme;

- Audiology Biokinetics, Exercise and Leisure Sciences;

- Dental Therapy;

- Nursing;

- Occupational Therapy;

- Optometry;

- Pharmacy;

- Physiotherapy; 
- Speech Language Therapy;

- Medical Sciences (Anatomy, Physiology and Biochemistry); and

- Honours in Medical Sciences (Anatomy, Physiology, Medical Microbiology and Medical Biochemistry)

The delivery of clinical teaching and learning for the College of Health Sciences is managed through the Memorandum of Understanding (MOU) between the University of KwaZulu-Natal and the KwaZulu-Natal Department of Health (KZN-DOH), which ensures both parties work efficiently and effectively in the delivery of health services to the consumers of health and provision of quality clinical training. Most of the clinical placement of students is managed under the Decentralised Clinical Teaching Platform (DCTP) across all public healthcare facilities of the KZN-DOH in the whole province.

\section{Clinical Placement as a Mode of Delivery of Clinical Teaching Versus Health Service Provision}

Clinical placement of health sciences students in healthcare settings is primarily for experiential learning purposes; service provision to patients is secondary. The primary responsibility of the national and provincial healthcare system is to provide comprehensive, quality healthcare to consumers of healthcare. Still, there is a strong commitment to the provision of a safe and supportive learning environment for all health science students on clinical placement. In simple terms, the clinical placement of health science students is a shared responsibility between the university and the KZN-DOH and both are bound by the Memorandum of Understanding to provide both the service to the consumers of healthcare and clinical training to health science students. At any given time, there are about 1000 senior and final-year health science students in the health facilities throughout the province of KwaZuluNatal. Medical students in pre-clinical years and health science students in junior years also receive clinical placement and clinical rotation at the same healthcare facilities. However, the focus is on experiential learning, while for senior and final-year health science students the focus is on providing quality health services under clinical supervision. Students are therefore an integral part of the human resource of the health services, because they provide the necessary clinical care, albeit under clinical supervision. 
The impact of the sudden withdrawal of health science students from clinical placement because of the national lockdown to flatten the curve of the spread of COVID-19 made a considerable dent in healthcare human resources at a time when more hands were needed for service provision to combat the COVID-19 epidemic. Senior and qualified health professionals who would normally provide clinical teaching and clinical supervision of students on clinical placement are moved towards COVID 19 management; for example, operating theatres are only handling emergencies, all elective and non-urgent cases have been put on hold. This leaves a gap in the availability of clinical learning opportunities and clinical supervision for students to meet the prescribed clinical learning outcomes in clinical areas deemed non-essential, even if students were to return to these health services for clinical placement. The non-availability of clinical learning opportunities in the so-called 'nonessential' health services could negatively affect the delivery of clinical programmes that require a range of clinical learning outcomes to be met by final-year health science students towards graduating and registration by their health professional bodies and commencement of internship and/or community service placement registration, If not managed properly, this disruption could result in the non-production of health professionals in 2021.

The desire for an early return of final-year health science students to the clinical services for clinical learning and the provision of health services is a reality that needs to be addressed even in the midst of the national lockdown and closure of universities. This will help to avert delays in the completion of all clinical programmes at UKZN and the registration of new graduates as qualified health professionals in line with the prescripts of the Health Professions Act 56 of 1974 (for medical doctors and other health professionals) and the Nursing Act 33 of 2005 for nurses. This reality is supported by the South African Committee of Health Sciences Deans (SACOHSD) which issued a letter to the Health Professional Councils supporting the development and implementation of contingencies or continuity plans to mitigate the impact of COVID-19 on the delivery of clinical teaching and learning in health science programmes in South Africa. Internationally, other universities are also calling for the return of students to clinical placement for service provision during the COVID-19 lockdown to allow students to assist in the fight against this pandemic (Farber 2020). The UKZN CHS, like other universities, has a legal and social responsibility and obligation to ensure that, as far possible, the delivery of the clinical 
programme and the production of future health professionals are minimally disrupted during the national lockdown and closure of higher learning institutions in response to the COVID-19 epidemic.

\subsection{The Sociotechnical Systems Theory as a Pragmatic Approach for Return of Students to Clinical Placement and Clinical Rotation}

Contingency plans for the return of final-year health science students for clinical placement and clinical rotation need to be approached in a pragmatic and ethically sound manner. This will avert shocking the healthcare system with an underprepared and unsafe student population while trying to meet the clinical exit-learning outcomes and minimum clinical requirements by the different health professional bodies. Failure to have such contingency plans may put both the patients and students at more risk for contracting and/or spreading COVID-19. Managing the return of the students to the clinical services for delivery of clinical teaching and learning and service delivery is a phenomenon that can best be understood by using the Sociotechnical Systems theory. According to the Sociotechnical Systems Theory, organizations such as schools and universities exist for the achievement of specific goals, which are accomplished through four major subsystems, including the human, tasks, structure and technology subsystems. These subsystems interact within the larger external social, political, economic, technological, legal, demographic ecological and cultural subsystems (Owens 1998).

\subsubsection{Human Subsystem Challenges}

According to the Sociotechnical System, the Human Subsystem of a university or school as an organization may include individuals' skills and values among other things. Another important human subsystem is leadership within the university in ensuring that the university achieves its goals of delivery of clinical teaching (Owens 1998). Focusing on students as a human subsystem, the challenges related to their early return to health services for clinical placement and clinical rotation include students' lack of skills and underpreparedness in managing COVID-19. While it can be argued that students should be placed in low-risk clinical areas for COVID-19, it may not always 
be possible, because a number of patients are asymptomatic, especially in the early stages of infection. This will also rob the final-year health science students of an ideal and probably the only learning opportunity of managing an epidemic before they graduate. This is against the goal of UKZN College of Health Sciences of producing the future 'fit for purpose' and safe health practitioners. Extensive training of final-year health science students on the practical use of Personal Protection Equipment (PPE), infection control measures and public health measures for combating the COVID-19 pandemic, needs to be put rolled out immediately for them to be in the frontline in fighting the CovidCOVID-19 epidemic. The infection control measured include competency in hand and respiratory hygiene to reduce the risk of contracting the corona virus in particular, and prevent its spread, as well as the clinical management of COVID-19. Theoretical aspects of this have been provided through online demonstration videos and online presentations, but the clinical training is a hands-on experience. Students have to be practically involved in order to become competent in the critical skills for combating future epidemics.

At UKZN, the students' need to return early for clinical rotation was driven by both self-efficacy and altruism. The former is one's belief about their ability to perform specific outcomes. The latter involves caring for others without expecting any gains for self (Avali, Zargham-Boroujeni \& Bahrami, 2017). Both are important values for health professionals. The pressure to be allowed to return clinical facilities for clinical rotation and to assist the country in fighting the epidemic came from mostly senior and final-year health science students. Speaking to the senior students revealed that their preference for a return to provide health service to COVID-19-affected patients was primarily driven by the need to complete the professional bodies' prescribed minimum clinical requirements towards registration and commencement of internship and/or community service placement. On the other hand, speaking to students in preclinical and junior years of training revealed an interest to serve as volunteers on health promotion and community health education in the prevention of COVID-19 epidemic. According to the SACOHSD (2020), volunteering activities may not count as formal clinical training, because these hours are not aligned with specific clinical learning outcomes. We at UKZN believe that volunteering needs to be nurtured, because it can help in promoting altruism, which is one of the values expected from health professionals. In aligning with the SACOHSD's caution and recognition of the implications of 
allowing preclinical junior students for volunteering activities, the plans for an early return to clinical facilities for clinical rotation are limited to final-year health science students only until such time that the lockdown is lifted and it is safe to place students in clinical facilities for clinical teaching and learning. However, we recommend that other students can contact the COVID-19 task team to be linked up with other non-patient contact health systems, including using telehealth to respond to patient questions and concerns or assist with nonpatient-facing tasks like making phone calls and writing clinical notes, while they recognize that such volunteering activities will not be recognized as training clinical hours.

Academic integrity is another important value that needs to prevail as decisions to place and rotate students in low risk clinical areas where they will be without clinical supervision, or to place them in the epicentre of COVID-19 epidemic and plenty of clinical supervision, but with fewer learning opportunities to meet the wide range of clinical learning outcomes. The CHS is currently grappling with how to balance clinical placement and rotation to meet all clinical learning outcomes versus fast-tracking the students to complete the clinical hours, irrespective of whether learning outcomes have been achieved or not. Academic integrity entails striking a good balance between the process and outcomes of learning and is highly valued along with other ethical standards in health professions (Piascik \& Brazeau 2010). Being concerned with outcomes, i.e. meeting the clinical requirements of professional regulatory boards, at the expense of the process, i.e. helping students to learn and become competent health practitioners through appropriate clinical rotation, constitutes a violation of academic integrity.

\subsubsection{Tasks Subsystem Challenges}

According to the Sociotechnical System, the Tasks Subsystem of a university or school as an organization may include mode of instruction, supervision, administration and student and staff support services (Owens 1998).

Clinical placement and clinical rotation of final year health science students should be delivered in a comprehensive manner that ensures the achievement of all programme-level outcomes before one can graduate. Placement of students at low-risk clinical facilities may not assist in achieving this goal for a number of reasons.

The current reallocation of senior and qualified clinicians to areas where 
their skills are needed the most in the management and prevention of COVID19 , means that the health professionals who would normally provide clinical supervision to students may no longer be available for clinical teaching and supervision. Because of an increase in the workload and the related exhaustion and emotional fatigue associated with the management of an increasing number of COVID-19 patients with poor prognosis, clinical teaching and supervision of students are likely to take a back seat. In addition, as novices, students lack competence and are at risk of contracting and spreading the virus. They have to be trained, closely mentored, and supervised (World Health Organization 2014). Regarding the careful planning of capacity recovery strategies such as the reduction in the staff, student ratios may need to be put in place for a smooth return of students to the clinical facilities during the lockdown and closure of universities. Staff and student morale may be severely affected due to the poor prognosis of COVID-19 epidemic. The WHO (2014) recommends that extra care should be paid to ensure that occupational health services are able to provide both staff and students support. However, the CHS should and cannot relinquish this role solely to the hospitals' occupational services. Instead, the College of Health Sciences should take the lead in providing psychosocial support to students and staff alike. Also, delivery of clinical teaching and learning during the national lockdown and the closure of university in response to the COVID-19 epidemic may necessitate stringent adherence to the following guidelines in order to ensure staff and students' safety and thus mitigating the risks of COVID 19 infection:

- Screening and testing of all health science students returning for clinical placement in response to COVID-19 to prevent putting them and others at risk for contracting and or spreading the virus;

- Identification of vulnerable students, such as pregnant students, those with comorbidities, etc.

- Contact tracing of all those who may have been in contact with students who test positive for the corona virus;

- Isolation for those students who test positive. This will require additional housing to accommodate students or returning them home and thus affects their time for completion of clinical placement requirements;

- Quarantine for those students who have been exposed to the virus. This may be at an additional expense for the university or individual student 
and may affect the time for completion of clinical placement requirements;

- Availability of Personal Protective Equipment (PPE) for the occupational safety of the students while caring for COVID-19 patients;

- For hand hygiene - availability of handwashing facilities or sanitizers where it is not possible to have handwashing facilities in all the living and working spaces;

- For respiratory hygiene - the availability of cloth masks for use in all public spaces;

- Students should, where feasible, be allocated according to their skill sets to low-risk/non-COVID-19 areas;

- All students to have 2020 seasonal influenza vaccination and certification before returning to clinical facilities;

- There will be a shift in the assessment approach towards on-site assessment, within the clinical setting, and a signing-off of achieved competencies; and

- Ongoing training is necessary for all students on the latest information around COVID 19, the proper use of PPE and clinical management of patients with COVID 19.

Key lead groups were developed to ensure the smooth return of students for clinical placement and clinical rotation and restore delivery of clinical teaching during the national lockdown and closure of the university, and these were facilitated through the COVID 19 war room. As a result, by the time of closure and the countrywide lockdown, no COVID 19 infections had taken place at UKZN. Subsequent to that, preparations for easing the lockdown took place, and a number of protocols were developed to limit the spread of COVID 19 at campus. This team functioned under the Deputy Vice-Chancellor of Health Sciences and reported directly to the Executive Management Committee. The protocols included prevention of spread measures in the utilisation of all teaching and learning facilities such as libraries, computer labs, classrooms, etc. Cleaning and the disinfection of campus and residences, student transport, including travel by students and staff protocols were developed.

A full risk assessment for all university spaces was conducted by occupational health and safety division to ensure the safe return of students and staff. A matrix of all regulations passed by the government was devised to 
ensure compliance through the assistance of legal office with human resources division.

Reopening the university will be aligned to the national policy of easing the lockdown. It will be a phased-in, risk-adjusted approach with a staggered intake. All UKZN employees who were identified at high risk and/or can carry out their work duties from home will be encouraged to do so, following engagement with their line manager about working remotely. Screening and testing protocols were all devised and the accredited on-site laboratories were all set up to assist with the COVID 19 testing. Plans and protocols for managing an outbreak were also devised through expert advice from COVID 19 task team working together with campus health clinics.

UKZN requires all staff, students and their families to observe the standard infection control practices including the use of cloth masks by ALL within the university in public spaces, accompanied by education on the safe use of such masks.

\subsubsection{The Structure Subsystem Related Challenges}

The structure subsystem in the university or school as an organization relates to authority, decision making, control planning, rules, departments and communication (Owens 1998). A number of questions regarding the role of the College and KZN-DOH can arise. For example, who has authority over students when they are at clinical facilities for clinical rotation during an epidemic; who makes decisions regarding how student rotation is carried out; or which controls are in place to ensure that students meet all the requirements of registration with professional bodies at the end of their training; regarding whether to place them in low-risk departments or in departments which are the actual epicentre of the epidemic. Careful consideration of these questions is critical prior to making a call for the early return of final-year health science students for smooth delivery of clinical teaching and university closure in response to an epidemic. Failure to engage all stakeholders, including students, $\mathrm{KZN}-\mathrm{DOH}$, and academics involved in the clinical teaching and supervision of students can preclude the achievement of the university's goals of the smooth return of students for clinical placement and clinical rotation for learning and service provision to fight the COVID-19 side by side with other health professionals. 


\subsubsection{Technology Subsystem-related Challenges}

A Technology Subsystem at the university or school as an organization may include equipment and materials for clinical teaching and health service provision, schedules such as the university calendar and timetables, curriculum and learning outcomes (Owens 1998). Any delay in the return of final-year health science students for clinical placement and clinical rotation is a ticking bomb that should be averted at all costs. Failure to achieve exit-level outcomes and meet the minimum requirements for professional registration by the end of 2020 may have many ramifications. Delay in the production of health professsionals will further affect the already weak economy of the country, in the wake of the recent Moody's downgrading of the national economy to a junk or subinvestment grade (Duvenage 2020). Predicting the impact of turmoil associated with the COVID-19 epidemic on the social, political, economic, demographic and cultural systems cannot be predicted yet. Still, a delay in production and graduating the final-year health science students at the end of 2020 can have future legal and ethical implications for UKZN CHS and KZN-DOH.

There are proposals to reschedule the clinical placement and clinical rotation time-table to allow students to 'work' night duty shifts to ensure completion of clinical requirements for professional registration, where applicable, While 'working' night duty shifts is not something new, it does have ethical implications, when it is obvious that there will be little or no clinical supervision, because senior and qualified staff have to focus on management of COVID-19 patients who are fighting for their lives.

\section{Challenges Related to the College of Health Science's Interaction with the Larger External System Challenges}

Most universities that offer clinical science programmes are in agreement with the early return of other final-year health science students and are all looking at means and ways of doing this without endangering the students' health and wellbeing. However, the Department of Higher Education and Training is reported to not to support this, citing putting students' lives at risk for contracting COVID-19, reversing the gains obtained from the national lockdown in terms of flattening the curve of the spread of COVID-19 among other reasons (SACOMD 2020). Heeding the warning from DHET is important, as CHS and other universities develop plans and strategies to ensure 
the smooth delivery of clinical teaching and learning during the national lockdown and closure of universities.

Legally, the other final-year health science students have a right to expect the CHS to deliver on their promise in terms of the programmes that students are registered. Students have the right to demand an early return in order to meet the clinical requirements of their professional regulatory boards. Legal disputes resulting from perceived and actual failure on the part of the CHS to meet its obligations in the delivery of clinical teaching and protection of students and staff from being infected with COVID-19 during this epidemic should be avoided. Legal experts within and outside the university may have to be done timely to ensure that all planned strategies for the early return of students are legally and ethically sound.

\section{Conclusion}

There is no best way of managing contingency and continuity plans for delivery of clinical teaching and learning during the national lockdown and closure of a university. However, using the sociotechnical systems theory provided us with a framework for a pragmatic approach to ensure challenges are identified and addressed from different angles. It also provided us with a lens to identify and address the legal and ethical implications associated with placing students in clinical settings during national lockdown and closure of higher education institutions in response to the COVID-19 epidemic.

\section{References}

Avali, A., A. Zargham-Boroujeni, A. Yousefy \& M. Bahram 2017. Altruism, the Values, Dimensions of Caring, Self-efficacy Concept in Iranian Pediatric Nurses. Journal of Education and Health Promotion 6:8. https://doi.org/10.4103/jehp.jehp 142 14

PMid:28546973 PMCid:PMC5433645

Department of Health. Nursing Act No. 33 of 2005. 2014. Regulations Setting out the Acts or Omissions in Respect of which Council may Take Disciplinary Steps. Regulation. Gazette No. 38047 of 01 October 2014. Available at:

https://www.gov.za/sites/default/files/gcis document/201410/38047rg10 282gon767.pdf 
Department of Health. Health Professions Act No.56 of 1974. Rules Relating to the Registration by Medical Practitioners and Dentists of Additional Qualifications. Available at:

https://www.ufs.ac.za/docs/librariesprovider25/cpd-documents/cpd-

health-professions-act-56-of-1974-1018-eng.pdf?sfvrsn=0

Duvenage, A. 2020. What the Moody's Downgrade Means for South Africa.

City Press 2020-03-30. Available at:

https://www.news24.com/citypress/business/what-the-moodys-

downgrade-means-for-sa-20200330

Faber, O.N. 2020. Medical Students can Help Combat COVID-19: Don't Send them Home. First Opinion. STAT. Available at:

www.Statnews.com/2020/ 03/14/Medical-Students-can-help-combartCOVID-19/

Owens, R.G. 1998. Organizational Behavior in Education. $6^{\text {th }}$ Edition. Needham Heights MA: Allan and Bacon.

Piascik, P. \& A. Brazeau 2010. Promoting a Culture of Academic Integrity. American Journal of Pharmaceutical Education 74,6. Viewpoints, Article 13: 1 - 2. https://doi.org/10.5688/aj7406113

South African Committee of Health Sciences Deans 2020. Letter to Health Professional Councils, dated 2 April 2020.

World Health Organization 2014. Hospital Preparedness for Epidemics.

Geneva, Switzerland: WHO. Available at:

https://www.who.int/publications/i/item/hospital-preparedness-forepidemics

Sinegugu Duma Dean of Teaching \& Learning College of Health Sciences University of KwaZulu-Natal

Durban Dumas1@ukzn.ac.za

Busisiwe Ncama Deputy Vice Chancellor and Head College of Health Sciences University of KwaZulu-Natal

Durban Ncamab@ukzn.ac.za 


\title{
Implications of the Minister of Higher Education's 'no child left behind' on an African Child during the Coronavirus Pandemic in South Africa
}

\author{
Christina Kgari-Masondo \\ ORCID iD: https://orcid.org/0000-0002-1850-6363
}

\section{Zoleka Mkhabela}

\section{Abstract}

The global decolonisation of education in higher learning encourages scholars to revisit the African past for inspiration to deal with contemporary education problems deterring students from enjoying the education they deserve. The current global Corona pandemic has expounded the inequalities existing in societies, leading to education institutions finding it difficult to ensure that all students access teaching and learning. In South Africa the majority of students are African and they reside in rural ecologies that lack infrastructure like electricity and running water. Many of such students lack resources to engage in the current technology-based education due to poverty and funding. Despite that, the Minister of Higher Education, Dr Blade Nzimande, introduced the principle of 'no child left behind' during the implementation of online teaching without providing ways of attaining that. This chapter thus interrogates the feasibility of not leaving any child behind, especially those in rural ecology who have no access to online teaching and learning gadgets and struggle with networks. Existing research indicates that there is lack of acknowledgement of African teachers' voices about solutions to their students' experiences drawing from indigenous knowledge in matters that the government introduces in varied contexts. Therefore, the chapter reports on a qualitative study through the auto-ethnographic observations and reflection of two African lecturers about the 'silenced' narratives of diverse African 
students' living contexts that need mitigation in the implementation of online teaching and learning to ensure they are not left behind during the era of pandemic. For this project we draw on one of the IsiZulu idioms, umuntu akalahlwa (a human person is not disposable), as a way of mitigating the concern of 'no child left behind'. The study concludes that umuntu akalahlwa is a pedagogy that can be used in unsilencing measures that inhibit students from accessing online teaching and learning as it, safeguards human rights of all students.

Keywords: Online teaching and learning; Corona virus; Higher Education; African child; Umuntu akalahlwa pedagogy.

\section{Introduction}

The Corona virus is a global crisis in the $21^{\text {st }}$ century that has affected both developed and developing countries alike. The effects of the virus range from health, economic, academic, cultural and political, among other ramifications. Academically, schools and higher education (HE) institutions have been hit hard by the virus especially in developing countries due to lack of resources. Closure of educational institutions interrupted many countries' teaching pedagogy. Zaharah and Kirilova (2020) argue that the major impact of the Corona virus in teaching and learning $(T \& L)$ is based on the fact that processes that take place at schools or in classrooms have to be moved to home through the use of online learning using various technological devices, such as smartphones, computers, and notebooks. Online learning is termed by most authors as access to learning experiences via the use of some technology (Carliner 2004; Conrad 2002; Crawford et al. 2020; Hodges et al. 2020). With online learning, students can access the course at any time at his or her own space and pace (Toquero 2020:3). However, with the vast inequalities that exist in the world, students from disadvantaged context will experience difficulties in engaging with online T\&L. The challenges of the Corona pandemic on education are also noted by the United Nations Educational, Scientific and Cultural Organization (UNESCO) (2020) that around 290.5 million students worldwide who come from disadvantaged contexts are those who tend to be affected the most by the closure of educational institutions. In South Africa most students come from a disadvantaged context, with inaccessibility to 


\section{Christina Kgari-Masondo \& Zoleka Mkhabela}

electricity, networks, data, laptops or smart phones. However, and in line with Minister Blade Nzimande's call for all involved in T\&L in HEs not to leave any child behind during this pandemic crisis, how will this be feasible?

Hence the objective of this is to reflect on the implications of the Minister of Higher Education's 'no child left behind' for an African child during the Corona virus pandemic in South Africa. The chapter also seeks to tease out the pedagogy that can be used to ensure that 'no child is left behind' during the crisis brought on by the pandemic. One can argue that one positive impact of the Corona virus is that it exposes the inequalities that are rife in the South African education system and it provides the poor students with an opportunity to chart a way forward on how they want to be taught. As proposed by Ramose (1998), African people must regulate the teaching, learning and content of their education grounded in their understandings for contextual relevance. It implies that solutions can also be drawn from African indigenous knowledge. Since language is the reservoir of knowledge and wisdom, there is a need to exhume some of the gems from African languages for the purpose of this chapter to investigate the feasibility of 'no child left behind' during the period of pandemic. For this chapter we draw on one of the isizulu idioms, umuntu akalahlwa (a human person is not disposable), as a way of thinking about some of the moral and ethical concerns confronting the online teaching currently in this context. This is part of umuntu akalahlwa pedagogy, as it promotes students' full participation in their learning, even within the povertystricken settings, so they are taught despite the context from which they come. The pedagogy ensures that all kinds of learning contexts are catered for in T\&L. An African student in this chapter refers to all indigenous black students of South Africa i.e. Sotho-Tswana, Nguni, Tsonga, Venda, coloureds and the Khoi-San (Gade 2012:486).

\section{Literature Review}

Historically, colonial and apartheid governments divided Higher Education institutions racially. They were funded differently, with black institutions receiving less funding. South Africa in general and $\mathrm{HE}$ are plagued by profound inequalities. The impact of these inequalities prevents some students from either accessing, participating or succeeding in areas where others flourish. Though efforts have been made to address inequalities in South Africa, not much has been done to address inequalities concerning students in 
HE (Ruswa 2019). As a result, many black institutions are geographically located in deep rural areas, homelands and are inadequately resourced (Maphiswana \& Noyoo 2016). Policies on HE endorsed in the South African Constitution of 1996 and the Higher Education Act and White Paper of 1997 directed $\mathrm{HE}$ institutions on how to realise profound and wide-ranging essentials and objectives of transformation in its institutions (DominguezWhitehead \& Moosa 2014). The transformation refers to the active removal of any institutional, social, material and intellectual barriers leading to the creation of a more equal, inclusive and socially just HE system (Leibowitz 2012). Literature on the current status of transformation in HE depicts that transformation is slow and that social, political and economic discrimination and inequalities of a class, race, gender, institutional and spatial nature profoundly shaped, and continue to shape, South African HE (Badat 2012; Bozalek \& Boughey 2012). This is the context most of African students in South Africa are faced with during the current pandemic crisis that has hit the world.

The dimensions of poverty may be thought of as individuals' financial resources; the family's financial resources; number of dependents; material resources such as the kind of accommodation students occupy; the physical conditions under which students learn on campus or at home; students' access to healthcare; students' well-being; the socio-cultural resources which are related to students' academic background; and the sustainability of these resources (Tinto 2003). Hence, Machika and Johnson (2015) suggest that HE institutions need to understand the full impact of the conditions of poverty under which many students live, think and learn while studying towards a degree or diploma, and how these conditions affect their academic success. Many of these students live in rural areas, of which (Jordan 2020) reports that a rural background may have a negative impact on individual student success; townships or peri-urban settlements where they do not have access to electricity, water, smartphones, Wi-Fi or even the internet.

Literature indicates that African students from disadvantaged backgrounds will suffer the most from the Corona epidemic in terms of their studies, especially if universities do not consider them (UNESCO 2020). Jones et al. (2008) outline that it seems as if HE institutions are not willing to accommodate students from disadvantaged backgrounds. Machika and Johnson (2015) also reiterate that it is important for universities to understand the needs of students who are poor to best support their academic needs. These 


\section{Christina Kgari-Masondo \& Zoleka Mkhabela}

scholars' views are also supported by Subotzky and Prinsloo (2011), who argue that if HE institutions do not understand the nature of their students' poverty better, they will not be able to understand how they may contribute to the reproduction of structural conditions of poverty and inequality. This suggests that, within the context of the Corona virus, HE institutions have to ensure that no students are left behind in order to ensure social justice and the non-disposal of students due to the social context that can impede them from engaging in online learning.

Arguments presented reveal that, while students' unpreparedness is well documented, institutional unpreparedness to meet the needs of an African child is less recognised. The Minister of HE publicized that HE institutions must understand that they meet the needs of all students, including an African child, but he fails to state what strategies must be adopted. Scholars like Owusu-Fordjour, Koomson and Hanson (2020) have brought forward the idea of training students and teachers to use online resources to deal with the challenges of closed schools during the pandemic period. However, the gap is visible in literature and the government policies about the T\&L of African students during the period of the Corona pandemic. Henceforth this chapter tries to fill that lacuna in academia and government policies by proposing practical strategies that can be implemented to meet the pedagogical needs to teach an African child, drawing from practitioners' narratives who are lecturers in $\mathrm{HE}$.

\section{Methodology and Theoretical Framework}

The feasibility and implications of the principle of 'no child left behind' during the crisis of Corona pandemic in HE in South Africa will be explored through the reflections of the authors who are lecturers on their own experiences and observations known as auto-ethnography. Denshire (2013) explains that autoethnography is a method of qualitative research in which authors use selfreflection and writing to explore their individual experience and attach these autobiographical narratives to wider cultural, political, and social meanings and understandings. It does not uncritically tell the author's story, but critically works with the broader context of the narrative. Brodkey (1996:28) articulates that auto-ethnography goes beyond the writing of selves and this chapter couples it with the analysis and observation of our students about online T\&L at the universities at which we teach. As argued by Zwozdiak-Myers (2012:3), 
teachers who are keen to improve in their professional practice constantly ask questions about their teaching practice, which inspires commitment to continuously learn and create or find new ideas. For this chapter, the sources are the authors' written reflective teaching journals, and secondary sources like books, articles, reports, and online materials. Embodied auto-ethnographic accounts of professional practice in education studies, such as the one in this chapter 'can function as something of a corrective to depersonalized and disembodied accounts of professional work' (Denshire 2014:840). In this sense, auto-ethnography is aligned with critical discourse analysis used in this chapter, as it highlights matters of power irregularities, manipulation, and structural injustices in fields such as education.

The study is qualitative, since it records the experiences of individuals and it is concerned with peoples' lived experiences (Delport et al. 2005). Selfreflection used in this chapter stems from what Brandenburg refers to as 'assumption interrogation', because it allows the researcher to cross-examine data through a reflection process so that new information emerges (cited in Tidwell \& Fitzgerald 2009: xix). Freese (2006) explains reflection as a consideration of experience and learning as in reflection, people recall, deliberate and evaluate their experiences generally to develop their practice and to improve their understanding of experiences. This in line with LaBoskey's (2004) view that the purpose of a reflective study is to enhance our knowledge of social justice, which is the purpose of this chapter.

The authors' reflections were teased out from the teaching journals of History since 2013 (Chris) at one university in KwaZulu-Natal and the other lecturer (Zo) from January 2020 at a university in the North West. Due to the Corona pandemic we then started to reflect on our own social setting as African lecturers in order to link our observations and the ones we discovered with our African students while teaching at university to detect how an African child is catered for pedagogically during and after the period of the pandemic in HE institutions. Data were analysed by transcribing our observations, using the constant comparative method of grounded theory (Glaser 2001). Grounded theory ensures that data collection, analysis and theory stand in reciprocal relationship with one another (Strauss \& Cobin 1990:23). A thematic method of analysis (Cho \& Healey 2008) was used (investigate the challenges faced by African students with online learning and whether the Minister of HE 'no child must be left behind' is realistic). To analyse our observation data we used 
written archival documents and other secondary sources to fill the gaps created by our nostalgia.

The approach used in this chapter is based on Africanisation of HE by representation of pedagogy from indigenous language - umuntu akalahlwa. The idiom is aligned with the Minister's principle of 'no child left behind' in $\mathrm{T} \& \mathrm{~L}$ as it promulgates that in all humans there is inherent value and therefore each person must be treated in a humane manner. Masondo (2018) argues that the idiom emphasises two facets; that is,

(a) the responsibility of care and love that one has to others; and

(b) dealing with idiosyncrasy.

This suggests that a human person cannot be thrown away. Umuntu akalahlwa is a further exposition of the epitome contained in ubuntu as it strengthens humanising others as key to being human. Deviation by disposing a person is a violation of human rights, as it is broadly perceived as anti-social activities and behaviour. There is a sense that, regardless of what has happened, there is always a possibility for reintegration. According to Bewaji (2004), 'the wellspring of morality and ethics in African societies is the pursuit of a balance of individual, with communal wellbeing'. This suggests that African ethics protects human rights of all people and that no person must be left behind in terms fostering community life.

The idiom relates with the ethnographic study that focuses on selfreflection of lecturers in this chapter on the feasibility and implications of 'no child left behind'. The reflections of the two African lecturers' tallies with the idiom of umuntu akalahlwa, as it permits them to empathise with the African students they teach, which is one way of defending human rights and maintaining social cohesion, because the experiences of the underprivileged are recorded to ensure that they are integrated in $\mathrm{T} \& \mathrm{~L}$ during the current pandemic.

\section{Presentation of Data}

The first narrative is by a lecturer (Chris) from one university in KwaZuluNatal. The students she teaches are mostly African and come from an underprivileged setting located in a rural context where homes are overcrowded, there is lack of electricity, running water and poverty is rife. 
Author two (Zo) lectures mostly white students who come from affluent areas that are urban located, with running water, electricity and are highly resourced. The two lecturers took a self-reflective narrative inquiry approach to make meaning from their experiences in teaching in $\mathrm{HE}$ during the era of crisis like the Corona pandemic.

Chris observed that the majority of the students she teaches come from poverty-stricken townships on the outskirts of South Africa, especially from KwaZulu-Natal.

I work for one of the leading universities in KwaZulu-Natal. The majority of our students are African and come from the informal settlements, townships and rural areas where there are problems with running water, electricity, and internet connectivity. Some students have indicated that university residences provided them with a conducive environment for learning, as they do not have to compete for space in their crowded homes. Their homes are normally four roomed and overcrowded with family members. Such students are funded by the National Student Financial Aid Scheme [NSFAS] and always struggle even to support themselves with the funds the government gives them. In such a context the Corona virus emerged as a major hit to the disadvantaged, because universities had to close and online teaching became the norm. The government, through the Minister of HE, informed universities to teach online, but lacked giving support on how this could be implemented. Moreover, the principle endorsed by the state is that 'no child must be left behind'. Worst of all, the poor students are yet again discriminated against as their social setting has been forgotten - overcrowding, data issues, technological needs, and funding. A paperless university is a problem as those who lack resources and funds are always left behind. As one of my African students said, the government, by not taking their economic background into consideration, is like balahliwe as the poor. My students request printed materials and recorded lectures saved on USBs, posted to students. It is because they prefer course outlines that are both online and hardcopies because network, electricity and funds inhibit them from going online to get course information.

Chris's reflection expounds that the issue of poverty is silenced in the 
Minister's narrative - it must be debunked and lecturers must create constructive ideas to assist poor students. However, the fact that the Minister made the announcement that 'no child must be left behind', he was thinking about those to whom online learning was going to be a problem. On a number of occasions, he warned universities not to go ahead without taking appropriate steps to accommodate all students. Her students proposes the use of both a mixed method type of teaching online and a return to printed course packs. What is interesting is that students do not oppose online teaching, but sees it as an opportunity to learn online, as they will be empowered with this important skill that the world has turned to in this $4^{\text {th }}$ industrial period. However, the context of such children must be taken into consideration if we are to use Elearning.

The other narrative is that of Zo who lectures at a university in the North West. Compared to Chris's students, most of her students are white and affluent, while the minority are African and come from rural areas in the North West Province. She observed that:

The university I am lecturing at in the North West attracts students from diverse backgrounds. The majority of my students are white and rich. The other calibre of students are those who come from rural areas and are African. I struggle with African students who complain about network issues, overcrowded homes and data issues. Not having these resources not only disadvantages these students, but does not allow for the grading to be a true representation of their work. It is worth mentioning that the university has been using an online platform for several years where students can access their module materials. During this pandemic, the university has worked together with various networks and have implemented a zero data charge, where students can access the online platform for T\&L. Hence the university is ensuring that no student is left behind. Nevertheless, although my university has done this, not all students have the resources to allow for $T \& L$ to occur and for the inequalities gap not to widen. African students request that course packs be printed and sent to them to complement online T\&L.

Zo's narrative reiterates Chris's reflection in that they both portray how African students propose to be taught during the era of pandemic. The 
pictures revealed in both reflections show that students do not want to be left behind. Hence urgency is required in dealing with the ramifications of inequality so that they are not left behind in T\&L. The narratives depict the context of poverty-stricken communities they teach and students who do not have the resources or funds to access their lecturers' resource material. Therefore, it is vital that an alternative is given to these students so that the principle of 'no child must be left behind' is achieved.

\section{Data Analysis}

To analyse our self-reflection data, we used written archival documents, papers and scrapbooks, and other secondary sources such as articles, books, on-line literature and newspapers to supplement the gaps. The key themes identified from our reflection journals were teased out based on the correlation with the purpose of this chapter, which ensured credibility and trustworthiness.

\subsection{Can 'no child must be left behind' be Achieved during the Coronavirus Pandemic?}

The Corona virus brought to light the practicalities of the politics of access to knowledge in HE, as indicated in the narratives of the two lecturers in this chapter. Inequalities are still rife (Ruswa 2019) as the Minister of HE reiterates 'no child must be left behind' as universities embark on online teaching. This suggests that transformation in T\&L is imperative and must accommodate all students' contexts, both rich and poor. Authorities have been silent about how this could be done. This chapter proposes that through the implementation of umuntu akalahlwa pedagogy, online teaching can be realised. The two practitioners bring forth information on the ground by narrating their experiences with students they teach who come from diverse backgrounds. The authors' narratives also depict that African students' context is silenced in the Minister's narrative. It indicates that mostly when the government takes decisions about $\mathrm{HE}$ it falls in the normative of excluding the knowledge of students' context. This renders itself to incomplete teaching pedagogy, because only one side of the teaching strategy (resourced) is favoured over that of the poor (poorly resourced) and this is tantamount to ukulahla umuntu (See Chris's narrative). 
Agency is key in during this time of the Corona virus - action must be taken by all involved in HE to ensure that education continues, and no child is left behind. The idiom umuntu akalahlwa depicts that the Minister's principle is feasible, as it calls for the equality of all in terms of access to education, despite the differences in socio-economic context. The narratives of the two lecturers also reveal that it is feasible to not leave any student behind, as long as the universities use both paper-based teaching and online. However, currently it is not feasible, as online teaching is the only teaching pedagogy currently used (Zaharah \& Kirilova 2020). African students suffer the most, due to the lack of requirements for online teaching such as electricity, data, network, and funds. Hence Zo maintains that, 'Not having these resources not only disadvantages these students, but does not allow for the grading to be a true representation of their work'. In addition, Chris's student suggests an important fact of not being disposed (ukungalahlwa) by proposing a pedagogy that will assist in ensuring that all students are accommodated during this time of the Corona virus.

\subsection{Implications of 'no child must be left behind': 'Umuntu akalahlwa' Pedagogy}

The implication of the Minister of HE's principle of 'no child must be left behind' is the introduction of umuntu akalahlwa pedagogy. The pedagogy suggests that the education system is not congruent with the needs of the society it serves, as students' contexts are not catered for in the current proposed online T\&L. UNESCO (2020) mentions that students that will suffer the most from the Corona epidemic in terms of their academic year, especially if universities do not consider them, are the ones from disadvantaged backgrounds. Chris argues that the Minister of HE, by not giving clear proposals on what can be done to assist the students and universities so that they will 'not leave any child behind' makes HE inaccessible for the poor, especially the African child who comes from the context of poverty as he/she cannot afford data, and other resources that will make education qualitative. This implies that 'knowledge is a commodity and access is the key', which means that those who do not possess and cannot access that knowledge are at a disadvantage (Dziuban, Moskal \& Hartman 2005: 11). Hence the Minister's principle is to ensure the pedagogy of umuntu akalahlwa to ensure that no 
student is rendered to a category of ukulahlwa (dispose students) during this time of the Corona virus.

Therefore, this chapter proposes the use of umuntu akalahlwa pedagogy during the Corona $\mathrm{T} \& \mathrm{~L}$ crisis, which acknowledges the context of poverty within which most students live. The pedagogy cannot be used in a crisis situation only - as an intervention it is necessary, but it should also be used as part of the academic processes going forward.

This is because systematic curriculum development, including materials, needs to ensure that diverse pedagogies are drawn together when narratives are told or written down (Waghid 2002:69). Naturally, lecturers who encompass both the rich and poverty context of students they teach would do a great job in taking into cognisance the two contexts together for themselves when they teach in times of crisis like the Corona pandemic. Though complex, this chapter has illustrated through the narratives of lecturers' teaching during the Corona pandemic that it requires committed practitioners who are willing to engage in umuntu akalahlwa pedagogy. As Masondo (2018) argues, the idiom emphasises the responsibility of care and love that one has to others, and dealing with idiosyncrasy. This suggests that a human person cannot be disposed of; instead, he always has to be integrated into the community. Thus, accommodating all students in T\&L during the crisis of the pandemic is part of humanising others as it is key to being human, As Bewaji (2004) articulates, 'the wellspring of morality and ethics in African societies is the pursuit of a balance of individual, with communal wellbeing'. This indicates that African ethics protects human rights of all people and safeguards equality to ensure social cohesion.

As part of community building and the integration of African students who are underprivileged and are unable to engage in online T\&L, umuntu akalahlwa pedagogy must be revisited in line with democratic principles and values of transformation of HE. Globally, universities introduced a paperless T\&L strategy, but in line with the context and proposals of African students from Chris and Zo's reflections, online teaching must be complemented by integrating a paper-based T\&L style. Chris mentioned that 'my students request printed materials, recorded lectures saved on USBs posted to students'. On the same note Zo states that 'African students request to for course packs to be printed and sent to them to complement online T\&L'. The two proposals can work together effectively and can assist students from all contexts to learn with ease and no child will be left behind. 
Umuntu akalahlwa pedagogy embraces both online and measures that can aid in bridging face-to-face contact teaching. The pedagogy allows teachers to understand different contexts as different and not superior to the other and in the process, students will understand their identity as diverse South Africans in a globalised world better. The pedagogy tallies well with the tenets of South Africa's Constitution, Act 108 of 1996 of equal treatment of everyone, and as such must be implemented, as the world currently faces the pandemic and must be part of the HE teaching policy.

\section{Conclusion}

Education has been the battleground of the poor and rich and as a result HE T\&L strategies still omit the integration of the poor so that they can enjoy quality education and 'no child must be left behind'. The Corona virus has highlighted the stringent gaps between the poor and rich students in HE. The reflections of the two lecturers in this chapter suggest that little has been done by the government and HE to bridge and make sure that the poor enjoy quality education amidst their challenges with resources within this context of Corona virus. The call of this chapter is that to ensure that 'no child must be left behind' during the Corona virus period as requested by the Minister of HE, the umuntu akalahlwa pedagogy as it promulgates integration of all students in their T\&L despite the context they come from. The reflections of two lecturers indicate that we have to move away from silencing students' context when we adopt teaching strategies that are accorded as significant, but due to political propaganda are pushed to the periphery.

Teaching pedagogy in South Africa must be relevant to the call of what education is driving us to - democratic principles of respect for all contexts that are silenced. This will contribute to nation building by empowering students in HE to embrace identity that is - inclusive of everyone in terms of class, culture, religion, sexual orientation and other ways. As the narratives of lecturers have pointed out, using umuntu akalahlwa pedagogy in the dispensation of any crisis or dispensation in education illustrates that any course can be taught to any student in any discipline as long as the pedagogy is effective and is aligned with the context of students and pushes them to deep learning. The chapter is a contribution to the topical global debate on decolonisation by stating that the social settings of poor students must be 
considered in HE while constructing T\&L strategies, especially during the era of the Corona virus pandemic.

\section{References}

Badat, S. 2012. Valuing Higher Education. In Joint Seminar of Higher Education South Africa and the Parliamentary Portfolio Committee on Higher Education and Training. Stellenbosch University: STIAS Wallenberg Research Centre 20: 98-106.

Bewaji, J.O. 2004. Ethics and Morality in Yoruba Culture. In Wiredu, KA (ed.): Companion to African Philosophy. Malden, Mass: Blackwell.

Bozalek, V. \& C. Boughey 2012. (Mis)framing Higher Education in South Africa. Social Policy \& Administration 46, 6: 688 - 703.

https://doi.org/10.1111/j.1467-9515.2012.00863.x

Carliner, S. 2004. An Overview of Online Learning. $2^{\text {nd }}$ Edition. Armherst, MA: Human Resource Development Press.

Chow, K. \& M. Healey 2008. Place Attachment and Place Identity: First-year

Undergraduates Making the Transition from Home to University. Journal of Environmental Psychology 28: 362 - 372.

Conrad, D. 2002. Deep in the Hearts of Learners: Insights into the Nature of Online Community. Journal of Distance Education 17, 1: 1 - 19.

Crawford, J., K. Butler-Henderson, J. Rudolph \& M. Glowatz 2020. COVID-

19: 20 Countries' Higher Education Intra-Period Digital Pedagogy

Responses. Journal of Applied Teaching and Learning 3, 1: 1 - 20.

https://doi.org/10.37074/jalt.2020.3.1.7

Delport, C., A. de Vos, C. Fouché \& H. Strydom 2005. Research at Grassroots: The Place of Theory and Literature Review in the Qualitative Approach to Research. Pretoria: Van Schaik.

Denshire, S. 2014. On Auto-ethnography. Current Sociology 62, 6: 831 - 850. https://doi.org/10.1177/0011392114533339

Denshire, S. 2013. Autoethnography, Sociopedia.isa 1-12. https://doi.org/10.1177/205684601351

Dziuban, C., P. Moskal \& J. Hartman 2005. Higher Education, Blended Learning, and the Generations: Knowledge is Power - No More. Elements 
of Quality Online Education: Engaging Communities. Needham, MA: Sloan Center for Online Education. Available at:

http://desarrollodocente.uc.cl

Freese, A. 2006. Reframing one's Teaching: Discovering our Teacher Selves through Reflection and Inquiry. Teaching and Teacher Education 22, 1: $100-119$.

https://doi.org/10.1016/j.tate.2005.07.003

Gade, C.B. 2012. What is Ubuntu? Different Interpretations among South Africans of African Descent. South African Journal of Philosophy 31,3: $484-503$.

https://doi.org/10.1080/02580136.2012.10751789

Glaser, B. 2001. The Grounded Theory Perspective: Conceptualization Contrasted with Description. Mill Valley, CA: Sociology Press.

Hodges, C., S. Moore, B. Lockee, T. Trust \& A. Bond 2020. The Difference between Emergency Remote Teaching and Online Learning. Educause Review 27. Available at:

https://er.educause.edu/articles/2020/3/the-difference-betweenemergency-remote-teaching-and-online-learning

Jones, B., G. Coetzee, T. Bailey \& S. Wickham 2008. Factors that Facilitate Success for Disadvantaged Higher Education Students. An Investigation into Approaches used by REAP, NSFAS and Selected Higher Education Institutions. Cape Town: Rural Education Access Program (REAP).

LaBoskey, V.K. 2004. The Methodology of Self-study and its Theoretical Underpinnings. In Loughran, J.E. \& M.C. Hamilton (eds.): International Handbook of Self-study of Teaching and Teacher Education Practices. Springer: Dordrecht.

https://doi.org/10.1007/978-1-4020-6545-3_21

Leibowitz, B. 2012. Introduction: Reflections on Higher Education and the Public Good. In Leibowitz, B. (ed.): Higher Education for the Public Good, Views from the South. Stellenbosch: SUN Press.

https://doi.org/10.18820/9781928357056/00

Masondo, S. 2018. Umuntu akalahlwa: An Exploration of an African Ethics. In Hewitt, R. \& H.C. Kaunda (eds.): Who is an African? Race, Identity and Destiny in Post-apartheid South Africa. Lexington Books/ Fortress Academic.

Ramose, M.B. 1998. Foreword. In Seepe, S. (ed.): Black Perspectives on Tertiary Institutional Transformation. Florida Hills: Virago Press. 
Implications of the Minister of Higher Education's 'no child left behind'

Mamphiswana, D. \& N. Noyoo 2016. Social Work Education in a Changing Socio-Political and Economic Dispensation Perspectives from South Africa. International Social Work 43, 1: 21 - 32.

https://doi.org/10.1177/a010518

Molema, S.M. 1920. The Bantu Past and Present: An Ethnographical and Historical Study of the Native Races of South Africa. Cape Town: Struik. Strauss, A. \& J. Corbin. 1990. Basics of Qualitative Research: Grounded Theory Procedures and Techniques. Newbury Park: Sage.

Subotzky, G. \& P. Prinsloo 2011. Turning the Tide: A Socio-critical Model and Framework for Improving Student Success in Open Distance Learning at the University of South Africa. Distance Education 32, 2: 177 $-193$.

https://doi.org/10.1080/01587919.2011.584846

Thomas, D. 1996. Education across Generations in South Africa. The American Economic Review 86, 2: 330-334.

Tinto, V. 2003. Learning better Together: The Impact of Learning Communities on Student success. Higher Education Monograph Series 1. Available at:

http://citeseerx.ist.psu.edu/viewdoc/download;jsessionid=28F5A032131 06290BCD013711005CFD2?doi=10.1.1.472.8470\&rep=rep1\&type=pdf Tidwell, D., M. Heston \& L. Fitzgerald 2009. Introduction. In Tidwell, D. (eds.): Research Methods for the Self-study of Practice. Volume 9. New York: Springer Science \& Business Media.

Toquero, C.M. 2020. Challenges and Opportunities for Higher Education amid the COVID-19 Pandemic: The Philippine Context. Pedagogical Research 5, 4: 1 - 5. https://doi.org/10.29333/pr/7947

Triacca, L., D. Bolchini, L. Botturi \& A. Inversini 2004. Mile: Systematic Usability Evaluation for e-Learning Web Applications. Association for the Advancement of Computing in Education Journal 12, 4. Available at: https://doc.rero.ch/record/5377/files/1 Botturi AACE 2004.pdf

UNESCO 2020. COVID-19 Educational Disruption and Response. Available at: https://en.unesco.org/covid19/educationresponse

Owusu-Fordjour, C., C.K. Koomson \& D. Hanson 2020. The Impact of COVID-19 on Learning - The Perspective of the Ghanaian Student. European Journal of Education Studies 88 - 101.

Waghid, Y. 2002. Democratic Education: Policy and Praxis. Stellenbosch: University Publishers. 
Zaharah, Z. \& G.I. Kirilova 2020. Impact of Coronavirus Outbreak: Towards Teaching and Learning Activities in Indonesia. SALAM: Jurnal Sosial dan Budaya Syar-i 7, 3: 269 - 282.

https://doi.org/10.15408/sjsbs.v7i3.15104

Zwozdiak-Myers, P. 2012. The Teacher's Reflective Practice Handbook. New York: Routledge.

Dr. Maserole Christina Kgari-Masondo Senior Lecturer Economic History and Development University of KwaZulu-Natal Durban Kgarimasondo@ukzn.ac.za

Ms. Zoleka Mkhabela Lecturer History Education North-West University

Potchefstroom zoleka.mkhabela@gmail.com 


\title{
Flipped Learning within Mathematics Teacher Education in KwaZulu-Natal, South Africa: Embracing Connectivism in Response to the COVID-19 Pandemic
}

\author{
Jayaluxmi Naidoo \\ ORCID iD: https://orcid.org/0000-0003-3433-5354
}

\section{Abstract}

The COVID-19 pandemic has disrupted life-encompassing societal and educational lockdowns globally. Higher Education Institutions are undertaking various approaches to complete the academic semester remotely while seeking to maintain academic integrity. Within the Fourth Industrial Revolution, digital tools are viewed as essential in facilitating remote learning. Globally, institutions are introducing virtual and remote learning within their curricula. In mathematics education contexts, coupled with embracing remote learning, are issues of what it means to incorporate flipped learning within the context of COVID-19. This chapter draws attention to a qualitative study that explored mathematics education students' perceptions of flipped learning within the context of the pandemic. The study was framed by connectivism, which is a network learning theory guided by the view that learning is a process whereby new information is continuously being acquired. Participants were invited to interactive virtual workshops focusing on flipped mathematics learning within the context of the COVID-19 outbreak. Subsequently, participants were interviewed online, based on their perceptions of flipped mathematics learning. The findings of this study indicate that there are challenges with using flipped learning and the advantages of collaboration inspired by flipped learning within the context of COVID-19. Globally, these findings have relevance when considering the perceptions and implications of flipped mathematics learning within the context of the COVID-19 pandemic.

Keywords: Connectivism, COVID-19, Digital Tools, Flipped Learning, Fourth Industrial Revolution (4IR), Mathematics 


\section{Introduction}

We have entered the era of the Fourth Industrial Revolution, and globally the use of digital tools is widespread (Pyper 2017). Digital tools are progressively displacing traditional pedagogy at educational institutions, and the use of the Internet and Information and Communication Technology (ICT) has revealed the capability to transform educational milieus (Du Plessis 2013). Currently, we are dealing with an unprecedented global health pandemic. At the time of completing this chapter (June 2020), globally, over 7.4 million people are infected, and more than 419000 people have lost their lives due to COVID-19 (Elflein 2020). Within South Africa, over 55400 people are infected, and more than 1200 people have lost their lives due to COVID-19 (Mkhize 2020).

The communicable coronavirus (COVID-19) disease, which originated in Wuhan, China, has dispersed swiftly, forcing people globally into lockdown conditions (Sahu 2020). Under lockdown conditions, people are not permitted to leave their homes except to obtain medical care, visit a pharmacy for medicine, purchase food and essential items, or to collect social grants.

Within these unique lockdown environments, Higher Education institutions are attempting to complete the academic semester remotely while seeking to maintain academic integrity. Since online pedagogy is considered as a way of confining the spread of the contagious COVID-19 disease (Murgatrotd 2020), large-scale, national initiatives to engage with digital tools to support online pedagogy during the pandemic are developing and progressing quickly. However, within the context of the pandemic, we need to establish if students and lecturers within South Africa are adequately prepared for remote and online pedagogy. This chapter reports on a study which sought to respond to the question: What are students' perceptions of using the flipped learning approach in a mathematics higher education milieu within the context of the COVID-19 pandemic?

\section{Fourth Industrial Revolution}

The Fourth Industrial Revolution involves innovative methods in which technology is embedded within societies and human bodies (Schwab 2016). Within the Fourth Industrial Revolution (4IR) era, technology, digital tools, robotics and artificial intelligence are transforming the way we exist. The rapid pace of this transformation is unsettling society, since the 4IR has transformed 
the way nations subsist. The 4IR is epitomised by merging the physical and virtual world (Schwab 2016), shaping a universally connected and advanced society. Within the context of COVID-19, as professionals in the education sector, we ought to embrace this transformation to engage and interact successfully with our students.

Students may be at different levels concerning preparedness for succeeding within the 4IR; students may be digital natives or digital immigrants. Digital natives are knowledgeable about the use of technologybased tools (for example the Internet, computers and other digital tools), and this term is generally used to typify individuals who have always been involved and associated with technology-based tools (Helsper \& Enyon 2009). These individuals are more likely to succeed in using technology-based tools when learning. In contrast, digital immigrants are individuals who may learn and understand how to use technology-based tools, but rather than going online for information or working online first, they may print out information to peruse before visiting the Internet for assistance or information (Helsper \& Enyon 2009). These individuals may need additional support with using technologybased tools. As is evident, lecturers need to know who their students are and what their abilities are concerning using technology-based tools when learning. This knowledge will assist when introducing the notions of the 4IR in the lecture room.

Also, our education structures need to be adapted to prepare students adequately to succeed within these conditions (Butler-Adam 2018). To develop the necessary capacity for the 4IR, education milieus ought to adapt quickly since the demand for remote and virtual pedagogy within this global health pandemic is increasing and progressing. Thus, the 4IR influences the function that Higher Education institutions play in preparing students for survival within our technologically progressive society. To take advantage of 4IR opportunities, we need to transform our pedagogy to include the effective use of digital tools.

\section{Using Digital Tools within Mathematics Education Contexts}

The digital world has entered education spheres, with technology progressively being used to deliver education in innovative ways (Grand-Clement, Devaux, Belanger \& Manville 2017). Within the domains of this chapter, digital tools are software platforms and web-based resources that may be used with 
computers or mobile gadgets that operate with text, pictures, audio, and video to support teaching and learning (Peachey 2017). For mathematics teaching and learning, Pope and Mayorga (2019) affirm that there are a plethora of online websites and an increasing number of educational applications that may influence students' learning and achievement. Within the 4IR and considering the novel COVID-19 pandemic conditions, Higher Education institutions are gravitating towards using digital tools for remote and online pedagogy.

Research (Cheung \& Slavin 2011) has shown that using digital tools when teaching mathematics has enriched student performance. Digital tools in mathematics education milieus may assist students that are both struggling and are thriving (Bruce 2012). However, within the context of remote and online pedagogy, it is overwhelming for the lecturer to select the appropriate digital tool to navigate the plethora of available online tools. The idea is to select the most effective digital tool to achieve the full potential of online pedagogy to scaffold students' learning. Thus, it is the lecturer's responsibility to facilitate advancement in education (Montrieux, Vanderlinde, Schellens \& De Marez 2015).

Since it is evident that digital tools are transforming the lecturer's role, we need to know how best to prepare and support lecturers during this transformation (Grand-Clement et al. 2017). Currently, the lecturer ought to use digital tools to enhance pedagogy within the 4IR while considering the reality and implications of the COVID-19 pandemic. Since pedagogy is transforming rapidly, one progressive approach to consider is the Flipped Learning Approach.

\section{Flipped Learning Approach}

The Flipped Learning Approach (FLA) is a combination of traditional teaching and teaching using digital tools (Ramakrishnan \& Priya 2016). This approach requires a transformation or conventional pedagogy inversion and is established on the concept of switching in-class teaching time with out-of-class practice time (Hwang, Lai \& Wang 2015). By using the FLA, students view subject matter using videos and PowerPoint presentations before the lesson. Hence, the use of digital tools is essential within the flipped learning environment. Within this environment, the lecturer is a guide or a facilitator.

Students and the lecturer collaborate actively within the lecture room based on prior planning. Rambe and Bere (2013) maintain that collaborative 
learning motivates the construction of knowledge through interactions within the group. Collaborative learning also enhances the learning process and promotes the learning experiences for students (Tran 2014). This supports the view that learning is a collaborative effort rather than an involuntary endeavour (Lawson 2011). Thus, the FLA requires obligatory collaboration and participation from both students and lecturer. For this study, due to the contagious nature of the COVID-19 disease, remote teaching and learning were employed. Hence, the virtual lecture room was utilised. In this study, virtual teaching and learning refer to online teaching and learning that occurs remotely. Primarily, the virtual lecture room encompasses interactions between the lecturer and students who are located at different places at the same time.

Within mathematics education settings, digital tools and websites, for example, Geogebra, Geometer's Sketchpad, Mathway and Mathwords provide support to students and lecturers (Rajkumar \& Hema 2017). Within the flipped learning environment, the lecturer is tasked with transforming pedagogy within a large lecture room to an individual learning environment by using digital tools (Hamdan, McKnight, McKnight \& Arfstrom 2013). In this learning environment, the student interacts with the content before the lecture. During the lecture, this content is explored further with classmates and the lecturer to clarify and promote understanding. Moreover, problem-solving activities are performed revolving around the material being studied.

Fundamentally, within the spheres of remote pedagogy, before attending the virtual lecture, students work with the content to participate in the lecture. During the virtual lecture, students deliberate collaboratively on their understanding, and via these deliberations they enhance their knowledge of the content under focus. The lecturer facilitates, probes and clarifies important concepts by means of videos and PowerPoint presentations before and during the lecture, and encourages students to contemplate dynamically and build on existing knowledge (Hwang, Lai \& Wang 2015).

\section{Theoretical Considerations: Embracing the Notions of Connectivism}

The use of the Internet and ICT is necessary for facilitating teaching and learning within the 4IR. Worldwide, digital tools and online pedagogy are progressing rapidly within educational contexts (Foroughi 2015). New developments in online pedagogy have provided prompt access for teachers to 
introduce various digital tools and interactive technology-based learning approaches within the 4IR education environment (Bailey 2019). The introduction of digital tools within the education environment, as well as the rapid developments in technology, has led to the promotion of the theory of connectivism (Goldie 2016).

Connectivism is not without critique, and researchers (Craig 2008; Verhagen 2006) argue that this theory is uncorroborated theorising and opinion of $21^{\text {st }}$-century proficiencies that do not sufficiently explain how individuals acquire knowledge. However, connectivism is significant for learning within the 4IR (Foroughi 2015), since connectivism is a network learning theory which is guided by the perception that learning is a process whereby new information is continuously being developed (Siemens 2005). Connectivism may also be understood as an extension of Vygotsky's theory of social constructivism (Kerr 2007). Siemens (2006) has maintained that a new learning theory is essential, due to the development and intricacy of information accessible on the Internet and for the ability to combine different data transmissions. Within the scope of connectivism, students engage with and interact within digital platforms, for example, social networking sites, blogs and online learning communities to deliberate on and advance existing knowledge (Goldie 2016).

The concept of networking is significant to connectivism since information is professed to be progressing from a network of people to a network of digital tools (Bell 2011). Hence, connectivism refers to networked social learning (Duke, Harper \& Johnson 2013) and emphasises distributed learning, which is inspired by technology and the idea that knowledge may reside within digital tools (Goldie 2016). Connectivism allows for a community of students working with digital tools to rationalise what they are learning (Bell 2011).

\section{Materials and Methods \\ 6.1 General Background}

This qualitative, interpretive study was situated within one mathematics Higher Education environment during the Level 5 National lockdown in South Africa. Gatekeeper access and ethical clearance were approved by the participating university's ethics committee. The study incorporated three interactive workshops and one semi-structured individual interview with postgraduate 
mathematics education students. These students were also mathematics teachers at secondary schools. The participants were purposively selected for convenience, since the researcher taught or supervised these students.

\subsection{Participants}

The population for the study were 35 postgraduate students who were invited to participate in the study. Participants were provided with an informed consent form describing the process of the research. Twenty-seven students responded positively (17 male and 10 female). Five participants were randomly selected to participate in the pilot study.

\subsection{Pilot Study}

Conducting the interactive virtual workshops and semi-structured interviews during the pilot study improved the study's trustworthiness, transferability, confirmability, and dependability. During the pilot study, internet connections were slow and unstable during the workshops, since the pilot workshops were conducted at peak times when internet service providers were dealing with many customers. This led to slower network speed and unstable connections. Hence, the workshops took more time than was allocated. Additionally, some participants were unclear about what was required of them for specific questions during the online interviews. To eliminate issues of this nature, during the main study, the workshops were held with the consent of all participants during off-peak times to ensure the speed and stability of internet connections. Moreover, to ensure that each interview question was understandable, questions were rephrased to avoid ambiguity. The language used during the interactive virtual workshops and online interview process was focused and well-defined to improve the dependability and credibility of the research tools and procedure.

\subsection{Main Study}

Twenty-two participants participated in the main study. Data were generated via three interactive virtual workshops and semi-structured online interviews. Although 22 participants participated in the virtual workshops, due to personal, family, or other obligations, only 11 participants were available to be 
interviewed. Six male and five female students were interviewed for the main study. To assure participants of their anonymity, pseudonyms were used as presented in Table 1.

Table 1 Participants who Participated in Online Interviews

\begin{tabular}{|l|l|l|l|}
\hline Participant \# & Pseudonym & Participant \# & Pseudonym \\
\hline 1 & Judy & 7 & Nozipho \\
\hline 2 & Themba & 8 & Anele \\
\hline 3 & Sizwe & 9 & Mandla \\
\hline 4 & Zodwa & 10 & Rajesh \\
\hline 5 & Lekha & 11 & Carl \\
\hline 6 & Gloria & \multicolumn{2}{|l}{} \\
\cline { 1 - 2 } & \multicolumn{2}{|l}{} \\
\cline { 1 - 2 } & & &
\end{tabular}

\subsection{Interactive Virtual Workshops}

A sequence of virtual interactive workshops $(\mathrm{N}=3)$ focusing on the FLA for mathematics was conducted with participants. The virtual workshops were facilitated by the researcher (lecturer), and participants were provided with supplementary online notes, PowerPoint presentations of case studies, and examples of online assessments focusing on using digital tools and free online websites within a virtual flipped mathematics education environment. In this virtual flipped learning environment, the lecturer shared resources with students online.

The virtual workshops focused on academic writing, assessment, providing feedback, identifying and correcting students' misconceptions in mathematics. At the end of the third virtual workshop, the participants were invited to online interviews scheduled during the Level 5 National lockdown in South Africa. This meant that each participant would have the opportunity to reflect on what they had learned from the workshops with a view to advanceing their pedagogy and thereby promoting their personal and professional development. The interview was conceived to explore students' perceptions of using the FLA in a mathematics higher education milieu within the context of the COVID-19 pandemic.

\subsection{Semi-structured Online Interviews}

The purpose of the interview was to explore students' perceptions of using the 
FLA in a mathematics higher education milieu within the context of the COVID-19 pandemic. Each interview was approximately 25 minutes. The interviews were conducted online using digital tools, for example, Zoom, Moodle, Skype and WhatsApp chats, at a time that was suitable for each participant. Each interview began with a few general questions to put the participant at ease. The interview then progressed to specific items, focusing on the participant's perceptions of flipped mathematics learning within the context of COVID-19. The interviews were semi-structured and concentrated on the following key questions:

- What are the participants' perceptions of the flipped learning approach for mathematics?

- Are online mathematics workshops beneficial to participants?

- What are the strengths of using the flipped learning approach for mathematics?

- What are the challenges of using the flipped learning approach for mathematics?

The online interviews were recorded and transcribed. Transcriptions were emailed to each of the eleven participants for scrutiny to ensure the correctness of each interview transcript.

\subsection{Data Analysis}

The data analysis process initiated the formation of codes for relating participant responses to each interview question. During data analysis, steps, as discussed by Tesch (as cited in Creswell 2014, 198) were followed to organise all unstructured data. The interview transcripts were carefully read, and notes were made. Each interview was then examined and analysed to explore what the information meant within the context of the study. Subsequently, a list of common topics was identified, and similar topics were clustered together. The topics were then shortened as codes. A descriptive word for each topic was defined and categorised. All interviews were later reexamined to establish a relationship between the categories. A final abbreviation for each category was used. The interviews were subsequently categorised/recoded using a definitive list of abbreviations (for example challenges or significance or advantages of flipped learning within the context 
of COVID-19) which were finally captured as themes.

The classification of themes also incorporated ideas established on Connectivism (for example, the effects of using digital tools for learning mathematics and contributions of online discussion forums for learning mathematics within the context of COVID-19). Two main themes were identified from the qualitative data analysis of the interview transcripts, which were the themes of challenges of using flipped learning and the advantages of collaboration inspired by flipped learning within the context of COVID-19.

\section{Findings and Discussion}

The findings and discussions are captured in the section that follows.

\subsection{Challenges of Using Flipped Learning within the Context of COVID-19}

7.1.1 Time Taken and Expenses Incurred for Downloading Free Online Resources

The participants downloaded and viewed the videos and PowerPoint presentations before attending the virtual workshops. The participants did not experience challenges with videos and presentations taken directly from the participating university's website or portal. However, some of the participants had difficulties due to the lack of infrastructure or resources outside of the lecture room. These ideas are supported by excerpts from the interview transcripts that follow:

Carl: ... it was tricky ... some resources that were free expected me to download apps ... took ... long ... used ... data ... could not get more data easily ... in lockdown ...

Gloria: ... the free websites ... took longer ... it was free but ... needed to download ... apps ... was a challenge ... took long ... lots of data ... expensive ... better to have the information sent to us ...

Lekha: ... problems with ... free resources ... not ... enough time to download ... information ... could access the videos that were sent ... it is better if the resources were ... university website ...

Mandla: ... free resources ... not free ... used ... my airtime and ... data to get information ... 
Sizwe: ... the free resources expected me to work on my computer ... problem ... my computer is also used by my children ... not always available to me ...

Themba: ... get used to using different websites at the same time ... not used to it ... complicated ... many instructions on ... free websites ... much time ... was difficult ...

Zodwa: ... finding the free resources you ${ }^{1}[$ the lecturer] ... to look at before the workshop ... took long ... data ... expensive ... slow ... asked my children to help ... they are used to working online...

The preceding transcript excerpts indicate that students are willing to embrace the 4IR and have a desire to welcome the FLA. However, the lack of material resources affects their ability and confidence in online learning (Klopfer, Osterweil, Groff \& Haas 2006).

Within this study, students indicated that the free resources were challenging, expensive and complicated to access. In contrast, some students had problems with accessing the necessary information to add on to their existing knowledge. They found the recommended free online resources complicated and expensive to use. While each student is distinctive in the manner in which he/she embraces online learning, within the ambits of connectivism, material and resources must be easily accessible to all students since accessibility has consequences for student interaction, performance and success (Gilbert 2015).

\subsubsection{Fulfilling Family Responsibilities During the COVID-19 Pandemic}

The participants believed that during the pandemic and the lockdown conditions, they needed to ensure that they could manage their time for learning strategically but felt that they needed to fulfil their family responsibilities first. These views are exhibited in the interview transcripts that follow:

Judy: ... had other responsibilities ... time wasn't only focused on learning during the lockdown ... I am a single parent ... young family to take care of ...

\footnotetext{
${ }^{1}$ Words in square brackets have been added by the author to clarify the interview transcripts for the benefit of the reader.
} 
Mandla: ... though at home ... my children are worried ... disease ... too busy to talk ... busy learning ...

Nozipho: ... many things were happening at home ... whole family is with me ... to ensure that all my work and cooking is done before the workshop ... need to have space and time to think ... workshop ... many distractions during ... lockdown ... helped having my video off ... feeling embarrassed about ... small ... crowded home ... need ... to plan myself ... not very good with working ... computer ... need to try things ... first before ... workshop ... used ... resources for more information...

Themba: ... was difficult especially ... with ... coronavirus ... my family is scared ... I am busy with workshops ...

Zodwa: ... was difficult ... my son was also sick during the lockdown ...

While the participants were attempting to embrace online learning within the domain of connectivism, they did experience challenges. They also had to fulfil their family responsibilities while trying to meet their academic obligations. Thus, lecturers ought to collaborate first with students to ensure that students are adequately equipped to embrace the FLA especially within the context of the COVID-19 pandemic where students also need to deal with social, family and emotional issues related to the lockdown conditions.

\subsubsection{Limitations Experienced by Students Who are Not Digital Natives}

It was evident that the participants of this study were not all digital natives and were not accustomed to using technology-based tools. The participants, therefore, needed to learn new skills (for example, how to use Dropbox) to participate effectively in the virtual workshop. This view is supported by Roper (2007), who indicates that to access and be successful with learning online, students are expected to have a specific set of skills for this type of learning. Some of the skills required for successful online learning include necessary computer skills, searching for information, communicating online, time management and collaboration skills (Morrison 2014). Participants also indicated that they needed to practise before the virtual workshop in order to transform their learning and embrace the FLA. These views are exemplified in the transcript excerpts that follow: 
Judy: ... I think about maths by working on paper ... difficult ... to go ... the Internet ... the virtual workshops took some time to get used to ...the interactive bit ... I was sometimes left behind because of my slow computer ...

Mandla: ... it took time to get used to ... I could work before the workshop to look for the information for the workshop ... take my time ... not rushed ... during the workshop ... time was limited ... had to work in pace with each other...

Rajesh: ...virtual workshop ... good idea ... things happening around us ... may not get a chance to ask ... questions ... need to ... plan before ... workshop ... need to think about ... questions ... important ... ask ... questions during ... workshops ... not good with technology ... taught myself how to use Dropbox ${ }^{2} \ldots$ an achievement for me ...

Themba: ... I had to look up information during the workshop ... working with two things at the same time on the screen was difficult ... I am not that good with using the computer ... have to practice and learn now ...

The challenges faced by the participants could be because the participants are digital immigrants. Acquiring new skills (for example, learning how to use Dropbox) and updating knowledge using technology and online networks are aligned to the theory of connectivism (Goldie 2016). Hence, for some participants, flipped mathematics learning was challenging since they were digital immigrants and not digital natives.

\subsection{Advantages of Collaboration Inspired by Flipped Learning within the Context Of COVID-19}

7.2.1 Forming Partnerships within the Virtual Lecture Room Lecturers who promote philosophies of empowerment within their lecture rooms are prepared to distribute control of the learning process to their

\footnotetext{
${ }^{2}$ Dropbox is a personal cloud storage service/online backup service that is frequently used for file sharing. Dropbox is available for Windows, Macintosh and Linux desktop operating systems. A basic Dropbox account is free and includes $2 \mathrm{~GB}$ of space.
} 
students. In the transcripts that follow, this idea is supported by Anele and Rajesh. Moreover, the participants suggested that participating in virtual workshops created a sense of partnership, collaboration, and enthusiasm. These views are reflected in the transcript excerpts that follow:

Anele: ... felt part of a team ... could work together ... felt a little better...bit calmer working online with my colleagues ... wanted to participate, ... my lecturer, became a part of the online class ...

Rajesh: ... was a better option than the traditional workshop ... wanted to be a part of the virtual workshop ... I felt excited to be a part of these sessions ... we could all work together with the lecturer to solve ... problems ... given time to process and discuss our ideas ... we were heard ... I could also improve on information ... obtaining more information from ... websites ... share this information on the class Dropbox ...

As was evident, within this transformed education environment, the lecturer became a collaborator with the students. The participants believed that the use of FLA inspired collaborative learning. The virtual lecture room within this study was viewed as a collaborative and encouraging space within which to work. Collaboration is supported within the notions of connectivism, whereby student learning is enhanced by participation (Duke, Harper \& Johnson 2013).

\subsubsection{Support Provided within the Virtual Lecture Room}

The participants were also comforted by the awareness that their peers and lecturer were available to support and guide them while they were learning within the context of COVID-19. During the lockdown, people are not allowed to meet colleagues or friends due to physical and social distancing. The workshops created a space to meet colleagues and friends virtually to discuss mathematics learning as well as issues of a personal nature. This contact reassured the participants. These sentiments are reflected in the excerpts that follow:

Gloria: ... using the flipped learning ... not ... uncomfortable ... had a few problems ... could ask for help ... it consoled me ... was a bit depressed during ... lockdown ... coronavirus was disturbing ...we talk 
to each other about the maths concepts and also ... how we are dealing with home life ... I don't feel alone ... the workshops also supported me emotionally ... help with understanding concepts ... it's more interesting ... it is not only working on your ... work together ... we are also supported with the websites ... we can always download information to update knowledge ... I can do much more with the help I am receiving ...

Zodwa: ... it was very hard for me during this time ... my son was ill ... I could ask my friends for help during the workshops and even after the workshops ... spoke on WhatsApp ${ }^{3} \ldots$

Gloria and Zodwa believed that they could rely on the participants of the virtual workshop for support and reassurance, and they felt consoled and calmed by the support they were receiving during these unique times. Within the scope of connectivism, learning is considered to be developing, whereby new information is continuously embraced (Siemens 2005), this view is supported by Gloria's comments.

\subsubsection{Group Learning within the Virtual Lecture Room}

Within this study, the students suggested that collaborative learning using virtual workshops supported their mathematics learning since they could actively interact with one another and their lecturer and learn from these interactions. For some participants, collaborative learning supported by the FLA transformed their preference for individual learning to group learning. The interview excerpts that follow support these ideas.

Nozipho: ... to have my video off ... only audio on ... felt more at ease ... workshops ... did not feel judged or shy ... made learning maths easier for me ... could also ask the group ... clarification ... prefer this ... learning ...

\footnotetext{
${ }^{3}$ WhatsApp is a free to download messenger app for smart devices. WhatsApp uses the internet to send messages, images, audio or video files. This app allows users the freedom to text, share audio files, photos and videos with individuals or groups.
} 
Sizwe: ... workshops opened my eyes ... always work on ... own ... working in ... group was better ... group helped me learn ... lecturer ... available ... to assist on the spot ...

The participants valued the group learning and maintained that they preferred this type of learning. Group learning also promotes the learning experiences for students (Tran 2014). Moreover, through digital tools, students learn through participating in the process of contributing and receiving academic assistance, knowledge sharing and problem-solving (Webb \& Mastergeorge 2003). Similarly, according to connectivism, knowledge is adapted and constructed by students who interact collaboratively within activities related to that knowledge (Mallon 2013). Within this study, it was evident that by incorporating flipped mathematics learning to include virtual workshops, the students successfully collaborated and discussed solutions and content in groups while the lecturer facilitated.

\section{Conclusions}

This study aimed to explore mathematics students' perceptions of using the Flipped Learning Approach (FLA) within the context of the COVID-19 pandemic. If the philosophies of connectivism are embraced within 4IR virtual environments, the FLA may amplify the benefits of meaningful student learning. The nature of $21^{\text {st }}$-century collaboration has changed, and technology-enriched environments are influenced by the ideas of connectivism. Characteristics of connectivism endorse collaborative strategies that are generally effective in easing mathematics anxiety and accomplishing successful learning outcomes. This was evident in this study, since the lecturer within this study transformed traditional pedagogy to create a collaborative and engaging technology-enriched virtual lecture room. This transformation supported students' learning. Participants in this study encompassed the ideas of connectivism, acquired new skills (how to use Dropbox) and updated their knowledge using technology and online networks. The participants also interacted collaboratively within digital platforms to discuss, adapt and reconstruct their experiences.

This chapter concludes with some suggestions for lecturers who wish to embrace online pedagogy. Firstly, the challenges of flipped learning within the context of COVID-19 is essential for lecturers to acknowledge. To alleviate 
this issue, lecturers ought to test out free online resources first to better inform their students of the critical requirements regarding the amount of data, cost of data and time required to download information. This may inform the students accordingly concerning whether they will be able to access information from these resources. The lecturer also ought to ensure that the resources are userfriendly, cost-effective, data-efficient and easily accessible. Moreover, when preparing for online teaching, lecturers ought to acknowledge that students also have family obligations.

Secondly, the advantages of the collaboration inspired by flipped learning within the context of COVID-19 is essential. Lecturers ought to acknowledge that students are sociable individuals and require feedback and communication from peers and the lecturer. Apart from conversations about the content being discussed, during lockdown conditions within the COVID19 pandemic, students may not have other individuals who may relate to what they are experiencing within their homes. Students need to engage, collaborate and interact with other individuals during this unprecedented era for emotional, social and health benefits.

Finally, based on the findings of this study, it was evident that for the successful integration of the FLA within the virtual lecture room, there is a need for lecturers to be involved in professional development workshops focusing on how to enhance student learning while integrating the FLA within their virtual milieus. These professional development workshops would be of benefit to lecturers globally as we embrace the 4IR more so, within the context of the COVID-19 pandemic.

\section{Acknowledgements}

This study was partially funded by the National Research Foundation: NRF Grant Number: TTK170408226284, UID: 113952.

\section{References}

Bailey, L.W. 2019. New Technology for the Classroom: Mobile Devices, Artificial Intelligence, Tutoring Systems, and Robotics Educational Technology and the New World of Persistent Learning. USA: University of Phoenix. https://doi.org/10.4018/978-1-5225-6361-7.ch001

Bell, F. 2011. Connectivism: Its Place in Theory-informed Research and Inno- 
vation in Technology-enabled Learning. The International Review of Research in Open and Distributed Learning, 12, 3: 98 - 118.

https://doi.org/10.19173/irrodl.v12i3.902

Bruce, C.D. 2012. Technology in the Mathematics Classroom: Harnessing the Learning Potential of Interactive Whiteboards What Works? Research into Practice 38, 1: 1 - 4.

Butler-Adam, J. 2018. The Fourth Industrial Revolution and Education. South African Journal of Science 114, 5: 1.

https://doi.org/10.17159/sajs.2018/a0271

Cheung, A.C.K. \& R.E. Slavin 2011. The Effectiveness of Educational Technology Applications for Enhancing Mathematics Achievement in K12 Classrooms: A Meta-analysis. Best Evidence Encyclopedia 1, 1: 1 - 48. Craig, D.A. 2008. Changing Theories of Learning. Paper presented at the Applied Linguistics Association of Korea (ALAK) Conference, Seoul, South Korea. http://www.academia.edu/download/38833854/Changing Theories of Learning.doc

Creswell, J.W. 2014. Research Design: Qualitative, Quantitative and Mixed Methods Approaches. $4^{\text {th }}$ Edition. CA: Sage: Thousand Oaks.

Du Plessis, A. 2013. Editorial. Information and Communication Technologies and Educational Change. Educational Research for Social Change (ERSC) 2, 1: 1 - 6.

Duke, B., G. Harper \& M. Johnson 2013. Connectivism as a Digital Age Learning Theory. The International HETL Review Special Issue. Avaialbel at: https://www.hetl.org/wp-content/uploads/2013/09/HETL Review2013Special IssueArticle1.pdf (Accessed on 15 April 2020).

Elflein, J. 2020. Coronavirus Disease (COVID-19) Pandemic - Statistics and Facts. Availeble at: https://www.statista.com/topics/5994/thecoronavirus-disease-covid-19-outbreak/ (Accessed on 11 June 2020).

Foroughi, A. 2015. The Theory of Connectivism: Can it Explain and Guide Learning in the Digital Age? Journal of Higher Education and Practice 15,5: 11 - 26.

Gilbert, B. 2015. Online Learning Revealing the Benefits and Challenges. (M.S. Special Education), St. John Fisher College, Rochester, New York. Available at: https://fisherpub.sjfc.edu/education ETD masters/303/ (Accessed on 18 April 2020.)

Goldie, J.G.S. 2016. Connectivism: A Knowledge Learning Theory for the Digital Age. Medical Teacher 38, 10: 1064 - 1069. 
https://doi.org/10.3109/0142159X.2016.1173661 PMid:27128290

Grand-Clement, S., A. Devaux, J. Belanger \& C. Manville 2017. Digital Learning: Education and Skills in the Digital Age. Availabel at: Cambridge, UK.

https://www.rand.org/pubs/conf proceedings/CF369.html (Accessed on 12 April 2020).

Hamdan, N., P. McKnight, K. McKnight \& K.M. Arfstrom 2013. The Flipped Learning Model: A White Paper Based on the Literature Review Titled a Review of Flipped Learning. Flipped Learning Network 1,1: 1 - 16.

Available at:

https://flippedlearning.org/wp-

content/uploads/2016/07/WhitePaper_FlippedLearning.pdf

Helsper, E., \& R. Enyon 2009. Digital Natives: Where is the Evidence? British Educational Research Journal 36,3: 1 - 18. Available at:

http://eprints.lse.ac.uk/27739/;

https://doi.org/10.1080/01411920902989227

Hwang, G., C. Lai \& S. Wang 2015. Seamless Flipped Learning: A Mobile

Technology-enhanced Flipped Classroom with Effective Learning

Strategies. Journal of Computers in Education 2, 4: 449 - 473.

https://doi.org/10.1007/s40692-015-0043-0

Kerr, B. 2007. A Challenge to Connectivism. Paper presented at the Online Connectivism Conference, University of Manitoba, Canada.

http://ltc.umanitoba.ca/wiki/index.php?title=Kerr_Presentation

Klopfer, E., S. Osterweil, J. Groff \& J. Haas 2006. Using the Technology of Today, in the Classroom Today. The Instructional Power of Digital Games Social Networking Simulations and How Teachers can Leverage them. The Educational Arcade 4, 2: 1 - 23.

Lawson, T. 2011. Empowerment in Education: Liberation, Governance or a Distraction? A Review. Power and Education 3, 2: 89 - 103. https://doi.org/10.2304/power.2011.3.2.89

Mallon, M.N. 2013. Extending the Learning Process: Using the Theory of Connectivism to Inspire Student Collaboration. Kansas Library Association College and University Libraries Section Proceedings 3, 1: 18 - 27. https://doi.org/10.4148/culs.v1i0.1833

Mkhize, Z. 2020. COVID-19/Novel Coronavirus. South African Government. https://www.gov.za/speeches/minister-zweli-mkhize-confirms-total-43434-cases-coronavirus-covid-19-5-jun-2020-0000 
(Accessed on 6 June 2020).

Montrieux, H., R. Vanderlinde, T. Schellens \& L. de Marez 2015. Teaching and Learning with Mobile Technology: A Qualitative Explorative Study about the Introduction of Tablet Devices in Secondary Education. PLOS ONE 10,12: 1 - 11. https://doi.org/10.1371/journal.pone.0144008

PMid:26641454 PMCid:PMC4671718

Morrison, D. 2014. Are you Ready to Learn Online? Five Need-to-have Skills for Online Students. Online Learning Insights 1, 1: 1 - 6. Available at: https://onlinelearninginsights.wordpress.com/2014/08/31/are-you-readyto-learn-online-five-need-to-have-skills-for-online-students/ Accessed on 12 April 2020.)

Murgatrotd, S. 2020. COVID-19 and Online Learning. Available at: https://www.researchgate.net/publication/339784057_COVID-

19_and_Online_Learning (Accessed on 12 April 2020.)

Peachey, N. 2017. Digital Tools for Teachers. Kent, UK: PeacheyPublications. Com.

Pope, S. \& P. Mayorga 2019. Enriching Mathematics in the Primary Curriculum. (Exploring the Primary Curriculum.) London: Sage.

Pyper, J.S. 2017. Learning about Ourselves: A Review of the Mathematics

Teacher in the Digital Era. Canadian Journal of Science, Mathematics and Technology Education 17, 3: 234 - 242.

https://doi.org/10.1080/14926156.2017.1297509

Rajkumar, R. \& G. Hema 2017. The Flipped Classroom: An Approach to Teaching and Learning Mathematics Education. Paper presented at the International Conference on Teacher Education in Digital Era, IQAC, Kongunadu College of Education.

Ramakrishnan, N. \& J.J. Priya 2016. Effectiveness of Flipped Classroom in Mathematics Teaching. International Journal of Research Granthaalayah 4, 10: 57 - 62.

https://doi.org/10.29121/granthaalayah.v4.i10(SE).2016.2469

Rambe, P. \& A. Bere 2013. Using Mobile Instant Messaging to Leverage

Learner Participation and Transform Pedagogy at a South African University of Technology. British Journal of Educational Technology 44, 4: 544 - 561.

https://doi.org/10.1111/bjet.12057

Roper, A.R. 2007. How Students Develop Online Learning Skills. EDUCAUSE Quarterly 1, 1: 62 - 56. 
Sahu, P. 2020. Closure of Universities due to Coronavirus Disease 2019 (COVID-19): Impact on Education and Mental Health of Students and Academic Staff. Cureus 12,4: 1-8. Available at:

https://www.cureus.com/articles/30110-closure-of-universities-due-tocoronavirus-disease-2019-covid-19-impact-on-education-and-mentalhealth-of-students-and-academic-staff\#article-information-publicationhistory; https://doi.org/10.7759/cureus.7541 (Accessed on 11 April 2020).

Schwab, K. 2016. The Fourth Industrial Revolution. Geneva, Switzerland.: World Economic Forum.

Siemens, G. 2005. Connectivism: A Learning Theory for the Digital Age. International Journal of Technology ad Distance Learning 1, 1: 1 - 9. http://www.itdl.org/Journal/Jan_05/article01.html

Siemens, G. 2006. Connectivism: Learning Theory or Pastime of the Selfamused? Available at:

http://www.elearnspace.org/Articles/connectivism self-amused.htm (Accessed on 5 June 2020).

Tran, V.D. 2014. The Effects of Cooperative Learning on the Academic Achievement and Knowledge Retention. International Journal of Higher Education 3, 2: 131 - 140. https://doi.org/10.5430/ijhe.v3n2p131

Verhagen, P. 2006. Connectivism: A New Learning Theory? Available at: https://www.scribd.com/doc/88324962/Connectivism-a-New-LearningTheory (Accessed 6 June 2020.)

Webb, N.M. \& A. Mastergeorge 2003. Promoting Effective Helping Behavior in Peer-directed Groups. International Journal of Educational Research 39, 2: 73 - 97. https://doi.org/10.1016/S0883-0355(03)00074-0

Jayaluxmi Naidoo Associate Professor of Mathematics Education Mathematics and Computer Science Education Cluster University of KwaZulu-Natal Durban naidooj2@ukzn.ac.za 


\title{
COVID-19: Raising the Bar on Education Technology to 'Flatten the Curve'
}

\author{
Vasanthrie Naidoo \\ ORCID iD: https://orcid.org/0000-0003-2740-5983
}

Maureen Nokuthula Sibiya

ORCID iD: https://orcid.org/0000-0003-1220-1478

\begin{abstract}
The World Health Organization has announced that the current outbreak of the Coronavirus disease (COVID-19) health crises has constituted a public health emergency of international concern. This has necessitated international lockdowns of countries as part of strict infection control protocol. The COVID19 pandemic has also become a major challenge for most learning institutions around the world, making this disease a pervasive force shaping and challenging higher education as it faces the new realities of distance education. The pandemic crises have affected the continuity of learning and the delivery of course material at higher education institutions. To remain relevant, tertiary education institutions have had to re-invent their learning environments in order to embrace distance education whilst still trying to maintain effective student-lecturer relationships. Various dimensions of quality assurance challenges often surround the facilitation and delivery of distance education or multimedia platforms of teaching and learning, prompting the need for rigid quality control principles to guide programme or course delivery. Notably, there is still a need to identify functional deficits and challenges of distance education programmes from a learning and teaching perspective. Sharing insight, based on our experience and research with distance education, this paper introduces essential knowledge and discusses key issues related to quality assurance practices with distance learning. Stimulating discussion and establishing a connectivity between quality assurance practices and online teaching and learning programmes, this article also offers valuable insight into
\end{abstract}


forthcoming as well as existing curriculum developers who plan to engage in distance education curriculum development and delivery.

Keywords: COVID19, Higher education, Distance education, Quality Assurance

\section{Introduction and Background}

The COVID-19 pandemic has overwhelmed the entire world, and not only has it demonstrated the fragility of the human race at the hand of Mother Nature; this horrific chapter of the world has reshaped the landscapes of the health systems and educational systems across nations. In this crises mode, there is no Plan B. There is only a Plan A, which stipulates that the only mode of survival is to remain confined in the safety of one's home and adhere to the national call for social distancing to 'flatten the curve'. Thus the increased use of educational technology and learning management systems to incorporate curricula changes for the better. Certainly, the corona virus has tested lecturer/student interaction and nowadays, lecturers and students simply interact via Skype, Zoom, TEAMS and WhatsApp online systems to facilitate and participate actively in distance education (DE) or flexible and distributed learning. According to Keok (2005), the phrase 'flexible and distributed learning' is used to include both distance learning and e-learning. In both cases, the awarding institution delivers courses through independent- learning materials or via distance technology such as online material, directly to the student without the need for a partnering institution. However, while DE may be seen as the only possibility to salvage the academic year, there are many questions that need answers. Existing literature on curriculum development in DE focuses on the value of this type of educational offering but show a paucity of evidence, particularly regarding the quality assurance practices surrounding DE in higher education sectors. Notably, there is potential for developing a more robust quality assurance discourse on distance educational initiatives, especially in view of the current turbulence surrounding the global academic sector as a result of the corona virus outbreak.

This article aims to identify inherent challenges associated with distance education, and illustrates pertinent questions that are raised in pedagogical practice, when experiences of academic leaders and students are 
explored. From a quality assurance perspective, we argue that DE nursing education programmes are still challenged owing to deficient governance structures. A literature search has revealed many publications relevant to international higher education collaboration, but distance nursing education in higher education remains an under-researched area.

The following questions are therefore suggested to stimulate discussion and establish connectivity between quality assurance practices and the successful implementation of any distance learning and teaching programme.

- What is the need for quality assurance mechanisms in distance education?

- How can a culture of quality within partnering institutions be promoted and what would be the elements of such a culture?

- What resources and training are needed?

- What role can the adoption of best practices play?

Whilst the authors of this paper do not represent any quality assurance bodies of any on-line teaching initiative, the service delivery and quality assurance deficiencies inherent in this type of education cannot be ignored. Reflections in this paper on the various dimensions of quality assurance challenges surrounding the distance education programmes should consequently be viewed as levers to improving service quality of its present and future teaching and learning programmes.

\section{Higher Education and Distance Education}

The current challenges in higher education delivery has given DE a new appeal, tapping into unexplored instructional areas. While learning institutions deal with limitations as they are encountered in this context of technological change, it is not surprising that higher education institutions have had no choice but to seize the educational technology market with the expectation of expanding their reach to students to salvage the academic year. The changing context of curricula delivery requires that learning institutions carefully consider revising original curriculum plans without comprising the outcomes of programmes, as the transition from face-to-face to online mode of learning and teaching is made (Chaubey \& Bhattacharya 2015). Educational 
technology and learning management systems are an important consideration in the design for the online higher education environment (Adzharuddin \& Ling 2013). Institutions are expected to make decisions about the planned curriculum and how they deliver this within the confines of international and national regulations. This involves making decisions about what knowledge is selected and how it will be sequenced and paced for the online modes. It also involves choices about pedagogies and assessments and their alignment to the intended learning outcomes.

Higher education constitutes a vital component of a country's culture and knowledge, serving as a conduit for the sustainability of national values and educational goals. It also plays an important role in a country's economy the generating new knowledge through research and innovation (Manyonga \& Ngubane-Mokiwa 2019). It is important to understand what is meant by distance learning or distance education, as technology is evolving and the definition of what distance learning is continues to change. According to King et al. (2014), the terms 'distance education' and 'distance learning' are often used interchangeably and are understood to occur when the teacher and learner are physically separated. With this type of education, there is acquisition of knowledge and skills through mediated information and instruction, which encompasses all technologies and other forms of teaching and learning, but at a distance. This distance between lecturer can be across provinces, states and even countries. Whilst distance education has some clear benefits, it can be grouped into two major categories, each having its own constraints (Mdakane, Els \& Blignaut 2016). The two categories are synchronous and asynchronous distance education. Synchronous situations provide benefits that allow some 'real-time' interaction with student and lecturer or instructor such as intermittent face to face interaction between both parties. Synchronous situations are more time sensitive but are known to be geographically insensitive. Examples of such situations would be teleconferencing, video conferencing and online-webinars (King et al. 2014).

\section{Quality Assurance in Distance Education Programmes}

Quality assurance is undoubtedly a significant 'player' in any form of higher education and countries around the world have different quality assurance systems for their education delivery, as necessitated by their unique national contexts. A recent study that focused on quality assurance practices of higher 
education teaching and learning found that some types of higher education programmes are no longer provided solely within national borders (Naidoo \& Sibiya 2018). The authors of the same study also agree that implementing and delivering a curriculum outside its country of origin is a globalisation strategy that is gaining increasing popularity among higher education institutions. Whilst being very rewarding for many global education institutions, this type of educational offering can increase the institution's profile, and provide openings for intercontinental business opportunities, consultative activities, and collaborative research. However, it can also be a costly exercise, with little reward for the lecturer and student, if not governed by proper quality assurance mechanisms. Notably, the calibre of staff participating in the programme, as well as teaching methods and assessment strategies, are all vital components to the successful implementation of ant distance learning programme.

The key findings from a study by Fearnside and Chang (2017) agree that globalised endeavours of distance education often involved the mobility of students, academics, institutions, programmes and quality assurance services. As a result, it is vital for educational institutions to have a clear rationale for their engagement in distance education ventures, ensuring that they are 'fit-for-purpose' in terms of the curriculum context and the expectations of the student, giving a clear understanding of the relevant legal frameworks that govern the roles of the respective stakeholders (Kemp et al. 2018). A study that explored the use of on-line teaching and learning at learning institutions have found that when learning management systems are introduced into more advanced communities, users should not experience issues such as low technical literacy, high workload, multiple languages and organisational constraints like poor technical support, infrastructure and internet access. The study further states that for on-line teaching and learning, in the case of distance education, to be truly inclusive and be a success in developing economies, contextual issues like resources need to be considered (Chaubey \& Bhattacharya 2015). Manyonga and Ngubane-Mokiwa (2019) agree that radical changes in any higher education teaching and learning, will need universities to provide the right kind of people to manage technical operations such as learning management systems (Manyonga \& NgubaneMokiwa 2019). This is strongly evidenced in the current plight of the global higher education sector in view of the COVID-19 implications on teaching and learning, which has led to anxiety and uncertainty about the interaction between these technological developments, distance education and the impact 
of digital transformation in the academic arena. According to Vlachopoulos (2020), the reliance on online and distance education as a solution to ensure continuity of learning in the face of the COVID-19 pandemic crisis, may well prove to be overly optimistic. The same study noted that ineffective quality control such as fragmented regulatory frameworks or accreditation guidelines and policies can make the delivery of distance education challenging.

Pedagogy has been influenced by the empowering aspects of an increased understanding of the social world, often allowing students to challenge and change them (Collins 2013). Thus, students involved in distance learning programmes often categorize quality indicators from the following two viewpoints. Whilst the quality of academic staff, quality of programmes, and university reputation are considered academic factors; financial assistance, counselling, support services, job placement service are considered nonacademic quality indicators (Gamage et al. 2008).

While much research attention is currently paid to quality assurance policies in developed countries such as in Europe, USA, Canada and Australia, there still exists a gap in knowledge related to other countries that may have more experience with the implementation of quality assurance, but an underdeveloped policy implementation system (Hashjin et al. 2015). Mendes and De Jesus Jose Gil Fradique (2014) agree that service quality is viewed as a critical aspect in organizational management and developing, and implementing assessment and monitoring strategies for quality control are key priorities in most organizations. Dhunpath, Amin and Khumalo (2017) state that autonomy-supported learning environments that bring together the emotional and cognitive aspects of learning can engender change and move the learning institution's system of education beyond the traditional disciplines, while Mendes and De Jesus Jose Gil Fradique (2014) argue that such distance education demands to staff to function in an environment that allows for planning and implementation of measures aimed at improving quality. Nguyen (2012) and Bednarz et al. (2010) have found that successful delivery of this type of education entails a collective effort of all its stakeholders. It has been argued that parallel to the opportunities distance or online education teaching and learning provide, there are challenges and potential pitfalls that can threaten its delivery, such as students in under resourced countries not enjoying the same benefits as their counterparts in developed countries (McBurnie \& Ziguras 2007). Kemp et al. (2018) agree and state that good practice in higher education relies on strong leadership and commitment from all parties, to 
ensure access to organizations, individuals and project sites A study focusing on best operating practices in higher education has revealed that although attempts are made to align DE to international standards, such as taking into consideration the country's cultural diversity, the absence of a quality control body still existed (Chiwandire 2019). The importance of this quality control body in distance education was summarised aptly, when Knight (2008) states that distance learning and teaching act as a catalyst to prepare students to live in a more interdependent and connected world and the necessity for governance and standardisation was crucial for students living in a globalised world. Parker and McMillan (2007) state that successful quality assurance processes can be achieved by controlling inputs such as students and educational resources as well as providing a quality educational programme. Lum (2006) agrees and further states that cultural differences and diverse learning styles of students should be considered as opportunities to design curricula that are locally relevant and culturally inclusive.

\section{Research Findings from Distance Education Nursing Programme Facilitation and Delivery Research Methodology}

An interpretive research paradigm was used together with a qualitative multiple case-study approach to identify functional deficits and challenges of DE nursing programmes nationally and internationally, to determine national and international best operating practices in the implementation and facilitation thereof. The use of a case study approach in this study allowed the researcher to gain an in-depth understanding of the situation and meaning for those involved in the programme, whilst addressing the uniqueness of individual cases and contexts. Given the international focus of this study, the researchers felt it was important to sample national and international participants, such as programme coordinators, facilitators and students. The population comprised national and international nursing education institutions, nursing graduates and academic leaders such as the directors of international nursing education projects, nursing faculty and departmental heads and lecturers. This assisted in drawing a comparison between national and international DE practices. During the interviews, participants articulated their responses by giving an in-depth and experiential understanding of the multiple realities surrounding their 
participation in the programme. Tables 1 and 2 below illustrate the type of questions that were posed to the different participants to facilitate discussions during the data collection processes. Table 3 outlines documents had been found to be useful to collection of information in this study.

\section{Table 1}

The following questions and topics guided the interviews with Academic Leaders:

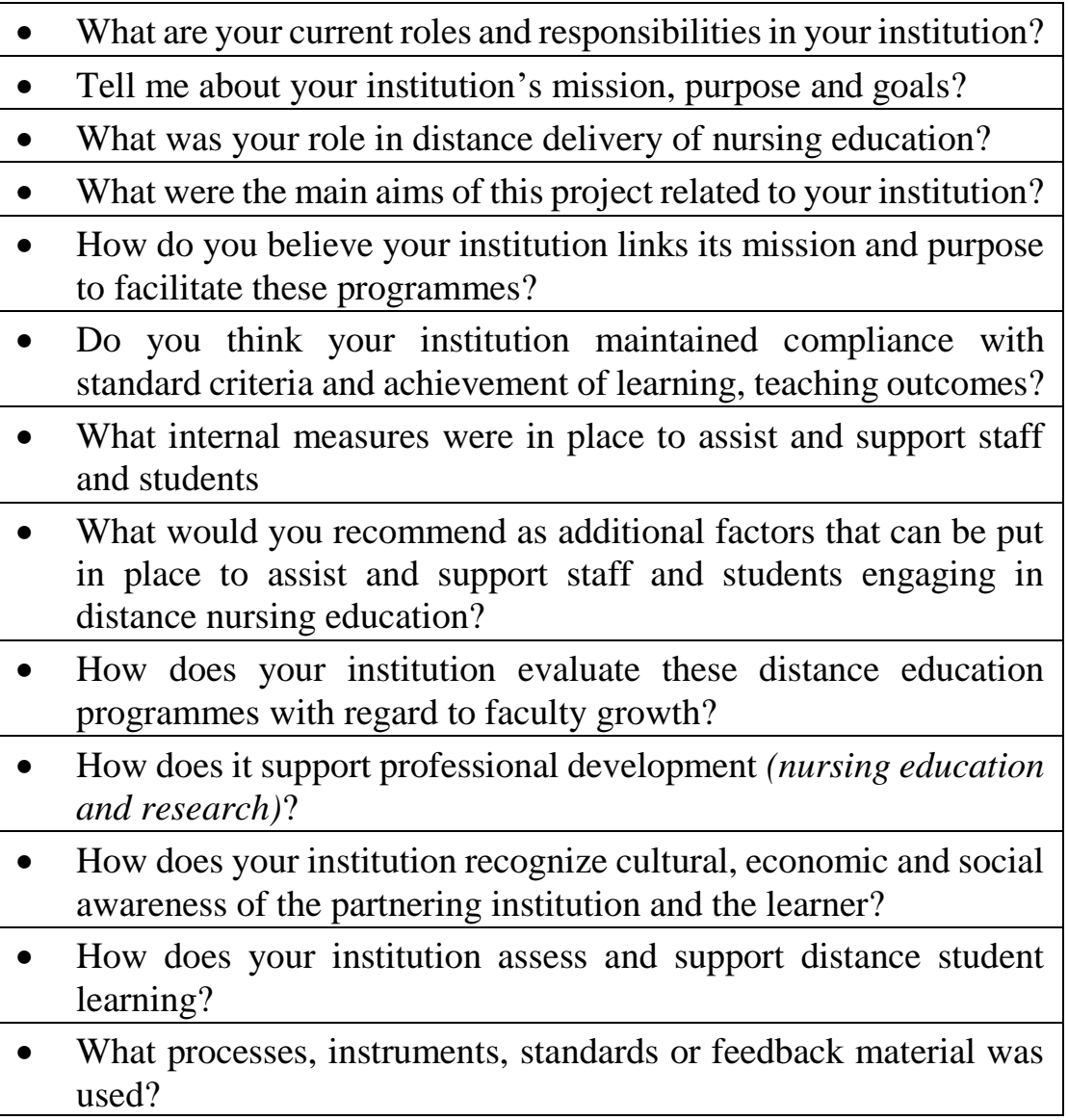


- What constraints did you encounter in this type of teaching/learning/administration?

- Describe any logistical, geographical, historical, political, economic, cultural, social, personal challenges that your institution may have encountered?

- Can you suggest further best operating practices with regard to distance education?

\section{Table 2}

The following questions and topics guided the interview with graduates of a distance nursing education program:

- What are your current roles and responsibilities in your profession?

- When were you involved with distance nursing education?

- Were you made aware of the main aims of this project?

- What were your thoughts on the recruitment and selection processes?

- Do you consider these distance education programmes to be adequately evaluated and how does it support your professional development?

- What challenges did you encounter during this type of teaching/learning or administration? (Logistical, geographical, historical, political, economic, cultural, social, personal)

- What would you recommend as additional factors or best operating practices that can be put in place to assist and support staff and students engaging in distance nursing education?

\section{Table 3: Record Review Guide}

Due to the case-study approach of the research, documents were an important part of this study. They assisted the researcher to understand policies and processes which are not observed and also supplement and verify information obtained from interviews. Only non-confidential documents were reviewed. 
The following documents were found to be useful to collection of information in this study:

- Documents that describe the mission, purpose, or goals of the
institution involved in distance education.
- $\begin{aligned} & \text { Documents that describe how the institution manages quality } \\ & \text { assurance as a whole with regards to distance nurse education. }\end{aligned}$
- $\begin{aligned} & \text { Documents that describe how the institution develops and reviews } \\ & \text { courses and programmes. }\end{aligned}$
- Documents that describe how the institution evaluates and
supports professional development of staff involved in distance
education.
- Other electronic or hard copies of the above documents for
collection by the researcher at the time of the institution visit.

As part of a case study approach to the research study, other sites of information and relevant documentation such as provider manuals, guidelines, policies or procedure manuals were used to for data collection and analysis purposes. Documentation in this study was analysed for descriptions and patterns related to three primary areas:

- Conceptual issues such as definitions of quality, purposes of having policies or guidelines regarding implementation of $\mathrm{DE}$

- Descriptions of structures and processes used to monitor, assess, or improve delivery of DE in reference to curriculum and programmes, student learning, teaching practices and decision-making processes.

- Contextual issues such as internal and external factors that impact or influence delivery of DE.

\section{Results}

All reviewed institutional records such as orientation records and brochures paint an optimistic and colourful picture, but no internal or external factor that pose a possible challenge to the student or programme delivery was mentioned. There also appeared to be variations in the information gathered from records, allowing for gaps and inconsistencies like unclear guidelines and rules 
governing the programmes. As views of academics and graduates were explored and best operating practices were compared and analysed, other functional processes and system deficits became apparent as follows.

\subsection{Recruitment and Selection}

Information received from participants on DE reflects that learning institutions often collaborate for mutual gains. There appeared to be no centralized selection, recruitment or registration processes and institutional policies dictating selection criteria ensured that most of these policies were tailor-made or suited to the needs of the learning institution offering the programme. This study concluded that effective and appropriate quality assurance policies and adoption of international best operating practices are vital during any recruitment and selection process and participants in this study strongly felt that the responsibility for the quality assurance of DE should rest with national authorities such as the accreditation bodies that govern higher education and training in the respective countries. Academic personnel such as coordinators and facilitators verbalized that it was imperative for them to have a sound understanding of institutional policies and procedures. Findings further revealed that the selection and recruitment of programme facilitators were not methodologically sound, as reference checks on teaching skills, experience, expertise and qualifications were surpassed. According to the findings of this study, organizational policies and standards are necessary to govern the recruitment and selection processes in DE, as they have an influence in shaping governments' regulatory frameworks related to the delivery of higher education. Some of the participants emphasized the importance of having quality assurance programmes and procedures such as proper orientation for students, coordinators and facilitators, workshops, seminars for students and teachers and e-learning mentorship programmes and webinars. They felt it would help clarify expectations, policies and prevent further challenges. It was also verbalized that coordinators and facilitators of the DE programmes need to understand the dynamics of on-line learning and teaching. This needed to be shrouded in cooperative teamwork and the utilization of a technologically sound integrated delivery system. Responses suggested that having competent, well-motivated and enabling workforce encouraged student cooperation, provided support and enhanced delivery of online teaching and learning especially in the absence of face-face interaction. 


\subsection{Monitoring and Regulatory Activities}

It was evident from documentation reviews that although programmes were developed within the educational framework of the country, they appeared to utilize methodologies based on international models. This appeared to be a direct conflict in the programme facilitation as it did not reflect the needs of the institution, the students and the regulatory and commercial environment or country from which the programme operated. The study also revealed that although educational institutions attempted to maintain high academic standards there was still a need to revise and adapt content, teaching practices and assessment strategies, as distance learning students did not always enjoy the privileges of first-world countries that have modern equipment and facilities like simulation laboratories and fully fledged library resources. Graduates felt that different educational systems created problems with accreditation and recognition causing increased frustration and delays in awarding of a qualification. These findings led the researcher to believe that there are significant implications in terms of consumer protection regarding $\mathrm{DE}$, as these programmes are poorly monitored and governed.

\subsection{Best Operating Practices}

It was also noted that within the DE environment, there were strengths, limitations and conflicting practices across educational institutions. The implementtation and utilization of current and emerging technologies and learning management systems was a best operating practice, which was particularly beneficial to students engaged in research outputs. While the e-learning platforms encouraged and facilitated distance learning and online communication between student and lecturer, it also allowed for the viewing or listening to recorded teaching sessions. This assisted with clarity and emphasized student selection into the type of educational programme students want to gain more insight into. It was also reported that DE policies are influenced by cultural awareness; therefore, DE programmes need to be structured in such a manner that they take into consideration cultural differences, ensuring congruency with the cultural orientation of the students and lecturers alike. However, the implementation and utilization of current and emerging educational technologies are another best operating practice that was noted which are particularly beneficial to students engaged in research outputs. 
These e-learning platforms encouraged and facilitated distance learning and online communication between student and lecturer.

\section{Discussion}

Quality assurance monitoring and control measures cannot be fragmented, disorganized, uncoordinated and ineffective in higher education spaces. According to Mdakane, Els and Blignaut (2016), a core function of HEIs is to promote quality in higher education, which is also reflected in the institution's teaching and learning policy, which aims to ensure the delivery of continuous high quality education for its students through cost effective academic programmes. The same study concludes that effective and appropriate quality assurance policies and adoption of international best operating practices are vital during recruitment and selection processes and that the responsibility for the quality assurance of distance learning should rest with national authorities and accreditation bodies that govern education and training. Academic personnel such as coordinators and facilitators should have a sound understanding of institutional policies and procedures, relevant teaching skills, experience, expertise and qualifications that encourage capacity building.

Although tertiary education programmes are developed within the educational framework of the country, they appear to utilize methodologies or base their programmes on international models. At times, Educational programmes are offered simultaneously in two different provinces, but educational systems are bound by bureaucracy and politically influenced programmes are known to be poorly monitored and governed (Adzharuddin \& Ling 2013). Additionally, there should be increased emphasis on the importance of having quality assurance programmes and procedures such as proper orientation for students, coordinators and facilitators, workshops, seminars for students and teachers and e-learning mentorship programmes prior to the commencement of such programmes (Dhunpath \& Narismulu 2011). These initiatives need to be properly negotiated and communicated to all relevant parties as they help to clarify expectations, policies and procedures of partnering institutions and prevent further challenges. The implementation and utilization of current and emerging technologies are another best operating practice that is particularly beneficial to students engaged in research outputs. Thus, e-learning platforms utilised in distance learning should also be user friendly, making pedagogy more relevant, research driven and responsive to 
the needs of postgraduate students in their own learning spaces. It is vital that an educational institution ensures rigid quality control measures and all programmes offered should be in line with the institution's vision, mission, while philosophies and should be governed by the same principles as all the other satellite learning centres. Such principles can mean having suitably qualified lecturers or teachers to coordinate and facilitate particular programmes, modes of delivery and contact time with its students. This appears to be a direct conflict in the programme facilitation, as it does not reflect the needs of the institution, the students and the regulatory, and commercial environment or country from which the programme operated. This was a cause for concern, especially if coordinators and facilitators of distance learning and teaching failed to maintain high academic standards, revise and adapt content, teaching practices and assessment strategies, as not all students enjoyed the privileges of first-world country resources and had modern equipment and facilities like simulation laboratories and fully-fledged library resources.

\section{This Study's Contribution to the Body of Knowledge}

Distance learning and teaching appears to be the way forward in this century. The findings and lessons learnt in this study signify the increased personal growth, cultural diversity awareness, adaptation to an unfamiliar environment, and increased self-efficacy of DE students. These findings are also relevant to all graduates engaged in other national and international partnerships related to non-nursing DE programmes and expands stakeholder knowledge, ensuring quality in DE. Further areas for research based on the findings are to explore other educational disciplines' experiences with DE facilitation. This could be done to ascertain further challenges from a different perspective. The findings of this study also suggest more research be done to determine whether learning institutions implement the best operating practices such as quality assurance programmes to govern DE programmes that serve the best interests of the student and institution.

\section{Conclusion and Recommendations}

This paper concludes that effective quality assurance governance structures can increase the credibility of the course offering whilst enhancing an institution's prestige and growing a country's educational economy. The global 
education market is changing rapidly and has its own concerns and challenges. New alliances both international and national are formed; and private and corporate sectors are increasingly active as DE providers. Whether distance education programmes are a way to develop a niche market for the country's economy, a more stringent control and approach towards quality assurance practices needs to fall within the ambit of good governance. There is a need for governmental and non-governmental bodies to develop quality assurance principles that will allow for the provision of ongoing quality improvement plans in the educational sector. Where national or institutional quality assurance bodies exist, they are an effective means of such control, and where they do not exist, they should be created. Quality assurance practices of distance education provision need urgent attention, especially in time of crises where traditional face-to-face learning and teaching have been replaced by online or distance education facilitation. So, when all is said and done, it is no consolation that currently the entire world's educational economy is a bleak picture and educationalists and academic experts are faced with one big burning question, 'How do we take a very digitalised student population into the future with distance learning and teaching?'

As governments around the world respond to the ravaging effects of the corona virus outbreak on the educational system, the world needs to come to terms with the reality of having on-line education as a support mechanism to decrease the viral load that this pandemic has placed on a country's educational sector. As much as we embrace the technological advancements of distance education, one constantly needs to question the quality assurance principles that guide the pursuit of excellence in distance teaching and learning.

\section{Acknowledgements}

Part of this paper is drawn from Vasanthrie Naidoo's PhD thesis, which was supported by the Faculty of Health Sciences, Durban University of Technology. The authors also acknowledge the editor and the anonymous reviewers for their constructive input in the crafting of this paper.

\section{References}

Adzharuddin, N.A. \& L.H. Ling 2013. Learning Management Systems (LMS) among University Students: Does it Work? International Journal of eEducation, e-Business, e-Management and e-Learning 3: 248-252. 
https://doi.org/10.7763/IJEEEE.2013.V3.233

Bednarz, H., S. Schim \& A. Doorenbos 2010. Cultural Diversity in Nursing Education: Perils, Pitfalls, and Pearls, Journal of Nursing Education 49, 5: 253 - 260. https://doi.org/10.3928/01484834-20100115-02

PMid:20143759 PMCid:PMC2921036

Chaubey, A. \& B. Bhattacharya 2015. Learning Management System in Higher Education. International Journal of Science Technology \& Engineering 2: 158 - 162.

Chiwandire. D. 2019. Universal Design for Learning and Disability Inclusion in South African Higher Education Curriculum. Alternation Special Edition 27: 6-6.

https://doi.org/10.29086/2519-5476/2019/sp27a1

Collins, A. 2013. Teaching Sensitive Topics: Transformative Pedagogy in a Violent Society. Alternation Special Edition 9: 128 - 149.

Dhunpath, R. \& P. Narismulu 2011. Diversity, Transformation and Student Experience in Higher Education Teaching and Learning. Alternation 18, 2:1 - 14 .

Dhunpath, R., N. Amin \& L. Khumalo 2017. Advancing Teaching Innovation and Research Excellence in Higher Education. Alternation 24, 2: 1 - 11.

Fearnside, R. \& K. Chung 2017. Cross-border Quality Assurance: Aase Study of Hong Kong and Macao. Higher Education Evaluation and Development 11, 2: 81 - 94. Available at:

https://doi.org/10.1108/HEED-07-2017-0002

(Accessed on 24 April 2020.)

Gamage, D.T., J. Suwanabroma, T.T. Ueyama, S. Hada \& E. Sekikawa 2008.

The Impact of Quality Assurance Measures on Student Services at the Japanese and Thai Private Universities. Quality Assurance in Education 16, 2: 181 - 98. Available:

https://doi.org/10.1108/096848808 10868457

(Accessed on 24 April 2020.)

Hashjin, A.A., B. Delgoshaei, D.S. Kringos, S.J. Tabibi, J. Manouchehri \& N.S. Klazinga 2015. Implementing Hospital Quality Assurance Policies in Iran: Balancing Licensing, Annual Evaluation, Inspections and Quality Management Systems. International Journal of Health Care Quality Assurance 28, 4: 343 - 355. Available:

https://doi.org/10.1108/IJHCQA-03-2014-0034

PMid:25982635 (Accessed on 25 April 2020.) 
Kemp, J., E.M. Bannon, M.M. Mwanja \& D. Tebuseeke 2018. Developing a National Standard for Midwifery Mentorship in Uganda. International Journal of Health Governance 23, 1: 81 - 94. Available at:

https://doi.org/10.1108/IJHG-09-2017-0051

(Accessed on 20 April 2020.)

Keok, C.B 2005. An Outcomes-based Framework for Assessing the Quality of Transnational Engineering Education at a Private College. Doctor of Education, University of Southern Queensland.

Knight, J 2008. Higher Education in Turmoil: The Changing World of Internationalization. Ontario, Canada: Ontario Institute for Studies in Education, University of Toronto.

https://doi.org/10.1163/9789087905224

Lum, L 2006. Internationally-educated Health Professionals: A Distance Education Multiple Cultures Model. Education + Training 48, 2/3: 112 126. https://doi.org/10.1108/00400910610651755

Manyonga, B. \& S. Ngubane-Mokiwa 2019. Curriculum Development: An Enriched Approach for Twenty-First Century Open Distance Learning. Alternation 27: 37-64.

https://doi.org/10.29086/2519-5476/2019/sp27a2

McBurnie, G. \& C. Ziguras 2007. Transnational Education: Issues and Trends in Offshore Higher Education. London: Routledge, Taylor and Francis Group. https://doi.org/10.4324/9780203968352

Mendes, L. \& M.J.G. de Jesus Jose Gil Fradique 2014. Influence of Leadership on Quality Nursing Care. International Journal of Health Care Quality Assurance 27, 5: 439 - 450. Available at: https://doi.org/10.1108/ IJHCQA-06-2013-0069 (Accessed on 20 February 2018.)

Naidoo, V. \& M.N. Sibiya 2018. Promoting the Well-being of Higher Education: Re-engineering of Transnational Nursing Education. South African Journal of Higher Education 32, 6: 351 - 369.

https://doi.org/10.20853/32-6-2961

Nguyen, T. 2012. Internal Quality Assurance in Vietnam's Higher Education: The Influence by International Projects, Evaluation and Assessment. Master of Science in Education Science and Technology. University of Twente, Amsterdam.

Parker, V. \& M. McMillan 2007. Challenges Facing Internationalization of Nursing Practice, Nurse Education and Nursing Workforce in Australia. Contemporary Nurse, Nurse Recruitment and Retention 2, 24: 128 - 136. 
https://doi.org/10.5172/conu.2007.24.2.128

PMid:17563321

Vlachopoulos, D. 2020. COVID-19: Threat or Opportunity for Online Education? Higher Learning Research Communication 10, 1:16 - 19.

Available at :https://doi.org/10.18870/hlrc.v10i1.1179 (Accessed on 22 December 2020.)

\author{
Vasanthrie Naidoo \\ Senior Lecturer \\ Department of Nursing \\ Durban University of Technology \\ Durban, KwaZulu-Natal \\ vasanthrien@dut.ac.za \\ Maureen Nokuthula Sibiya \\ Deputy Vice Chancellor \\ Executive Management \\ Durban University of Technology \\ Durban, KwaZulu-Natal \\ nokuthulas@dut.ac.za
}




\title{
Covid-19: A Liability or Serendipity for Teacher Education? Exploring Lockdown as an Opportunity for 'Innovative Disruption' in TEPs.
}

\author{
Aruna Ankiah-Gangadeen \\ ORCID iD: https://orcid.org/0000-0002-4106-3951
}

\section{Yesha Mahadeo-Doorgakant Seema Goburdhun}

\begin{abstract}
The sudden onslaught of the Covid-19 pandemic around the globe has forced the shut-down from the outside world, compelling everyone to review existing practices at all levels. The norms derived from life - personal and professional - as it used to be lived, are no longer relevant during the pandemic and new practices are being adopted to cope within confinement measures. This paper studies the impact of confinement on Teacher Education Programmes (TEPs) within a Mauritian Tertiary Education Institution (TEI) where, for years, management invested massively in technological resources and attempted to bring about a paradigm shift in teaching, but with little success. It was, however, noted that, following the lockdown, teaching shifted from prevailing and predominant face-to-face sessions to online modalities within a span of days. With teacher educators having been propelled out of their comfort zones and being currently engaged with new modes for course delivery, the authors sought to understand how the lockdown has unleashed new potential and possibilities with regard to TEPs, at the level of curriculum content and transaction. Rather than adopting a deficit view of the situation, knowing fully well that the abrupt shift to online teaching inevitably carries its dose of liabilities and problems, the authors deliberately focused on positive expe-
\end{abstract}


riences and fresh perspectives that may serve to revamp TEPs as far as scope and currency are concerned.

The case study on which this paper is based, was anchored in Appreciative Inquiry and adopted a grounded approach to data generation and analysis. To allow for the production of rich textured data emanating from varied perspectives, participants constituted teacher educators with different areas of specialisation. The findings revealed that the forceful shift to online learning brought about an awareness of opportunities afforded by online teaching and learning modes as well as more willingness to continue along these lines in the future. It also provided insights into the shortcomings of the TEPs with regards to skills and attitudes to be developed.

Keywords: Teacher Education curriculum, disruption, online teaching and learning, Appreciative Inquiry

\section{Introduction}

The paradox of closure and simultaneous opening up has perhaps never been more evident than what academics are living during the Covid-19 pandemic. As shutters rolled down all over the world and crisis hit the Mauritian shores, awakening its people to the harsh reality that geographical insularity is no longer a saving grace in the global world, academics have had to engage forcibly with new modes of teaching. Academics at the Mauritius Institute of Education (MIE), where the study from which this paper emanates is situated, are currently experiencing what their local and foreign counterparts are undergoing. Ironically, it must be acknowledged, what constant encouragement and entreaties from Management to adopt more technologybased pedagogy and massive investment ${ }^{1}$ did not succeed in doing on such a scale, the pandemic has achieved. Overnight, the modality changed to online teaching to reach out to students. As academics moved out of their niche and took on the challenge of e-teaching, it could be noted that the paradigm shift was not as turbulent as may have been expected. Albeit some hiccups that were,

${ }^{1}$ Over the past few years, the institution invested in such tools as laptops with Office 365 for all academics, interactive whiteboards and interactive TV panels as well as ran capacity-building workshops for academics to help them develop the requisite technical know-how. 
for instance, related to online registration, some difficulties encountered by part-time lecturers, and conducting practical sessions, most academics displayed a positive attitude as they navigated through their online courses. This situation prompted the authors to study lockdown as a trigger for 'innovative disruption', to borrow Clayton Christensen's concept. 'Innovative disruption', which was initially a business theory, eventually broadened towards an application in the field of education where Christensen et al. (2006) brought out the possibilities of online learning. In this chapter, while we remain in the sphere of online learning, the concept is used to describe how the disruption of customary teaching practice (namely face-to-face sessions) due to confinement, proved to be an opportunity for academics to,

(i) adopt new pedagogical resources and thereby discover new possibilities and potential within that area; and

(ii) reflect critically on the relevance and currency of the type of pedagogical know-how they aimed to develop in their trainees in the current times where order and the known may no longer be the norm.

\section{Literature Review}

The advancement in information and communication technology (ICT) has greatly influenced our lives. The exponential use of emails, WhatsApp, and Skype to name a few, reveals the extent to which the global adoption of the internet has transformed the way people communicate. The fundamental change visible in social life, commerce and governance is echoed in the education sector, as seen through the steady proliferation of online education worldwide. In this connection, Ho and Kuo (2010) opine that e-learning has become a major form of training and development within organisations. Concurring with them, Arunachalam (2019), Palvia et al. (2018), and Arkorful and Abaidoo (2015) posit that many Higher Education Institutions offer fully online and/ blended courses, combining online instruction with face-to-face teaching. They further stipulate that virtual learning environments provide healthier learner interactions for students. In fact, Trust and Horrocks (2017) mention that, not only students, but academics too benefit from this mode of teaching as it is time saving and helps with course management and student tracking. Furthermore, online teaching and learning at Higher Education Insti- 
tutions offer potential for addressing critical issues such as growth in student numbers, the inconveniences arising from the timings for courses (Hoven 2006), and cost effectiveness (Richardson et al. 2017; Van Mourik Broekman et al. 2014). Under such circumstances, online teaching provides a practical solution for all stakeholders. Further highlighting the benefits of online teaching and learning, Arunachalam (2019) and Liaw and Huang (2013) contend that it provides students with the opportunity of accessing the course at a time and place that is convenient and comfortable to them. Moreover, with asynchronous interactions, discussions can remain on track since learners have the opportunity of crafting their responses. Such a mode thus creates the space for them to work collaboratively by creating online groups to share conversations and discussions. It can then be argued that online teaching not only reconceptualises content delivery, but also redefines traditional educational roles and provides opportunities for learning, thereby leading to learner autonomy. Palloff and Pratt (2013:30) corroborate with the above claim, stating that 'the online classroom is a potentially powerful teaching and learning arena in which new practices and new relationships can make significant contributions to learning'. However, it cannot be denied that, just like in brick and mortar classrooms (Seaman, Allen \& Seaman 2018), online teaching needs a strong pedagogical practice. Thus, Palloff and Pratt (2013) emphasise the need for training so that tutors, not only use technology, but also shift from the customary ways in which they organise and deliver material. However, Blin and Munro (2008:489) go a step further and call for '(m)ore radical transformations of the overall social and cultural context of the university teaching practices', especially since factors such as inadequate understanding of online pedagogy and online learning styles, as well as lack of administrative support for online education (Kentnor 2015) can adversely affect students' learning.

The momentum that online teaching has been gaining over the years reflects how the educational sphere has been adapting to changes in the wider context. Similarly, the nature and goals of education have evolved over time, in line with these changes. 'Education should always be about preparation for the future, but the future is uncertain and unknowable. It has always been this way. Presently, the key characteristic is the intensity of change and the super complexity of the world that humans navigate' (Burden et al. 2016: 4). This statement could not be more than apt to describe the current upheaval and chaos into which the education sector has been thrown with Covid 19 compelling countries across the globe to go into lockdown mode. Teacher Education has 
been the subject of much research in the past decades (Darling-Hammond 2012; Dengerink \& Lunenburg 2020; Loughran \& Hamilton 2016) and much has been said about how it should be conducted and improved. Emphasis is laid upon the fact that TEPs need to align themselves with the complexity of an ongoing changing societal system (Bentley 2012; Griffin 2013). Moreover, some researchers have also argued that the future of TEPs resides in understanding that contemporary teacher trainees construct their knowledge by making use of technologies as well as social media which is a paramount tool in their learning (Williams 2005; Royle et al. 2014). Burden et al. (2016:8) claim that ' $(w)$ hat is beyond question, however, is the global impact of (the) technological changes which are set to confront many of the fundamental assumptions and tenets upon which teacher education is constructed'. They further stipulate that some of the ways that technologies can impact on teacher education will be to destabilise the temporal space of learning. In the twentieth century, it was assumed that TEPs would be delivered within one spot and at one specific time. However, the authors argue that the advent of current technologies and social media will have an impact on the temporal space within which teaching and learning is conducted and boundaries will no more be fixed and rigid, but will be flexible as teaching and learning happens beyond the notion of a fixed temporal space. Such shifts entail reviewing existing TEPs and how/how far current technologies are embedded within its design and construct. Although online teaching and learning has evolved considerably in developed countries, Jaffer, Ngámbi and Czerniewicz (2007) argue that multiple levels of challenge exist in developing nations with regard to online teaching and learning. Small island developing states like Mauritius are no exception to this condition. It therefore goes without saying that a sudden shift from traditional methodologies is inevitably 'disruptive'; the term being here understood as meaning a serious transformation or alteration of the structure of teaching and learning activities taking place in formal education, with a particular focus on those transformations arising from an institution-wide deployment of e-learning technologies (Blin \& Munro 2008:476). Until now, Blin and Munro (2008) believe, technology - in the form of PowerPoint presentations and the interactive whiteboard, for instance - has predominantly been used to support traditional teaching approaches and "when the introduction of a new object or of a new tool ... results in a serious alteration of the internal structure of the teaching activity system, we can infer that the activity system has been disrupted' (ibid., 477 - e.a.). 
Change is hard, as Earl et al. (2018:1112) posit, citing research that indicates how individuals are limited 'because of force of habit', and adopting digital education involves jumping into 'a site of struggle and intense conflict ... on a number of fronts - from the allocation of resources and maximisation of profit, to concerns with epistemology or equality of educational opportunities' (Selwyn 2013:2). And yet, when evolving circumstances bring out that working smarter is the only way out, isn't disruption a necessary evil? Can 'creative disruption' indeed 'facilitate the 'creative destruction' mode of education into realising its full potential'? (Zainuddin et al. 2012:34). As Richardson et al. (2017:18) point out, 'True disruption occurs when existing institutions fail to embrace the forces of transformation'. Thus, at a time when the online mode of instruction is the call of the day, we attempt to understand academics' successful use of technology in a Higher Education Institution and the emerging personal and professional innovation in online teaching during the Covid crisis.

\section{Methodology}

The study on which this paper is based was situated within the constructivist paradigm. Constructivism is built upon the premise of a social construction of reality (Adom et al. 2016; Reed et al. 2008; Ehrich 2006; Gregory 2003; Honebein 1996), and one of the advantages of this approach, is the close collaboration between the researcher and the participants which is key to enabling the latter to tell their stories (Baxter \& Jack 2008). These stories, which bring out the participants' views of reality, enable a better understanding of the individuals' action. Furthermore, the three concepts of Appreciative Inquiry: appreciation, inquiry and wholeness (Bushe 2011; Cooperrider et al. 2008; Fineman 2006) that provided the framework for the study are epistemologically rooted in constructivism. Thus, guided by the prescript of our philosophical assumptions, we undertook a case study, which Ebneyamini and Moghadam (2018), Yin (2014), and Crowe et al. (2011) posit is an empirical inquiry that investigates a contemporary phenomenon in depth and within its real-life context, to explore and understand teacher educators' experiences of online teaching and learning in a tertiary institution during the lockdown period.

Given that data production took place during confinement, convenience sampling was opted for and participants with whom we had already 
established a rapport (Etikan 2016) were singled out. The literature abounds with arguments highlighting how the researcher-researched relationship is crucial in allowing the smooth production of rich qualitative data (Blackledge \& Creese 2010; Feldman et al. 2003; Heller 2008; Wanat 2008). Therefore, the choice of participants was founded on these premises and twelve teacher educators were chosen to take part in the study. Care was taken to select teacher educators with different areas of specialisation- such as languages, Performing Arts, Home Economics, Business Studies, Physical Education, Education Studies, Curriculum Studies - to get a deeper insight into the phenomenon. This not only allowed for relative ease in producing data while homebound, but also enabled the production of thick textured data that brought forth varied perspectives of the phenomenon.

Fedyuk and Zentai (2018:172) claim that interviews are 'essential to scholarly endeavours that pursue collaborative knowledge production and participant research (and are) used to carve a space directly for the respondents' voices and analysis of the situation'. They further elaborate on how different types of interviews such as unstructured interviews or informal conversations allow 'the researcher to map out those areas not originally seen as part of the inquiry'. Thus, for this study, we chose to have informal conversations with the participants to allow for the individual voices of each participant to shape the research inquiry. These conversations established a discursive space within which we used our emanating reflections to probe further into the participants' responses, thereby leading to the generation of rich data. In a reflexive act, the tools for data production were adapted for the circumstances and online modes were used so that communication took place through phone calls, emails, WhatsApp chats, as well as Teams interviews which were recorded with the participants' permission. Despite sharing the reality of the participants, we did not step into the field with a priories, preferring to allow the data to emerge. For data analysis, a grounded approach was adopted to identify recurrent themes. It must be pointed out, that even though the participants did mention constraints they were facing, the positive aspects were focused on, in line with the purpose of the study and research methodology.

\section{Findings}

As the lockdown compelled teacher educators to shift from customary teaching practices, several benefits of online teaching emerged. In the first instance, the 
flexibility online applications afforded became more obvious, with teacher educators realising that they could henceforth record sessions for students who could not attend classes due to illness or other reasons, as well as during times when classes were suspended due to climactic conditions. In the current context, a student who had to go to the Social Security office was able to catch up in her own time. Such a measure thus helps cut down on tutorials. On the other hand, both the teacher educator and students could later view the sessions to identify areas that require clarification. Taking the idea further, a teacher educator pointed out that the gradual development of a repertoire of recorded lessons could be a valuable and time saving tool for use with future cohorts. In fact, pre-recorded lessons could also be used as a precursor to highlight important points to be tackled in the forthcoming session, thereby laying the foundation for teaching a topic.

Online tools do not merely allow teaching and learning to transcend time and space; they also allow teacher educators to push the boundaries and embrace innovative pedagogical practices. While a Home Economics teacher educator was able to conduct a practical cookery session on Teams - something she would never have envisaged previously - a Performing Arts teacher educator capitalised on the circumstantial constraints to trigger enriching insights. By prompting the students to record their monologues individually in lieu of a group performance - and experiment with different ways of structuring these 'instalments' to produce an extended story, she enabled a better understanding of the effect of genres. Not only did students have the prospect of playing around with chronology, but they could also reflect on such technicalities as the direction each person is facing, how the use of different props can enable one person to play different characters, and even the need to memorise dialogue as they do for a live performance. Online learning even allowed her to debunk certain notions that students had of stage performance. At her own level, the experience made her more conscious of the 'audience' when preparing her PowerPoint presentations so that these became more 'humorous' with the insertions of comments - some with a touch of humour directed at the students so that they felt that someone was talking to them. Further, the distancing confinement brought about was curbed through the shift from 'basic' to interactive PowerPoint presentations on Teams that directed students to get back 'to class' after watching a video. Infusing the presentations with 'a voice', to an extent allowed the students to experience the authenticity of drama sessions. 
As seen above, with no alternative than to move out of their comfort zones, teacher educators had to reinvent the way they taught. This shift led to their professional growth with respect to their dispositions, attitudes, as well as personal skills. One teacher educator mentioned how the realisation that she could handle online teaching made her more confident in her teaching, which in turn impacted positively on her interaction with the students. Another teacher educator explained how having to resort to online teaching forced her to revisit the materials she had been using in face-to-face teaching. The process empowered her to create new materials that were more meaningful for online teaching sessions. As they started navigating out of their comfort zones, teacher educators grew more confident in deconstructing their own understanding and knowledge of their practices and reconstructing them to meet their students' needs on online platforms.

Online teaching during the lockdown also culminated in more effective management of online teaching and learning sessions through the optimal use of applications available on Microsoft 365 as well as the other online platforms such as Moodle or Google classrooms. Given that he had to cater for pre-primary trainees who had a number of issues engaging in the online mode, which was foreign to them, a teacher educator had to devise means of making his online sessions as effective as his face-to-face sessions. This meant he had to 'grapple with content' and ensure that all the readings and slides that he sent to his trainees were 'meaningful' as he would not be present to provide additional information. Moreover, he also availed himself of the different chat options to enable his trainees to interact more effectively with him. Further, to accommodate the different types of questions, he used the chat options for short answer questions available within Microsoft Teams while the Moodle forum discussion platforms and google classroom were used for survey style open-ended questions.

Moreover, delving into online teaching during the confinement has encouraged teacher educators to reflect on and be open to new possibilities that are now available to them in future. Given that the current BEd primary course is being taught predominantly online and with few face-to-face sessions, a teacher educator suggested that the use of Teams - which she had just been introduced to - would pave the way for more 'interactive' sessions than the more 'static' ones that are on the Moodle platform which is being used. Speaking of his ongoing research on the variety of tools that are available for use during online sessions, a teacher educator also mentioned that, in the future, 
he would use the support of both audio resources and videos to encourage further interaction. Online sessions, according to several participants, were also a convenient way of addressing attendance problems for students who had to leave their evening classes early due to transport constraints, especially in winter. This mode of teaching would allow trainees to use their time more productively and engage better in their learning.

While most participants admitted that they were familiar with certain features of Moodle and Teams but had previously used them only occasionally, preferring the face-to-face modality, the unprecedented situation created by the lockdown provided an opportunity for both teacher educators and students to develop their pedagogical know-how with respect to the use of technology for teaching and learning. Being compelled to use new methods of online teaching allowed teacher educators to discover and sharpen their skills, which probably would not have been the case otherwise. A teacher educator who had used Teams for group presentations was encouraged by the fact that this had worked exceedingly well with a big class and intended to use this format in the future. Another teacher educator added that the online method of teaching and learning had allowed Performing Arts students to record and view themselves, thereby enabling them to discover a novel way of documenting their introspection and awareness of self in their reflective journals. Viewing themselves had given the students the possibility for critical self-reflection and self-evaluation.

The participants believed that the lockdown, which had forcibly prompted teacher educators and students alike to adopt the online mode, had a silver lining. They observed that this new mode of teaching made learners autonomous in their learning. One of the teacher educators stated that the students were now more engaged in self-study and took ownership of their learning. This autonomy in using the new tool was experienced by the teacher educators as well. Some of them pointed out that the various features and applications of 'Teams' made them rely less on technical support, especially from other colleagues. Encouraged by the nature of the tool, another participant added that they could post materials, readings and videos on Teams, thereby allowing probing and further conversations among learners. Although most of the teacher educators felt that the online mode of teaching cannot replace face-to-face sessions, they were of the view that the lockdown had opened avenues for adopting a new mode of teaching by making them reflect on and realise the opportunities that online teaching and learning provides. For 
instance, virtual workshops for trainees as well as the integration of digital technology and social media in their practice would broaden the spectrum of learning experiences and enable trainees to learn from one another through the use of research-based instructional and learning strategies.

Another salient outcome of the forced lockdown and ensuing turn to a new teaching modality was its contribution to the development of a better rapport between teacher educators and trainees. A teacher educator who works with large cohorts of part-time trainees indicated how she is often unable to listen to students' personal and professional problems due to time constraints as trainees tend to rush away after evening classes. Holding classes on Teams provided the students with opportunities to share personal anecdotes and professional experiences, leading to a better understanding on both sides. Had it not been for the lockdown, she would not have been able to address the emotional and psychological needs of her students. The lockdown had undoubtedly prompted teacher educators to see their students from a fresh perspective. Unsurprisingly then, for another teacher educator, the most positive aspect of this situation was the development of empathy towards his students. Unable to remain insensitive to his students' 'actual physical, financial and familial challenges', he engaged in restructuring the learning process for them. This entailed revisiting not only the content that he had to deliver, but also carefully thinking through how to deliver that content so that it made sense to his trainees who were navigating with online learning for the first time. What can be noted then, is that the pandemic has allowed teacher educators not only to revisit the way they taught but their own persona as teacher educators.

Last, but not the least, confinement and the turn to online teaching awakened teacher educators to the shortcomings of the TEPs on offer (and to the development of which they were party), where no provision was made to develop the students' ability to undertake online teaching. Yet again, programme development was conceived within traditional boundaries where only face-to-face sessions prevailed. Teacher educators realised that, at no point during their training were students given the opportunity to prepare and trial or conduct e-lessons. Thus, their training needs had also been premised on the belief that stability would always be the norm or that the only method of teaching is in a physical classroom. As a teacher educator commented, even though ICT modules are taught at the MIE, these fail to develop the practical skills and know-how that trainees require to undertake online teaching. The 
shortcomings are even more blatant in a context where decisions in that direction emanating from the Ministry of Education created ripples among the teaching community. The present circumstances however partly addressed the issue with trainees having hands-on experiences with online modes and 'learning by doing'. Their involvement has made them more conscious of the potential as well as difficulties of e-teaching and learning. Nevertheless, teacher educators did acknowledge that this lacuna in the TEPs should hereafter be addressed in an explicit manner, more so as the students are now more inclined to adopt this mode and pre-service trainees ${ }^{2}$ learn fast and have a predisposition for the use of technology.

\section{Discussion and Conclusion}

This study has shown that disruption can indeed act as a catalyst and trigger a transformational experience whereby academics (also creatures of habit) adopt and appreciate new ways of teaching and learning. Disruption, in this study, is seen to occur at three levels: pedagogical, attitudinal, and relational. At the pedagogical level, teacher educators explored new vistas, displayed an appreciation of the possibilities thereby afforded, and developed confidence in an area they had previously explored in a limited manner. Their professional growth is seen through their willingness to embrace online resources henceforth and adopt a blended teaching approach, which in turn reveal that they are gradually developing adequate mastery of the tools they had earlier been grappling with. The compelling shift in paradigm also brought about more criticality which culminated into an awareness of the limitations of the TEPs (with regard to the skills and attitudes trainees were equipped with) and a reflection on the requisite changes.

With respect to the teacher educators' attitudinal shift, this is not only seen on the pedagogical front but also in the way the teacher educators took to the new work culture online teaching brings in its wake. In addition to adjusting to new teaching methodologies, they understood the need for and accommodated themselves within new relational parameters whereby learner autonomy and responsibility replaced the more regimented structures that exist within physical classrooms. With teacher educators growing more humane and

${ }^{2}$ Pre-service trainees are those who have just completed their schooling and can be described as 'digital natives'. 
empathetic towards trainees, necessary modifications were made to ensure that learners had positive learning experiences.

As pointed out previously, change never occurs seamlessly. However, anchoring the study within the Appreciative Inquiry framework provided the scope for an alternative to discourses of deficiency and foregrounding prospects. Bearing in mind the fact that this study was undertaken during the first month of confinement, the transformative result of disruption should not be undermined - more so as teacher educators operating from their homes had only limited technical support. The outcome leaves us with little doubt that the creative potential of disruption is a valuable asset for innovation and professional growth. In the context of the institutional drive for the promotion of technologically oriented methodologies, it can be said that the teaching and learning experiences during the lockdown have provided a fertile terrain for the shift to materialise. As the world gradually settles into the 'new normal', it may be expected that online teaching will gain grounds.

\section{References}

Adom, D., A. Yeboah \& A.L. Ankrah 2016. Constructivism Philosophical Paradigm: Implication for Research, Teaching and Learning. Global Journal of Arts Humanities and Social Sciences 4, 10: 1 - 9.

Arkorful, V. \& N. Abaidoo 2015. The Role of e-Learning, Advantages and Disadvantages of its Adoption in Higher Education. International Journal of Instructional Technology and Distance Learning 12, 1: 29 - 42.

Arunachalam, T. 2019. An Investigation on the Role of Perceived Ease of Use and Self-efficacy in Determining Continuous Usage Intention Towards an e-Learning System. The Online Journal of Distance Education and eLearning 7, 4.

Baxter, P. \& S. Jack 2008. Qualitative Case Study Methodology: Study Design and Implementation for Novice Researchers. The Qualitative Report 13, 4: 544 - 559 .

Bentley, T. 2012. Learning beyond the Classroom: Education for a Changing World. London \& New York: Routledge.

https://doi.org/10.4324/9780203201756

Blackledge, A. \& A. Creese 2010. Multilingualism: A Critical Perspective. London: Continuum.

Blin, F. \& M. Munro 2008. Why hasn't Technology Disrupted Academics' 
Teaching Practices? Understanding Resistance to Change through the Lens of Activity Theory. Computers \& Education 50: 475 - 490. https://doi.org/10.1016/j.compedu.2007.09.017

Burden, K., P. Aubusson, S. Brindley \& S. Schuck 2016. Changing Knowledge, Changing Technology: Implications for Teacher Education Futures. Journal of Education for Teaching 42, 1: 4 - 16.

https://doi.org/10.1080/02607476.2015.1125432

Bushe, G.R. 2011. Appreciative Inquiry: Theory and Critique. In Boje, D., B.

Burnes \& J. Hassard (eds.): The Routledge Companion to Organizational Change. Oxford, UK: Routledge.

Christensen, C.M., H. Baumann, R. Ruggles \& T.M. Sadtler 2006. Disruptive Innovation for Social Change. Harvard Business Review. Available at: http://www.cnid.cl/wp-content/uploads/ 2015/10/Disruptive-Innovationfor-Social-Change_2006.pdf (Accessed on 10 April 2020)

Cooperrrider, D.L., D. Whitney \& J.M. Stavros 2008. Appreciative Inquiry Handbook. $2^{\text {nd }}$ Edition. Brunswick, OK: Crown Custom Publishing.

Crowe, S., K. Creswell, A. Robertson, G. Huby, A. Avery \& A. Sheikh 2011. The Case Study Approach. BMC Medical Research Methodology, 11, 1: 100. Available at: http://dx.doi:10. 1186/1471-2288-11-100 (Accessed on 23 April 2020) PMid:21707982 PMCid:PMC3141799

Darling-Hammond, L. 2012. Powerful Teacher Education: Lessons from Exemplary Programs. John Wiley \& Sons.

Dengerink, J.J. \& M. Lunenberg 2020. Selection of the Dutch Knowledge Base for Teacher Educators 2012 - Reconstructed. Available at:

https://research.vu.nl/en/ publications/selection-of-the-dutch-knowledgebase-for-teacher-educators-2012- (Accessed on 22 April 2020.)

Earl, A., R. van Wynsberghe, P. Walter \& T. Straka 2018. Adaptive Education Applied to Higher Education for Sustainability International. Journal of Sustainability in Higher Education. 19, 6: 1111 - 1130.

https://doi.org/10.1108/IJSHE-08-2017-0131

Ebneyamini, S. \& M.R.S. Moghadam 2018. Towards Developing a Framework for Conducting Case Study Research. International Journal of Qualitative Methods. 17: 1-11. Available at:

http://journals.sagepub.com/doi/full/10.1177/1609406918817954 (Accessed on 23 April 2020)

Ehrich, J.F. 2006. Vygotskian Inner Speech and the Reading Process. Australian Journal of Educational and Developmental Psychology. 6: 12 - 25. 
Etikan, I., S.A. Musa \& R.S. Alkassim 2016. Comparison of Convenience Sampling and Purposive Sampling. American Journal of Theoretical and Applied Statistics 5, 1: 1 - 4.

https://doi.org/10.11648/j.ajtas.20160501.11

Fedyuk, O. \& V. Zentai 2018. The Interview in Migration Studies: A Step towards a Dialogue and Knowledge Co-production? In Zapata-Barrero, R. \& E. Yalaz (eds.): Qualitative Research in European Migration Studies. Cham: Springer.

https://doi.org/10.1007/978-3-319-76861-8_10.

Feldman, M.S., J. Bell \& M.T. Berger 2003. Gaining Access: A Practical and Theoretical Guide for Qualitative Researchers. Walnut Creek, CA: AltaMira.

Fineman, S. 2006. On Being Positive: Concerns and Ccounterpoints. Academy of Management Review 31, 2: 270 - 291.

https://doi.org/10.5465/amr.2006.20208680

Gregory, V.L. 2003. Student Perceptions of the Effectiveness of Web-based Distance Education. New Library World 104, 10: 426 - 431. Available at: http://dx.doi.org/10.1108/0307 4800310504366 (Accessed on 23 April 2020)

Griffin, D. 2013. Education Reform: The Unwinding of Intelligence and Creativity. Switzerland: Springer Science \& Business Media.

Heller, M. 2008. Language and the Nation-state: Challenges to Sociolinguistic Theory and Practice. Journal of Sociolinguistics 12, 4: 504 - 524.

https://doi.org/10.1111/j.1467-9841.2008.00373.x

Hoven, D. 2006. Designing for Disruption: Remodelling a Blended Course in Technology in (Language) Teacher Education. Proceedings of the $23^{\text {rd }}$ Annual Conference of the Australasian Society for Computers Learning in Tertiary Education: 'Who's learning? Whose technology?' ASCILITE 2006, The University of Sydney. Available at:

https://pdfs.semanticscholar. org/4a6c/b805415f0fddd867fce800a694069ed7f774.pdf?ga=2.5511411. 1535298102.1588147821-583854554.1581073465 (Accessed on 23 April 2020)

Ho, L.A. \& T.S. Kuo 2010. How can One Amplify the Effect of e-Learning? An Examination of High-tech Employees Computer Attitude and Flow Experience. Computers in Human Behaviour. 26: 23 - 31. https://doi.org/10.1016/j.chb.2009.07.007 
Honebein, P.C. 1996. Seven Goals for the Design of Constructivist Learning Environments. In Wilson, B.G. (ed.): Constructivist Learning Environments: Aase Studies in Instructional Eesign. Educational Technology Publications. New Jersey: Englewood Cliffs.

Jaffer, S., D. Ng'ambi \& L. Czerniewicz 2007. The Role of ICTs in Higher Education in South Africa: One Strategy for Addressing Teaching and Learning Challenges. International Journal of Education and Development Using ICT (Online) 3, 4. Available at:

http://ijedict.dec.uwi.edu/ viewarticle.php?id=421

(Accessed on 22 April 2020)

Kentnor, H.E. 2015. Distance Education and the Evolution of Online Learning in the United States: Curriculum and Teaching Dialogue. Information Age Publishing, Charlotte 17, 1/2: 21 - 34.

Liaw, S.S. \& H.M. Huang 2013. Perceived Satisfaction, Perceived Usefulness and Interactive Learning Environments as Predictors to Self-regulation in e-Learning Environments. Computer \& Education 60: 14 - 24.

https://doi.org/10.1016/j.compedu.2012.07.015

Loughran, J. \& M.L. Hamilton (eds.). 2016. International Handbook of Teacher Education. Springer Science and Business Media. https://doi.org/10.1007/978-981-10-0369-1

Palloff, R. M. \& K. Pratt 2013. Lessons from the Virtual Classroom. $2^{\text {nd }}$ Edition. San Francisco, CA: Jossey-Bass.

Palvia, S., P. Aeron, P. Gupta, D. Mahapatra, R. Parida, R. Rosner \& S. Sindhi 2018. Online Education: Worldwide Status, Challenges, Trends, and Implications. Journal of Global Information Technology Management 21, 4: 233 - 241. https://doi.org/10.1080/1097198X.2018.1542262

Richardson, M.D., W. Jenkins \& P.A. Lemoine 2017. Planning for Innovation and Disruption in a Global Environment. Educational Planning 24, 3: 11 $-24$.

Reed, P., B. Smith \& C. Sherratt 2008. A New Age of Constructivism: 'Mode Neutral'. E-Learning and Digital Media 5,3: 310 - 322. Available at: https://journals.sagepub.com/doi/10.2304/ elea.2008.5.3.310 (Accessed on 23 April 2020)

Royle, K., S. Stager \& J. Traxler 2014. Teacher Development with Mobiles: Comparative Critical Factors. Prospects 44, 1: 29 - 42. https://doi.org/10.1007/s11125-013-9292-8

Seaman, J.E., I.E. Allen \& J. Seaman 2018. Grade Increase: Tracking 
Distance Education in the United States. Wellesley: The Babson Survey Research Group, MA, USA.

Selwyn, N. 2013. Discourses of Digital 'Disruption' in Education: A Critical Analysis. Paper presented to Fifth International Roundtable on Discourse Analysis. City University, Hong Kong, 23 - 25 May. Available at: $\underline{\text { www.academia.edu }}$

(Accessed on 23 April 2020)

Trust, T. \& B. Horrocks 2017. 'Í never feel alone in my classroom': Teacher Professional Growth within a Blended Community of Practice. Professional Development in Education 43, 4: 645 - 665. https://doi.org/10.1080/19415257.2016.1233507

Van Mourik Broekman, P., G. Hall, T. Byfield, S. Hides \& S. Worthington 2014. Open Education: A Study in Disruption. London: Rowman \& Littlefield International. Available at:

http://www.rowmaninternational.com/books/open-education (Accessed on 5 April 2020.)

Wanat, C.L. 2008. Getting Past the Gatekeepers: Differences between Access and Cooperation in Public School Research. Field Methods 20, 2: 191 208. https://doi.org/10.1177/1525822X07313811

Williams, P. 2005. Lessons from the Future: ICT Scenarios and the Education of Teachers. Journal of Education for Teaching 31, 4: 319 - 339.

https://doi.org/10.1080/02607470500280209

Yin, R.K. 2014. Case Study Research Design and Methods. $5^{\text {th }}$ Edition. Thousand Oaks, CA: Sage.

Zainuddin, M.N., M.F. Abd Rahim \& M.R.M. Rejab 2012. Reconstruct Creative Destruction Knowledge through Creative Disruption. On The Horizon 20, 1: 34 - 48.

https://doi.org/10.1108/10748121211202053

Prof Aruna Ankiah-Gangadeen Head of School of Arts and Humanities

Mauritius Institute of Education a.ankiah@mie.ac.mu

Dr. Yesha Devi Mahadeo-Doorgakant Mauritius Institute of Education y.doorgakant@mie.ac.mu 
Exploring Lockdown as an Opportunity for 'Innovative Disruption'

Prof Seema Goburdhun Head of Social Studies Department Mauritius Institute of Education s.goburdhun@mie.ac.mu 


\section{Understanding Remote Teaching and Learning Challenges amidst the COVID-19 Pandemic to Enhance Professional Development: A Systematic Review of Peer-Reviewed Journal Articles, 2012-2020}

\section{Vino Paideya \\ ORCID iD: https://orcid.org/0000-0002-5231-2458}

\section{Abstract}

Remote teaching and learning for many higher educational institutions nationally and internationally have become a growing response to enacting contingency plans to contain and manage the effects and impact of the COVID 19 virus pandemic. This chapter explores the challenges experienced with novice online teaching and learning practices in a systematic review of 2012 to 2020 literature as a means of professional development of academics for the remote teaching experiences.

There is a need to identify credible novice online teaching and learning practices during the transition from face-to-face to online learning and provide a contemporary picture of challenges that can be avoided with the implementation of remote teaching and learning. Although several reviews exist that focus on specific aspects of online teaching and learning and blending learning practices, there has been no broad overview of literature exploring recent trends and challenges of remote teaching and learning. Data sets were divided into three main themes: the student, lecturer, curriculum needs. Research analysis over this period suggests that challenges in remote education need to be addressed through ongoing provision of professional development for lecturers, trainings for students, and technical support for content development.

Keywords: Challenges, Remote teaching and learning, COVID 19 pandemic and higher education 


\section{Introduction}

The Covid-19 pandemic has resulted in the closure of contact universities globally with regard to face-to-face teaching and learning. All teaching and learning have transitioned to remote teaching and learning. According to Hodges, Moore, Lockee, Trust and Bond (2020), there is a difference between online learning and remote learning. Remote learning strives to recreate the classroom environment as the student learns through the computer. This means the student logs in to the virtual classroom environment at scheduled times to view lectures or participate in group learning activities. In contrast, online learning is not designed to mirror the traditional classroom and is more flexible by nature. Although remote learning is said to mirror the traditional classroom, all the benefits of the classroom are not realised in the home environment.

The coronavirus pandemic has resulted in a rise in 'emergency remote' teaching and learning, as colleges and universities had to shut their doors to protect their faculty and students (Hodges et al. 2020). Students were sent home to study remotely. In higher education globally, the impetus has been to ensure that students complete their university semester uninterruptedly, despite the tragic disruptions of the Covid-19 pandemic. Multiple online teaching guides, resources, webinars and videos are being prepared in rapid fire to this end to support academics to upskill and transition to remote teaching platforms ,or go fully online in the interim amongst uncertainty with respect to the control of the pandemic. Prolific online resources have flourished and the internet and social media are brimming and bursting with new tools, tips and tricks and techniques for the new (quick) fixes to go online with teaching and learning.

The University of KwaZulu-Natal is no different, where academics have been advised to move their lecturing online as part of the effort to salvage the academic year and support students during this uncertain time. As academics grapple with the new ways of communicating with their students away from lecture theatres, it is a good time to reflect on how this disruptive Covid-19 crisis can help us redefine what learning should look like for the Generation $\mathrm{Z}$ student. However, in the same breath we need to be aware of the challenges as well as the opportunities that the new method of remote teaching and learning might unfold for both students and academics.

A large number of students in our educational institutions today are from Generation $\mathrm{Z}$, a generation that has grown up with a truly global 


\section{Vino Paideya}

perspective of the world.

This generation is defined by technology, where the terms FOBA (Fear of Being Alone) and FOMO (Fear of Missing Out) express their expectation of instant communication and feedback, effected through apps like Instant Messenger, Snapchat and WhatsApp (Luthra 2020).

Despite them being technology canny, they may lack the theoretical knowledge base required for digital navigation. Evidence in support can be found in the study by O'Sullivan (2018), who strongly advocates that many young people, the so-called digital natives, have shown limitations in their use and knowledge of technology. In considering the Covid-19 pandemic, the World Bank further reiterates that most students will have great difficulty accessing online learning, especially those in rural areas and areas with poor Internet access and who are subject to numerous other social and academic disadvantages (World Bank 2020b). However, in our decisions for change, never before have we had such an acute understanding of modernity, advancement, internationalisation, and our human interconnectedness in our global community.

This systematic research review is aimed to support academics by highlighting credible research findings of novice online practices to improve the educational outcomes for students experiencing remote learning. Further, the World Bank has stressed that academics working remotely need to be trained and supported (World Bank 2020b). Subsequently, they urge that staff be supported technically, socially and morally so that they can deliver remote classes effectively.

The aim of this chapter is to highlight how these challenges may or may not influence or guide the remote teaching and learning strategies that are proposed within the context of the Covid-19 pandemic. The trends and advances in knowledge from 2012 to 2020 will be highlighted, with particular focus on the challenges experienced in newly developed online courses. This period was chosen as the frequency of publications in the area of online education was greater for the South African context. In addition, this research aims to highlight ways to navigate through remote teaching and learning and will indicate possible directions for future research. A systematic review of this nature will serve as a repository which can be employed positively by faculty members, having to improvise quick solutions in less-than-ideal circumstances (Hodges et al. 2020). 
This systematic review can serve as an effective body of knowledge while we grapple with ways to effectively engage the greater majority of our student body with respect to curriculum conceptualisations, technical skills development and pedagogical innovations to protect the integrity of what is being taught, learnt and assessed across different programmes during the Covid-19 lockdown. Further, as we observe in many countries around the world, many students in rural areas are unable to access online content, while television or radio broadcasting is often found to be more effective (Martin \& Furviv 2020). It is therefore envisioned that a systematic review that highlights potential challenges and suggests possible solutions with online practices might inspire capacity building and implementation of remote quality teaching.

\section{Systematic Review as a Methodological Framework}

A systematic literature review can be defined as a method of critically appraising, summarising and attempting to reconcile existing research on a particular issue of concern (Andrews 2005a; Hallinger 2013). Hence it is a 'secondary research activity which reviews primary and secondary research in attempt to take stock of what is known in a particular field' (Andrews 2005a:207). However, the essential quality of a systematic literature review is that it is an exploratory review of the evidence from clearly formulated questions that uses systematic and overt methods to identify, select and critically appraise relevant primary research in a way that is explicit, transparent, replicable, and accountable (Andrews 2005a; 2005b).

A systematic literature review was conducted by adopting the guidelines proposed by Kitchenham (2004). In this review, a highly structured process is followed that involves:

(1) Specifying research questions;

(2) Conducting searches of databases;

(3) Selecting studies;

(4) Filtering the studies by evaluating their pertinence;

(5) Extracting data;

(6) Synthesising the results; and

(7) Writing the review report.

Hence, papers published between 2012 and 2020 inclusive were reviewed. Publications outside this range are not included in the formal analysis, but may 


\section{Vino Paideya}

be included in discussion, where appropriate. In selecting papers for review, a clear distinction between those involving novice online teaching and learning challenges within the South African context formed the focus for this review. Furthermore, this study has a limited scope pertaining to online teaching and learning or blended learning within higher education. Some papers in these areas which are not within the South African context are still included in the discussion, only if they contribute to the principal focus on novice online teaching and learning courses.

The results were then depicted in a model which shows the challenges affecting the teaching of online courses and the relationship among these issues. For the purpose of this study, remote teaching and learning are defined as tertiary education and credit bearing coursework completely delivered through online courses via a learning management system (LMS) such as Blackboard or Moodle. The focus of this study is on challenges affecting online courses offered via a LMS by higher educational institutions including public and private universities in South Africa.

\subsection{Research Questions}

This review aims to explore the literature of novice and remote teaching and learning practices by identifying publications that create awareness about the challenges and trends in online teaching and learning, the contributions of these publications, and the evidence for any research findings that they report. The specific research questions are:

1. What aspects of novice online teaching and learning challenges have been the focus of the literature within the South African context?

2. What trends and challenges have been reported in novice online teaching and learning practices between 2013 and 2020?

3. What evidence has been reported when addressing challenges and trends in different aspects of novice online teaching and learning practices?

\subsection{Conducting Searches}

The following databases were utilised in scanning literature on online teaching and learning: SABINET, EBSCO Host, JSTOR and Google Scholar. Selecting 
search terms for a broad and inclusive review of introductory online teaching and learning literature proved challenging. Terms that were too general resulted in an unwieldy set of papers, while specific terms were likely to miss relevant papers. The following combined search phrases were selected with a focus on the area of interest in higher education:

'remote teaching challenges' OR 'introduction to online teaching and learning 'OR 'novice online teaching' OR 'blended learning' OR 'learning to teach online in South Africa' OR 'challenges of teaching emergency remote classes' OR 'Online distance learning'.

\subsection{Selecting Studies}

Based on the described procedure, 246 articles were found. The next stage of the systematic review was to select the papers that would form the basis for this review. The search results were examined with each title and abstract, and the corresponding full paper, if required, to determine its relevance to the review with respect to answering the research questions. Papers that were less than four pages long (such as poster reviews), and papers that were clearly identified as work in progress were eliminated.

\subsection{Filtering and Data Analysis}

After the selection process, 25 research studies fulfilled all selection criteria. Content analysis approach (Strauss 1987) was used to analyse the collected articles based on research on online teaching and learning. Following the selection of papers, a brainstorming of general categories followed, which was then refined and rationalised. The categories were then gathered into three high-level groups: the student, lecturer and curriculum. In a systematic literature review conducted according to Kitchenham's (2004) guidelines, available papers should be filtered at this point according to quality. This process was followed to a limited extent: some papers were eliminated upon initial perusal and others upon closer examination. However, the focus was more on the relevance of papers to the subject area than on their intrinsic quality, so at this stage there was some deviation from Kitchenham's guidelines. 


\section{Results and Discussion}

Table 1 shows the number of papers in each group and the subgroups into which some or all of these papers were classified. Table 1 answers research questions 1 and 2. Three main aspects of novice online teaching and learning challenges have been the focus of the literature within South African context, broadly categorised as challenges facing the student, the lecturer and the curriculum. The majority of papers were classified into the 'student' category, describing either students' lack of self-regularity skills, technological skills or time management skills. A substantial number of papers focused on the challenges lecturers experienced. Curriculum content and papers on assessment of online teaching and learning was minimal. Assessment as a category was not considered, as it featured with other broad categories.

Table 1: Classification of papers, some classified into two or more groups or subgroups with respect to online teaching and learning trends /challenges.

\begin{tabular}{|l|l|l|l|}
\hline Group & Papers & $\begin{array}{l}\text { Trends } \\
\text { Challenges } \\
\text { (RQ 2) }\end{array}$ & Related Sources \\
\hline Student & 15 & $\begin{array}{l}\text { Assessment } \\
\text { student } \\
\text { engagement, } \\
\text { peer learning, } \\
\text { External factors, } \\
\text { technological } \\
\text { skills, } \\
\text { student } \\
\text { experience, } \\
\text { student literacy, } \\
\text { student ability, } \\
\text { underrepresented } \\
\text { groups, } \\
\text { student } \\
\text { motivation, }\end{array}$ & $\begin{array}{l}\text { - } \\
\text { - }\end{array}$ \\
\hline
\end{tabular}


Remote Teaching and Learning to Enhance Professional Development

\begin{tabular}{|c|c|c|c|}
\hline & & $\begin{array}{l}\text { time } \\
\text { management, } \\
\text { financial } \\
\text { resources, } \\
\text { self-regulated } \\
\text { learning }\end{array}$ & $\begin{array}{l}\text { - Bagarukayo \& Kalema } \\
\text { (2015) } \\
\text { - Kgovinyane (2019) } \\
\text { - Geduld (2013) }\end{array}$ \\
\hline Lecturer & 7 & $\begin{array}{l}\text { Teaching tools, } \\
\text { teaching styles } \\
\text { and experiences, } \\
\text { training, } \\
\text { communication, } \\
\text { digital divide, } \\
\text { perceptions and } \\
\text { challenges, } \\
\text { lack of } \\
\text { confidence, } \\
\text { time } \\
\text { management } \\
\text { pedagogical } \\
\text { approaches }\end{array}$ & $\begin{array}{l}\text { - Upfold and Bell (2019) } \\
\text { - Van den Heyde (2019) } \\
\text { - Czeniewicz \& Trotter, } \\
\text { Haupt (2019) } \\
\text { - Isabirye \& Dlodlo (2014) } \\
\text { - Tshabala \& Ndeya- } \\
\text { Ndereya (2014) } \\
\text { - Vaughan, Reali, Stenbom, } \\
\text { Van Vuuren \& Mac } \\
\text { Donald (2017) } \\
\text { - Balfour, Van der Walt, } \\
\text { Samer, } \\
\text { Tshivhase (2015) }\end{array}$ \\
\hline Curriculum & 3 & $\begin{array}{l}\text { Role of } \\
\text { academic } \\
\text { developer, } \\
\text { paradigms }\end{array}$ & $\begin{array}{ll}\text { - } & \text { Van de Heyde \& Siebrits } \\
& (2019) \\
\text { - } & \text { Cloete (2017) } \\
\text { - } & \text { Mpungose (2020) } \\
\end{array}$ \\
\hline
\end{tabular}

In attempting to answer research question 3, the discussion which follows will explore the evidence reported when addressing challenges and/or trends in different aspects of novice online teaching and learning practices within the three broad categories: 
Vino Paideya

\subsection{Issues Related to Students}

A review of literature on novice online learning challenges experienced by students revealed that issues related to students may be broadly summarised into:

Students' expectations,

Student readiness,

Student identity, and participation as shown in Table 1.

Student's expectations can be challenging and can also interfere with teaching online courses effectively (Luyt 2013). Some students may have untimely expectations such as expecting instant feedback on their online comments and assignments, or may appear rude and demanding in their emails. Some may question their grades and others may not take the assignment deadlines seriously ( $\mathrm{Li} \&$ Irby 2008). It is therefore suggested that clear guidelines be communicated to students at the beginning of the course to circumvent these inappropriate expectations by students.

The ability to identify and adopt online learning styles and skills, which is a prerequisite for online courses, can be challenging for students (Mayes et al. 2011; Luyt 2013). It was established that students need to be selfmotivated and self-directed to be successful with online learning. Other key findings indicate that student training for online learning as well as facilitator assistance can offer the support required to students for online participation.

It is believed that training reduces anxiety and increases technological self-efficacy, which in turn, increases motivation to study online (Wang, Shannon \& Ross 2013). This positive feedback loop discovered by Wang et al. offers hope to struggling students. It is suggested that the more online courses they take, the more the students become accustomed to effective learning strategies, which results in increased motivation to study online.

In addition, students may feel isolated and disconnected in online courses (McInnery \& Roberts 2004), which may affect learning. A study by Venter (2019) reveals that the students' identity can be engaged through an affiliation with the online learning community. Students engage in various formal and informal collaborative learning activities that constitute the creation of personal learning environments (PLEs). PLEs reveal the role of student agency as students coordinate their options. Social capital theory demonstrates 
how different types of social ties in PLEs provide for bonding and bridging of social capital in the learning process.

Further, hesitance to participate in collaborative work and discussion forums emerged in studies by Bharuthram and Kies (2012). Freeman (1997) proposes systems where students could remain anonymous and where new online students are guided in participation techniques. It is believed that for the African student, learning in support groups is a cultural practice and without such, students tend to experience isolation and frustration (Geduld 2013). It is suggested that to prevent feelings of isolation by students, lecturers are encouraged to create discussion forums and WhatsApp groups within which students could operate during remote lessons.

A strong lecturer presence is said to be vital in online learning, perhaps more so in developing countries (Roll \& Ventresca 2020). As the driver of the learning experience, the lecturer is encouraged to stimulate the acquisition of technological skills, constructivist learning techniques, nurture the online learning community, encourage and facilitate discourse, and provide prompt feedback on assessment (Butcher 2014; Mbati 2012). While students hold some responsibility for creating social presence, most of it resides with the lecturer (Blackmom \& Major 2012). It is therefore advised that lecturers be trained adequately for this role. Cook (2012) advises considering the group profile and creating a social presence that builds and supports learning while establishing a sense of belonging. Technological tools and activities can engage students via content, peers, and the lecturer.

In the study by Bagarukayo and Kalema (2015), which was an evaluation of e-learning at South African universities, several challenges were reported, such as insufficient time for studies, which indicated students' inability to manage time. They experienced anxiety and role conflict in their efforts to prioritise and manage their time, career, family and community responsibilities. Most of the participants in the qualitative data phase relied on external regulation and lacked the confidence to work independently with limited support from lecturers. It is suggested that these requirements, challenges and demands of Online Distance Learning (ODL) in the study are not unique and also apply to ODL students in developed countries. However, the prevailing challenges and barriers for this group of ODL students were their poor English proficiency, their dependence on lecturers and peers, and their inexperience with technology. These challenges of poor time management and lack of organisational skills seem like a common problem experienced by the 


\section{Vino Paideya}

greater majority of students who learn online. However, it is proposed that, when compounded with poor language proficiency and the lack of selfregulated learning, this could result in devastating results with the lack of training and support.

\subsection{Issues Related to Lecturers/ Facilitators}

Issues related to the lecturer included the five specific categories of e-teaching tools, training to transition from face-to-face to online, communication with students, the digital divide and teaching styles. A few of these categories will be discussed to highlight the current trends and challenges in novice online education. The research findings by Van de Heyde and Siebrits (2019) add to the debate on physics education specifically, and provide a new way of conceptualising an e-learning ecosystem. It is advocated that an academic developer-mediator should step in to mediate between academics, tutors and emerging e-tools through a structured developmental process for learning and teaching.

Czeniewicz (2020) brings to the fore three important aspects of remote teaching that educators need to consider for effective online teaching, namely training of both lecturers and students to counteract under-preparedness for online teaching and learning; effective communication between students and lecturers to ensure that nobody is left behind; and lastly, to take cognisance of the digital divide and be aware of students who might have issues with technology and/or connectivity.

In analysing issues of teaching and curriculum development, the article by Balfour et al. (2015) highlights two problems in connection with blended learning. The first, in view of the dynamic and fluid nature of the field, 'blended learning' cannot be defined conclusively, and the other is, that 'best practice' has not been examined in connection with blended learning. Hence, blended learning 'can involve a mix of delivery modes, teaching approaches and learning styles ... ways that support and enhance the teachers' role, the students' individual cognitive experiences, as well as the social environment; three key elements in successful learning and teaching' (Bath \& Bourke 2010:1). Secondly, it is suggested that the teacher engages with curriculum design, considers the implications technology will have for students' learning styles, especially those involved in distance learning and blended learning. It is further proposed that if the design element (the blend of technology with 
learning) is foregrounded, this will enable better access to, and engagement with, the content and delivery mode.

The qualitative study by Isabirye and Dlodlo (2014) explored the perceived inhibitors of online teaching practice through the experiences of ten academics at a university of technology (UoT). These inhibitors were identified in the study as technical problems, logistical issues, staff resistance to change, absence of e-policy and lack of staff motivation and training.

In addition, a study by Vaughan et al. (2017) compares and contrasts four international faculty development programs for blended learning to understand the benefits, challenges, lessons learned, and recommendations from such initiatives. In terms of challenges, all four programs emphasize the lack of time and resources to support a faculty through the complete cycle of designing, developing, implementing and evaluating blended courses. The biggest challenge appears to be a lack of common institutional definition and understanding of blended learning, as well as a lack of time and resources to support a faculty in the redesign of its courses. With regard to lessons learned, each program emphasises the need for all institutional stakeholders to be involved in supporting the initiative and that blended learning does not simply imply adding digital technologies to an existing face-to-face course. The key recommendation from this study is that faculty development programmes for blended learning need to be clearly aligned with the institution's vision and mission.

The selected papers were further analysed with respect to year of publication to determine current trends and practices and the evolution of certain trends in online teaching and learning, which is depicted in Fig. 1 below.

From Figure 1, which attempts to answer research question 2, it is clear that the number of publications with respect to novice online or blended learning courses within the South African context is increasing over time. Further, the number of publications on all three categories established for novice online teaching and learning have increased from 2017 to 2019. It is apparent from the sample that there has been limited research and publications in all three categories within the South African context until 2017. Most of the papers derived in the category of curriculum development from the data searched had to be eliminated, as they were global in horizon and approach. This indicates a gap in the knowledge with respect to curriculum design, innovation and challenges within the South African context. Also, we see that 


\section{Vino Paideya}

studies from 2012 to 2016 focus more on the students' experience. This is probably due to the increase in technology-enhanced pedagogical practices during this period, referred to as the fourth phase of technological learning or 'an era of mobile learning and social media' (Ng'ambi, Brown, Brozalek \& Gachago 2016:15). This phase was said to increase professional development of higher education staff to improve their technical skills and the development of pedagogical strategies.

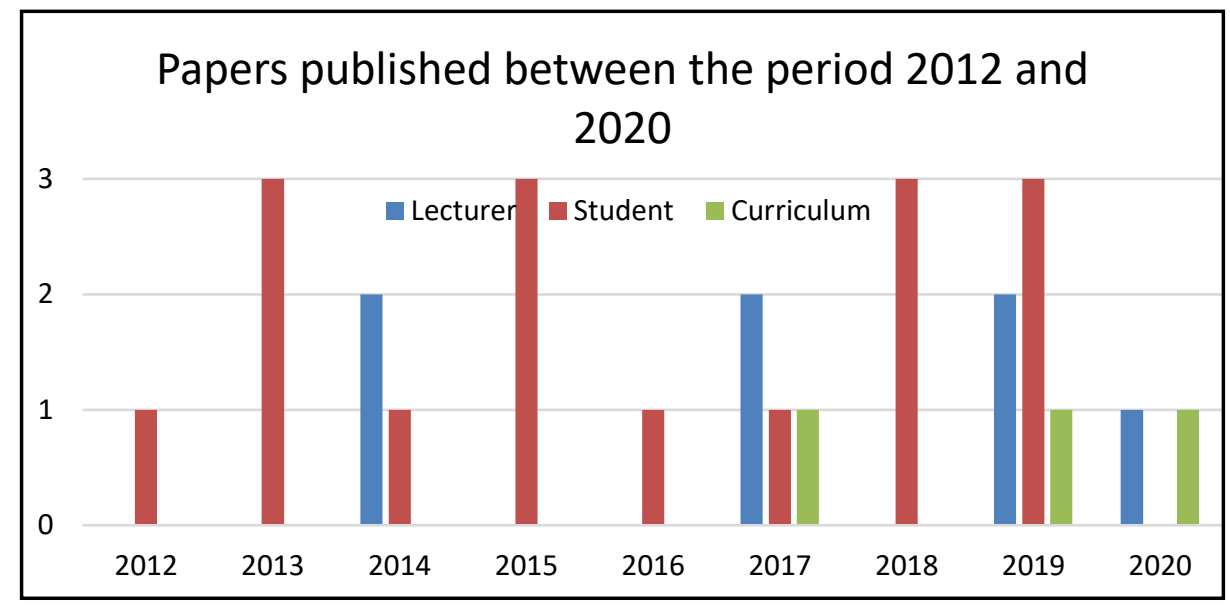

Figure 1 shows the number of papers that were identified in the data set, arranged by year.

Providing a detailed model such as shown in Figure 1 is very valuable, as it highlights major issues in online education and informs academics, curriculum developers, and policy makers. Additionally, papers about topics that apply across the broader spectrum of online teaching and learning are unlikely to refer specifically to novice online practices, so while they may inform the field, they are not discussed here. It should be clear that by no means does this review cover all possible papers on novice or remote teaching and learning. However, a broad cross-section of the literature has been identified and should be regarded as a relatively large and objective sample of the work on novice online teaching and learning challenges, which will be able to inform remote teaching and learning. 


\section{Conclusion}

Due to the threat of COVID-19, colleges and universities in South Africa and globally are facing challenges on the continuation of teaching and learning while keeping their faculty, staff, and students safe from a public health risk. Many institutions have opted to cancel all face-to-face classes, including labs and other learning experiences, and have mandated that faculties move their courses online to help prevent the spread of the COVID-19 virus. Moving instruction online can enable the flexibility of teaching and learning anywhere, anytime. However, the limited time for transitioning to online instruction is unprecedented and overwhelming, while being acutely aware of the anxiety and uncertainty that online teaching and learning present for both academics and students. The world as we know it is in a state of flux, and it will take collective courage, agility and commitment to fend off the effects of this pandemic and to adapt to new ways of teaching and learning.

Adopting an online learning environment is not just a technical issue as reflected by the reviewed literature; it is also poses a pedagogical and instructional challenge. As such, ample preparation of both teaching and curriculum materials and assessment knowledge is vital to online education. Technology is the means for delivery and requires a close cross-collaboration between instructional, content, and technology teams. Closing universities and taking students and lecturers out of the classroom is a pedagogical transformation that requires rapid mobilization across all university staff and resources (CoSN, 2020).

One challenge is recreating the dynamics of face-to-face instruction in an online teaching session. This systematic review of literature suggests that; firstly, maintaining a successful relationship between students and lecturer during online education is crucial; and secondly, that both lecturers and students be trained and supported to maintain an engaging interaction through the new system of teaching and learning in South Africa.

Not all faculty members are comfortable with virtual classrooms. There is a digital divide among those who have never used the basic technological equipment, relying on blackboards and flipcharts, in contrast to younger faculty members, who are aware of and adept at current communication technology trends (Govindarajan \& Srivasastava 2020). Therefore, as students across the nation enter online classrooms, they should be adequately prepared and supported to take on this new form of learning. 


\section{Vino Paideya}

This systematic review of literature, although not exhaustive, has provided an overview of current trends and described as well as delineated major patterns of challenges found in the literature for teaching online courses. It is hoped that higher education institutions and academics in South Africa as well as the international community would consider these challenges when initiating their online courses. As recommended, institutions are advised to provide the necessary professional development for online facilitators. In addition, training for students and adequate support for technical issues and multimedia integration must also be considered to further enhance the quality of online education.

\section{Recommendations}

Based on the foregoing analysis, the study makes following recommendations with respect to online or blended learning:

- There should be institutional promotion of student involvement in the process.

- There is a need for greater variety of support for blended and online courses in order to meet the needs of different faculty groups, students and programs at the university.

- Institutional change takes time and is a dynamic process that requires continuous review and perseverance of blended learning.

- Online and blended learning should be a strategic initiative aligned with the mission and vision of the institution and supported with time and resources for development.

- There is a need to build the online initiative on a solid research-based foundation.

- The four support areas of research, education, development, and technology should be considered as one that will become more integrated with supporting the design, development, implementation, and evaluation of online courses.

- A series of workshops will help a faculty and its students to understand concepts, models, and planning processes required to succeed with online or blended learning.

- Opportunities should be created for the sharing of best practices by working with other faculty members. 


\section{Limitations of the Study}

The literature search for the studies was extensive and systematic, using a framework to find as many related studies as possible; however, the review was not exhaustive. The findings were limited to the results that emerged in the searched databases using the aforementioned keywords. It is reasonable to assume there were other related studies in the literature that did not emerge and were not included in this review.

\section{References}

Andrews, R. 2005a. Systematic Literature Reviews: The Impact of Networked ICT on Literacy Education. In Goodwyn, A. \& A. Stables (eds.): Learning to Read Critically in Language and Literacy. London, U.K.: Sage.

Andrews, R. 2005b. The Place of Systematic Reviews in Education Research.

British Journal of Educational Studies 53,4: 399 - 416.

https://doi.org/10.1111/j.1467-8527.2005.00303.x

Bagarukayo, E. \& B. Kalema 2015. International Journal of Education and

Development using Information and Communication Technology (IJEDICT) 11,2: 168 - 183.

Balfour, R.J., J.L. van der Walt, E.J. Spamer \& A.C. Tshivhase 2015. Blended

Learning, and Open and Distance Learning: Implications for Best Practice in Higher Education. Progressio. 37,1: 1 - 18.

https://doi.org/10.25159/0256-8853/569

Bath, D. \& J. Bourke 2010. Getting Started with Blended Learning. Griffith

University, Australia: Griffith Institute of Higher Education. Available at: http://www.griffith.edu.au/ data/assets/pdf file/

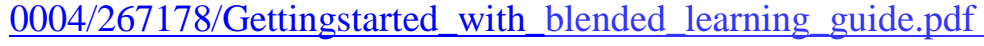

(Accessed on 8 April 2020)

Bayat, A. \& V. Naicker 2012 Towards a Learner-centred Approach: Interactive

Online Peer Assessment. South African Journal of Higher Education 26,5: 891 - 907. https://doi.org/10.20853/26-5-200

Bharuthram, S. \& C. Kies 2013. Introducing e-Learning in a South African Higher Education Institution: Challenges Arising from an Intervention and Possible Responses. British Journal of Educational Technology 44,3: 410 - 420. https://doi.org/10.1111/j.1467-8535.2012.01307.x

Blackmom, S.J. \& C. Major 2012. Student Experiences in Online Courses: A 
Vino Paideya

Qualitative Research Synthesis. The Quarterly Review of Distance Education 13,2: 77 - 85.

Botha, J. 2019. Student Satisfaction with a Blended Learning Approach: Implementation, Evaluation of Three Honours Programmes in Education. Thesis presented in partial fulfilment of the requirements for the degree of Master of Philosophy in Higher Education in the Faculty of Education at Stellenbosch University. Stellenbosch University.

https://scholar.sun.ac.za

Butcher, N. 2014. Technologies in Higher Education: Mapping the Terrain. Moscow: UNESCO Institute for Information Technologies in Education. Available at:

http://iite.unesco.org/pics/publications/en/ files/3214737.pdf

Cloete, A.L. 2017. Technology and Education: Challenges and Opportunities. HTS Theologiese Studies/ Theological Studies 73,4: 1 - 7.

https://doi.org/10.4102/hts.v73i4.4589

Cook, V. 2012. Learning Everywhere, All the Time. The Delta Kappa Gamma Bulletin, International Journal of Professional Educators Spring,78,3: 8 $-51$.

Czerniewicz, L. 2020. What we Learnt from 'Going Online' during University Shutdowns in South Africa. Available at:

https://philonedtech.com/what-we-learnt-from-going-online-duringuniversity-shutdowns-in-south-africa/

Freeman, M. 1997. Flexibility in Access, Interaction and Assessment: The Case for Web-based Teaching Programs. Australian Journal of Educational Technology 13,1: 23 - 39. https://doi.org/10.14742/ajet.1917 Geduld, B. 2013. Students' Experiences of Demands and Challenges in Open Distance Education: A South African Case. Progressio 35,2: 102 - 125. Hallinger, P. 2013. A Conceptual Framework for Systematic Reviews of Research in Educational Leadership and Management. Journal of Educational Administration 51,2: 126 - 149.

https://doi.org/10.1108/09578231311304670

Hodges, C., S. Moore, B. Lockee, T. Trust \& A. Bond 2020. The Difference between Emergency Remote Teaching and Online Learning. EDUCAUSE Review. https://er.educause.edu/articles/ 2020/3/the-difference-betweenemergency-remote-teaching-and-online-learning (Accessed on 15 April 2020)

Isabirye, A.K. \& N. Dlodlo 2014. Perceived Inhibitors of Innovative e-Learn- 
ing Teaching Practice at a South African University of Technology. Mediterranean Journal of Social Sciences 5,4: 390 - 398.

10.5901/mjss.2014.v5n4p390

Kitchenham, B. 2004. Procedures for Performing Systematic Reviews. Keele, UK: Keele University.

Koehler, M.J., P. Mishra, K. Hershey \& L. Peruski 2004. With a Little Help from your Students: A New Model for Faculty Development and Online Course Design. Journal of Technology and Teacher Education 12: 25 55.

Kgosinyane, E.M. 2019. Open Distance Learning (ODL): A 'Shock' to Learners in South Africa. University of South Africa. The $4^{\text {th }}$ Annual International Conference on Public Administration and Development Alternatives. 03-05 July 2019, Southern Sun Hotel, OR Tambo International Airport, Johannesburg, South Africa.

Letseka, M. \& V. Pitsoe 2013. Reflections on Assessment in Open Distance Learning (ODL): The Case of the University of South Africa (UNISA). Open Praxis 5,3: 197 - 206. https://doi.org/10.5944/openpraxis.5.3.66

Li, C. \& B. Irby 2008. An Overview of Online Education: Attractiveness, Benefits, Challenges, Concerns, and Recommendations. College Student Journal Part A 42: 449 - 458.

Luthra, P. 2020. Four ways COVID-19 Could Change How we Educate Future Generations. World Economic Forum. https://www.weforum.org/ agenda/2020/03/4-ways-covid-19-education-future-generations/

(Accessed on 30 March 2020.)

Luyt, I. 2013. Bridging Spaces: Cross-cultural Perspectives on Promoting Positive Online Learning Experiences. Journal of Educational Technology Systems 42: 3 - 20.

https://doi.org/10.2190/ET.42.1.b

Maboe, K.A. 2016. Perspectives of Distance Higher Education Students on Online Interaction. Progressio 38,1: 17 - 32. https://upjournals. co.za/index.php/Progressio; https://doi.org/10.25159/0256-8853/467

Mafenya, P.N. 2013. An Investigation of First-Year Students' Pedagogical Readiness to e-Learning and Assessment in Open and Distance Learning: A University of South Africa Context. Mediterranean Journal of Social Sciences MCSER Publishing, Rome-Italy 4,13: 353 - 360.

Mayes, R., J. Luebeck, H. Ku, C. Akarasriworn \& O. Korkmaz 2011. Themes and Strategies for Transformative Online Instruction: A Review of 
Vino Paideya

Literature and Practice. The Quarterly Review of Distance Education 12,3: $151-166$.

Mbati, L.A. 2012. Online Learning for Social Constructivism: Creating a Conducive Environment. Progressio 34,2: 99 - 119.

McInnery, J. M. \& T.S. Roberts 2004. Online Learning: Social Interaction and the Creation of a Sense of Community. Educational Technology \& Society 7: $73-81$.

Mpungose, C.B. 2020. Is Moodle a Platform to Decolonise the University Curriculum? Lecturers' Reflections. Africa Education Review 17,1: 100 115. https://doi.org/10.1080/18146627.2018.1479645

Msomi, A. \& S. Bansilal 2018. The Experiences of First-year Students in Mathematics in Using an e-Learning Platform at a University of Technology. South African Journal of Higher Education 32,5: 124 - 139. https://doi.org/10.20853/32-5-2507

Mtshali, M., S.M. Maistry \& D.W. Govender 2015. Online Chats: A Strategy

to Enhance Learning in Large Classes. South African Journal of Education 35,4: 01 - 09.

https://doi.org/10.15700/saje.v35n4a1215

Ng'ambi, D., C. Brown, V. Bozalek \& D. Wood 2015. Technology Enhanced Teaching and Learning in South African Higher Education - A Rearview of a 20 Year Journey: 20 Years Reflection on Technology Enhanced Learning. British Journal of Educational Technology 47,5: 3 - 22.

https://doi.org/10.1111/bjet.12485

Padayachee, P., S. Wagner-Welsh \& H. Johannes 2018. Online Assessment in Moodle: A Framework for Supporting our Students. South African Journal of Higher Education 32,5: 211-235.

https://doi.org/10.20853/32-5-2599

Queiros, D.R. \& M.R. de Villiers 2016. Online Learning in a South African Higher Education Institution: Determining the Right Connections for the Student. International Review of Research in Open and Distributed Learning 17,5: 165 - 184. https://doi.org/10.19173/irrodl.v17i5.2552

Sibanda, M. \& S. Donnelly 2014. The Impact of e-Learning on Student Performance: A Case Study of an Entry-Level Module at a South African University. Mediterranean Journal of Social Sciences 5: 478 - 485.

Strauss, A.L. 1987. Qualitative Analysis for Social Scientists. Cambridge, England: Cambridge University Press. 
Tshabalala, M., C. Ndeya-Ndereya \& T. van der Merwe 2014. Implementing Blended Learning at a Developing University: Obstacles in the Way. Electronic Journal of e-Learning 12,1: 101 - 110.

UNESCO 2020. COVID-19 Educational Disruption and Response. Available at: https://en.unesco.org/covid19/educationresponse/

Upfold, C. \& K. Bell 2019. The Influence of Learning Style Theory within a Blended Learning Environment: A Systematic Review. Rhodes University. Grahamstown. South Africa. Available at:

http://sacla2019.unisa.ac.za/Preprints/FP_Upfold_Learning\%20Style\%2 0Theory.pdf (Accessed on 13 April 2020.)

Van de Heyde V. \& A. Siebrits 2019. The Ecosystem of e-Learning Model for Higher Education. South African Journal of Science 115: 1 - 6.

https://doi.org/10.17159/sajs.2019/5808

Vaughan, N., A. Reali, S. Stenbom, M.J. van Vuren \& D. MacDonald 2017. Blended Learning from Design to Evaluation: International Case Studies of Evidence-based Practice. Online Learning 21,3: 103 - 114.

https://doi.org/10.24059/olj.v21i3.1252

Venter, A. 2019. Social Media and Social Capital in Online LearningResearch. South African Journal of Higher Education 33,3: 241 - 257. https://doi.org/10.20853/33-3-3105

Wang, C., D.M. Shannon \& M.E. Ross 2013. Students' Characteristics, Selfregulated Learning, Technology Self-efficacy, and Course Outcomes in Online Learning. Distance Education 34,3: 302 - 323. https://doi.org/10.1080/01587919.2013.835779

World Bank 2020a. Guidance Note: Remote Learning \& COVID-19. Available at:

http://documents.worldbank.org/ curated/en/531681585957264427/pdf /Guidance-Note-on-Remote-Learning-and-COVID-19.pdf (Accessed on 18 May 2020.)

Dr. Vino Paideya

Senior Lecturer School of Chemistry and Physics University of KwaZulu- Natal Durban paideya@ukzn.ac.za 


\title{
Redressing Inequalities while Envisioning University Student Teaching during COVID-19 Lockdown: Lessons from \#RhodesMustFall and \#FeesMustFall
}

\author{
Lungi Sosibo \\ ORCID iD: https://orcid.org/0000-0002-2424-7337
}

\section{Abstract}

The COVID-19 first reared its ugly face in the city of Wuhan, China in December 2019 and quickly spread throughout the world, leaving hundreds of deaths on its trail. The intensity of this disease is currently not the same in developed and developing countries. It appears that developed countries are heavily burdened by COVID-19 pandemic. Nonetheless, the effect of COVID-19 is gradually being felt in South Africa where, during the completion of this paper, there were 2456 deaths, 138000 infections and 68925 recoveries, respectively. The instability brought about by this pandemic has serious ramifications for the country's economy and schooling at all levels. In order to flatten the curve, the South African government implemented the lockdown of the country, which meant no contact learning could occur. Consequently, consideration was made by departments of education, schools and universities to offer remote teaching and learning. This paper reports on the efforts made by one South African higher education institution (HEI) to save the 2020 academic project in the midst of COVID-19 lockdown, based on the author's experiences and observations. Results revealed that during the COVID-19 lockdown, HEIs operated at different stages of preparedness regarding provision of remote teaching and learning. The author argues that prioritising remote teaching and learning after the 2015-2016 \#RhodesMustFall and \#FeesMustFall student protests should have prepared South African HEIs better to meet curriculum demands emanating from COVID-19 lockdown. Furthermore, had all institutions increased capacity development and ensured wider staff and student accessibility to resources, the 
curriculum would have been delivered efficiently during the COVID-19 lockdown. The paper concludes by showing how the COVID-19 lockdown has transformed and reshaped the manner in which teaching should be done in the future.

Keywords: inequalities, COVID-19 pandemic, online teaching and learning 2020 academic project, \#RhodesMustFall and \#FeesMustFall

\section{Introduction}

The United Nations Educational, Scientific and Cultural Organization (UNESCO) (2020) released results which showed that COVID-19 brought education of approximately 1.37 billion students around the world to a halt as of 23 March 2020. Abrupt closure of universities in South Africa is not a new phenomenon. The two students' campaigns - \#RhodesMustFall (\#RMF) and \#FeesMustFall (\#FMF), which broke out at the University of Cape Town (UCT) and the University of Witwatersrand (Wits) threatened to topple the South African higher education academic project in 2015. The source of \#RMF was racial discrimination that Black students allegedly experienced at historically white universities (HWUs), whereas \#FMF arose out of allegations of inadequate funding by the same group of students. These students felt that both factors adversely affected their success and wellbeing at South African universities. The campaigns signalled a call for the transformation and decolonisation of curriculum at South African higher education institutions (HEIs) (Nyamnjoh 2017). Paul and Case (2018) argue that these protest movements exposed higher education's failure to facilitate social mobility and redress, as well as many other realities that the youth face across the country.

These protests severely disturbed the normal order of teaching and learning at universities. It is the author's argument that the protests yielded unintended consequences: they signalled the imminence and inevitability of alternative teaching and learning modes at HEIs, such as, online and blendedlearning approaches. In a way, they also indirectly sent a signal to universities to be better prepared for future turbulent times such as the COVID-19 pandemic faced by the whole world. South Africa HEIs have entered unchartered territory, as COVID-19 gives them a test of time and puts them 


\section{Lungi Sosibo}

under unprecedented pressure to demonstrate their readiness and preparedness for online teaching.

In this paper, the author shares insights into the efforts of a South African HEI in completing the 2020 academic project in the midst of the COVID-19 lockdown. Online and blended learning are not new, but they are already in place and have become a norm at some universities, albeit in varying degrees. It would therefore appear that the eruption of COVID-19, although unprecedented and a natural phenomenon, challenges and puts in the spotlight those universities that might have ignored the call for blended and online learning during or after the \#RMF and \#FMF students' protests. Evidently, universities that turned to these modes of teaching after these protests would be more prepared to implement them during COVID-19 than those that did not. In this paper, online and e-learning are used interchangeably.

\section{Literature Review}

The literature review covers the following themes: E-learning in South African higher education and COVID-19, South-African university responses to COVID-19 lockdown, and COVID-19 and inequalities in South African higher education. These themes are presented in the next section.

\section{1 e-Learning in South African higher education and COVID-19}

The use of e-learning at South African universities is becoming increasingly popular (Bharuthram \& Kies 2012). Universities are using it to expand access to higher education and training opportunities for all students. Provision of elearning is in line with providing teaching methods and technologies that cater to the diverse needs of students, including those who experience barriers to learning due to factors such as geographic locations (Department of Higher Education [DHET] 2017). It also caters to the needs of a technologically savvy new generation of students who may find learning through conventional pedagogic approaches frustrating.

Different concepts are used to refer to e-learning, including blended learning and online education (Czerniewicz, Trotter \& Haupt 2019; Swingler 2018; Al-Adwan, Al-Adwan \& Smedley 2013; UCT Policy 2017). Blended 
learning refers to the use of a combination of online teaching and learning methods with traditional face-to-face classroom (Czerniewicz et al. 2019; Swingler 2018; Al-Adwan et al. 2013). In spite of the different terms used, the thread that runs through them is that e-learning takes place through information and communication technology (ICT), which generally refers to devices, networking components, applications and systems that facilitate interaction with the digital world. According to the UCT Policy (2017:2),

Online education is the use of educational technologies to mediate the curriculum, and can refer to offerings where learning activities take place fully online as well as the use of blended or mixed methodologies.

The DHET (2017 and 2012) is very careful not to have e-learning misconstrued or equated with open or distance learning. To differentiate between these concepts, the DHET (ibid) describes e-learning as characterised by the following: It,

(i) uses ICT to access learning;

(ii) involves the use of electronic devices (e.g. computers, laptops, tablets, and smart phones) to provide access and to allow students to interact with learning materials, with one another and with lecturers; and to participate in discussions remotely and to be assessed;

(iii) is mediated through the use of digital resources (usually combinations of text, audio and visual/video files) and software applications;

(iv) can be offered online, offline, or in a combination of both online and offline; and

(v) can be used in face-to-face and distance teaching. It is beyond the scope of this paper to provide the definitions of open and distance learning. For full definitions of these terms, please refer to DHET (2017) and DHET (2012).

Although e-learning is still debatable as an effective learning tool, there is research which shows that adopting it has benefits for students and teachers (Reed 2019; Anderson 2018; Cook 2018; Arkorful \& Abaidoo 2015; Bharuthram \& Kies 2012; Bora \& Ahmed 2013; Karaksha et al. 2013; Sampson et al. 2013). Reed (2019) highlights the convenience that e-learning 


\section{Lungi Sosibo}

provides to students by allowing them to pace their own learning and by providing them with unlimited access to content. Research shows that elearning promotes a community of practice (COP) (Lave \& Wenger 1996) by enhancing relationships and easing communication among students, thus enabling them to assist one another to develop the skills (Arkorful \& Abaidoo 2015). Karaksha et al. (2013) conducted a study in a pharmacology course which used online learning tools, in which they investigated the effect elearning would have on student engagement. They found that proper promotion of e-learning increased engagement, including active and collaborative learning, stimulation, time to think, and meeting high teacher expectations. Cook (2018); Bora and Ahmed (2013) and Sampson et al. (2013) are of the view that because e-learning is not bound by geography and time, it provides convenien-ce and flexibility of learning, as students can interact with the teacher and be examined anytime and anywhere without necessarily being in the classroom. For teachers, Anderson (2018) mentions how e-learning provides teachers with a comprehensive package by boosting knowledge, motivation and confidence.

There are limitations to e-learning as well. For example, the use of elearning can present challenges if students' different social contexts are not taken into cognisance, causing those students from disadvantaged backgrounds to lag behind those from advantaged backgrounds (Bharuthram \& Kies 2012). Unfortunately, for students, this situation could lead to low self-esteem and alienation resulting from the feeling of being excluded from university community. Arkorful and Abaidoo (2015) cite cheating, negative effect on the development of students' communication skills, and negative impact on students' socialisation skills as disadvantages of e-learning.

Murphy, Walker and Webb (2001) explain that e-learning is not meant to replace conventional modes of curriculum delivery but rather to supplement them. In countries such as the United States of America, it has become clear during the lockdown that the presence of technology does not and cannot outweigh the physical presence of a teacher. Rosemead (2020) argues that technology can never replace a well-trained creative teacher, because learning is a social process. This resonates with Vygotsky (1987) and Bruner's (1966) social constructivism theory, according to which the teacher should scaffold or mediate learning at the zone of proximal development (ZPD) through teacherstudent interaction. This fact is supported by Bharuthram and Kies (2012), who maintain that teachers should use the scaffolding approach in order to develop 
students' expertise. Interaction or dialogic encounter facilitates student's transition from potential development (what the student knows) to actual development (what the student is capable to know through the assistance and support of the most knowledgeable other). The most knowledgeable other could be a teacher, peers, family (parents, siblings, etc.) or anybody that a student interacts with. The same applies to technology- students need proximal interaction with the teacher in order to process new knowledge, bu t with time, they develop mental representations of technology which make it possible for them to use them creatively and to develop further skills on their own without mediation by the teacher (Somekh \& Mavers 2010). E-learning is shared learning: students can also acquire these skills from their peers and family. This shows that teaching and learning are social processes that are not confined to the traditional classroom.

The debate that teachers are indispensable in the teaching-learning situation dashes the hopes of assuming that during COVID-19 lockdown, remote learning will help students to cover the lost time and salvage the 2020 academic curriculum on their own. On the contrary, students should adopt selfdirected learning (SDL) by which, according to Knowles' (1989) andragogical model, they take on an active role to identify their problems (e.g. gaps in their knowledge, skills they lack); devise ways and means of how they acquire that knowledge and skills (how they learn to learn); try things out and self-correct; set their learning pace and evaluate their own learning. The term 'andragogy' derives from the Greek words andr- (man/ adult) and agogos (to lead). Andragogy refers to the art and science of teaching adults. By adopting andragogy as a student-centred approach, students take charge and selfregulate their learning. During the COVID-19 lockdown, interacting and soliciting support and guidance from the knowledgeable others around them, as well as a high level of motivation and self-determination to achieve their learning goals, will be essential for students to cope with remote learning. Factors of accountability will also play a big role in how students manoeuvre this unchartered territory without the physical presence and support from lectures. Nonetheless, it is hoped that the valuable skills attained by being selfdirected, independent and autonomous, coupled with intrinsic and extrinsic motivation and support from the MKOs, might also drive students' accountability while engaged in remote learning during COVID-19 lockdown. 


\subsection{South African University Responses to the COVID-19 Lockdown}

As mentioned earlier, the COVID-19 pandemic led to a lockdown which forced the country and institutions, including schools and universities, to shut down. In an effort to salvage whatever was left of the 2020 academic year in the midst of the COVID-19 pandemic, universities across the globe including those in South Africa, started gearing themselves up for online teaching and learning. In the context of South Africa, it became clear that universities' responses varied widely. For example, in a newspaper article that Asma (2020) published on 15 April 2020, four (4) historically advantaged universities (HAUs) reported to have made strides in preparing for online remote teaching and learning. Similarly, Dell's article released on 17 April 2020 mentioned that ten of the 26 public South African universities were ready to resume online remote teaching and learning, while the eleventh one was still undecided (Dell 2020). Four of these universities quickly announced in the media that they were lending laptops to their needy students and providing them with data to access Wi-Fi to expedite the online remote teaching-learning process, while one mentioned providing students with data only. Of these, only one was an HDU. In the same article, Dell (ibid) cited three HDUs at which she revealed that the situation was a bit more complicated or unclear. One of these universities indicated that they had put a moratorium on assessments due to students' unequal access to resources. Nonetheless, in the articles dated 30 April 2020, Ngqakamba (2020) and Herald Reporter (2020) revealed that one of these HDUs was issuing 12000 laptops and data to needy students to be able to transition to remote teaching and learning. Sadly, by the month of May, it was clear that the HDU was struggling to get remote online learning going (Segar 2020). This is in vast contrast to the six HAUs and one HDU which had already shared how they were implementing remote online teaching-learning amidst the COVID-19 lockdown (Staff Reporter 2020).

Based on this information, it is evident that universities' responses to the provision of resources and implementing remote online teaching-learning during COVID-19 university closures varied widely (Asma 2020; Dell 2020; Herald Reporter 2020; Ngqakamba 2020; Staff Reporter 2020). History and context appeared to play a significant role in this discourse, with HAUs at the forefront and exhibiting a higher level of preparedness (Asma 2020; Dell 2020; Staff Reporter 2020) than their HDUs counterparts (Dell 2020; Segar 2020). 
Nonetheless, one HDU appeared to make strides towards ensuring a transition to remote online learning (Dell 2020).

\subsection{COVID-19 and Inequalities in South African Higher Education}

After the release of the White Paper 3: A Programme for the Transformation of Higher Education (Department of Education (DoE) 1997), 'massification of education' (Kraak 2000) occurred when masses of Black students flocked to the HEIs, some of which were only reserved for Whites before South Africa obtained democracy in 1994. It is the majority of these masses that James (2020) refers to, who have limited access to digital connectivity and also lack equipment such as laptops, smart phones and tablets to connect to the internet.

In South Africa, inequalities abound, transformation is slow, and education appears to be a right to a select few (Maimela 2015). Therefore, transition to online teaching and learning might be a tall order and a dangerous move that could have detrimental effects on the masses of students from underprivileged backgrounds. Due to inequalities, the employment of sophisticated e-learning technology may lead to the exclusion of many students who lack access to gadgets and reliable internet connectivity. Expressing its opposition to online learning, the People's Coalition (2020: 2 - 3) put it succinctly as follows:

The move to online teaching and learning ignores inequalities engineered by colonialism, apartheid, capitalism, patriarchy, homophobia, xenophobia and neoliberalism. It reinforces nationality, class, race and gender inequities. Current 'alternative strategies' being put forward will mark, stigmatise and ghetto-ise many of the most vulnerable and marginalised communities. 'Going online' and providing 'alternative strategies' will render the economically deprived the proverbial sacrificial lamb while the privileged few benefit and move ahead with the curriculum.

COVID-19 has put the South African higher education system in the spotlight and unearthed the economic and digital divide that privileges affluent students, while it deprives impoverished students from accessing digital technologies 
equitably. Neumann (2020) puts it succinctly, asserting that the COVID-19 pandemic has highlighted inequalities in the South African education system. Neumann (2020:1) laments the fate of impoverished township students who 'were never brought up to par with the resources, facilities, opportunities and support structures' available to their counterparts from affluent backgrounds. Due to social inequalities that persist in South Africa, it becomes almost impossible for HEIs to offer online teaching and learning equitably without leaving masses of students behind.

Mathiba (2020:1) acknowledges the challenge brought about by COVID-19 in as far as universities having to transition from face-to-face to online teaching and learning, arguing that 'the feasibility is doubtful given the wide disparities among students in terms of access to adequate resources and the internet'. Jansen (2020b) echoes the same sentiments, contending that COVID-19 will simply intensify inequality of outcomes for the rich and poor students, because students in privileged classrooms are familiar with online modes of teaching and learning.

The discourse on inequalities is further raised by the Council on Higher Education (CHE) (2020:1), which notes that,

It is clear that capacities, infrastructure, access to devices, and access to the internet are unevenly distributed across the sector and among the student population. These pose a tremendous challenge to institutions to ensure that whatever remote teaching, learning, support and assessment technologies are utilised should not lead to disadvantage to those without devices and internet access.

Jansen (2020a:4) contends that 'In elite schools it is easy to make the switch to online learning should the shutdown continue for weeks or even months'. Keenan (2020:1) concurs with Jansen (2020a), that 'During the lockdown more affluent schools have adopted distance learning as a model for education's way forward, but it is a distant dream for the poor'. To support Jansen (ibid) and Keenan (2020), James (2020) raises the issue of the costs involved in accessing high-speed connectivity, which children from underprivileged backgrounds cannot afford. Czerniewicz et al. (2019) highlight the same concerns that some academics had with the adoption of blended learning at UCT during the \#RMF and \#FMF, that its use would benefit the wealthy students and exacerbate the digital divide among students from different socio-economic backgrounds. 
Besides costs, race appears to play a role in the lack of accessibility to online learning, as shown by James (2020:2), that 'Broken down by racially defined groups, just more than a fifth of black and coloured people are internet users, contrasted with white South Africans, two-thirds of which have access'. Evidently, COVID-19 replicates inequalities based on the same disadvantages that led to the \#RMF and \#FMF.

What these facts reveal is that in the context of COVID-19 university closures, it is those students from underprivileged backgrounds who bear the brunt of the virus (Jansen 2020a). Due to ingrained inequalities in the South African social and education fabric, COVID-19 creates a heavy burden on the poor masses of society. To put this situation into context, Keenan (2020:2) argues that,

The disparity between the affluent and the poor has been highlighted in the Covid-19 lockdown, and the difference in educational opportunities between those who have and those who do not is now startlingly obvious.

Shaw (in Keenan 2020:3) raises the same issue, that,

It is very worrying because the poor will be the most disadvantaged. Covid-19 will unfortunately shake up the academic order, and only the rich will be advantaged.

The unequal online-learning playing field among students from different backgrounds is a reality that cannot be denied, as acknowledged by a deputy vice-chancellor of academic affairs cited in Asma (2020a:3), where she highlighted the 'the unevenness in access to online platforms and the very real concerns about students lacking connectivity, devices and adequate work space to successfully engage in online learning'.

Students have also voiced concerns about the switch to online teaching and learning by universities, as demonstrated by university student representative councils (SRCs) from different HEIs, student unions such as SAUS and by virtual protests by UJ and students in other HEIs. Their bone of contention is unequal access to online learning emanating from their different social contexts and high costs related to obtaining data. Mpai (in the South African Broadcasting Commission [SABC] online 2020:2) echoed the 


\section{Lungi Sosibo}

sentiment that 'they [universities] haven't addressed the elephant in the room which is that majority of the students come from poor working class and they don't have resources to access'. Khofi (in Asma 2020b:2) echoes the same sentiment, tweeting that 'In reality, however, not everyone has access to the internet, so many would be disadvantaged'. Evidently, the issue of inequalities dominating the higher education discourse in South African HEIs has serious implications for offering online teaching and learning during COVID-19 university closures.

Although he was speaking about COVID-19 in the context of public health, in his speech on television, António Guterres, the United Nations (UN) Secretary General, stated that COVID-19 is an economic, social and human crisis that is fast becoming a human rights crisis. He emphasised that the response to this virus had to be guided by human rights principles, ensuring that no one was left behind. Evidently, providing online learning to some while leaving underprivileged students out in the cold violates some students' basic human rights of equal access to educational opportunities. It results in education becoming accessible to only the elite (Jansen 2020a). A situation which divides students into haves and have-nots is untenable, unsustainable, and intolerable: it violates the principle of Ubuntu (humanity). A middle ground has to be found to ensure that all students, regardless of their backgrounds, access education in an equitable manner during the COVID-19 lockdown. The question arises regarding how equity can be achieved when some universities are already ahead with offering online teaching whereas others are far from beginning to do so? Clearly, the principle of no student left behind becomes lip service and an elusive dream.

\section{Support for Students}

South African universities have their hands full trying to find ways of completing the 2020 academic project without exposing students to the danger of the COVID-19 pandemic. As shown earlier, some HEIs have taken advanced steps to mitigate the potential threat posed by COVID-19 on the academic project. This section reports on the activities undertaken at a South African university during the lockdown to either support students or inform steps to be taken to salvage the 2020 academic year. Some of the activities reported in this section were done at university and departmental levels simultaneously. These efforts include: Conducting university and departmental 
needs-assessment surveys; Adherence to the principle of no student left behind; Capacity-development training workshops; and Application of low-technology teaching strategies. It appears that, unlike Jansen (2020b), HEIs have not given up on the 2020 academic year, but they believe something can still be done to salvage whatever is left of it.

\subsection{Conducting University and Departmental Needs' Assessment Surveys}

Perhaps conducting surveys is the step that all the universities have followed to determine the needs of their students in relation to access to online learning. For example, the Staff Reporter (2020) reports on an online access survey that one of the HAUs conducted, the results of which yielded a response rate of $90.4 \%$ and revealed that a majority of students had access to devices and WiFi. Similarly, Asma (2020a), Du Plessis (2020), Hlati (2020) and Mathiba (2020) report on online and text message surveys conducted by different universities in order to determine whether or not students had access to devices, Wi-Fi and a conducive space for studying. Having said this, I argue that if \#RMF and \#FMF had been anything to go by and lessons from them had been heeded, the universities would have long assessed students' needs by the time the COVID-19 lockdown came into effect. Yet, as shown earlier, even those HEIs that had been directly affected by student protests conducted needs assessment surveys. Czerniewicz (2020) reports on the survey they conducted during \#RMF and \#FMF student protests, but since it was more than three years ago, before the COVID-19 pandemic, they perceived a need to conduct another survey to determine current students' digital needs. What these surveys illustrate is that generally, HEIs did not quite heed lessons that should have been learnt from the students' protests of the previous years and that if they had, they would have made these needs-assessment surveys part and parcel of planning for each subsequent academic year, instead of waiting until COVID19 showed its ugly face.

Clearly, the pace at which the surveys were conducted varied drastically. For example, on 2 April 2020, Ahmed Bawa, the chief executive officer of Universities South Africa (USAf) which represents South Africa's 26 universities, reported that at least three universities had already conducted surveys to establish their students' access to the internet, data and equipment, such as, computers, laptops, tablets and smart phones (Dell 2020). Immediately 


\section{Lungi Sosibo}

thereafter, four universities distributed laptops and data to their students. As shown earlier, not all universities were on par in as far as distributing resources to students.

The university on which this paper is based fell in the latter category. It was only towards the end of April 2020 that data were collected from students to determine this HEI's ICT capability of offering online teaching and whether it qualified for assistance as promised by DHET (Shoba 2020). The question of institutions' ICT capability had been posed by a member of the Democratic Alliance (DA) at a meeting at which the DHET briefed the Higher Education Parliamentary Committee on university and TVET plans for the 2020 academic year (Department of Higher Education, Science and Technology 2020a). Considering the strides made by those universities that had already distributed laptops and data, one could argue that this HEI's survey was conducted at a later stage. Clearly, the former had completed this process much earlier (Dell 2020; Hlati 2020). The DHET deadline of 26 March 2020 for universities and TVET colleges to indicate their eligibility for assistance also confirms this assertion (Department of Higher Education, Science and Technology 2020b; Shoba 2020).

Besides institution-wide online surveys, departments in various faculties also conducted surveys of a similar nature to their respective students. The challenge with the departmental surveys was lack of uniformity, with each department at different campuses and faculties using their own. The other challenge was that in some departments, the university-wide survey overlapped with the departmental ones, thereby creating an overload on students. Survey results were generally low. For example, online surveys from two departments yielded response rates of $35 \%$ and $44 \%$, respectively. A follow-up with class representatives revealed that the majority of students could not respond to the surveys due to the lack of data and devices. Evidently, many surveys could not reach the intended recipients. Similarly, university online surveys yielded moderate results, proving that not many students had participated in them, probably due to the same reasons. The university unsuccessfully conducted further surveys after the initial ones, but by this time, students might have suffered from survey fatigue. These poor response rates were not unprecedented. They were a reflection of inequalities and the digital divide prevalent among students in the South African Higher Education Institutions. They also highlighted the bleakness of the prospects of online teaching during the lockdown. 


\subsection{Adherence to the Principle of no Student Left Behind}

During the period when needs-assessment surveys were conducted, the university was careful not to embark on online teaching, as this would perpetuate inequalities among those students with access and those with no access. Essentially, the university refused to succumb to the temptation of leaving some students out in the cold. Indeed, providing online teaching to some students and not to others raises questions about how and when those universities would assist the missing middle; that is, those students whose parents earn an above-average income, but that income is not high enough for them to afford their children's tuition fees. According to the former Wits University's Vice-Chancellor Adam Habib, these students are 'too rich to qualify for the scholarship but in reality too poor to afford their education' (Habib, in Fihlani 2019: 3). The other question is: if universities let some students continue with online teaching and learning and others remain behind, how do they (universities) justify having two systems - one for the haves and the other for the have-nots, running parallel to one another? Dividing students into haves and have-nots renders the principle of leaving no student behind to sheer rhetoric.

The university in question implemented a moratorium on teaching and learning during the COVID-19 lockdown which was supposed to last until 16 April 2020 but was extended till 30 April 2020. The motivation for this moratorium was to mitigate leaving those students who did not have access to resources behind, and also to observe inclusivity, equity, equality and participation by all, as stipulated in the White Paper 6 (Department of Education 2001) and Ubuntu (humanity). Implementing moratoria is not new. For example, one of the public universities reportedly issued a moratorium on assessments during the lockdown (Asma 2020a; Fengu 2020).

In line with the principle of no student left behind, staff and students were informed that teaching and learning would only begin after it had been established that all students had access. How long will the moratorium last? This remains to be seen. The challenge is whether a point will be reached when all students have equitable access to resources. If this point is not reached, will moratorium after moratorium be implemented at this university, thus confirming Jansen's (2020b) assertion that the 2020 academic year is lost for these students, or will the university continue with those who have access and leave those without behind? This situation puts this institution in a fix, calling 


\section{Lungi Sosibo}

for the DHET's immediate intervention, as suggested by Members of Parliament (MPs) at the meeting during which the Department of Higher Education and Training (DHET) briefed the Parliamentary Committee of Higher Education on university and TVET plans for the 2020 academic year (Department of Higher Education, Science and Technology 2020).

\subsection{Capacity-development Training Workshops}

Czerniewicz (2020) shows how academics in her institution were caught off guard when they had to switch to blended learning during \#RMF and \#FMF, as online learning was a new phenomenon at many HEIs. She emphasises how important it was for staff at the university's centre of teaching and learning to support academic staff, which she reports was facilitated by departmental- and discipline-specific training workshops. Czerniewicz et al. (2019) also mention the support structures that were developed at their institution during the 20152016 student protests in order to assist academics with going online. These workshops allowed academics to ask questions and obtain answers, share knowledge and to form disciplinary CoPs (Lave \& Wenger 1996), a fact raised by Arkorful and Abaidoo (2015) earlier. During the COVID-19 lockdown, many universities acknowledged that not all academics were well prepared to offer online teaching. Consequently, one of them developed a university teach online strategy (TOS) which familiarised and helped academics to adopt a culture of using technology to teach creatively and to conduct online assessments (Staff Reporter 2020). A Vice-Rector of Teaching and Learning at one of the universities acknowledged the need to develop staff and students' capacity on the use of technology (Staff Reporter 2020). He maintained that the Online Transition and Orientation period would familiarise staff and students with online teaching-learning environments and enhance new ways of communication, relationships, and interaction between the two parties, thus enhancing the teaching-learning processes. During the COVID-19 lockdown, challenges with teaching online were inevitable, which could point to the fact that the 2015-2016 student protests might not have succeeded in prompting universities to prioritise online learning and to develop academic staff capacities. Due to COVID-19, the university in question facilitated virtual staff training workshops in order to observe social distancing imposed by the virus, a fact highlighted by Czerniewicz (2020). Even though this process might have been too little too late, considering that some universities had already 
embarked on online teaching, suggesting that they were equipped with these skills, this training will prove beneficial when the university embarks on online teaching and if student protests erupt in the future.

\subsection{Application of Low-technology Teaching Strategies}

Disappointing as the results of the departmental survey mentioned earlier were due to the low response rate, they did prompt the department to explore alternative strategies that could be used to facilitate teaching and learning during lockdown, while the university made efforts to cater to all students' needs. Czerniewicz (2020) reports that during the 2015-2016 student protests, there was no one strategy but multiple strategies that allowed more asynchronous teaching with less bandwidth-intensive, or low technologies. The idea was 'to use what students have, and keep it simple' (Czerniewicz 2020: 4), so as to be able to accommodate those students without or with limited access to resources. Academics identified several low-technology strategies that included sending notes and PowerPoint presentations via WhatsApp as attachments to the class representatives (class reps) who would in turn send them to the subject groups of the different levels. This was possible, as class reps represented all the subject groups and programme levels. Another option was to have lecturers create WhatsApp or Facebook subject groups through which they could send the learning materials directly to the students instead of using the class reps. Nonetheless, the team was disheartened that they had to resort to low technologies, as they felt that student teachers had to experience learning through technology so that they would in turn be handson and be pioneers of teaching with sophisticated technologies by the time they graduated from university.

Furthermore, it was agreed that when the teaching and learning moratorium had been lifted, some of the learning materials would be posted online for those with access to Blackboard. WhatsApp voice notes and audio recordings were another preferred mode of curriculum delivery considered, as it is possible to send them via WhatsApp or to post them on Blackboard. Facebook was identified as another platform that could be used, since many cell-phone companies sell social data for WhatsApp and Facebook cheaper than Internet data.

The Cluster Heads also considered print media, but the challenges they identified were that the post offices were closed during Level 5 of the lockdown 


\section{Lungi Sosibo}

but, more importantly, was the challenge of the high cost of printing, photocopying and postage. Consequently, this idea was abandoned. The issue of those subjects that include the practical components posed another threat, as practicals could not be done through online platforms. The team agreed that during the lockdown, the focus would be on covering the content, with the practicals to be done when face-to-face learning resumed. Regarding teaching practice (TP), it was agreed that the portfolio guides could be sent to students as attachments using the different platforms so that students could familiarise themselves with the contents. However, visits to schools would need to be planned when the COVID-19 dust has settled.

\section{Discussion and Conclusion}

It is clear that the COVID-19 lockdown has had an enormous impact on global education. Not only this, but it has also shaken HEIs from their comfort zone and challenged them to rethink ways of salvaging whatever is left of the 2020 academic project. This paper has demonstrated that while this pandemic ravages the world, online teaching is seemingly the best preferred approach to help with salvaging the 2020 academic curriculum. Questions arise as to why there have been no plans all along to invest in online teaching (Department of Basic Education 2020). The same question applies to HEIs in South Africa, where students' protests arising from \#RMF and \#FMF signalled the imminence and inevitability of investing in online teaching and learning, due to the disruptions on the academic activities. Czerniewicz (2020) and Czerniewicz et al. (2019) mention how during \#RMF and \#FMF student-led protests, their institution unexpectedly opted to switch to blended learning in order to allow students to complete their academic year, and how their institution has incorporated the practice of providing all students on financial aid with laptops on arrival. This is an indication that this institution learnt some lessons from 2015-2016 student protests. They report that even though the university has adopted online teaching and learning, contradictions and tensions that permeated this mode of teaching and learning during protests interfered with its adoption as a norm. Clearly, if online teaching and learning had been normalised, transition to the online mode would have been much smoother than it was. It is worth noting that this institution is one of those that were among the first to offer online teaching and learning during the COVID19 lockdown. It might be possible that the others who were at the forefront of 
online teaching and learning during this pandemic had learned some lessons from \#RMF and \#FMF shutdowns.

Having said this, issues of privilege for HAUs and disadvantage for HDUs cannot be ruled out. The fact that HAUs acted faster and HDUs slower in embarking on online teaching and learning is itself a symbol of privilege. This could be because the majority of students at the former is privileged and familiar with learning with technology, unlike their underprivileged counterparts at HDUs who come across a computer for the first time when they enter university. In fact, as shown earlier, the COVID-19 lockdown has exacerbated inequalities and disparities among students in South African universities, which led to the People's Coalition (2020:3) advocating social pedagogy and arguing that 'Our efforts to flatten the viral curve must not sharpen the social inequality curve [among students'. Granted, there was one HDU that also embarked on online teaching and learning at the same time as the HAUs, and another that distributed laptops to needy students around the same time that HAUs did (Ngqakamba 2020; Herald Reporter 2020). Nonetheless, the number of these HEIs is too low compared with their HAU counterparts. The fact that HDUs were generally not on par with their HAU counterparts might not be because HDUs did not learn any lessons from the 2015-2016 student protests. Instead, it might be a reflection of their low socioeconomic status, which might have prevented them from acting as quickly as their advantaged counterparts. Therefore, inequalities should not be overlooked in the discourse of the COVID-19 lockdown and online teaching at South African HEIs.

Results have also revealed that at the heart of university efforts to save the 2020 academic year is the principle of equality of opportunities for all students, as shown by the rule of no student left behind. This is apparent in how, as shown earlier, some universities provided technology equipment and data to their needy students, opted for low-tech approaches, and put moratorium on teaching and learning, as well as in some cases on assessments (Asma 2020a; Fengu 2020) until all students have access. All these are commendable acts of tolerance, inclusion and transformation embedded in the White Paper 3 (Department of Education 1997) and White Paper 6 (Department of Education 2001).

Several lessons could be learned from the COVID-19 pandemic. Like this virus, \#RMF and \#FMF protests should have changed the teaching and learning processes forever. If these protests did not change these processes, 


\section{Lungi Sosibo}

perhaps the COVID-19 lockdown will change them in a way that academics and students will never experience education the same way as before this pandemic. Perhaps the lessons learnt from \#RMF and \#FMF that Czerniewicz (2020) identifies in her research on university shutdown and going online apply to the COVID-19 lockdown and the future of higher education. Czerniewicz (2020) highlights how these shutdowns have taught them lessons about inequalities among students, staff and institutions. In addition, shutdowns taught them about the significance and role of data ownership and use of data (datafication) and its impact on students. They also learnt about academic and student experiences of online learning and the role of media communication, as well as surveillance in teaching and learning. Some of these lessons, if not all of them, resemble those learnt from the COVID-19 lockdown and as such, should inform policy of education in the future.

The COVID-19 lockdown demands a change of attitudes, mind-sets and practices regarding how knowledge in higher education will and should be imparted. Rodny-Gumede (2020) maintains that COVID-19 has placed increased focus on online learning, thus exerting pressure on universities to adapt course content to online environments. Similarly, Nguyen and Pham (2020) perceive the COVID-19 pandemic as an opportunity through which online teaching and learning could be strengthened. If COVID-19 has taught us one thing, it is that investment should be made in the infrastructure of online teaching and learning. Not only this, but also that investment should be made in developing academic capacities for online teaching and learning. Moreover, assessment of students' digital needs should not be once-off, but should be packaged in the academic curriculum. In addition, emphasis will have to be placed on self-directed learning, so that students are able to regulate their own learning during tumultuous times, such as presented by the \#RMF and \#FMF protests and by the COVID-19 lockdown. This requires students having the tools to learn on their own and being curious to continue learning (Department of Basic Education 2020: 11). Additionally, inequalities that permeate the higher education landscape should be attended to, and ways of transforming the higher education system should be found.

Conclusions that could be drawn in this paper are that COVID-19 has transformed and reshaped the manner in which teaching should and will be done in the future. Another conclusion is that, as is the case at other HEIs already, technology in education will be central in the education of the current and future generations. Moreover, it is clear from the contents of this paper that 
if the HEIs did not heed the central role that online teaching and learning played during the \#RMF and \#FMF, now is the time for them to redefine its role. The conclusion is, therefore, that HEIs need to align their curriculum with flexible modes of teaching that make education accessible anywhere and anytime through technology, while being mindful of inequalities that exist among students from different backgrounds. So, while there is so much destruction along the COVID-19 path, there are also vital lessons that the pandemic has contributed to the education landscape as a whole.

\section{References}

Al-Adwan, A., A. Al-Adwan \& J. Smedley 2013. Exploring Students' Acceptance of e-Learning using the Technology Acceptance Model in Jordanian Universities. International Journal of Education and Development Using Information and Communication Technology 9,2: 4 -18.

Anderson, K. 2018. Why e-Learning is Beneficial for Aspiring Teachers. Available at: https://edtechreview.in/e-learning/3148-why-e-learning-isbeneficial-for-aspiring-teachers

Arkorful, V. \& N. Abaidoo 2015. The Role of e-Learning, Advantages and Disadvantages of its Adoption in Higher Education. International Journal of Instructional Technology and Distance Learning 12,1: 29 - 42.

Asma, A.D. 2020a. Covid-19: Universities Prepare to Switch to Remote Online

Learning. Available at https://www.dispatchlive.co.za/news/2020-04-15covid-19-universities-prepare-to-switch-to-remote-online-learning.

Asma, A.D. 2020b. 'No student will be left behind' by e-Learning: Universities

SA. Available at: https://www.timeslive.co.za/news/south-africa/202004-20-no-student-will-be-left-behind-by-e-learning-universities-sa/.

Bharuthram, S. \& C. Kies 2012. Introducing e-Learning in a South African Higher Education Institution: Challenges Arising from an Intervention and Possible Responses. British Journal of Educational Technology 44,3: 410 - 420. https://doi.org/10.1111/j.1467-8535.2012.01307.x

Bora, U.J. \& M. Ahmed 2013. e-Learning Using Cloud Computing. International Journal of Science and Modern Engineering (IJISME) 1,2: 9 - 13.

Bruner, J. 1966. Toward a Theory of Instruction. Cambridge, MA: Harvard University Press. 
Cook, J. 2018. Benefits of e-Learning for Students. Available at: https://www.techsling.com/benefits-of-e-learning-for-students/.

Cape Peninsula University of Technology 2020. CPUT Convocation Covid Fund - \# KeepCreatingFutures. Available at:

https://www.cput.ac.za/about/covid-19/cput-convocation-covid-fund.

Council on Higher Education 2020. Memorandum on COVID-19 Crisis Actions Aimed at Completing the Academic Year. Pretoria: Council on Higher Education.

Czerniewicz, L. 2020. University Shutdowns - What we Learnt from 'Going

Online'. Available at: https://www.universityworldnews.com/post. php? story $=20200325160338881$

Czerniewicz, L., H. Trotter \& G. Haupt 2019. Online Teaching in Response to Student Protests and Campus Shutdowns: Academics' Perspectives. International Journal of Educational Technology in Higher Education 16,43: 1 - 22. https://doi.org/10.1186/s41239-019-0170-1

Dell, S. 2020. Universities Prepare for Online Teaching and Learning. Available at: https://www.universityworldnews.com/post.php?story= 20200417150627516.

Dell, S. 2020. Universities Mull Scenarios in Bid to Complete Academic Year.

Available at: https://www.universityworldnews.com/post.php? story $=20200402082839691$.

Department of Education 2001. Education White Paper 6: Special Needs Education- Building an Inclusive Education and Training System. Pretoria: Department of Education.

Department of Basic Education 2020. Draft Framework for Curriculum Recovery Post COVID-19. Pretoria: Department of Basic Education.

Department of Higher Education \& Training 2017. Draft Policy Framework for the Provision of Open Learning and Distance Education in South African Post-School Education and Training. Pretoria: Department of Higher Education \& Training.

Department of Higher Education \& Training 2012. Draft Policy Framework for the Provision of Distance Education in South African Universities. Pretoria: Department of Higher Education \& Training.

Department of Higher Education, Science and Technology 2020a. COVID-19 Response: University \& TVET Plans for 2020 Academic Year; DSI Work on COVID-19 with Minister. Available at https://pmg.org.za/ committeemeeting/30102/. 
Department of Higher Education, Science and Technology 2020b. Minister Blade Nzimande: Government's intervention measures on Coronavirus COVID-19. Pretoria: Department of Higher Education, Science and Technology. Available at https://www.gov.za/speeches/ response-covid19-24-mar-2020-0000.

Du Plessis, S. 2020. Students: Important Information for Online Learning in Term. Available at http://www.sun.ac.za/english/Lists/news/Disp Form.aspx?ID=7283.

Fengu, M. 2020. TUT Considers Cancelling Exams as Varsities Scramble to Save Academic Year. Available at: https://www.news24.com/citypress/ News/tut-considers-cancelling-exams-as-varsities-scramble-to-saveacademic-year-20200513.

Fihlani, P. 2019. 'We are students thanks to South Africa's \#FeesMustFall protests'. Available at: https://www.bbc.com/news/world-africa47952787.

Guterres, A. 2020. We are all in this Together: Human Rights and COVID-19

Response and Recovery. Available at: https://www.un.org/en/uncoronavirus-communications-team/we-are-all-together-human-rightsand-covid-19-response-and

Herald Reporter 2020. Fort Hare to Provide 12,000 Student Laptops. Available at: https://www.timeslive.co.za/news/south-africa/2020-04-30-fort-hareto-provide-12000-student-laptops/.

Hlati, O. 2020. Universities' Academic Year could Stretch into 2021. Available at: https://www.iol.co.za/capetimes/news/universitiesacademic-year-could-stretch-into-2021-46821108.

James, W. 2020. South African Schools without a Teaching Alternative is not Ideal. Available at: https://www.dispatchlive.co.za/news/opinion/ 202004-13-south-african-schools-without-a-teaching-alternative-is-not-idealwilmot-james/.

Jansen, J. 2020a. Closing Schools just Means Poor Kids Bear the Brunt of the Virus. Available at: https://select.timeslive.co.za/ideas/2020-03-19closing-schools-just-means-poor-kids-bear-the-brunt-of-the-virus/.

Jansen, J. 2020b. Let's Face Facts. The 2020 School Year is Lost. So What to Do? Available at: https://www.heraldlive.co.za/opinion/2020-04-09-letsface-facts-the-2020-school-year-is-lost-so-what-to-do/.

Karaksha, A., G. Grant, S. Anoopkumar-Dukie, S.S. Niru Nirthanan \& A.K. Davey 2013. Student Engagement in Pharmacology Courses Using 
Online Learning Tools. American Journal of Pharmaceutical Education 77,6: 1 - 10. https://doi.org/10.5688/ajpe776125

PMid:23966728 PMCid:PMC3748306

Keenan, T. 2020. Distance Learning Highlights Economic Divide. Available

at: https://www.dispatchlive.co.za/news/2020-04-14-distance-learning-

highlights-economic-divide/.

Knowles, M.S. 1989. The Making of an Adult Educator: An Autobiographical Journey. San Francisco: Jossey-Bass.

Kraak, A. 2000. Changing Modes: A Brief Overview of Mode 2 Knowledge Debate and its Impact on South African Policy Formulation. In Kraak, A. (ed.): Changing Modes: New Knowledge Production and its Implications for Higher Education in South Africa. Pretoria: HSRC Press.

Lave, J. \& E. Wenger 1996. Practice, Person, Social World. In Daniels, H. (ed.): An Introduction to Vygotsky. London, NY: Routledge.

Maimela, D. 2015. South African Higher Education Transformation: What is to be Done? A Working Paper in Key Policy Issues from a Student Movement Perspective, Annexure 16. Prepared for the Second National Higher Education Transformation Summit held at the Inkosi Albert Luthuli, 15 - 17 October 2015, International Conference Centre, Durban. Mathiba, G. 2020. Covid-19 and South African Universities: A Raft of Problems to Ponder. Available at:

https://www.dailymaverick.co.za/ opinionista/2020-04-09-covid-19-andsouth-african-universities-a-raft-of-problems-to-ponder/.

Murphy, D.R., R. Walker \& J. Webb 2001. Online Learning: Teaching with Technology. London: Kogan.

Ngqakamba, S. 2020. Fort Hare University to Issue Laptops, Data as it Moves to Online Learning. Available at:

https://www.news24.com/news24/ SouthAfrica/News/lockdown-forthare-university-to-issue-laptops-data-as-it-moves-to-online-learning20200430.

Nguyen, H. \& T. Pham 2020. COVID-19 an Opportunity to Strengthen Online Teaching? Available at: https://www.universityworldnews.com/post. php?story $=20200512154252178$.

Nuemann, W. 2020. Lives of our Children Matter and Schools should Open Only once it Truly is Safe for Them. Available at:

https://www.iol.co.za/ capeargus/opinion/lives-of-our-children-matterand-schools-should-open-only-once-it-truly-is-safe-for-them-47132507 
Nyamnjoh, A. 2017. The Phenomenology of Rhodes must Fall: Student Activism and the Experience of Alienation at the University of Cape Town. 2017. Strategic Review for Southern Africa 39,1: 256 - 277.

Paul, A. \& J.M. Case 2018. Introduction. In Paul, A. \& J.M. Case (eds): Higher Education Pathways: South African Undergraduate Education and the Public Good. African Higher Education Dynamics. Series 4. Cape Town: African Minds.

People's Coalition 2020. Public Universities with a Public Conscience: A Proposed Plan for a Social Pedagogy Alternative in the Time of Pandemic. Available at:

https://c19peoplescoalition.org.za/statement-plan-for-a-social-pedagogy/ Reed, D. 2019. 9 Benefits of e-Learning for Students. Available at: https://studybreaks.com/tvfilm/elearning-benefits/

Rodny-Gumede, Y 2020. Universities can Use this Covid-19 Moment to Reinvent the Way they Teach. Available at:

https://www.timeslive. co.za/sunday-times/opinion-and-analysis/ 202004-19-universities-can-use-this-covid-19-moment-to-reinvent-the-waythey-teach/

Rosemead, B.B. 2020. Letters to the Editor: Technology can't Replace Teachers, and Coronavirus Closures Prove it. Available at: https://www.latimes.com/opinion/story/2020-04-05/technology-cannotreplace-teachersr-coronavirus.

SABCNewsOnline 2020. UJ's Online Learning Decision met with Virtual Protest. Available at:

https://www.sabcnews.com/sabcnews/ujs-online-learning-decision-metwith-virtual-protest/.

Sampson, D., P. Isaias, D. Ifenthaler \& M. Spector 2013. Ubiquitous and Mobile Learning in the Digital Age. New York: Springer.

https://doi.org/10.1007/978-1-4614-3329-3

Segar, S. 2020. Already on the Back Foot, can Fort Hare Save its Academic

Year? Available at: https://www.universityworldnews.com/ post.php?story=20200506123543639.

Serdyukova, N. \& P. Serdyukov 2014. e-Pedagogy: A Model for Online Education. Available at: http://www.aabri.com/ HC2014Manuscripts/ HC14024.pdf.

Shoba, S. 2020. As South Africa Goes into Lockdown, Higher Education Department Prepares for Online Learning. Available at: 
https://www.dailymaverick.co.za/article/2020-03-24-as-south-africagoes-into-lockdown-higher-education-department-prepares-for-onlinelearning/.

Somekh, B. \& D. Mavers 2010. Mapping Learning Potential: Students'

Conceptions of ICT in their World. Assessment in Education: Principles,

Policy \& Practice 10,3: 409 - 420.

https://doi.org/10.1080/0969594032000148217

Staff Reporter 2020. This is How SA Varsities are Implementing Online

Teaching amid Covid-19 Lockdown. Available at: https://www.iol. co.za/capeargus/news/this-is-how-sa-varsities-are-implementing-onlineteaching-amid-covid-19-lockdown-46930129.

Swingler, H. 2018. Academics Conflicted by Blended Learning during Protests. Available at: https://www.news.uct.ac.za/article/-2018-07-24academics-conflicted-by-blended-learning-during-protests .

University of Cape Town 2017. Online Education Policy. Available at: https://www.uct.ac.za/sites/default/files/image tool/images/328/about/po licies/Online Education Policy 2017.pdf.

UNESCO 2020. 1.37 Billion Students now Home as COVID-19 School Closures Expand, .... Available at: https://en.unesco.org/news/137billion-students-now-home-covid-19-school-closures-expand-ministersscale-multimedia.

University of the Western Cape 2020. Backabuddy: Where Cause Meets

Crowd. Available at:

https://www.backabuddy.co.za/charity/ profile/uwc\#associatedprojects. Vygotsky, L.S. 1987. The Collected Works of L.S. Vygotsky. New York: Plenum.

Lungi Sosibo Head of Department Senior Phase and Further Education \& Training Cape Peninsula University of Technology Mowbray, Cape Town SosiboL@cput.ac.za 


\title{
Leadership amidst the COVID-19 Crisis: Exploring a Curriculum for Servant Leadership in HE and Beyond
}

\author{
Kasturi Behari-Leak \\ ORCID iD: https://orcid.org/0000-0001-9744-510X \\ Suren Behari \\ ORCID iD: https://orcid.org/0000-0002-8700-2644
}

\begin{abstract}
The novel Coronavirus (COVID-19) has spread rapidly across the globe, leaving practically no-one unaffected. Evidence suggests that this virus does not discriminate against anyone: every race, gender, class, faith, ethnicity and nation has experienced disorder as a result. It is a demonstration of our common humanity, of our sameness. Through participant observations, the authors, located in South Africa and the United States, offer personal perspectives, observations and experiences of leadership practices at local, national and international levels. By means of this chapter, they explore how leadership as agency can be strengthened and consolidated in the Higher Education curriculum. The chapter draws on the scholarship and theoretical principles of leader-less and leader-full models, to advance an argument for 'servant-leadership' at the individual, community, organisation, national and global echelons of society. The proposed action-oriented leadership curriculum is based on a model of servant leadership that encourages us all to work together to devise ways to make each individual and citizen more capable of managing and responding to change and disruption in critical, empathic and socially responsive ways.
\end{abstract}

Keywords: COVID-19 pandemic, Higher Education Curriculum, Theory of Change, Leader-less, Leader-full, Servant Leadership 


\section{Introduction}

The Coronavirus (also known as COVID-19) is currently a household name everywhere. It has earned this status at the micro-level of the family unit, but also at the macro-level of governments and multinationals (Cho 2020). Not for prestigious reasons though, but as an uninvited guest. It has taken a seat at the proverbial table and occupies our consciousness from when we wake up until we bed down. Household routines and chores are punctuated with the latest news bulletins, social media feeds and WhatsApp discussions on the trajectory of the virus, not just locally but across the globe. It has become the "new normal' by dominating our discourse and demanding our attention in every way possible and we are constantly aware of the presence of the imminent threat of our uninvited guest, even if our families are safe and not (yet) infected. Some argue that life will never be the same again. Social, political, economic, environmental, technological, legal and other spheres of life as we knew them, will not be able to revert to a business-as-usual mode, post-COVID-19 (Muller 2020). Perhaps we should ask, should it?

COVID-19 has spread throughout the world indiscriminately, showing no respect for geopolitical borders or all the markers of difference that usually separate us into 'Us' and 'Them'. Despite this, we have rallied together across the globe to protect ourselves from a new colonizer that has occupied our mental, physical and social bodies. In an ironic twist of fate, while the virus has kept us apart through social distancing protocols, it has also united us in a common fight against it. If the COVID-19 crisis has taught us anything, it is that we, independently and collectively, can affect a system. We are alone, together (Turkle 2011).

As participant-observer-authors located in South Africa (SA) and the United States of America (US), alone and together, we are inspired by the strong demonstration of individual and collective agency by both civilians and governments across a diverse spectrum of organisations, institutions and social contexts during the crisis. We believe that Higher Education (HE) can learn much from this agency by leveraging what people have done during the crisis to build a critical and active citizenry through education for the future. In this chapter and acknowledging the great efforts by our leaders thus far, we explore alternative forms of leadership, such as servant leadership, relevant to these times. We conceptualise leadership as a form of agency, negotiated as shared understandings among a group of interacting individuals. Leadership from this perspective is seen as a process in which one harnesses the agentic capabilities 
of others, to serve goals that lie beyond any one individual (Spender 2008) in service of the community they belong to.

We explore how leadership as agency can be strengthened and consolidated in the HE curriculum in the future to incorporate the gains made in the social sphere right now. We draw on the scholarship and theoretical principles of leader-less and leader-full models, to advance an argument for servant-leadership at the individual, community, organization, national and global strata of society. We propose that this can be amplified through a taught curriculum on leadership, from primary to tertiary levels. Such a curriculum model would need to engender a deeper dialogue with broader constituencies outside the academy, to embed a more inclusive and socially just transdisciplinary curriculum with an explicit focus on individual and collective agency (Klemenčič 2015), understood as an alternative genre of leadership.

As scholar-practitioners, we use our lived experiences in organizational and institutional work in both the US and SA to offer personal perspectives, observations and experiences of leadership practices at local, national and international levels. By offering insights into a new social technology that requires a deeply reflective inner journey, we explore the leadership capabilities that reside in us all. This chapter thus serves to inspire each individual to rise to the occasion, see their potential, and understand the need for us all to show up and stand up as leader-full leaders, especially when leading from the wings.

\section{Higher Education amidst COVID-19}

The Coronavirus Disease 2019 (COVID-19) has had massive and overarching ramifications in $\mathrm{HE}$ globally (Abbey et al. 2020). The unprecedented pandemic has cast a dark cloud of uncertainty and fear on the completion of the academic year, in an increasingly tenuous and unpredictable situation. HE has been challenged to re-invent itself and re-imagine different scenarios to keep the academic project afloat, at minimal cost to all.

In South Africa, the unanimous decision to migrate the academic project to online teaching and learning in an Emergency Remote Teaching (ERT) mode, has drawn acute attention to the extant deep fissures and unlevelled schisms of inequality in education, already present in the face-toface mode (F2F), especially in under-resourced contexts (Macupe 2020). The crisis has also revealed deep gaps across differentiated institutions nationally. 
In a country like South Africa, riddled with deep social and financial inequalities, the ethical question of who will be left behind is an imperative. Social justice concerns such as these make the gap between the privileged communities and their counterparts stark and exacerbates an already fragile link between those who have and those who do not have. Economic, social, cultural, personal and collective injustices are still at play in $\mathrm{HE}$, even though in a different mode (MacGregor et al. 2020).

In the US, Harvard University announced that the university would be transitioning to virtual instruction on 10 March 2020, until further notice (Sidamon-Eristo 2020). Many other colleges and universities quickly followed suit, and virtually overnight, a huge share of the nation's roughly 15 million college students found themselves taking their spring classes online from home, using platforms such as Zoom, and other video conferencing platforms (Sidamon-Eristo 2020). The traditional model of HE in the United States has been a four-year residential college programme that includes life on campus, with lectures, seminars, labs, dorms, social and cultural activities, and institutionalized sports. This comes at an increasingly unjustifiable cost, though. While moving instruction online offers a unique opportunity to reinvent the traditional residential campus model, student debt has more than quadrupled over the last 15 years (Cadden 2020).

Student debt also disproportionately burdens disadvantaged and vulnerable students, whose communities have historically experienced many barriers to higher education (The Citizen 2020). Thus, instead of being an equaliser to close the wealth-gap between the rich and the poor, higher education in the US seems to reproduce inequality. It increases the indebtedness of communities who already suffer from high levels of income insecurity and economic precarity. It reinforces the cycle of poverty and the paycheck-to-paycheck life many marginalised families are forced to live, even if they are better educated. The economic fallout of the pandemic threatens to make this situation that much worse.

Given the two geographical contexts discussed above, in relation to HE responses to COVID-19, it is evident that those students who are the most vulnerable now are going to be far worse off post COVID-19. Whether it is due to student debt, no access to data, connectivity issues or an inability to navigate asynchronous on-line learning independently, students globally will have an incommensurate ability to embrace the new platform and online mode of $\mathrm{HE}$, as a result of the unequal playing fields already in place now, in the F2F 
mode (Cadden 2020).

While we appreciate that this unprecedented situation has pushed the academy to take extreme and quick decisions to manage the crisis, we question whether this pandemic is allowing us to tap into the best expertise and knowledge that $\mathrm{HE}$ can offer society. If we look at how university curricula, programmes, disciplinary expertise and other specialist units and resources are being deployed now, we do have to ask a deeper question about whether we are applying our intellectual and social capital and resources in relevant, responsive and collaborative ways. Are humanitarian and collaborative concerns at the centre of our HE solutions to COVID-19?

A related question we pose here is the question of what forms of leadership are needed now so that no-one is indeed left behind. People live and interact in a social field or in community, and unlike the dominant tradition of centring leadership within the individual (Raelin 2011), leadership emerging from a social field can find expression as an outcome of social interaction and social construction among people who share intersubjective meanings to build collective consciousness of the community (Hosking 2000). Scharmer (2009) describes a social field as having a visible dimension, where we see what people are doing and how they are making decisions and an invisible dimension, where we see the source and interior condition from which we operate. Could these pathways to social fields be translated into a curriculum offering in $\mathrm{HE}$ to teach students how to be leaders and how to deal with change, complex as it is?

\section{3 (How) can We All be Architects and Agents of Change?}

Whenever an organization experiences a transformation, be it a simple change in policy or a complex organizational shift, it is not uncommon to hear the questions: Who is driving this change? Is there a change manager? Your response should be: It's you. We all need to be architects and agents of change in this crisis as we move forward. We are cognizant that contextual aspects prevent people from rising to the challenge but through education programmes we could all learn how to step up, raise our hand and become an active part of the change, by defining and driving the outcome of the change for the benefit of all. It is important for each of us to awaken the leader and change-maker within us because we all have the potential to lead and manage change by looking inward and outward (Boaz \& Fox 2019). 
In the COVID-19 crisis, people across the globe have shown that they are leaders in their own right, faced with the challenge of managing their lives and their families, the sick, elderly, infants, communities, work, home schooling, deaths and funerals, religious service, financial woes and mental health issues in this crisis (Tamrat \& Tefferra 2020). While most people have been compliant in flattening the curve, very few are waiting for direction on what to think, how to think and how to act in their own lives, especially in lockdown. People across the spectrum, in all spheres of life are demonstrating their collective and individual agency by responding creatively and passionately in authentic ways. People have shown that they are not always static until mobilized by others, making agency an intersubjective collaborative process that can reproduce and change our social realities (Scott \& Bhaskar 2015). At the heart of it, when faced with life or death, it seems that people possess tacit knowledge on how to lead from their experience and practice. They use some sort of implicit theory of change to marshal their efforts and garner a unique energy at both intellectual and emotional levels to make themselves heard and felt, and to do what it takes to be safe.

We are advocating a similar change in HE curricula to ensure that students and academics are in a position to learn how to be change agents and innovative leaders in times of any crisis. By exploring their agency through education, students and staff might be able to use their circles of influence to expand the effects outwards. While COVID-19 is an acute crisis affecting us all now, many people live with chronic crises daily as a result of inequality and social injustice. In South Africa, the student protest years of 2015-2017 were a period of intense crisis and change, but also a time of significant gains. We began to see disruption as a necessary intervention to reimagine the university's practices and traditions in the interest of social justice and redress. In their book entitled Leading Schools in Disruptive Times - How to Survive Hyper-Change, Carter and White posit that 'education leaders must recognise what is happening, constantly adapt to a changing environment, and use the disruptions to their advantage' (2018: 19).

Through its disruption of lives, the COVID-19 experience should yield similar benefits for $\mathrm{HE}$, in recognizing the need for students and academics to be agents and architects of change, who can learn how to use their individual and collective agency to rally together for the benefit of the whole. This agential response to change is what we are theorising in this chapter as servantleadership, which will be discussed under the Prospective Leadership Frame. 


\section{A Proposed Curriculum for Servant-leadership}

Drawing on key concepts in leadership theory, we propose a new curriculum offering for all students, from primary to tertiary levels, to provide opportunities to develop their innate leadership skills. This will vary across cohorts depending on cultural and contextual factors but we believe it would be an important gain of the crisis if we could leverage this to make all our students future-ready, as graduates and concerned citizens.

This curriculum suggests a particular epistemological thread, linked with the key ontological arguments advanced thus far, i.e. our sense of individual being is explicitly linked to our social being. The coherence between these two onto-epistemic domains will ensure that the knowledge generated will aspire to be socially just and socially aware. Future leaders (our students) will engage in scholarly/experiential praxis to get a solid grounding in models of social leadership that prepare them to react and response to any critical crisis they face, but with a keen understanding that no one should be left behind. Motsohi (2018), in his book Fit For Purpose, lists the following key attributes for successful leaders during turbulent times: exceptional courage; putting the public interest first; integrity and self-discipline; high ethical standards; political/social/economic sensitivity or contextual intelligence; inclusiveness; flexible and adaptable leaders and ability to communicate. We think that these dispositions would be relevant for the envisaged cohort of future servantleaders.

In our proposed curriculum, leadership knowledge and praxis are vital components (Buschlen \& Guthrie 2014) to ground leadership practice in real contexts. The rationale is to offer generative and emerging options for $\mathrm{HE}$ in this crisis and beyond, based on what we have gleaned from across the globe thus far. We believe that a curriculum module on servant-leadership should be embedded in each course, at different levels of complexity and challenge, from inception to graduation and linked to the disciplinary content of the course. Throughout a student's education trajectory, they should engage with servantleadership practices linked to their courses to enable them to think critically, socially and academically about how we can change the world for the betterment of all.

We present this proposed curriculum in three frames: retrospective, circumspective and prospective (Behari-Leak 2015). All three frames are critical for a holistic and well conceptualised leadership curriculum. We will 
now expand and unpack each frame by reflecting on relevant theory in relation to our specific geographical and social locations in South Africa and the US. This does not mean that these ideas cannot be applied equally well to other contexts too.

\subsection{Retrospective Leadership Frame}

This frame involves critically analysing past models of leadership to assess whether past exemplars of the leader-follower model serve us best today and if these are relevant and appropriate for our context right now. Leadership scholarship has traditionally used specific models of management and organisational intelligence to define leadership knowledge as a reliance on learning from past experiences and past leaders (Maxwell 2011). This genre also traces the history of conventional and cultural leadership models in organisations, education and government (Quantz et al. 2016).

In this frame, students would need to critique the leader-follower model, in relation to its reliance on attributes of leaders in command of a situation or as individuals who are exceptional compared to their followers. Leadership in this frame is understood as an individual property or the physical or mental capacity of any one individual (Neculae \& David 2017). Individual property, however, cannot be disentangled from its context. Leadership in this sense cannot be decontextualized from its source and its intention.

Also known as 'command-and-control leadership', this model has been touted across cultural groups as a decisive model to acquiesce people's anxiety in a crisis of uncertainty and prospective failure (Groysberg \& Slind 2012). The need for a command-and-control leader is premised on a weak theorization of the follower as always having experiential and existential anxiety, which a leader then assuages as part of this dyad (Grint 2010). Followers are thought of as incapable of exercising authentic internal authority or authoring their own agency (Woods 2004).

This individualistic account of leadership which constitutes a dominant view to date, surfaces many blind spots in the COVID-19 moment. In South Africa, we have seen abuse of this model when the army and defence forces were summoned to enforce the COVID-19 protocols and regulations, with devastating effects on poorer communities. Research has shown that coercive state measures are generally less effective than steps that leverage the moral norms within society (Paterson 2020). 
Command-and-control leadership is based on an influence relationship between leader and follower which can quickly translate into leaders' (mis) use of their position to promote self-interests, narcissism, patriarchy and dictatorships through protracted terms of office, for example. In South Africa, corruption has been a particular challenge and leadership has been embroiled in protracted legal action in this regard (Sibanda 2020).

\subsection{Circumspective Leadership Frame}

This frame involves looking around at our current circumstances in light of COVID-19, to critically assess the present models of leadership best suited to the context today. This challenges us to consider the most appropriate solutions needed as well as the process of arriving at these solutions. We need to question in whose interests, decisions are being made and whose interests are being served. We have an ethical obligation as social beings to ensure that all interests, especially those under- or not represented in decisions taken already, are widely canvassed. Inclusion of all voices, especially the poor, downtrodden, homeless, jobless and other vulnerable sectors is critical now as we come together as a global community. With COVID-19 ushering in a new global society and renewed ways of being human in a technology-high world, we need to redefine, now more than before, what it means to be relational human beings and decide what kind of future society we want to live in and co-create (Kolzow 2014).

Relational leadership derives its signature from the interconnectedness among social actors (Sklaveniti 2016). It occurs beyond hierarchical roles and positions and endorses a culture of learning and participation within and across a system. In such an ethos, change agents are supported at multiple levels (Raelin 2011) to come into their own. Relational leadership privileges the development of independence and interdependence and rely on reflexive discourse to be conducive to the many forms of public engagement needed (Raelin 2011), especially in the crisis we face now, to ensure that all perspectives are considered.

In the US, an example of relational agency and collective leadership in this time of crisis, is the initiative that medical students at Harvard Medical School undertook by developing, writing, and compiling a curriculum on COVID-19 (HMS COVID-19 Student Response Team 2020). The inspiration for these students' creativity came from the need to deepen their knowledge of 
the situation but to also share with their peers, who did not have the time and resources to do so. Students recognized the lack of clarity in the current moment as well as the uncertainty regarding the future. As a service to the community, and the world at large, this team of students collated and synthesized the vast volumes of information and data about the pandemic into a curriculum of eight modules that are constantly updated as new information on the pandemic surfaces (Buckley 2020).

The public's response to COVID-19, although determined in large part by nation state protocols and regulations, have been organic and creative. In smaller communities where religion, spiritual practice and cultural exchange are important, people have come into their own by using creative ideas to hang on to practices that they hold dear. Online Easter masses, music concerts across the globe, house parties and zoom parties show a kind of leaderless action, initiated to address common needs. As social beings who thrive on human contact, touch, hugs and closeness, we have been challenged to be as inhuman as the virus is, complying with lock down imperatives to be confined in our homes. The simple humanitarian act of clapping or singing from balconies to acknowledge the sacrifices of those in essential services is a demonstration of relational agency and leadership. This form of spontaneous leadership, not imposed by the authorities, is thought of as leaderless leadership which shows the huge potential people have to think collectively, outside the national protocol box and to come up with ways to address their needs (Taggart 2016). The leaderless movements are an example of collective leadership that show how decision-making happens through transparent, open, honest and public dialogue as an important mechanism of democracy. The organisational ability of leaderless movements shows how traditional power can be reimagined and re-purposed through social media for example.

Another leadership practice relevant to our proposed curriculum in this frame is a form of leadership known as leaderful (Raelin 2011) practice. This stems from the work of organizational developers and psychologists who see leadership as being 'full' of components that people can achieve together through the practice of and emergence of leadership in context and as a lived practice (Raelin 2011). Leaderful practice is based on the principles of being collective, concurrent, collaborative and compassionate (Raelin 2011). Compassionate leadership, where people commit to preserving the dignity of every single member of the group, regardless of background, status, or point of view (Raelin 2011), is needed more than ever to make sure no one is left 
behind through this crisis.

In Africa, an online letter from more than 90 African intellectuals (including Wole Soyinka) to African leaders about the continent's handling of the COVID-19 pandemic, captures critical perspectives on the need for compassionate leadership (Zevounou, Niang \& Sylla 2020). In a related article entitled 'On the necessity to govern with compassion', the authors make a plea to all leaders to seize the opportunity of the coronavirus crisis to join efforts in re-thinking an African state in the service of the well-being of its people.

Leaderful practice is based on a democratic ideology that calls for the co-creation of a community. An example of leaderful practice at scale in the US, is the way artists of different music genres, such as Lady Gaga, Paul McCartney, The Rolling Stones, Billie Eilish, Taylor Swift, Lizzo, Celine Dion and Andrea Bocelli collaborated, alone and together, to provide live streams of entertainment to empathize with society (Christian 2020). With this gesture these artists put everything aside to celebrate and support healthcare workers in the frontline during this pandemic, demonstrating leader-full practice from the wings.

The proposed curriculum is based on a similar conceptualization of leaderful practice. The aim is not to teach about leadership or teach lists of traits to aspiring leaders (Mintzberg 2004) but to engage with it as praxis. We assert that by embedding leadership as a theorised practice in the curriculum, we will enable every student, academic, administrator or any other stakeholder, to bring their experience into the proverbial classroom, to develop a form of leadership gaze as a rich source of learning how to respond to challenging situations from multi-disciplinary and social perspectives.

In South Africa right now, mainly medical experts have been called in to find solutions to the COVID-19 crisis (Paterson 2020). This one-sided approach totally ignores the social scientists who have much to offer to bolster the effectiveness of the government's response (MacGregor et al. 2020). In other countries, social scientists, such as historians, specialists on philosophy and law and pedagogical experts have been called in with medical experts to address key ethical and political issues around state responses by asking 'difficult questions' about the pandemic that might otherwise go unanswered. The lockdown, in South Africa, for example, has been disastrous for a vast majority of citizens who exist below the bread line and live in appalling conditions in informal settlements and townships across the country. Using leaderful practice in this context would ensure that these diverse perspectives 
would be used to make sure that all South Africans are represented at the table and that relief is forwarded to those most affected by the virus.

Similarly, in the United States, the COVID-19 outbreak has highlighted the economic inequalities and a fragile social safety net that leaves vulnerable communities to bear the economic brunt of the crisis. Inequality in the US is rarely in the spotlight when compared to South Africa, but evidently very present. While the virus infects people regardless of wealth, the poor in the US are most affected due to longstanding segregation by income and race, reduced economic mobility, and the high cost of medical care. Low-income communities are more likely to be exposed to the virus, have higher mortality rates, and suffer economically. In times of economic crisis, these vulnerabilities will be more pronounced for marginal groups, identified by race, gender, and immigration status (Ro 2020). In the US, economic inequality is closely linked to a racial divide in income and wealth. Incomes and wealth are lower, and poverty is the most acute among Blacks and Latinos (IQ Latino 2020).

Leaderful practice is also understood as being embedded in the social sites where temporary clusters of events, people, and meaning compose one another (Schatzki 2005). We have seen leader-full clusters of events in action across the globe as a new paradigm of research communication is emerging to respond to immediate needs of these times. Ordinary people, not just academies, are writing prolifically now, using social media and technology to disseminate their perspectives and insights. Articles, thought pieces and academic papers are now shared exponentially, making the drawn-out journal publication cycles seem superfluous. These alternative methods are immediate, informative, rich, contextualized and in real-time. The timing and immediacy of online publications such as tweets and blogs mean that academics can easily be shoulder-tapped to respond in the here and now and in ways that have direct impact and use. This contributes to collaborative knowledge generation, which in turn shapes people's thoughts and action in the crisis. The university can no longer claim it is the only (or most legitimate) source of credible and powerful knowledge, now or in the future.

\subsection{Prospective Leadership Frame}

This frame involves looking to the future (from where we are located now) to envisage emerging patterns and to learn from what is surfacing from futureoriented models of leadership. In the time of COVID-19, we are being 
awakened to a new world, one that is making space for a new global society, new awareness and new ways of thinking, where new mental and social structures are emerging. We need new forms of leadership to embrace these future-oriented schema and frames.

In a Prospective Leadership Frame, we are interested in looking ahead of the curve, to see what future-ready models of leadership will be contextually appropriate to the collateral damage and gains of COVID-19. It is going to take a long while before countries, universities and students who were in a compromised position before the crisis, recover and get back on their feet. What kinds of future-ready leadership are needed to recuperate a compromised system, dented in human and fiscal resources by the virus?

A prospective frame allows us to think about future-ready leadership as a public good; not an individual property or middle-class value. A public good perspective is in alignment with the African philosophy of Ubuntu (Ramose 2019) which is based on a relational view of existence.

In South Africa, the losses incurred have been disproportionately placed on our most vulnerable and high-risk citizens. There is a need to use our agency and our historical and social context and resources to value every human being regardless of status, over and beyond any logic of profit-making, domination or power capture (Zevounou, Niang \& Sylla 2020). To assist this, leading social scientists are calling for greater inclusion and involvement in contributing to mitigation policies regarding financial and other losses due to the COVID-19 virus.

In the US, the scale of the coronavirus crisis calls to mind $9 / 11$ or the 2008 financial crisis - events that reshaped society in lasting ways, from how we travel and buy homes, to the level of security and surveillance. For many American companies right now, navigating the COVID-19 crisis is a complex managerial and leadership challenge (Buckley 2020).

Across the globe, there is a need to do things differently. Business-as-usual might be something of the past post-COVID-19 and we need to be prepared to tackle the future (which is already here in many ways), with new lenses, paradigms and practices. In this frame, we foreground a contemporary model of leadership theory and practice, namely Servant-Leadership, which originated in the writings of Greenleaf (1977). While servant leadership is an oxymoron because it defies a common sense understanding which seems incongruent with leaders being servants at the same time (Shinagel 2016), it is an approach that offers a unique perspective to HE. 
Although servant leadership has been of interest to scholars for over four decades, most academic and non-academic writing on the theory has been prescriptive, focusing on how servant leadership should ideally be, rather than focusing on what servant leadership should do (Van Dierendonck 2011). Servant leadership challenges our assumptions about the traditional, hierarchical mode of leadership (Allen et al. 2016) which we have internalised as leaders who influence with a sense of authority, while others follow. Servant leadership invites us to consider a model based on community, teamwork and involving others in decision making (Greenleaf 2003). Servant leaders have a strong calling to serve others and are humble, neither needing nor seeking recognition for achievement and success (Wheeler 2012). Other core attributes include authenticity, self-awareness, responsibility, moral courage, and wisdom. According to Northouse (2016),

Servant leadership begins with the natural feeling that one wants to serve, to serve first. Then the conscious choice brings one to aspire to lead ... The difference manifests itself in the care taken by the servant - first to make sure that other people's highest priority needs are being served. The best test ... is: do those served grow as persons; do they, while being served, become healthier, wiser, freer, more autonomous, more likely themselves to become servants? (Northouse 2016: 225256).

A contemporary US corporate exemplar of servant leadership in action is the Starbucks ${ }^{\circledR}$ Coffee Company owning 39.8\% of the US Coffee Market. Starbucks ${ }^{\circledR}$ describes its organizational culture as, 'a culture of belonging, inclusion and diversity' (Starbucks 2020b). The primary pillars of Starbucks' organizational culture are Servant Leadership, Relational-driven approach, Openness, and Inclusion and Diversity. The company's motto With our partners, our coffee and our customers at our core, we live these values ... (Starbucks 2020a), is an excellent example of servant leadership to improve organizational performance.

Servant leadership could be introduced in HE if leadership is attentive to the concerns of their followers, empathize with them, and support them (Allen et al. 2016). Servant leaders put followers first, empower them, and help them develop their full personal capacities (Russell \& Stone 2002; Mahembe $\&$ Engelbrecht 2013). Furthermore, servant leaders are ethical and lead in ways 
that serve the greater good of the organization, community, and society at large (Spears 2010). There is an abundance of literature that deals with servant leadership and higher education (provide a few sources here to strengthen this argument), however, literature on servant leadership and higher education during times of crises is scarce.

There are many synchronicities between Servant- and TeacherLeadership, where both forms of leadership are emergent and focused on the actions one takes rather than a position, authority or title (Northouse 2016). Today's leaders in higher education should adopt a more holistic approach and future-orientation to individuals' development, by cultivating a disposition that is in service of the people they lead - their students. Traditional teacher-centred classrooms that focus mainly on what the teacher does and says, amplify the teacher in a position of power as knowledgeable expert, while students are seen as passive recipients of the curriculum and knowledge.

When servant leadership is applied to the HE classroom, it can change the power dynamics between teacher and students by placing the student at the centre of all pedagogical engagements so that students are active, participative and collaborative (Biggs 1999). This mirrors some of the central tenets that servant leadership advocates, namely putting the needs of other first, sharing power, helping individuals develop and optimising performance (Allen et al. 2016). Servant leadership also helps with community building and trust in classroom spaces (Spears 2010) through the teacher's or servant leader's commitment to individual growth to cultivate an environment of academic freedom and effective scholarship (Allen et al. 2016). Certain characteristics of the servant leader such as listening, empathy, healing, persuasion, awareness and foresight are dispositions that caring and effective university teachers want to emulate as well (Spears 2010).

In the US, there is evidence that only about a 100 universities teach servant leadership in the classroom, as part or all of a class on leadership (Greenleaf Center for Servant Leadership 2010). There are a number of institutions in the US that offer servant leadership as degree, non-degree, certificate, noncertificate, online and campus-only programmes (Modern Servant Leader 2020). These programmes have an emphasis on service learning but this is not what we are proposing.

We are advocating a curriculum that locates servant leadership as a critical intervention for dealing with crises, such as the current COVID-19 crisis. Servant leadership should be cultivated in the classroom at all 
educational levels, from elementary, middle, and high schools through to higher education (Mattingly 2014). Servant leadership should not only be offered as a stand-alone course or programme, but the elements of servant leadership should be embedded into the curricula of every subject, course, or programme taught. It is also imperative to shift from service learning to servant leadership.

\section{Conclusion}

At some point, the Covid-19 pandemic will come to an end, and most aspects of daily life might return to normal, but HE may never be the same again. Our colleges and universities are now engaged in the largest, most drastic, and most disruptive technology-enabled pedagogical experiment. Unless we take the time to pause now and take care of everyone, marginalized students will find it difficult to succeed through and after the crisis. In South Africa, this is evidenced by students from these communities who continue to have internet connectivity challenges, availability of data, studying in conditions that are not conducive to support success, etc. This will have a ripple effect on the families that they intend to support financially, and this will impact the economy negatively in general. If a knowledge economy is what we are investing in, the outcome of this crisis will be counter-productive to the sustainability of those objectives in the long run.

The curriculum we have proposed is based on a range of leadership models that encourage us all to work together to devise ways to make each individual and citizen more capable of managing and responding to change and disruption in critical, empathic and socially responsive ways. We highlight the aptness of servant-leadership as a model for crises as it responds directly to the needs of those in crisis and encourages all people to take responsibility and exercise their agency in meaningful ways.

In $\mathrm{HE}$, this brings attention to the need for agency to be foregrounded as important and necessary in educational practice in the class and for conditions to be created for students and academics to practice their agency in ways that make a difference in the world by mobilizing social actions.

We assert that even in varying degrees, everyone is fit to lead and must be supported to do so, in any and all aspect of their lives. Nelson Mandela proclaimed, 'The youth of today are the leaders of tomorrow'. That proclamation has never been truer than today. The current leadership in power 
has a duty to cultivate the servant leader in our youth so that they are equipped to persuade, heal, listen, and empathize. Everyone has leadership capabilities, but often these leadership traits that reside within an individual remain dormant because they were never cultivated as a child. It is vital to awaken the leadership potential in our youth today in order to prepare them for their future that lies ahead. This links to earlier discussions in this chapter on relational, collective, collaborative, decentralized, and leaderful practices that constitute a leader in service of the needs of the community, society, or organization they serve.

In conclusion, we advocate an action-oriented leadership curriculum that serves the public good and does not become a middle-class value that inheres only for the privileged. In this way, we imagine that all, especially the marginalised and vulnerable students and their communities, will be taught the means through which they can exercise agency in their own lives, even though beholden to the nation states in which they live and on which they depend. Such an intervention seeks to preserve the humanity and dignity of those less able to have control over their lives right now, in the COVID-19 crisis.

\section{References}

Abbey, E., E. Adu-Danso \& E. Aryeetey 2020. Research Universities' Multiple Responses to COVID-19. University World News: Africa Edition.

Available at: https://www.university worldnews.com/post.php?story $=20200420091917110$

(Accessed on 3 April 2020).

Allen, G.P., W.M. Moore, L.R. Moser, K.K. Neill, U. Sambamoorthi \& H.S. Bell 2016. The Role of Servant Leadership and Transformational Leadership in Academic Pharmacy. American Journal of Pharmaceutical Education 80, 7. https://doi.org/10.5688/ajpe807113

PMid:27756921 PMCid:PMC5066916

Behari-Leak, K. 2015. Conditions Enabling and Constraining the Exercise of Agency among New Academics in HE, Conducive to the Social Inclusion of Students. Unpublished doctoral dissertation. Rhodes University, South Africa,

Biggs, J. 1999. What the Student Does: Teaching for Enhanced Learning. Higher Education Research \& Development 8, 1: 57 - 75. https://doi.org/10.1080/0729436990180105 
Boaz, N. \& E.A. Fox 2019. Change Leader, Change Thyself: Anyone who Pulls the Organization in New Directions must Look Inward as Well as Outward. Available at:

https://www.changemakercommunities.org/thought-pieces-

full/2019/2/25/change-leader-change-thyself

(Accessed on 10 June 2020).

Buckley, M.R.F. 2020. A COVID-19 Curriculum. Available at: https://hms.harvard.edu/news/ covid-19-curriculum (Accessed on 10 June 2020).

Buschlen, E. \& K.L. Guthrie 2014. Seamless Leadership Learning in Curricular and Cocurricular Facets of University Life: A Pragmatic Approach to Praxis. Journal of Leadership Studies 7, 4: 58 - 64.

https://doi.org/10.1002/jls.21311

Cadden, L. 2020. Young People Need a Bailout: Cancel Student Debt Held by National Banks. Mail and Guardian. Available at:

https://mg.co.za/education/2020-05-08-young-people-need-a-bailoutcancel-student-debt-held-by-national-banks/ (Accessed on 2 May 2020).

Carter, D. \& M. White 2017. Leading Schools in Disruptive Times: How to Survive Hyper-change. California, USA: Corwin Press.

https://doi.org/10.4135/9781506384337

Cho, E. 2020. Examining Boundaries to Understand the Impact of COVID-19 on Vocational Behaviours. Journal of Vocational Behaviour 119, Article 103437. https://doi.org/10.1016/j.jvb.2020.103437

PMid:32390657 PMCid:PMC7205716

Christian, C. 2020. One World Together at Home Concert Highlights: All the Best Bits from Taylor Swift to Celine Dion, Lady Gaga and Andrea Bocelli. The Union Journal. Available at: https://theunionjournal.com/one-world-together-at-home-concerthighlights-all-the-best-bits-from-taylor-swift-to-celine-dion-lady-gagaand-andrea-bocelli/ (Accessed on 4 May 2020).

Crippen, C. \& J. Willows 2019. Connecting Teacher Leadership and Servant Leadership: A Synergistic Partnership. Journal of Leadership Education 18, 2. Available at:

https://journalofleadershiped.org/jole articles/connecting-teacherleadership-and-servant-leadership-a-synergistic-partnership/ (Accessed on 10 June 2020).

https://doi.org/10.12806/V18/I2/T4 
Greenleaf Center for Servant Leadership 2010. Servant Leadership in Higher Education: Issues and Concerns. Available at:

https://www.greenleaf.org/ (Accessed on 2 May 2020.)

Greenleaf, R.K. 1977. Servant Leadership: A Journey into the Nature of Legitimate Power and Greatness. New York, NY: Paulist.

Grint, K. 2010. The Sacred in Leadership: Separation, Sacrifice and Silence. Organization Studies 31, 1: 89 - 107.

https://doi.org/10.1177/0170840609347054

Groysberg, B. \& M. Slind 2012. Leadership is a Conversation. Harvard Business Review 90, 6: 76 - 84.

HMS COVID-19 Student Response Team. 2020. Medical Student COVID-19

Curriculum. Available at: https://curriculum.covidstudentresponse.org/ (Accessed on 2 May 2020.)

Hosking, D.M. 2000. Ecology in Mind, Mindful Practices. European Journal of Work and Organizational Psychology, 9, 2: 147 - 158.

https://doi.org/10.1080/135943200397914

IQ Latino 2020. When Confinement is Harmful (II): Low Income People and Population in the Slums. Available at: https://iqlatino.org/2020/whenconfinement-is-harmful-ii-low-income-people-and-population-in-theslums/ (Accessed on 10 June 2020).

Klemenčič, M. 2015. What is student Agency? An Ontological Exploration in the Context of Research on Student Engagement. In Klemenčič, M., S. Bergan \& R. Primožič (eds.): Student Engagement in Europe: Society, Higher Education and Student Governance. Council of Europe Higher Education Series No. 20. Strasbourg: Council of Europe Publishing.

Kolzow, D.R. 2014. Leading from Within: Building Organizational Leadership Capacity. Available at:

http://www.iedconline.org/clientuploads/Downloads/edrp/Leading from _Within.pdf

(Accessed on 10 June 2020.)

Kumashiro, K. 2002. Against Repetition: Addressing Resistance to Antioppressive Change in the Practices of Learning, Teaching, Supervising, and Researching. Harvard Educational Review 72, 1: 67 - 93.

https://doi.org/10.17763/haer.72.1.c1161752617k46v6

MacGregor, H., M. Leach, A. Wilkinson \& M. Parker 2020. COVID-19-A

Social Phenomenon Requiring Diverse Expertise. Institute of Developmental Studies. Available at: 
https://www.ids.ac.uk/opinions/covid-19-a-social-phenomenonrequiring-diverse-expertise/ (Accessed on 10 June 2020).

Macupe, B. 2020. Higher-education Institutions around Africa Close as the World Combats Covid-19. Mail and Guardian. Available at: https://mg.co.za/article/2020-03-17-higher-education-institutionsaround-africa-close-as-the-world-combats-covid-19/ (Accessed on 12 June 2020.)

Mahembe, B. \& A.S. Engelbrecht 2013. The Relationship between Servant Leadership, Affective Team Commitment and Team Effectiveness. SA Journal of Human Resource Management 11, 1: 1 - 10.

https://doi.org/10.4102/sajhrm.v11i1.495

Mattingly, A. 2014. Servant Teaching: Applying the Principles of Servant Leadership to the Classroom. Available at:

http://edtheory.blogspot.com/2014/11/servant-teaching-applyingprinciples-of.html (Accessed on 12 June 2020).

Maxwell, J.C. 2011. The 5 Levels of Leadership: Proven Steps to Maximize your Potential. New York: Center Street.

Mintzberg, H. 2004. Managers, not MBAs: A Hard Look at the Soft Practice of Managing and Management Development. San Francisco: BerrettKoehler Publishers.

Modern Servant Leader 2020. Academic Programs for Servant Leadership.

Available at: https://www.modernservantleader.com/academicprograms-list/ (Accessed on 14 June 2020).

Muller, S. 2020. South Africa's One-sided Lockdown: Coercing the Poor, Coddling the Rich? Available at:

https://africasacountry.com/2020/04/south-africas-one-sided-lockdowncoercing-the-poor-coddling-the-rich (Accessed on 12 June 2020).

Neculae, G-E. \& S. David 2017. Leadership Approaches - A Comparative Analysis. In Hugues, S. \& N. Cristache (eds.): Risk in Contemporary Economy. Iasi, Romania: LUMEN Proceedings.

https://doi.org/10.18662/lumproc.rce2017.1.44

Quantz, R., N. Cambron-McCabe, M. Dantley \& A.H. Hachem 2017. Culturebased Leadership. International Journal of Leadership in Education 20, 3: 376 - 392.

Raelin, J. 2011. From Leadership-as-Practice to Leaderful Practice. Leadership 7, 2: 195 - 211. Available at: http://lea.sagepub.com/content/7/2/195 (Accessed on 12 June 2020.) 
https://doi.org/10.1177/1742715010394808

Ramose, M. 2019. A Philosophical Investigation into the Conceptual History of Decolonisation in Africa. Presentation at the Unisa Decoloniality Summer School, Pretoria, South Africa.

Ro, C. 2020. Coronavirus: Why Some Racial Groups are More Vulnerable. BBC Future. Available at: https://www.bbc.com/future/article/20200420coronavirus-why-some-racial-groups-are-more-vulnerable (Accessed on 12 June 2020).

Russell, R.F. \& G.A. Stone 2002. A Review of Servant Leadership Attributes:

Developing a Practical Model. Leadership \& Organization Development Journal 23, 3: 145 - 157. https://doi.org/10.1108/01437730210424

Scharmer, C.O. 2009. Theory U: Learning from the Future as it Emerges. San Francisco: Berrett-Koehler Publishers.

Schatzki, T.R. 2005. Peripheral Vision: The Sites of Organizations. Organization Studies 26, 3: 465 - 484.

https://doi.org/10.1177/0170840605050876

Scott D. \& R. Bhaskar 2015. Being and Knowing. In Bhaskar, R. (ed.): Springer Briefs in Education. Cham: Springer.

https://doi.org/10.1007/978-3-319-19836-1

Shinagel, M. 2013. The Paradox of Leadership. Harvard Division of Continuing Education: Professional Development. Available at:

http://www.dce.harvard.edu/professional/ blog/paradox-leadership

(Accessed on 10 June 2020).

Sibanda, O.S. 2020. All Corrupt Presidents and Leaders must Face Prosecution, No Matter Where They are in the Wworld. Available at: https://www.dailymaverick.co.za/opinionista/2020-05-22-all-corruptpresidents-and-leaders-must-face-prosecution-no-matter-where-they-arein-the-world/ (Access on 12 June 2020.)

Sidamon-Eristo, A. 2020. Online Learning Finds Its Moment. Available at: https://www.city-journal.org/covid-19-online-education-revolution (Accessed on 12 June 2020.)

Spender, J.C. 2008. Can Simon's notion of 'bounded rationality' Give us New Ideas about Leadership? Leadership 4, 1: 95 - 109.

https://doi.org/10.1177/1742715007085771

Sklaveniti C. 2016. Relational Leadership Theory. In Farazmand, A. (eds.): Global Encyclopedia of Public Administration, Public Policy, and Governance. Cham, Switzerland: Springer. 
https://doi.org/10.1007/978-3-319-31816-5 2196-1

Spears, L.C. 2010. Character and Servant Leadership: Ten Characteristics of

Effective, Caring Leaders. The Journal of Virtues \& Leadership 1, 1: 25

- 0. Available at: https://www.regent.edu/wp-

content/uploads/2020/12/Spears Final.pdf

Starbucks 2020a. Our Mission. Available at:

https://www.starbucks.com/about-us/company-information/mission-

statement (Accessed on 24 April 2020).

Starbucks 2020b. Diversity \& Inclusion at Starbucks. Available at:

https://www.starbucks.com/ responsibility/community/diversity-and-

inclusion (Accessed on 24 April 2020).

Taggart, J. 2016. Are You a Spontaneous Leader? Available at:

https://changingwinds. wordpress.com/2016/07/10/are-you-a-

spontaneous-leader/ (Accessed on 14 June 2020).

The Citizen 2020. Cosatu Calls for Student Debt to be Scrapped amid Covid-

19 Economic Fallout. Available at: https://citizen.co.za/news/southafrica/education/2297147/cosatu-calls-for-student-debt-to-be-scrappedamid-covid-19-economic-fallout/ (Accessed on 14 June 2020)

Turkle, S. 2011. Alone Together: Why we Expect More from Technology and Less from Each Other. New York: Basic Books.

Van Dierendonck, D. 2011. Servant Leadership: A Review and Synthesis. Journal of Management 37, 4: 1228 - 1261. Available at:

https://journals.sagepub.com/doi/abs/10.1177/01492 06310380462

(Accessed on 15 June 2020).

https://doi.org/10.1177/0149206310380462

Wheeler, D.W. 2012. Servant Leadership for Higher Education: Principles and Practices. John Wiley \& Sons.

Zevounou, L., A. Niang \& N.S. Sylla 2020. On the Necessity to Govern with Compassion. Available at: https://africasacountry.com/2020/04/the-timeto-act-is-now (Accessed on 2 May 2020.)

Dr. Kasturi Behari-Leak Associate Professor: Academic Staff and Professional Development Centre for Higher Education Development

University of Cape Town

Cape Town, South Africa kasturi.behari-leak@uct.ac.za 
Leadership amidst the COVID-19 Crisis

Dr. Suren Behari Adjunct Lecturer: School of Management \& Enterprise Faculty of Business, Education, Law \& Arts University of Southern Queensland Toowoomba, Queensland, Australia suren.behari@usq.edu.au 


\section{Acknowledgement of Reviewers}

We wish to acknowledge the participation of the following reviewers in the production of AASBS volume \#03.

Prof. Colleen Aldous, School of Clinical Medicine, UKZN, aldousc@ukzn.ac.za

Prof. Tshotsho Baba, University of Fort Hare, BTshotsho@ufh.ac.za

Prof. Thabisile Buthelezi, School of Education, UKZN, Buthelezit10@ukzn.ac.za

Prof. André du Plessis, Nelson Mandela University, andre.duplessis@mandela.ac.za

Dr. Roshni Gokool, School of Arts, UKZN, Gokoolr@ukzn.ac.za

Dr. Phephani Gumbi, School of Education, UKZN, Gumbip1@ukzn.ac.za

Prof. Ruth Hoskins, School of Social Sciences, UKZN, HoskinsR@ukzn.ac.za

Dr. Magda Kloppers, Faculty of Education, NWU, Magda.Kloppers@nwu.ac.za

Mandisa Makhaye, UNIZULU, MakhayeM@unizulu.ac.za

Prof. Raj Mestry, Faculty of Education, University of Johannesburg, rajm@uj.ac.za

Dr. Jeffrey Siphiwe Mkhize, School of Education, UKZN, MkhizeJ3@ukzn.ac.za

Dr. Pinkie Mthembu, School of Education, UKZN, Mthembup@ukzn.ac.za

Dr.. Siphiwe Mthiyane, School of Education, WITS University, siphiwe.mthiyane@wits.ac.za

Nelly Mwale, University of Zambia, nelmwa@gmail.com

Prof. Dion Nkomo, Rhodes University, d.nkomo@ru.ac.za

Dr. Nomalungelo Ngubane, School of Education, UKZN, ngubanen3@ukzn.ac.za

Prof. Vivian Ojong, School of Social Sciences, UKZN, Ojong@ukzn.ac.za Sershen, Research Fellow, University of Western Cape, snaidoo@inr.org.za 